\title{
Development of Inactive High Level Waste Envelope D Simulants for Scaled Crossflow Filtration Testing
}

\author{
G. R. Golcar \\ K. P. Brooks \\ J. G. Darab \\ J. M. Davis \\ L. K. Jagoda
}

August 2000

Prepared for BNFL, Inc. under

Contract No. W375-SC-98-4168

Battelle, Pacific Northwest Division

Richland, Washington 99352

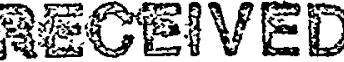

OCT 132000

C.STI 
.

' 


\section{DISCLAIMER}

This report was prepared as an account of work sponsored by an agency of the United States Government. Neither the United States Government nor any agency thereof, nor any of their employees, make any warranty, express or implied, or assumes any legal liability or responsibility for the accuracy, completeness, or usefulness of any information, apparatus, product, or process disclosed, or represents that its use would not infringe privately owned rights. Reference herein to any specific commercial product, process, or service by trade name, trademark, manufacturer, or otherwise does not necessarily constitute or imply its endorsement, recommendation, or favoring by the United States Government or any agency thereof. The views and opinions of authors expressed herein do not necessarily state or reflect those of the United States Government or any agency thereof. 


\section{DISCLAIMER}

Portions of this document may be illegible in electronic image products. Images are produced from the best available original document. 


\section{Summary}

As part of the development of the full-scale filtration system for the River Protection Project-Waste Treatment Plant (RPP-WTP), a multi-tube crossflow filter is to be tested on non-radioactive simulants at British Nuclear Fuel, Ltd.'s (BNFL's) Sellafield plant. The data collected from this pilot-scale unit will be used in conjunction with the results from the actual waste testing with a single-tube crossflow filter to assist in the scale-up effort. The objective of this work was to develop the non-radioactive, physical simulants for use in the multi-tube filter. Two simulant compositions have been targeted: a neutralized current acid waste (NCAW) developed from a composite of AZ-101 and AZ-102 tank compositions, and a high-heat tank waste, based on the composition of the waste in Tank C-106. The second objective of this work was to verify the simulant properties and performance relative to the actual waste.

These simulants were developed to mimic only the sludge properties important to crossflow filtration testing. The simulants were to contain the primary tank waste constituents and be non-hazardous, low cost, and easy to prepare and reproduce. As a first step, the aspects of the high-level waste (HLW) sludge properties that were expected to determine the crossflow filtration performance were identified. The key waste properties for crossflow filtration were determined to be

- the size distribution of particles or agglomerates

- agglomerate compactness and deformation behavior under shearing flow conditions

- major mineral phases contributing to the waste morphology

- major ions

- ionic strength of the supernatant

- the $\mathrm{pH}$ of the supernatant

- slurry solids loading

- rheological properties of the slurry at a given solids loading.

Then, the actual waste elemental compositions for the NCAW and the C-106 tank wastes were used to derive a simple chemical composition of the solids and supernatant for simulant formulation. The simulants were tested in the cells unit filter (CUF), and their formulations were adjusted to obtain a specification that performs similarly to actual waste in a crossflow filtration unit.

Table S. 1 lists the solid and supernatant components of the AZ-101/102 filtration simulant, and Table S. 2 summarizes the composition of the $\mathrm{C}-106$ filtration simulant.

The C-106 Filtration was evaluated with the $0.5-\mu \mathrm{m}$ Mott filter element to compare its filtration performance with previous experimental data obtained with an actual C-106 sample by Geeting et al. (1997). The testing in both actual and simulant cases was performed at $8 \mathrm{wt} \%$ insoluble solids. The filtrate flux for all conditions using the simulant was reasonably close in magnitude and curve shape to the actual waste. The simulant filtrate flux decreased at a continuous rate over the course of an individual run condition due to deformation of a wide spectrum of agglomerates (from soft to hard agglomerates) under imposed shearing of a run condition. Generally, the C-106 simulant filtration fluxes were less than $30 \%$ higher than those obtained with the actual waste on the basis of averaged fluxes for individual run 
conditions. The difference in averaged fluxes between the simulant and actual waste was partly due to the difference in the shape of flux-verses-time profiles. The C-106 simulant exhibited a uniform decline in the filtration flux whereas the actual waste filtration flux profile showed a rapid decline in the beginning followed by an approximately flat profile in the course of each individual condition. Further, in many cases, there is more significant variability between the first and the second 30 minutes in the actual waste testing than between the actual waste testing and the simulant testing. All of these results suggest that the simulant accurately model the actual waste in its filtration characteristics.

Table S.1. Inactive AZ-101/102 Filtration Simulant Composition

\begin{tabular}{|c|c|c|c|c|c|}
\hline \multicolumn{6}{|c|}{ Solids Components } \\
\hline $\begin{array}{l}\text { Compópounds } \\
\text { Beáring: }\end{array}$ & Wt $\%$ & Mineral Phase & Powder Grade & $\begin{array}{l}\text { Mean Volume PSD } \\
\text { (Distribution) }\end{array}$ & $\mathbf{W t} \%$ \\
\hline \multirow{3}{*}{ Iron } & \multirow{3}{*}{58} & \multirow{3}{*}{ Hematite } & Iron Oxide No: $07-5001$ & $22 \mu \mathrm{m}$ & 17.400 \\
\hline & & & Red Iron Oxide No: $07-3752$ & $2-3 \mu \mathrm{m}$ & 29.000 \\
\hline & & & $\begin{array}{l}\text { Synthetic Red Iron Oxide No: } 07- \\
2568\end{array}$ & $0.6 \mu \mathrm{m}$ & 11.600 \\
\hline \multirow{5}{*}{ Aluminum } & \multirow{5}{*}{24} & Beohmite & HiQ-10 Alumina & $0.0028-0.004 \mu \mathrm{m}$ & 7.200 \\
\hline & & \multirow{3}{*}{ Gibbsite } & C-231 Ground White Hydrate & $14 \mu \mathrm{m}$ (broad) & 8.400 \\
\hline & & & SpaceRite S-23 Alumina & $7.5 \mu \mathrm{m}$ (broad) & 5.040 \\
\hline & & & SpaceRite S-11 Alumina & $0.25 \mu \mathrm{m}$ (narrow) & 3.360 \\
\hline & & \multicolumn{4}{|c|}{ Gibbsite/Beohmite Ratio: 2.33} \\
\hline Zirconium & 13 & $\begin{array}{l}\text { Zirconium } \\
\text { Hydroxide } \\
\end{array}$ & $\begin{array}{l}\text { Zirconium Hydroxide; Product Code: } \\
\text { FZO922/01 }\end{array}$ & $15 \mu \mathrm{m}$ & 13.000 \\
\hline Silicon & 5 & Nepheline & Spectrum A 400 Nepheline Syenite & $.10 \mu \mathrm{m}$ & 5.000 \\
\hline \multicolumn{6}{|c|}{ Supernatant Components } \\
\hline Componen & \multicolumn{5}{|c|}{ 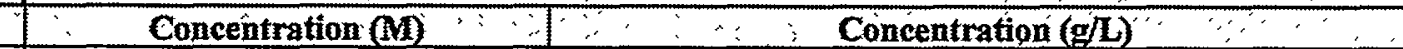 } \\
\hline $\mathrm{NaOH}$ & \multicolumn{3}{|c|}{0.8} & \multicolumn{2}{|l|}{32} \\
\hline $\mathrm{NaNO}_{3}$ & \multicolumn{3}{|c|}{1.0} & 85 & \\
\hline
\end{tabular}

The available rheological results for actual C-106 sludge (Urie et al. 1997) were not applicable for designing the C-106 filtration simulant because the rheology of actual C-106 waste was conducted at too low of solids loading. As a result, the actual C-106 waste rheological data was not used for designing the $\mathrm{C}-106$ filtration simulant.

No actual waste AZ-101/102 CUF data were available during this work, however, efforts were made to create a simulant that would have a decreasing flux over time, similar to that seen in most actual waste samples. The testing matrix was performed with the simulant prepared at 5 and $15 \mathrm{wt} \%$ insoluble solids. The filtrate flux profiles obtained with the simulant at $5 \mathrm{wt} \%$ insoluble solids loading were about $70 \%$ higher than the filtrate flux obtained with the simulant at $15 \mathrm{wt} \%$ solids loading. The results indicated an overall decrease in filtrate flux over time, similar to what was seen during actual waste testing. 
Table S.2. Inactive C-106 Filtration Simulant Composition

\begin{tabular}{|c|c|c|c|c|c|}
\hline \multicolumn{6}{|c|}{ Solids Components } \\
\hline $\begin{array}{l}\text { Compounds } \\
\text { Bearing: }\end{array}$ & Wt $\%$ & Mineral Phase & Powder Grade & $\begin{array}{c}\text { Mean Volume PSD } \\
\text { (Distribution) }\end{array}$ & Wt \% \\
\hline \multirow[b]{2}{*}{ Iron } & \multirow[b]{2}{*}{31.25} & \multirow[b]{2}{*}{ Hematite } & Red Iron Oxide No: 07-3752 & $2-3 \mu \mathrm{m}$ & 18.750 \\
\hline & & & $\begin{array}{l}\text { Synthetic Red Iron Oxide } \\
\text { No: } 07-2568\end{array}$ & $0.6 \mu \mathrm{m}$ & 12.50 \\
\hline \multirow{5}{*}{ Aluminum } & \multirow{5}{*}{36.46} & Beohmite & HiQ-10 Alumina & $0.0028-0.004 \mu \mathrm{m}$ & 18.230 \\
\hline & & \multirow{3}{*}{ Gibbsite } & SpaceRite S-23 Alumina & $7.5 \mu \mathrm{m}$ (broad) & 10.938 \\
\hline & & & SpaceRite S-11 Alumina & $0.25 \mu \mathrm{m}$ (narrow) & 3.646 \\
\hline & & & SpaceRite S-3 Alumina & $1 \mu \mathrm{m}$ (narrow) & 3.646 \\
\hline & & \multicolumn{4}{|c|}{ Gibbsite /Beohmite Ratio: 2.33} \\
\hline Zirconium & 28.12 & $\begin{array}{l}\text { Zirconium } \\
\text { Hydroxide } \\
\end{array}$ & $\begin{array}{l}\text { Zirconium Hydroxide; Product Code: } \\
\text { FZO922/01 }\end{array}$ & $15 \mu \mathrm{m}$ & 28.125 \\
\hline Silicon & 4.17 & Nepheline & Spectrum A 400 Nepheline Syenite & $10 \mu \mathrm{m}$ & 4.166 \\
\hline \multicolumn{6}{|c|}{ Supernatant Components } \\
\hline Component & & Concentration $(\mathrm{M})$ & \multicolumn{3}{|c|}{ Concentration $(g / L)$} \\
\hline $\mathrm{NaOH}$ & & 1.07 & \multicolumn{3}{|c|}{42.8} \\
\hline $\mathrm{NaNO}_{3}$ & & 1.00 & & \multicolumn{2}{|l|}{85.0} \\
\hline
\end{tabular}

The rheological results of the radioactive NCAW were available (Gary et al. 1990 and 1993) and used to develop the AZ-101/102 crossflow filtration simulant. The instantaneous viscosity profiles indicated that the AZ-101/102 simulant emulated the viscosity behavior of the actual NCAW waste (core samples from Tanks $101-\mathrm{AZ}$ and $\mathrm{AZ}-102$ wastes) very well at 10,30 , and $40 \mathrm{wt} \%$ undissolved solids concentrations as a function of shear rate. At shear rates of less than $30 \mathrm{~s}^{-1}$, the instantaneous viscosity of the AZ-101/102 simulant slurries at all solids loading represented higher values, which rendered the AZ-101/102 simulant slurries conservatively viscous. The yield stress values for the core samples and the simulant slurries at similar solids contents were comparable. The yield stress values for the AZ-101/102 simulant slurries were higher than the radioactive slurries by a factor of 2 , but the differences were considered insignificant in discriminating the flow and rheological behavior of the simulant and radioactive slurries.

Rapko et al. (1997) measured the particle-size distribution (PSD) of AZ-101/102 actual waste. These results were compared with the AZ-101/102 simulant PSD under similar conditions using the same particle size analyzer. On a volume-weighted distribution, the actual waste and the simulant exhibited a poly-dispersed behavior, and the simulant encompassed the spectrum of the particle sizes encountered in the actual waste. Despite the slight differences in the distribution shape and the location of the peaks for the actual AZ-101/102 waste and simulant, the overall mean volume and number distribution of the actual waste compare very well with those measured with the simulant. For example, the mean volume and number distribution of the actual waste are $9.93 \mu \mathrm{m}$ and $0.63 \mu \mathrm{m}$, respectively whereas those of the simulant are $9.32 \mu \mathrm{m}$ and $0.77 \mu \mathrm{m}$, respectively. Overall, the particle size distribution and rheology of the actual NCAW slurry were replicated very well by the AZ-101/102 filtration simulant. 
Finally, the declining behavior in the filtration flux due to filter fouling and/or particle deagglomeration over the course of testing were not seen in previous simulant studies. The declining behavior of the current HLW AZ-101/102 and C-106 filtration simulants is consistent with actual waste. 


\section{Terms and Abbreviations}

BNFL BNFL, Inc; subsidiary of British Nuclear Fuels, Ltd.

CUF cells unit filter

DI deionized (water)

DST double shell tank

HLW high-level waste

NCAW neutralized current acid waste

NIST National Institute of Standards and Technology

PSD particle-size distribution

PUREX plutonium-uranium extraction

RPP-WTP River Protection Project-Waste Treatment Plant

SEM scanning electron microscopy

SST Single-shell tank

TEM transmission electron microscopy

TMP trans-membrane pressure 


\section{Units}

$\begin{aligned} \mathrm{cm} & \text { centimeter } \\ { }^{\circ} \mathrm{C} & \text { degrees Celsius } \\ \mathrm{ft} / \mathrm{s} & \text { feet per second } \\ \mathrm{g} & \text { gram } \\ \mathrm{kg} & \text { kilogram } \\ \mathrm{kg} / \mathrm{m}^{3} & \text { kilogram per meter }{ }^{3} \\ \mathrm{~g} / \mathrm{L} & \text { gram per liter } \\ \mathrm{gpm} / \mathrm{ft}^{2} & \text { gallon per minute per feet }{ }^{2} \\ \mathrm{~m}^{2} / \mathrm{g} & \text { meter per gram } \\ \mathrm{m} / \mathrm{s} & \text { meter per second } \\ \mu \mathrm{m} & \text { micrometer } \\ \mathrm{mL} / \mathrm{s} & \text { milliliter per second } \\ \mathrm{mPa} . \mathrm{s} & \text { millipascal per second } \\ \mathrm{min} & \text { minute } \\ \mathrm{M} & \text { molarity or moles per liter } \\ \mathrm{nm} & \text { nanometer } \\ \mathrm{Num} \% & \text { number percent } \\ \mathrm{mPa} . \mathrm{s} & \text { millipascal per second } \\ \mathrm{Pa} & \text { pascal } \\ \mathrm{s}^{-1} & \text { reciprocal second } \\ \mathrm{Vol} \% & \text { volume percent } \\ \mathrm{wt} \% & \text { weight percent }\end{aligned}$




\section{Contents}

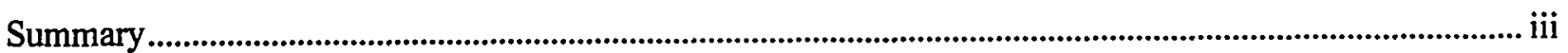

Terms and Abbreviations ............................................................................................................................... vii

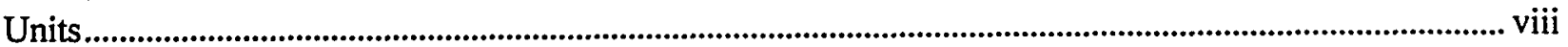

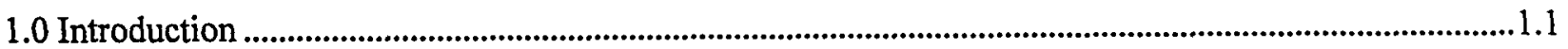

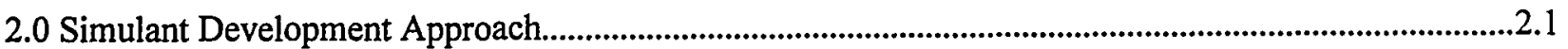

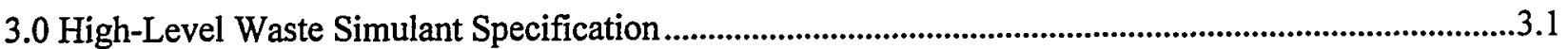

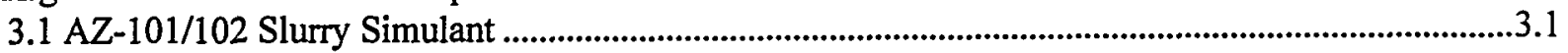

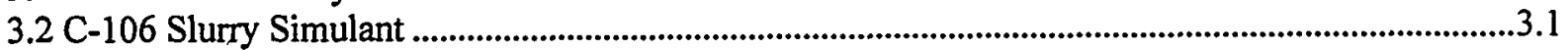

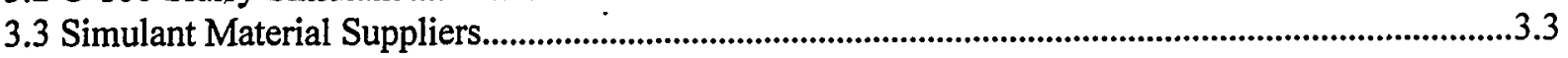

4.0 Chemical Composition and Mineral Phases.......................................................................................................4.1

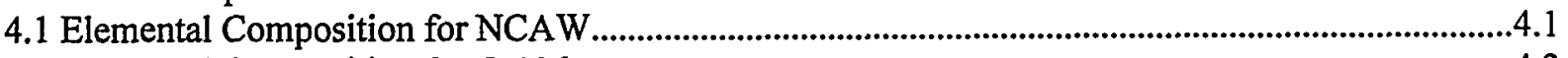

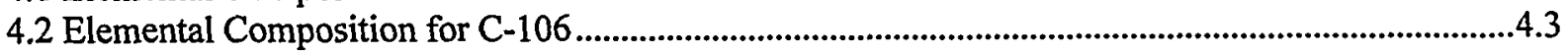

4.3 Major Mineral Phases..........................................................................................................................

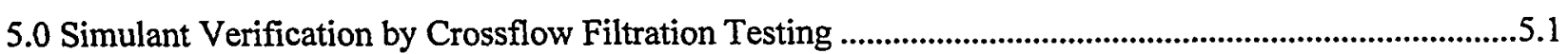

5.1 Testing Overview and Apparatus ..........................................................................................................5.1

5.2 C-106 Simulant Slurry Crossflow Filtration ..............................................................................................5.3

5.3 AZ-101/102 Simulant Slurry Crossflow Filtration .................................................................................5.6

5.4 Comparison to Other Simulant and Actual Waste Tests.....................................................................5.8

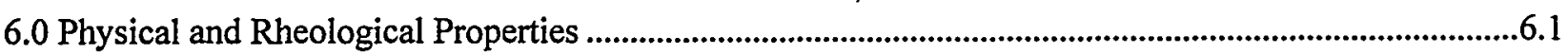

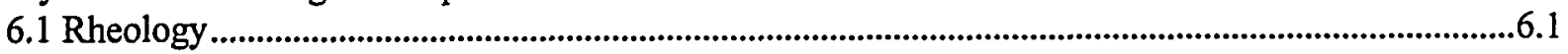

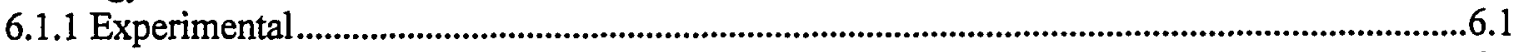

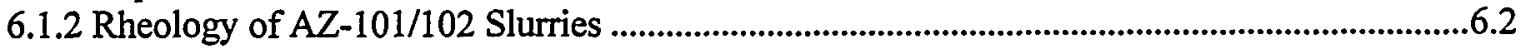

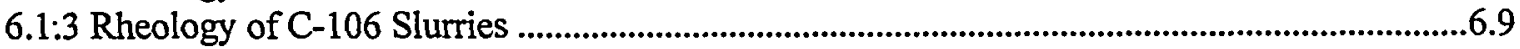

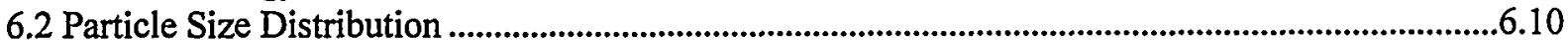

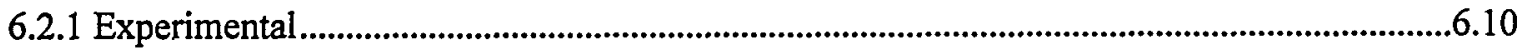

6.2.2 Particle Size Distribution of AZ-101/102 Slurry.........................................................................6.11

6.2.3 Particle Size Distribution in Crossflow Filtration and X-100 Particle Analyzer .....................6.15

6.2.4 Particle Size Distribution of C-106 Slurry............................................................................6.16

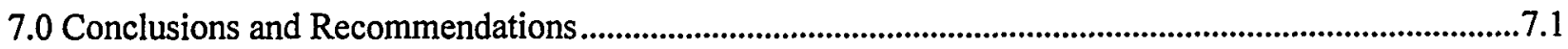

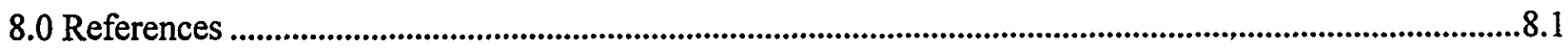

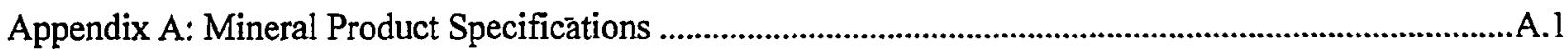

Appendix B: Material Safety Data Sheets ..........................................................................................................

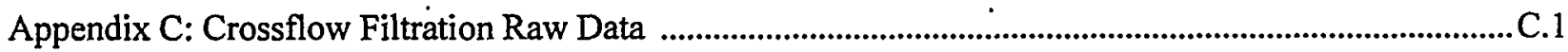

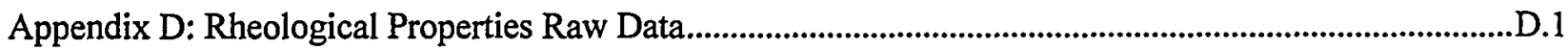

Appendix E: Particle Size Distribution Raw Data ............................................................................................. E.1 


\section{Figures}

2.1. Simulant Development Approach ........................................................................................................

4.1 TEM and EDS of Large Sample Area of the Untreated C-106 Solids....................................................4.6

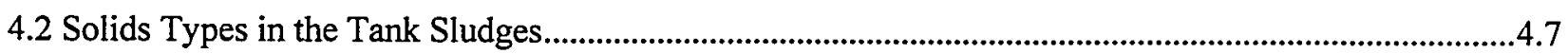

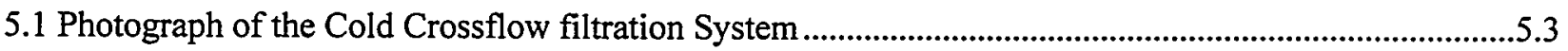

5.2 Filtrate Flux as a Function of Time for Actual and Simulated C-106 using a 0.5-Micron

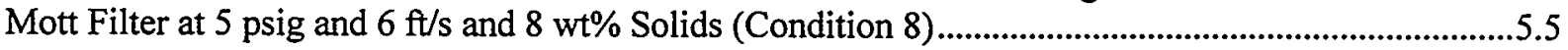

5.3 Filtrate Flux as a Function of Time for Actual and Simulated C-106 using a 0.5-Micron

Mott Filter at $20.0 \mathrm{psig}$ and $3 \mathrm{ft} / \mathrm{s}$ and $8 \mathrm{wt} \%$ Solids (Condition 9)..................................................5.5

5.4 Initial, Average, and Final Filtrate Flux for Each Test Condition with the C-106 Simulant

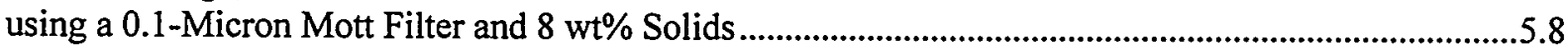

5.5 Average Filtrate Flux for Each Test Condition with the Simulated AZ-101/102

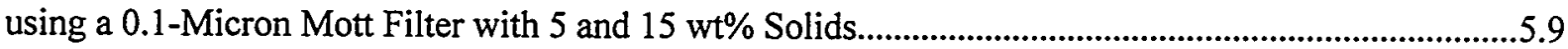

5.6 Comparison of Average Filtrate Flux for the Initial and Final Conditions of the CUF Filtration Matrix

6.1 Viscosity as a Function of Shear Rate at $25^{\circ} \mathrm{C}$ for the $\mathrm{AZ}-101 / 102$ Filtration Simulant

6.2 Shear Stress verses Shear Rate at $25^{\circ} \mathrm{C}$ for the AZ-101/102 Filtration Simulant.

6.3 Shear Stress verses Shear Rate at $25^{\circ} \mathrm{C}$ for the $\mathrm{AZ}-101 / 102$ Filtration

Simulant Ascending and Descending Profiles.

6.4 Shear Stress verses Shear Rate for the AZ-101/102 Actual Waste

6.5 Viscosity as a Function of Shear Rate for the Actual AZ-101/102 waste and the AZ101/102 Filtration Simulant.

6.6 Viscosity as a Function of Shear Rate at $25^{\circ} \mathrm{C}$ for the C-106 Filtration Simulant

6.7 Shear Stress Verses Shear Rate at $25^{\circ} \mathrm{C}$ for the C-106 Filtration Simulant.

6.8 Cumulative Under-Size Percentage Distribution for Actual AZ-101/102 and C-106 Wastes

Verses the AZ-101/102 and C-106 Filtration Simulant Slurries

6.9 Volume-Weighted Distribution for AZ-101/102 Actual Waste and AZ 101/102 Filtration Simulant.

6.10 Volume-Weighted Distribution for AZ-101/102 Actual Waste and AZ-101/102

Filtration Simulant Before and After Sonication.

6.11 Volume-Weighted Distribution for C-106 Actual Waste and C-106 Filtration Simulant.

6.12 Volume-Weighted Distribution for C-106 Actual Waste and C-106 Filtration Simulant before and after Sonication. 


\section{Tables}

3.1. Inactive AZ-101/102 Filtration Simulant Composition........................................................................2

3.2. Inactive C-106 Filtration Simulant Composition........................................................................................2

3.3. Inactive AZ-101/102 Simulant Material Suppliers ..................................................................................3.3

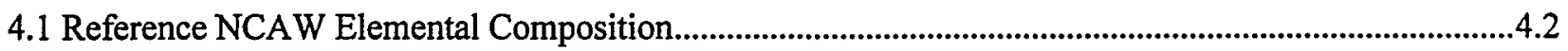

4.2 Target Composition of AZ-101/102 Filtration Simulant................................................................................

4.3 Reference C-106 Elemental Composition.................................................................................................4.4

4.4 Target Composition of C-106 Filtration Simulant......................................................................................5

5.1 Test Conditions and Average Filtrate Flux for the C-106 Simulated and Actual Waste using the

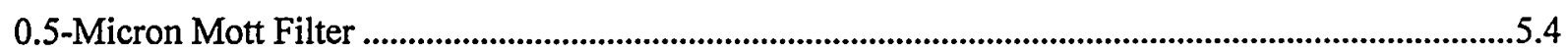

5.2 Test Conditions for the C-106 Simulant Slurry using a 0.1-Micron Mott Filter ......................................5.7

5.3 Test Conditions and Average Filtrate Flux for the AZ-101/102 Simulant using a 0.1-Micron Mott

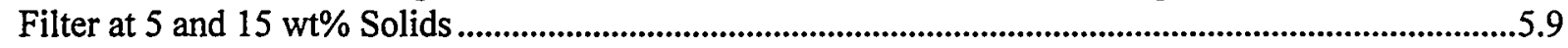

6.1 Results from the Fit to the Rheological Models for the NCAW Radioactive Slurries ..............................6.6

6.2 Yield Stress for the Actual NCAW and AZ-101/102 Filtration Simulant .............................................6.7

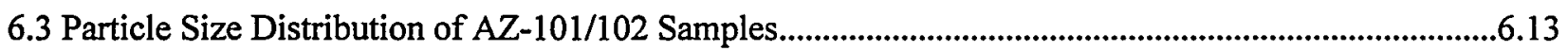

6.4 Calculated Reynolds Number for the Crossflow Filtration and Particle Analyzer.................................6.15

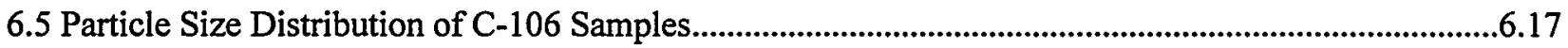




\subsection{Introduction}

BNFL, Inc (BNFL) developed flowsheets for the River Protection Project-Waste Treatment Plant (RPP-WTP) in which they made plans to use crossflow filtration for the solid-liquid separation of the Envelope D Hanford sludge (DOE-RL 1996). Unlike traditional dead-end filtration in which a filter cake grows on the surface of the filter medium and slows the rate of filtration, in crossflow filtration, the fluid flows across the medium and sweeps the filter cake away. This filtration method is especially beneficial when there are very fine particles and when system simplicity is required.

As part of the development of the full-scale filtration system for the RPP-WTP, a multi-tube crossflow filter is to be tested on non-radioactive simulants at BNFL's Sellafield plant. The data collected from this pilot-scale unit will be used in conjunction with the results from the actual waste testing with a single-tube crossflow filter to assist in the scale-up effort.

The objective of this work was to develop the non-radioactive, physical simulants for use in the multitube filter. Two simulant compositions have been targeted: a Neutralized Current Acid Waste (NCAW) developed from a composite of AZ-101 and AZ-102 tank compositions, and a high-heat tank waste, based on the composition of the waste in Tank C-106. These simulants were developed to mimic the sludge properties important to crossflow filtration testing. The simulants were to contain the primary tank waste constituents and were to be non-hazardous, low cost, and easy to prepare and reproduce.

The second objective of this work was to verify the simulant properties and performance relative to the actual waste. Particle size and rheological data available from past experimental efforts were compared to these high-level waste (HLW) simulants. The simulants were also tested in the cell unit filter (CUF) single-tube crossflow filter, providing a comparison between the simulant results and the available data with actual waste. By comparing the filtration and rheological behavior of actual and simulated waste, the validity of the simulants can be verified. Furthermore, a comparison between the simulant behavior in the CUF unit and in the multi-tube pilot-scale unit provides insight into the impacts of process scale-up.

This report describes the approach taken in developing the AZ-101/AZ-102 and C-106 tank waste simulants. It also provides the simulant formulation, including vendor purchasing information. The utility and limitations of the simulant are also delineated to define acceptable applications. The rheological, filtration, and particle size properties for each simulant are delineated. These properties are compared to the actual waste data, where available. This report also provides a means of transmitting to BNFL the raw filtration, rheological, and particle-size data for the simulants. 


\subsection{Simulant Development Approach}

Simulants are usually designed with a specific process or processes in mind. A simulant that is appropriate for testing one process might be inappropriate for another. In this work, simulants are designed for multi-tube crossflow filtration testing. Thus, the simulants are emulating those aspects of the HLW sludge properties relevant to the performance of crossflow filtration. The approach used to develop non-radioactive HLW physical simulants for multi-tube crossflow filtration is illustrated in Figure 2.1. Additional discussions on the methodology used to develop physical simulants are presented in Golcar et al. (1997 and 2000).

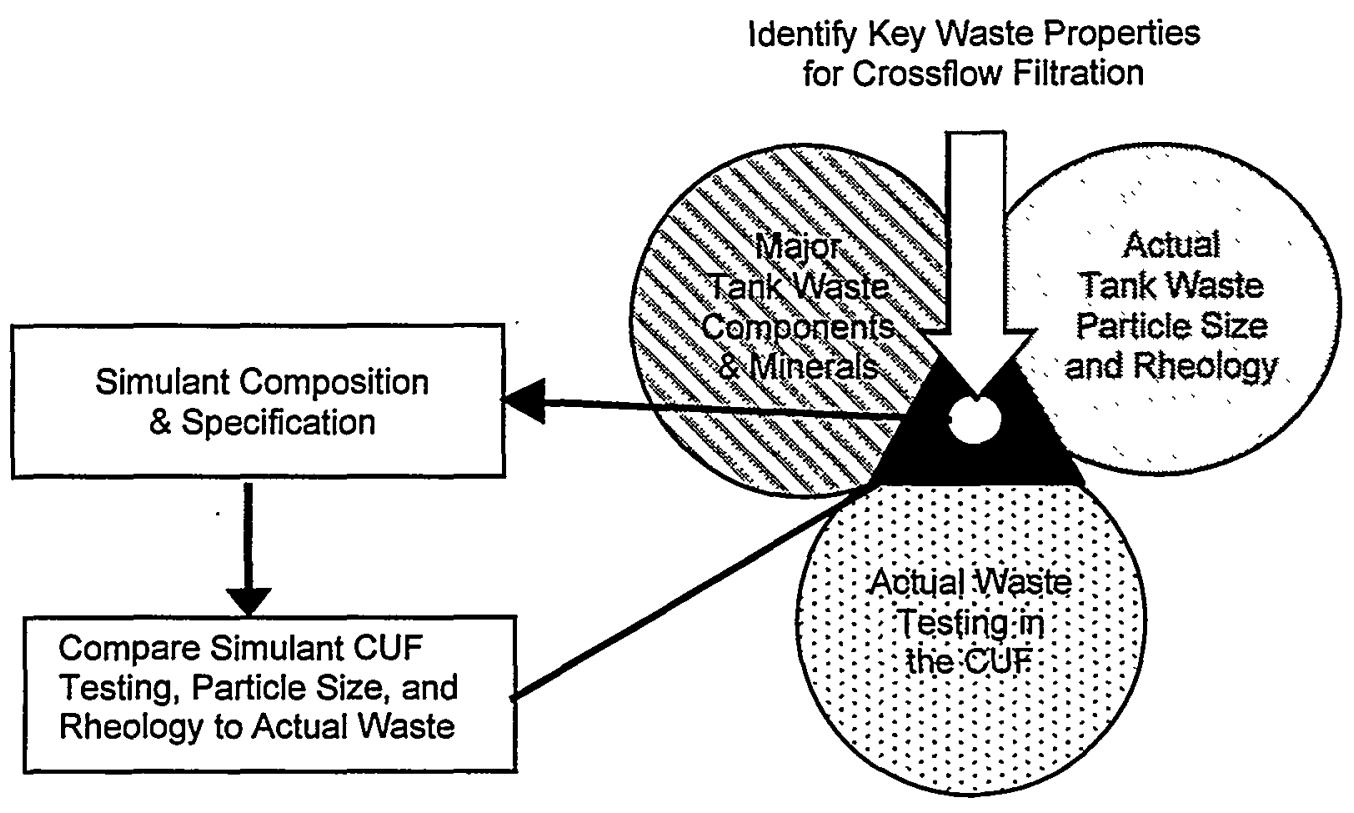

Figure 2.1. Simulant Development Approach

The first step was to identify the waste properties that were expected to determine the crossflow filtration performance. Literature reviews, CUF testing results, and consultation with experts were conducted to determine the mechanisms by which the crossflow filtration process operated. This knowledge was used to develop a list of expected key physical and chemical properties for the crossflowfiltration process. The relevant waste properties for crossflow filtration were determined to be

- Particle-size distribution (PSD): Particle or agglomerate size is likely the most important property for the filtration since it impacts filterability according to their arrangement in the filter cake to form a compressible verses an incompressible film.

- Rheological properties of the slurry at given solids loading: The rheology of the slurry will control the slurry-transporting characteristic in the CUF circulation loop. This information is . needed to determine design parameters of velocity and pressure drop across the pipeline. 
- Slurry solids loading: The slurry solids loading impact the rheology of the slurry. Obviously, the lower the solids content of slurry, the lower the viscosity over the measurable range of shear rates.

- Agglomerate strength and shearing properties: Agglomerate strength and shearing properties are important due to vigorous mixing and continual pumping that gradually breaks up particles and changes the filtration characteristics by altering the film or cake structure deposited on the membrane surface. As small fine particles are generated, they plug the filter cake, and the filtrate flux could decrease very rapidly to necessitate back flushing to regenerate the membrane.

- Major mineral phases and their contribution to the waste morphology: The mineral types provide inherent characteristics of shape and strength for individual particles that impact rheology and the nature of agglomerates.

- Major ions, the ionic strength, and the $\mathrm{pH}$ of the supernatant: The ionic strength and $\mathrm{pH}$ of the supernatant will affect the degree of agglomeration or dispersion and the solubility of particles.

The second step was to review the existing actual waste-characterization data for the NCAW and the C-106 tank wastes. These results were used to determine the chemical composition of the solids and supernatant for each waste type. The PSD and the rheological results of the radioactive waste samples were compiled, and their relevance to crossflow filtration simulants was evaluated. Further, the expected range of magnitude for PSD and rheological properties was established and used to develop simulants that fall within these estimates.

The mineral phases of waste were reviewed and replicated in simulants to the extent practical. Mineral phases of solids were selected from the existing electron beam techniques (scanning and transmission electron microscopy [SEM, TEM] with $\mathrm{x}$-ray analysis) of the C-106 waste. Since such data were not available for the NCAW solids, candidate mineral phases were selected from the TEM data conducted on sludge samples from 20 other single-shell tanks (SSTs) and 4 double-shell tanks (DSTs). The waste mineralogy and chemical composition were simplified according to their practicality and significance in terms of size, shape, and solubility (to a certain extent) for the crossflow filtration performance. From the standpoint of simulant quality control and the high cost of some minerals identified by TEM, compromises were made in selecting minerals for simulant formulation. These minerals were substituted with other solid forms of the same component with a similar PSD and shape that were commercially available at reasonably low costs. The mineral phases and their selection criterion are discussed in detail in section 4.3.

In the case of the C-106 simulant, the available small-scale radioactive CUF results were available. Thus, the final step in the simulant-development process was to compare the CUF data using simulant slurry with the radioactive CUF results. Adjustments to the $\mathrm{C}-106$ simulant composition were made to improve the confidence in the validity of the simulant for crossflow filtration.

Simulant compositions were formulated using commercial minerals. The rheology (viscosity and yield stress) and PSD of the simulants were measured. Each formulation was tested in the cold CUF, and its performance was evaluated. The simulant formulation was adjusted numerous times to obtain the final formulation, which was similar to actual waste in filtration, rheological, and PSD properties. 


\subsection{High-Level Waste Simulant Specification}

The specifications and preparation procedures for the inactive HLW - Envelope D filtration simulants are presented in this section. These simulants were developed for the purpose of testing crossflow filtration systems. The applicability of these simulants for filtration studies using washed and leached solids is uncertain and requires additional evaluation. These simulants have not been developed to mimic the chemical properties of the sludge, and their use for washing and causticleaching experiments is not recommended. Applicable sludge properties for crossflow filtration were discussed in Section 2.0. Specifications outlined below are for

- AZ-101/102 waste simulant slurry for the NCAW from Hanford Tanks AZ-101 and AZ-102

- C-106 waste simulant slurry for the high-heat tank waste from Hanford Tank C-106. It should be noted that the actual C-106 waste has recently been transferred to Hanford Tank AY-102. The C-106 waste simulant replicates the Hanford tank C-106 waste and it does not replicated the AY-102/C-106 mixed waste.

\subsection{AZ-101/102 Slurry Simulant}

Table 3.1 lists the solid and supernatant components of the inactive AZ-101/102 waste filtration simulant. Note that the concentration of the solid components is reported on a $100 \%$ dry solids basis. For aluminum- and iron-bearing compounds in the simulant several metal oxide/hydroxide powder grades of various PSD ranges were used to produce the required rheological and filtration characteristics. The product descriptions for each mineral, including density and particle size, are provided in Appendix A. The material safety data sheets for listed source chemicals are provided in Appendix B.

\subsection{C-106 Slurry Simulant}

Table 3.2 lists the solid and supernatant components of the inactive C-106 waste filtration simulant. Similar to the inactive AZ-101/102 simulant, the concentration of the solid components is reported on a $100 \%$ dry solids basis. For aluminum- and iron-bearing compounds in the simulant several metal oxide/hydroxide powder grades of various PSD ranges were used to produce the required rheological and filtration characteristics. Appendix A provides the product descriptions for each mineral, including density and particle size. Appendix B provides the material safety data sheets for listed source chemicals.

Following is the procedure for preparing both the AZ-101/102 and C-106 simulants:

- Determine the wt\% insoluble solids and the total mass of simulant desired. This simulant should mimic actual waste over the range of 3 to $40 \mathrm{wt} \%$ solids loading. At lower than $3 \mathrm{wt} \%$ solids loading, the supernatant composition becomes more significant than the particle characteristics. Further development of the supernatant may be required to mimic the actual waste. Additionally, higher than $40 \mathrm{wt} \%$ solids loading has not been evaluated in this study. Further validation at these higher concentrations would be required before using these simulants above $40 \mathrm{wt} \%$.

- Weigh out and combine the solid components described in Table 3.1 or 3.2 for the 1) total simulant mass, and 2) wt\% solids desired. The order of addition to the mixture is not important.

- Prepare sufficient simulated supernatant for the total mass of slurry at desired solids loading with the molarity specified in Table 3.1 or 3.2 . 
- Add this simulated supernatant to the dry solids mixture until the total mass of slurry simulant desired is reached. Mix with a stirrer for $20 \mathrm{~min}$ immediately after addition and before use.

Table 3.1. Inactive AZ-101/102 Filtration Simulant Composition

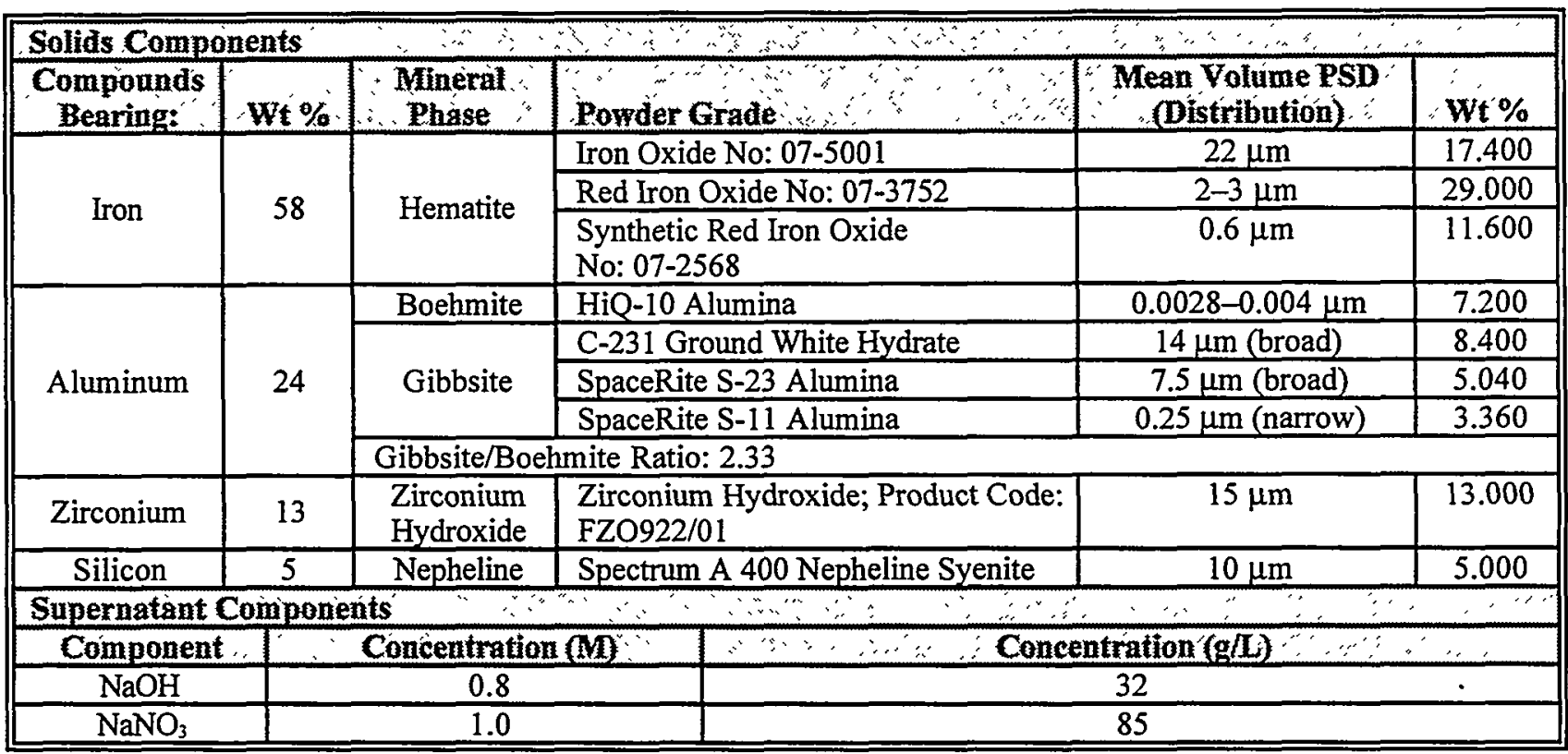

Table 3.2. Inactive C-106 Filtration Simulant Composition

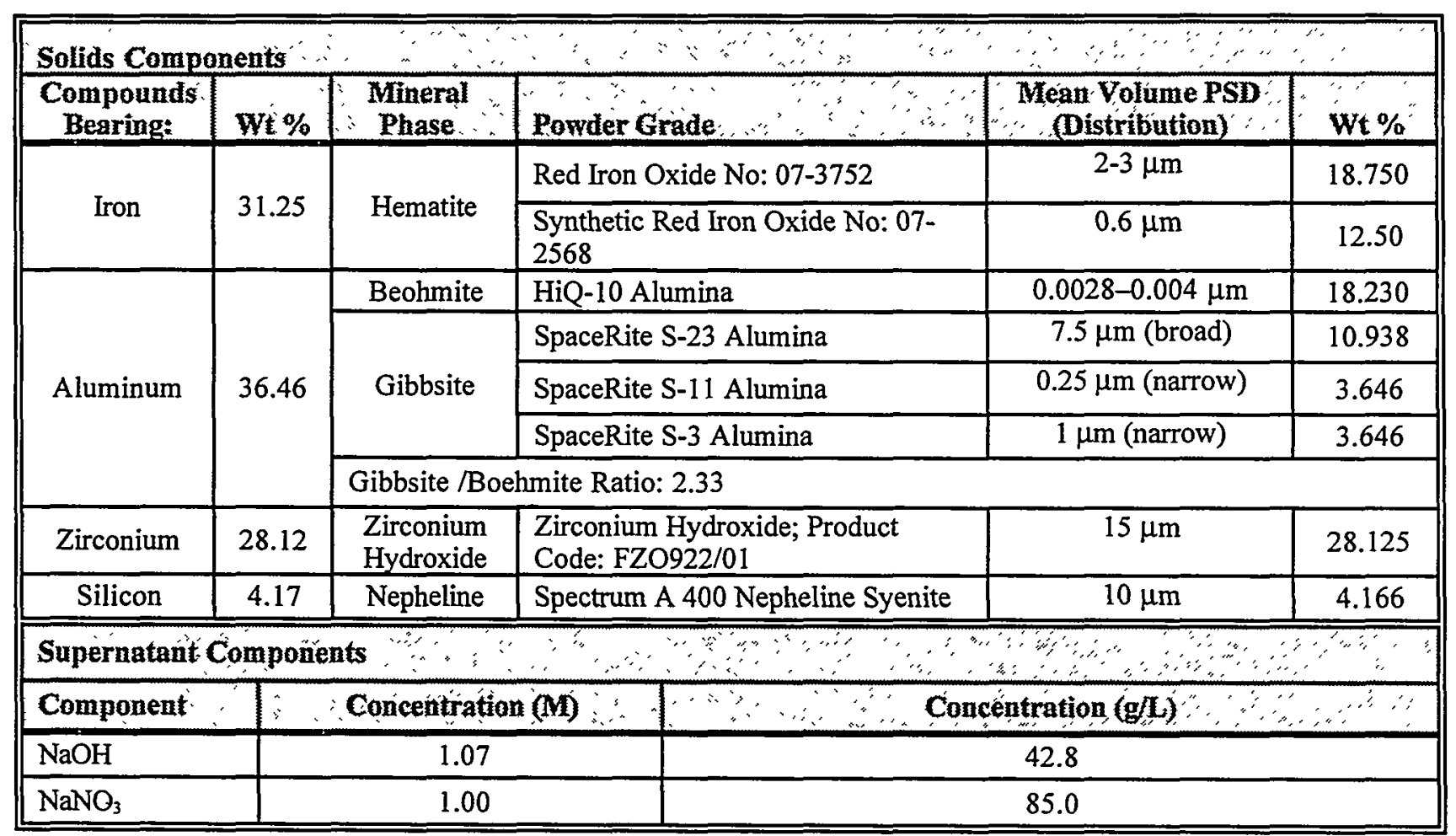




\subsection{Simulant Material Suppliers}

Simulant properties, such as particle size distribution and mineral composition, will vary from those listed in this report if alternative sources for simulant components are used. The brand names of each simulant component are given in Table 3.3.

Table 3.3. Inactive AZ-101/102 and C-106 Filtration Simulant Material Suppliers

\begin{tabular}{|c|c|c|}
\hline Manufacturer & Simulant Material & Powder Grade \\
\hline \multirow{3}{*}{$\begin{array}{l}\text { The Prince Manufacturing Company } \\
\text { http://www.princemfg.com/ }\end{array}$} & Iron Oxide, Hematite & Iron Oxide No: 07-5001 \\
\hline & Iron Oxide, Hematite & Red Iron Oxide No: 07-3752 \\
\hline & Iron Oxide, Hematite & $\begin{array}{l}\text { Synthetic Red Iron Oxide } \\
\text { No: } 07-2568\end{array}$ \\
\hline $\begin{array}{l}\text { Alcoa - Port Allen , LA } \\
\text { http://www,alcoa,com/ } \\
1-800-860-3290\end{array}$ & Beohmite, AlOOH & HiQ-10 Alumina \\
\hline \multirow{4}{*}{$\begin{array}{l}\text { Alcoa- Bauxite, AR } \\
\text { http://www,alcoa.com/ } \\
1-225-382-3338\end{array}$} & \multirow{4}{*}{ Gibbsite, $\mathrm{Al}(\mathrm{OH})_{3}$} & C-231Ground White Hydrate \\
\hline & & SpaceRite S-23 Alumina \\
\hline & & SpaceRite S-11 Alumina \\
\hline & & SpaceRite S-3 Alumina \\
\hline $\begin{array}{l}\text { Magnesium Electron INC. (MEI) } \\
\text { http://www,zrchem,com/ } \\
1-800-366-9596\end{array}$ & Zirconium Hydroxide & $\begin{array}{l}\text { Product Code: FZO922/01 from } \\
\text { FZO } 922 \text { series. }\end{array}$ \\
\hline $\begin{array}{l}\text { Hammill \& Gillespie } \\
\text { http://www.hamgil.com/ } \\
\text { 973-994-3847 }\end{array}$ & $\begin{array}{l}\text { Nepheline, } \\
(\mathrm{Na}, \mathrm{K}) \mathrm{AlSiO}_{4}\end{array}$ & Spectrum A 400 Nepheline Syenite \\
\hline
\end{tabular}

Detailed simulant characterization and crossflow filtration performance testing are required if alternative commercial products are used. Such results should be similar to the simulant properties documented in this report. Further, the chemical and physical properties listed in Appendix A need to be matched as closely as possible if another commercial source is used. 


\subsection{Chemical Composition and Mineral Phases}

The basis for the elemental and mineral phase content of the simulants is presented in this section. The elemental composition of the NCAW and the C-106 slurries were estimated using analytical results and historical information on the generation of the waste. The elemental compositions were then simplified to meet the simulant development criteria for crossflow filtration testing. Compositions are listed in this section. Further, the rationale for selecting the mineral phases used in the simulant formulation and the significance of these minerals to crossflow filtration is explained.

\subsection{Elemental Composition for NCAW}

The actual NCAW solids composition was taken from Hodgson (1995) and Lambert (1998). The tank inventories and their percentages on a "sodium-free" and "water-free" basis are provided in Table 4.1. The sodium is removed because it is assumed to be present as either an intrinsic constituent of compounds generated from the analytes in Table 4.1 or as soluble sodium nitrite/nitrate which dissolves or is diluted during the retrieval process. Thus, it is not included in the solids composition. The data in Table 4.1 indicate that approximately 88 to $92 \mathrm{wt} \%$ of the NCAW solids are dominated by minerals formed from the following analytes: iron $(\sim 22$ to $43 \mathrm{wt} \%)$, aluminum $(\sim 11$ to $22 \mathrm{wt} \%)$, silicon $(\sim 2$ to 3 wt\%), zirconium ( -6 to $15 \mathrm{w} \%)$, uranium $(\sim 2$ to $9 \mathrm{wt} \%)$, manganese $(\sim 1$ to $9 \mathrm{wt} \%)$, cadmium ( $\sim 2$ to 5 $w t \%)$ and nickel ( $\sim 2$ to $3 w t \%)$.

As shown, approximately 42 to $43 \mathrm{wt} \%$ of NCAW sludge consists of iron compounds because a large quantity of iron sulfamate was used in the plutonium-uranium extraction (PUREX) process, which is noted by historical accounts (Ryan 1995). The PUREX process produced the NCAW tank sludges. Aluminum compounds are the second main constituents of sludge, followed by uranium and zirconium compounds. The rest of the analytes (silicon, manganese, cadmium, and nickel) constitute the remainder of the solids.

Uraninite $\left(\mathrm{UO}_{2}\right)$ minerals were not added to the list of simulant chemical sources (despite representing 2 to $9 \mathrm{wt} \%$ of NCAW solids), because they are radioactive. While uranium-bearing materials are typically dense hard minerals, it was not expected to have a significant impact on the filtration properties because the filterability of slurry is not directly influenced by these properties (see Section 2.0). Therefore, we did not add any dense hard minerals (such as tungsten oxide) as surrogates for uranium.

Manganese oxides and/or hydroxides were also excluded from the simulant materials list to simplify the iterative process of formulation. Manganese oxide or hydroxides tend to be grouped into tight bundles and columnar massive forms of "hard" agglomerates. The behavior of these particles is dominated by the body-force interactions (inertial and frictional forces) rather than colloidal interactions. In this context it is assumed that they behave similar to iron oxide or aluminum trihydroxide described in detail in Section 4.3. 
Table 4.1. Reference NCAW Elemental Composition.

\begin{tabular}{|c|c|c|c|c|}
\hline Solids Analyte & Al $101(\mathbf{k g})$ & $\begin{array}{l}\text { Sodium-Free } \\
\text { (Wt } \%)\end{array}$ & Ap102 (kg) & $\begin{array}{l}\text { Sodium-Free } \\
\text { (Wt \%) }\end{array}$ \\
\hline $\mathrm{Ag}$ & 78.2 & 0.17 & 242 & 0.22 \\
\hline $\mathrm{Al}^{*}$ & 5320 & 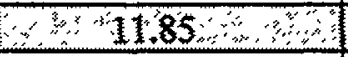 & 24200 & 22.35 \\
\hline As & 111 & 0.25 & - & - \\
\hline $\mathrm{B}$ & 57.8 & 0.13 & - & - \\
\hline $\mathrm{Bi}$. & - & - & - & - \\
\hline $\mathrm{Ca}$ & 467 & 1.04 & 1080 & 1.00 \\
\hline $\mathrm{Cd}$ & 91070 & 2,38 & $15360^{\circ}$ & 4.95 \\
\hline $\mathrm{Ce}$ & 234 & 0.52 & - & - \\
\hline $\mathrm{Cr}$ & 343 & 0.76 & 3930 & 3.63 \\
\hline $\mathrm{Cu}$ & 83 & 0.18 & - & - \\
\hline $\mathrm{Fe}$ & 19100 & $\therefore \because 42.5, \because \because$ & $46800^{6}$ & $\because 43.22$ \\
\hline $\mathrm{K}$ & 1260 & 2.81 & 918 & 0.85 \\
\hline $\mathrm{La}$ & 724 & 1.61 & 1610 & 1.49 \\
\hline $\mathrm{Li}$ & 14 & 0.03 & - & - \\
\hline $\mathrm{Mg}$ & 118 & 0.26 & - & - \\
\hline$\because \mathbf{M n}$ & $44260 \ldots$ & $\because 9.49 \cdots$ & $\therefore 1030$ & 0.95 \\
\hline Mo & 24 & 0.05 & - & - \\
\hline $\mathrm{Na}$ & 17300 & 0.00 & 19880 & 0.00 \\
\hline $\mathrm{Nd}$ & 518 & 1.15 & - & - \\
\hline$: \mathrm{Ni}$ & $855, \cdots \cdots$ & 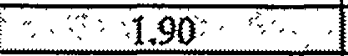 & 3160 & 2.92 \\
\hline $\mathrm{P}$ & 558 & 1.24 & 164 & 0.15 \\
\hline $\mathrm{Pb}$ & 101 & 0.22 & 394 & 0.36 \\
\hline $\mathrm{Re}$ & 11 & 0.02 & - & - \\
\hline $\mathrm{Rh}$ & 83 & 0.18 & - & - \\
\hline$\because \mathbf{S i}$ & $\because 1130$ & $\because \quad \because 2.52 \%$ & $3390 \ldots$ & 3.13 \\
\hline $\mathrm{Sr}$ & 95 & 0.21 & 117 & 0.11 \\
\hline $\mathrm{Te}$ & 374 & 0.83 & - & - \\
\hline $\mathrm{Ti}$ & 127 & 0.28 & - & - \\
\hline $\bar{U}$ & 1070 & $\because 238: \cdots:$ & $\therefore 9670$ & 8.93 \\
\hline $\mathrm{V}$ & - & - & - & - \\
\hline $\mathrm{Zn}$ & 79 & 0.18 & & 0.00 \\
\hline$-\mathrm{Zr}$ & 6720 & $\therefore \quad 1496 \quad \cdots$ & $6-6470 \%$ & $\ldots, 57$ \\
\hline \multicolumn{5}{|c|}{$\begin{array}{l}\text { (a) Projected inventory using core } 1 \text { sample composition (Hodgson 1995). } \\
\text { (b) Calculated sludge based on Section } 4.0 \text { of the } 1995 \text { Tank Characterization Report (Lambert 1998). } \\
\text { * Shaded analytes are the major compound-bearing elements in NCAW solids. }\end{array}$} \\
\hline
\end{tabular}

Neither nickel nor cadmium compounds are used in deriving simulant formulation. Cadmium compounds are extremely toxic. Nickel is known to form stable mixed oxides with $\mathrm{Al}, \mathrm{Fe}, \mathrm{Cr}$, etc. In the alkaline conditions typically encountered in NCAW nickel most likely occur in related mixed oxy hydroxides. It is speculated that the co-precipitation of mixed nickel oxides and hydroxides would not . alter the nature of agglomerate compactness common to for example iron-bearing oxides and hydroxides. 
Thus, it is assumed that these oxides behave similar to iron oxides, and their inter-particle interactions are governed by body-force type interactions.

Based on the indicated discussions, the elemental composition of the solids fraction of the AZ-101/102 simulants was normalized with the relative proportions of only the four elements of aluminum, iron, silicon, and zirconium. This composition is shown in Table 4.2.

Table 4.2. Target Composition of AZ-101/102 Filtration Simulant

\begin{tabular}{|c|c|c|c|}
\hline \multicolumn{4}{|c|}{ Sollds components } \\
\hline Analyte & $\begin{array}{l}\text { Normalized } \\
\text { Estimates } \\
(\mathbf{W} \% \%\end{array}$ & Trrget Analyte Bearing Minerals & $\begin{array}{l}\text { Target Mineral } \\
\text { composition } \\
(W t \%)\end{array}$ \\
\hline Aluminum & $17-30$ & $\begin{array}{c}\text { Boehmite; } \mathrm{AlOOH} \\
\text { Gibbsite; } \mathrm{Al}(\mathrm{OH})_{3} \\
\text { (combined) }\end{array}$ & 24 \\
\hline Iron & $57-60$ & Hematite; $\mathrm{Fe}_{2} \mathrm{O}_{3}$ & 58 \\
\hline Silicon & $3-5$ & Nepheline; $(\mathrm{Na}, \mathrm{K}) \mathrm{AlSiO}_{4}$ & 4 \\
\hline Zirconium & $8-21$ & Zirconium Hydroxide; $\mathrm{Zr}(\mathrm{OH})_{4}$ & 13 \\
\hline \multicolumn{4}{|c|}{ Supernatant components } \\
\hline Compound & $\begin{array}{l}\text { Target } \\
\text { Concentration }(\mathrm{M})\end{array}$ & \multicolumn{2}{|c|}{ Significance } \\
\hline $\mathrm{NaOH}$ & 0.80 & \multicolumn{2}{|l|}{ Liquid viscosity, $\mathrm{pH}$} \\
\hline $\mathrm{NaNO}_{3}$ & 1.00 & \multicolumn{2}{|l|}{ Liquid viscosity, ionic strength } \\
\hline
\end{tabular}

The composition of the supernatant simulant replicates the $\mathrm{pH}$ and ionic strength expected in the feed after the sludge waste is fluidized from the holding tanks with dilute caustic $(0.01 \mathrm{M} \mathrm{NaOH})$ to yield slurry of metal hydroxide precipitates. Sodium hydroxide, nitrite, and nitrate are the primary soluble compounds in the waste. Since sodium nitrate and nitrite make similar contributions to the ionic strength, only sodium nitrate was included in the supernatant formulation.

\subsection{Elemental Composition for C-106}

The elemental composition of the C-106 solids is estimated from analytical results and projected inventory from the 1996 grab sample (Schreiber et al. 1996) and projected inventory of waste (Kirkbride et al. 1999) in Tank C-106. The tank inventories and their percentages on a "sodium-free" and "waterfree" basis are provided in Table 4.3. The data indicate that approximately $98 \mathrm{wt} \%$ (a) of the non-sodium C-106 solids are dominated by minerals formed from following analytes: aluminum ( $\sim 31$ to $33 \mathrm{wt} \%)$, iron $(\sim 26$ to $40 \mathrm{wt} \%)$, silicon $(\sim 4$ to $16 \mathrm{wt} \%)$, zirconium $(\sim 1$ to $26 \mathrm{w} \%)$, manganese $(\sim 1$ to $3 \mathrm{wt} \%)$, calcium $(\sim 1$ to $2 \mathrm{wt} \%)$, and phosphorus $(\sim 2 \mathrm{wt} \%)$.

(a) The sodium is assumed to be present as either an intrinsic constituent of compounds generated from the analytes in Table 4.3 or as soluble sodium nitrite/nitrate which dissolves during the retrieval process. Thus, it is not included in the solids composition. 
Aluminum is the main constituent of C-106 sludge ( $~ 31$ to $33 \mathrm{wt} \%)$ closely followed by iron and zirconium compounds. The rest of the analytes (silicon, manganese, and calcium) constitute the remainder of the solids.

Table 4.3. Reference C-106 Elemental Composition

\begin{tabular}{|c|c|c|c|c|}
\hline 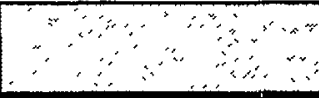 & $\mathrm{c} 106(\mathrm{~kg})^{(\mathrm{n})}$ & $\begin{array}{l}\text { Sodhum Free } \\
(W+\%)\end{array}$ & C106 kg) & $\begin{array}{l}\text { Sodfum-Free } \\
\left(W t^{\circ} \%\right)\end{array}$ \\
\hline $\mathrm{Ag}$ & 1390 & 1.20 & $<1$ & - \\
\hline$\therefore A^{*}$ & $36000 \div:$ & 3314 & 56873 & $32.97 \ldots$ \\
\hline $\mathrm{B}$ & 53 & 0.05 & 0 & 0 \\
\hline $\mathrm{Ba}$ & 221 & 0.19 & 7.77 & 0 \\
\hline $\mathrm{Bi}$ & 0 & 0 & 4.536 & 0 \\
\hline$\because \because \mathrm{Ca}$ & $981^{2}$ & 0.85 & 2866 & 1.66 \\
\hline $\mathrm{Cd}$ & 24 & 0.02 & 0 & 0 \\
\hline $\mathrm{Ce}$ & 158 & 0.14 & $<1$ & - \\
\hline $\mathrm{Cr}$ & 475 & 0.41 & 1067 & 0.62 \\
\hline $\mathrm{Cs}$ & 0 & 0 & 10 & 0 \\
\hline $\mathrm{Cu}$ & 79 & 0.07 & 0 & 0 \\
\hline$\overline{\mathrm{Fe}}$ & $46800^{\circ}$ & 40.48 & 45506 & 2638 \\
\hline $\mathrm{Hg}$ & 0 & 0 & 78 & 0.05 \\
\hline $\mathrm{K}$ & 774 & 0.67 & 803 & 0.47 \\
\hline $\mathrm{La}$ & 57 & 0.05 & 228 & 0.13 \\
\hline $\mathrm{Mg}$ & $\because 197$ & 0.17 & $\because \therefore<1$ & 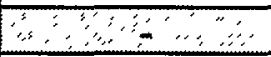 \\
\hline $\mathrm{Mn}$ & 1610 & 1.39 & 4977 & 2.89 \\
\hline $\mathrm{Na}$ & 145000 & 0.00 & 60015 & 0 \\
\hline $\mathrm{Nd}$ & 129 & 0.11 & 0 & 0 \\
\hline $\mathrm{Ni}$ & 455 & 0.39 & 1912 & 1.11 \\
\hline $\mathbf{P}$ & $\therefore 1800$ & $\therefore \quad 1.56 \ldots$ & 3337 & , \\
\hline $\mathrm{Pb}$ & 1740 & 1.50 & 1278 & 0.74 \\
\hline $\mathrm{S}$ & 2120 & 1.83 & 530 & 0.31 \\
\hline$\because \mathbf{S i}, \cdots$ & $" 18400^{\prime}$ & $\therefore 1591 \%$ & $\therefore 7573$ & 439 \\
\hline $\mathrm{Sr}$ & 30.7 & 0.03 & 55 & 0.03 \\
\hline $\mathrm{Ti}$ & 96.7 & 0.08 & 0 & 0 \\
\hline $\mathrm{U}$ & 1400 & 1.21 & 14 & 0.01 \\
\hline $\mathrm{Zn}$ & 48 & 0.04 & 0 & 0 \\
\hline$\because Z \mathrm{Zx}$ & $\therefore 587$ & $\therefore 0.51$ & 45372 & 2630 \\
\hline \multicolumn{5}{|c|}{$\begin{array}{l}\text { (a) Projected inventory using grab sample taken in } 1996 \text { (Schrieber et al. 1996) } \\
\text { (b) Projected inventory using tank transfer plans where the C-106 will be transferred to Tank } \\
\text { AZ101 or Tank AZ102 (Kirkbride et al. 1999). } \\
\text { * Shaded analytes are the major compound-bearing elements in C-106 solids. }\end{array}$} \\
\hline
\end{tabular}

Based on similar logic presented in Section 4.1, the elemental composition of the solids fraction of the $\mathrm{C}-106$ simulants was normalized to $100 \%$ with the relative proportions of four major elements (aluminum, iron, silicon, and zirconium). This composition is shown in Table 4.4 . 
Table 4.4. Target Composition of C-106 Filtration Simulant

\begin{tabular}{|c|c|c|c|}
\hline \multicolumn{4}{|c|}{ Solids Components } \\
\hline Analyte & $\begin{array}{l}\text { Normalized } \\
\text { Estimates } \\
\text { (Wt \% }\end{array}$ & Target Analyte Bearing Minerals & $\begin{array}{l}\text { Target Mineral } \\
\text { composition } \\
\text { Wt \%) }\end{array}$ \\
\hline Aluminum & $35-37$ & $\begin{array}{c}\text { Boehmite; } \mathrm{AlOOH} \\
\text { Gibbsite; } \mathrm{Al}(\mathrm{OH})_{3} \\
\text { (combined) }\end{array}$ & 37 \\
\hline Iron & $29-46$ & Hematite; $\mathrm{Fe}_{2} \mathrm{O}_{3}$ & 31 \\
\hline Silicon & $5-18$ & Nepheline; $(\mathrm{Na}, \mathrm{K}) \mathrm{AlSiO}_{4}$ & 4 \\
\hline Zirconium & $29^{(a)}$ & Zirconium Hydroxide; $\mathrm{Zr}(\mathrm{OH})_{4}$ & 28 \\
\hline \multicolumn{4}{|c|}{ Supernatant compónénts } \\
\hline Compound & $\begin{array}{c}\text { Target } \\
\text { Concentration }(M)\end{array}$ & Significance & \\
\hline $\mathrm{NaOH}$ & 1.07 & \multicolumn{2}{|l|}{ Liquid viscosity, $\mathrm{pH}$} \\
\hline $\mathrm{NaNO}_{3}$ & 1.00 & \multicolumn{2}{|l|}{ Liquid viscosity, ionic strength } \\
\hline
\end{tabular}

\subsection{Major Mineral Phases}

In order to replicate various factors of PSD, shape, surface charge, rheological properties, agglomeration, and deformation (under shearing flow conditions) of the actual waste, the mineral phases need to be accounted for. Incorporating all of the aluminum, iron, silicon, and zirconium-bearing mineral phases into the simulant design can easily become complicated. Thus, the AZ-101/102 and C-106 slurry simulants were designed to encompass major mineral phases that govern the expected physical and rheological properties as well as filter-cake agglomeration and deformation (under shearing flow conditions). The major phases identified in the actual waste and the criterion for using individual minerals in the simulant design are described below.

The characterization of mineral compounds by electron beam techniques (scanning and transmission electron microscopy with $x$-ray analysis) were conducted on sludges from 21 SSTs and 4 DSTs (Lafemina et al. 1995a, 1995b, 1995c). Considering the compositional variety of tank wastes, relatively few major solids phases were present. The major aluminum-containing precipitates were determined to be gibbsite $\left[\mathrm{Al}(\mathrm{OH})_{3}\right]$ and boehmite $[\alpha-\mathrm{AlOOH}]$. Iron-containing compounds were well-crystallized oxyhydroxide minerals, goethite $(\alpha-\mathrm{FeOOH})$ and hematite $\left(\mathrm{Fe}_{2} \mathrm{O}_{3}\right)$. Much of the silicon in the tank wastes appeared to be in various forms, including zeolites such as cancrinite, amorphous aluminosilicate, clay minerals, feldspar, and sand (Lafemina et al. 1995a, 1995b, 1995c). 
The AZ-101/102 tank waste mineral compounds were postulated using described major minerals for the 25 Hanford tank sludges because microscopy measurements were not performed on actual AZ-101/102 sludge samples. On the other hand, microscopy measurements were conducted on the untreated radioactive C-106 sludge solids (Lumetta et al. 1996). The TEM coupled with the EDS and electron diffraction of the untreated C-106 solids is shown in Figure 4.1.

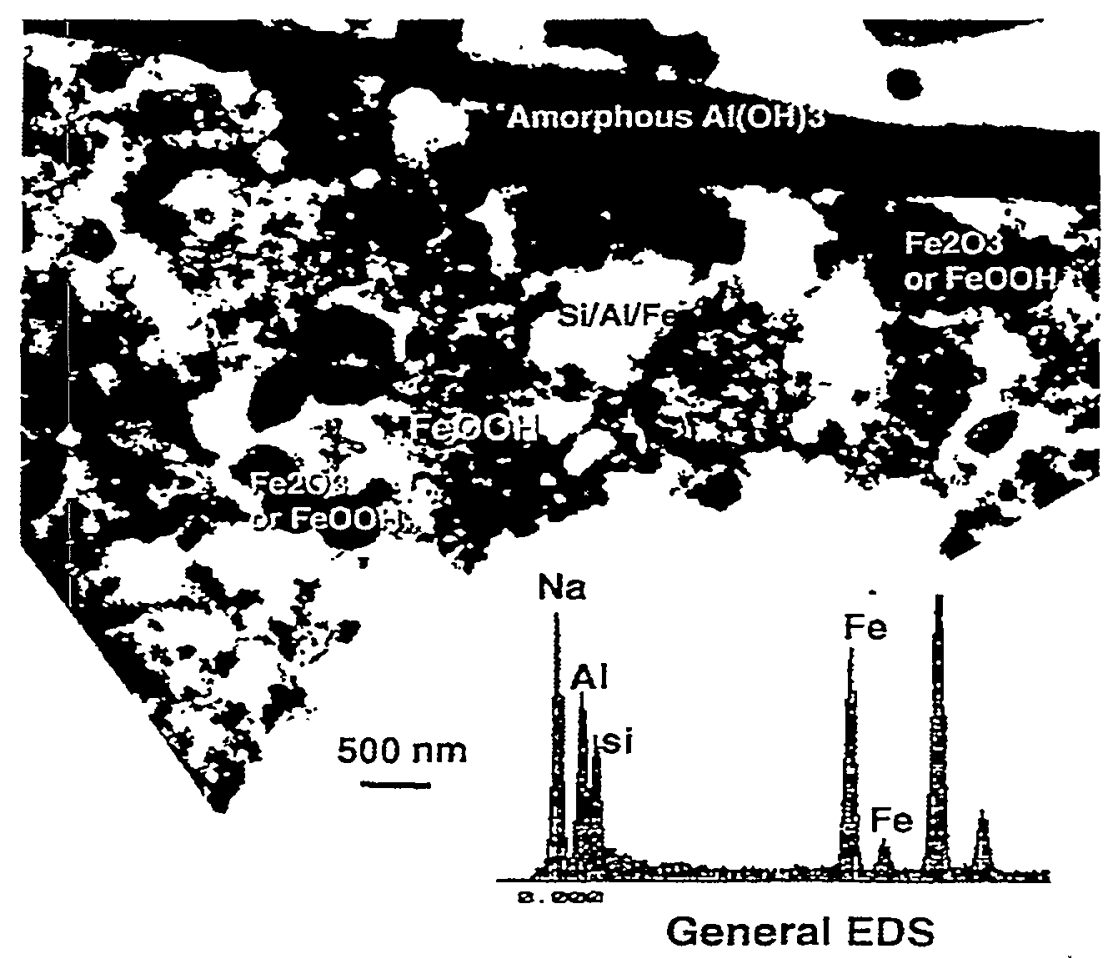

Figure 4.1. TEM and EDS of Large Sample Area of the Untreated C-106 Solids (Lumetta et al. 1996)

Similar to minerals reported in the other 24 tank sludges, the $\mathrm{C}-106$ sludge solids are dominated by gibbsite $\left[\mathrm{Al}(\mathrm{OH})_{3}\right]$, boehmite $[\alpha-\mathrm{AlOOH}]$, goethite $(\alpha-\mathrm{FeOOH})$, hematite $\left(\mathrm{Fe}_{2} \mathrm{O}_{3}\right)$ and aluminum/iron bearing silicates. Lumetta at al. (1996) indicated that $\mathrm{FeOOH}$ was present in both highly crystalline and poorly crystalline forms.

In terms of solids size, the primary particles and agglomerates in actual tank sludges were observed to span five orders of magnitude (Lafemina et al. 1995a, 1995b, 1995c). As shown schematically in Figure 4.2 , the solids are ranging from-1 $\mathrm{nm}$ to $100 \mu \mathrm{m}$ in diameter and vary widely in shape. The small colloidal size particles $(\sim 10 \mu \mathrm{m})$ were found to be zirconium oxide/ hydroxides (1 to $10 \mathrm{~nm}$ ), geothite $(<100 \mathrm{~nm})$, various silicates. $(<100 \mathrm{~nm})$, and boehmite ranging from $100 \mathrm{~nm}$ to $1 \mu \mathrm{m}$. These sub-micron particles tend to form homogeneous or mixed heterogeneous agglomerates that can be as large as $100 \mu \mathrm{m}$ (see Figure 4.2). Single crystals of gibbsite and hematite can exceed $20 \mu \mathrm{m}$ in diameter. 


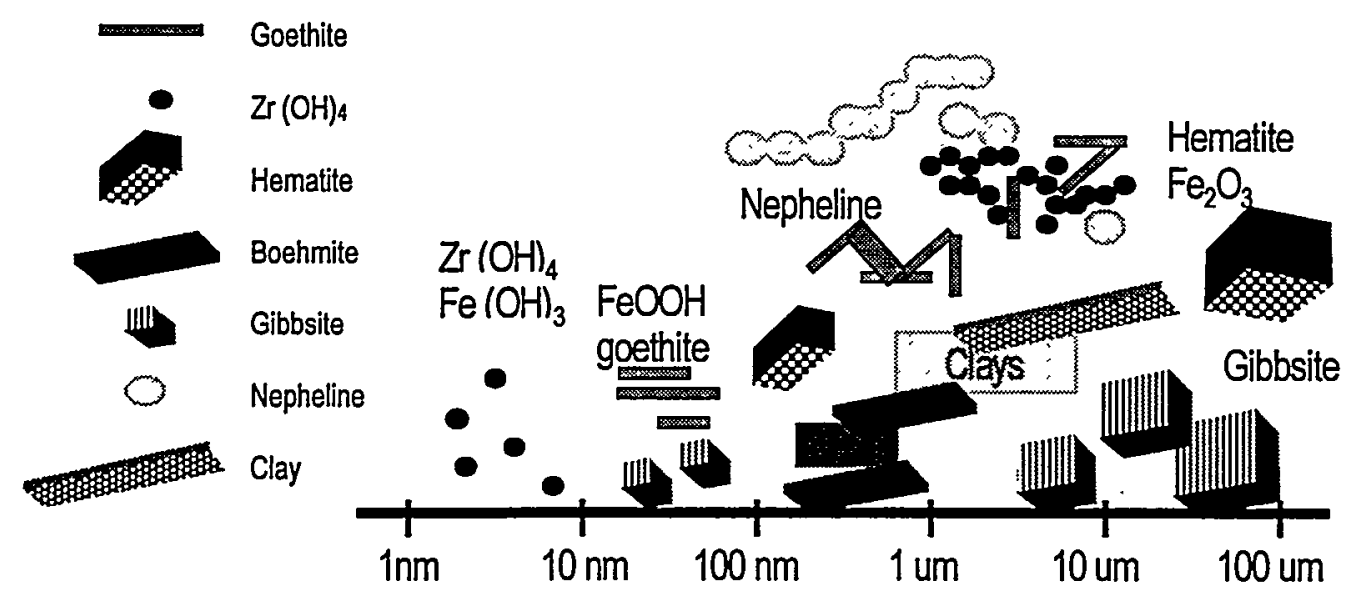

Figure 4.2. Solids Types in the Tank Sludges ${ }^{(a)}$

The illustration of Figure 4.2 demonstrates that mineral phases found in the actual waste represent a wide variety of particle shapes. For example, the boehmite particles are acicular and/or plate-shape particles that have a specific surface area of approximately $280 \mathrm{~m}^{2} / \mathrm{g}$, and gibbsite particles are tabular on the order of 5 to $50 \mathrm{~m}^{2} / \mathrm{g}$. The hematite crystals are approximately spherical (rounded hexagonal) with a surface area on the order of $50 \mathrm{~m}^{2} / \mathrm{g}$. Thus, particles of various forms of spherical, plate like, and needle shapes were accounted for in choosing the simulant minerals.

To design filtration simulants, commercially available powder grades of aluminum, iron, silicon, and zirconium bearing minerals were selected that represent a diverse spectrum of observed actual tank primary particle sizes (less than $10 \mathrm{~nm}$ to $100 \mu \mathrm{m}$ ). Particle or agglomerate size is likely the most important property for the filtration since it impacts filterability. Also, minerals were selected to mimic the formation of both soft and hard agglomerates that behave in different manners under crossflowfiltration shearing flow conditions. Powder grades of boehmite and gibbsite minerals were used since they comprise a large fraction of aluminum-containing minerals. Gibbsite was added in several powdergrade size ranges and ratios to replicate primary gibbsite particles, which either accumulate in soft agglomerate clusters or represent compact crystalline bundles.

Hematite in several size ranges was used for iron-bearing minerals. Powder-grade hematite minerals of narrow $0.6-\mu \mathrm{m}$ size range, broad $2-\mu \mathrm{m}$ size range, and $22-\mu \mathrm{m}$ broad size distribution at various ratios were included in the filtration simulant ${ }^{(b)}$ Although the goethite phase was observed in many actual tank waste sludges, from the standpoint of simulant quality control, it was not considered as a simulant component. The geothite phase is typically synthesized using the Fe (II) or Fe(III) salt solutions. This synthesize path can be time consuming and requires substantial morphological analysis to achieve

(a) Adapted from a view graph presentation by Bruce Bunker et al.

(b) In this text the terms "narrow particle size range" and "broad particle size range" are used to describe the width of a particle peak distribution qualitatively. Details of peak width distribution are provided in Appendix E. 
uniformly consistent sizes. Commercially available powder-grade goethite is expensive to acquire ( $\$ 250$ U.S. currency/5 grams) in large quantities. Thus, geothite was not used in the filtration simulant.

Nepheline $\left[(\mathrm{Na}, \mathrm{K}) \mathrm{AlSiO}_{4}\right]$ and/or $\left(\mathrm{Na}, \mathrm{AlSiO}_{4}\right)$, an aluminosilicate mineral of the feldspathoid group, was used as the silicon-bearing phase. This mineral is commercially available and used as a substitute for cancrinite $\left[\mathrm{Na}_{4} \mathrm{Al}_{3}\left(\mathrm{SiO}_{4}\right)_{3} \mathrm{CO}_{3}\right]$ zeolite seen in tank waste sludges. Nephaline was selected because it contains large openings in the crystal structure similar to cancrinite zeolite and has similar particle characteristics. Once again, a powder-grade nepheline with a broad size distribution of $10 \mu \mathrm{m}$ was used in simulant formulation. A powder-grade zirconium hydroxide was used as the zirconium-containing solid phase.

The minerals described above and illustrated in Figure 4.2 were used as solid-particle building blocks to replicate the PSD results (see Section 6.2) of the actual AZ-101/102 and C-106 wastes and mimic the resulting colloidal and body force inter-particle interactions. Furthermore, close attention was made to encompass a wide spectrum of particle physics that were determined from the mineral phases found in the actual waste. The shape of particles and their surface roughness also affect the rheological properties of the slurry as well as the solids size distribution and the state of agglomerates. By incorporating these factors, unexpected and/or undesirable rheological properties can be evaluated at solids loading of interest. For instance, non-spherical shapes can all provoke particle-particle collisions inducing shearthickening behavior. 


\subsection{Simulant Verification by Crossflow Filtration Testing}

The CUF parametric tests were conducted at various phases of the AZ-101/102 and C-106 simulantdevelopment efforts. The filtrate flux values and the flux-versus-time results from these tests were compared to results available from filtration tests with actual waste samples. All actual waste samples tested show a continuous reduction in filtrate flux over the course of the experiment as a result of floc deagglomeration, particle grinding, and irreversible filter fouling (Geeting et al. 1997; Brooks et al. 2000a, $2000 \mathrm{~b}$ ). In addition, in the course of an individual run condition, the filtrate flux declined. An attempt was made to match the flux decline over the course of an individual run condition for both the $\mathrm{AZ}-101 / 102$ and $\mathrm{C}-106$ filtration simulants.

Results of CUF testing conducted with an actual C-106 sample were used to validate the C-106 simulant (Geeting et al. 1997). In both cases, 0.5- $\mu \mathrm{m}$ Mott filter elements were used. The same transmembrane pressure and axial velocity conditions of the actual waste trials were replicated with the simulant to simplify the comparison. The test matrix and the CUF results are presented and compared in detail in Section 5.2. Further, the final C-106 formulation was tested using a BNFL-specified testing matrix and the BNFL baseline 0.1- $\mu \mathrm{m}$ Mott filter.

During the development of the AZ-101/102 simulant formulation, filtration results for the actual AZ-102 sample were not available. Consequently, the objectives of the AZ-101/102 simulant development effort were to replicate the PSD and rheological characteristics of the actual NCAW slurry. Additionally, the simulant was developed to exhibit a reduction in filtrate flux over the course of an individual condition as well as throughout the entire experiment. The reduction in filtrate flux over an individual condition is believed to be caused by a build-up in material on the filter surface. The reduction in filtrate flux throughout the entire experiment (in spite of backpulsing) is believed to be caused by deagglomeration of the particles by induced shearing in the CUF circulation loop as well as filter fouling. This phenomena has been seen many times with actual waste, but is more difficult to obtain with simulants (see Geeting et al. 1996, 1997). Thus, during the CUF trials, the AZ-101/102 simulant formulation was checked and adjusted several times to obtain a simulant that exhibits a decreasing filtrate flux as a function of time. The final simulant formulation was evaluated using a BNFL-specified testing matrix that was similar to the test matrix used for testing the actual AZ-102 sample. The results of the CUF testing with the AZ-101/102 simulant are discussed in Section 5.3.

\subsection{Testing Overview and Apparatus}

Crossflow filtration testing of both HLW Envelope D filtration simulants was conducted on a Battelle-modified CUF, with the following specifications:

- single tube filter module, 61-cm-long tube; 0.952-cm ID

- a Mott liquid-service stainless steèl filter

- re-circulation flow such that $5 \mathrm{~m} / \mathrm{s}(15 \mathrm{ft} / \mathrm{s})$ maximum linear crossflow velocity can be achieved through the filter tube with water

- maximum transmembrane pressure 80 psid with water. 
A photograph of the CUF used for this testing is shown in Figure 5.1. The slurry feed is introduced into the CUF through the slurry reservoir. An Oberdorfer progressive cavity pump (powered by an air motor) pumps the slurry from the slurry reservoir through the magnetic flow meter and the filter element. The axial velocity and trans-membrane pressure are controlled by the pump speed (which is controlled by the pressure of the air supplied to the air motor) and the throttle valve position. Additional details of the CUF equipment are provided in Brooks et al. (2000a, 2000b).

The C-106 simulant was tested in the CUF at conditions similar to those used for the actual C-106 sample. For both tests, the filtrate was recycled back into the feed tank to maintain the steady-state solids concentration. Each condition was run for $60 \mathrm{~min}$ with backpulsing once after 30 minutes of operation during the condition similar to the actual C-106 trials. The data were taken every 5 minutes. Between each condition, the system was backpulsed twice. The slurry temperature was maintained at $25 \pm 5^{\circ} \mathrm{C}$ for all filtrate rate testing. The temperature was corrected (for both simulant and actual waste) to $25^{\circ} \mathrm{C}$ using the formula (Equation 5.1) provided by BNFL to correct for viscosity and surface tension changes:

$$
\text { Flux }_{25 C}=F_{T} e^{1200\left(\frac{1}{273+T}-\frac{1}{298}\right)}
$$

where.Flux $25 \mathrm{C}$ is the corrected filtrate flux, and $\mathrm{T}$ is the temperature $\left({ }^{\circ} \mathrm{C}\right)$ at the flux measurement $\left(\mathrm{Flux}_{\mathrm{T}}\right)$.

The C-106 and AZ-101/102 simulants were also tested with a $0.1-\mu \mathrm{m}$ Mott liquid-service stainless steel filter. For these tests, the BNFL HLW filtration test conditions are based on an empirically derived matrix to determine the optimum de-watering conditions for the feed slurry. A 5-point matrix around the center-point at $50 \mathrm{psid}$ and $12.2 \mathrm{ft} / \mathrm{s}$ tests the conditions of TMP ( $30 \mathrm{psid}, 50 \mathrm{psid}, 70 \mathrm{psid}$ ) and velocity $(9.1 \mathrm{ft} / \mathrm{s}, 12.2 \mathrm{ft} / \mathrm{s}, 15.2 \mathrm{ft} / \mathrm{s})$. The filtrate was recycled back into the feed tank to maintain the steady-state solids concentration for testing. Each condition was run for 60 minutes with data taken every 5 minutes similar to the current BNFL HLW testing plans (see Brooks et al. 2000a,b). The system was backpulsed twice between each condition, but was not backpulsed during the testing at each condition. The slurry temperature was maintained at $25 \pm 5^{\circ} \mathrm{C}$ for all filtration testing.

Following the filtration tests with each simulant formulation, the slurry was drained from the CUF and the CUF was rinsed thoroughly with water. One liter of $1 \mathrm{MHNO}_{3}$ was then circulated in the CUF for approximately 30 minutes, or until high filtration fluxes were attained. The acid was drained, and the system was flushed with water. After the CUF had been thoroughly cleaned, testing to establish a background filtrate flux was conducted with de-mineralized water, prefiltered using a 0.1 micron absolute rated Millipore filter. Clean water flux testing was performed in the CUF at 20,10, and 30 psid. Once the filtration flux exceeded $2.5,1.0$, and $2.8 \mathrm{gpm} / \mathrm{ft}^{2}$, respectively, the filter was considered clean, and the next set of tests could be performed. These flux values were found during the initial filter testing with water. 


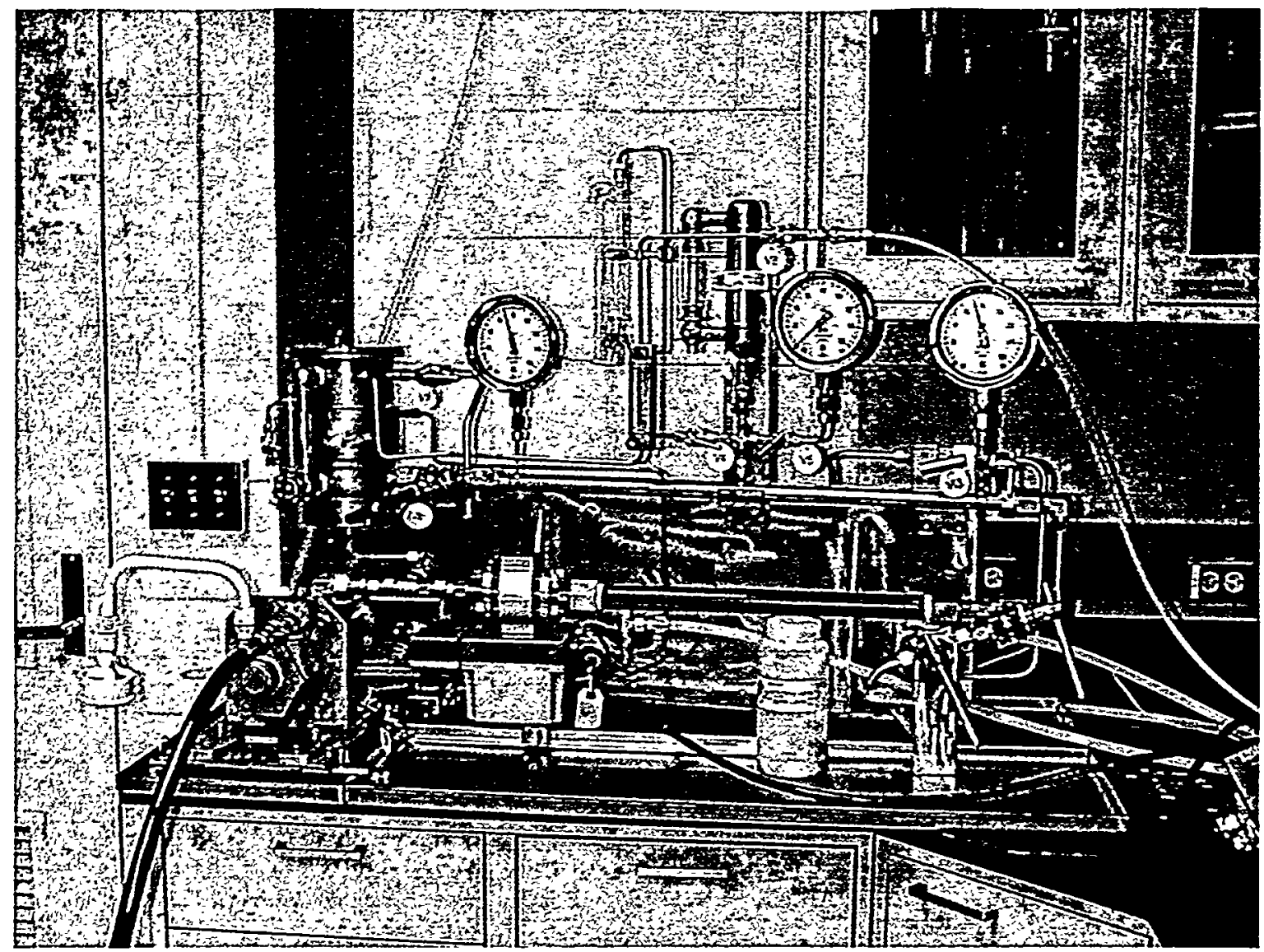

Figure 5.1. Photograph of the Cold Crossflow Filtration System

\subsection{C-106 Simulant Slurry Crossflow Filtration}

The C-106 simulant developed during this effort was evaluated with the 0.1 - and $0.5-\mu \mathrm{m}$ Mott filters. The $0.5-\mu \mathrm{m}$ rated filter testing provided a comparison with previous experimental data obtained with an actual C-106 sample (see Geeting et al. 1997). The results obtained with the $0.1-\mu \mathrm{m}$ rated filter provide a means of comparing the results of the small-scale CUF tests to the results of the Sellafield pilot-scale tests.

The results of test matrices comparing simulated and actual C-106 filtration are shown in Table 5.1. Actual velocities and pressures for both tests were within 5\% of the target values, and both test matrices were performed at $8 \mathrm{wt} \%$ insoluble solids. Representative flux vs. time curves are presented in Figures 5.2 and 5.3. These curves are the results of testing Conditions 8 and 9, respectively. The filtrate flux curves for all other Conditions are provided in Appendix $\mathrm{C}$. The figures show the filtrate flux decline is reasonably close in curve shape to the actual waste. In most cases, the average filtrate flux of the simulant is within $30 \%$ of the actual waste filtrate flux. The filtrate flux for the simulant, however, is generally slightly greater than the filtrate flux for the actual waste. The difference in filtrate flux is greatest for condition 8 (Figure 5.2), which is also the condition of lowest pressure. For simulant 
Condition 9 shown in Figure 5.3, the filtrate fluxes are reasonably similar. This is the condition of lowest axial velocity. Overall, the simulant filtrate fluxes are closest to the actual waste filtrate fluxes at conditions that produce low filtrate fluxes. The filtrate flux profiles for simulant and the actual waste at each condition are presented and compared in detail in Appendix $\mathrm{C}$.

Table 5.1. Test Conditions and Average Filtrate Flux for the C-106 Simulated and Actual Waste using a 0.5-Micron Mott Filter

\begin{tabular}{|c|c|c|c|c|c|c|c|}
\hline \multirow{2}{*}{$\begin{array}{c}\ddots \\
\text { Condition } \\
\ddots\end{array}$} & \multirow[b]{2}{*}{$\begin{array}{l}\text { Target } \\
\text { Yelocity } \\
\text { (ft/s) }\end{array}$} & \multirow{2}{*}{$\begin{array}{l}\text { Target } \\
\text { Pressure } \\
\text { (nsid) }\end{array}$} & \multicolumn{4}{|c|}{ Average Filtrate Flux (gpm/ft) } & $\therefore$ \\
\hline & & & $\begin{array}{l}\text { Simulant } \\
\left(1^{\text {si }} 30 \text { min }\right)\end{array}$ & Simalant & $\begin{array}{l}\text { Actual } \\
\text { Waste } \\
\text { (10 } 30 \text { min) }\end{array}$ & $\begin{array}{l}\text { Actual } \\
\text { Waste } \\
(20 \text { min })\end{array}$ & $\begin{array}{l}\% \% \\
\text { Difference (a) } \\
\therefore\left(1^{\text {st }} / 2^{\mathrm{nd}}\right)\end{array}$ \\
\hline 1 & 6 & 20 & 0.046 & 0.039 & 0.032 & 0.031 & $36 \% / 23 \%$ \\
\hline 2 & 4.5 & 12.5 & 0.027 & 0.029 & 0.024 & 0.024 & $12 \% / 19 \%$ \\
\hline 3 & 9 & 20 & 0.052 & 0.047 & 0.044 & 0.050 & $17 \% /-6 \%$ \\
\hline 4 & 6 & 35 & 0.032 & 0.027 & 0.024 & 0.028 & $29 \% /-4 \%$ \\
\hline 5 & 4.5 & 27.5 & 0.026 & 0.026 & 0.023 & 0.022 & $12 \% / 17 \%$ \\
\hline 6 & 6 & 20 & 0.034 & 0.033 & 0.029 & 0.029 & $16 \% / 13 \%$ \\
\hline 7 & 7.5 & 12 & 0.045 & 0.048 & 0.035 & 0.036 & $25 \% / 29 \%$ \\
\hline 8 & 6 & 5 & 0.043 & 0.054 & 0.018 & 0.028 & $82 \% / 26 \%$ \\
\hline 9 & 3 & 20 & 0.018 & 0.019 & 0.016 & 0.017 & $12 \% / 11 \%$ \\
\hline 10 & 7.5 & 27 & 0.042 & 0.039 & 0.033 & 0.032 & $24 \% / 20 \%$ \\
\hline 11 & 6 & 20 & 0.033 & 0.029 & 0.026 & 0.028 & $24 \% / 4 \%$ \\
\hline
\end{tabular}

(a) Relative Percentage Difference $=\left(2\left(V_{s}-V_{a}\right) /\left(V_{s}+V_{a}\right)\right) \times 100$ where: $\quad V_{s}=$ Average simulant filtrate flux $\geq 10 \mathrm{~min}$

$\mathrm{V}_{\mathrm{a}}=$ Average Actual waste filtrate flux $\geq 10 \mathrm{~min}$ 


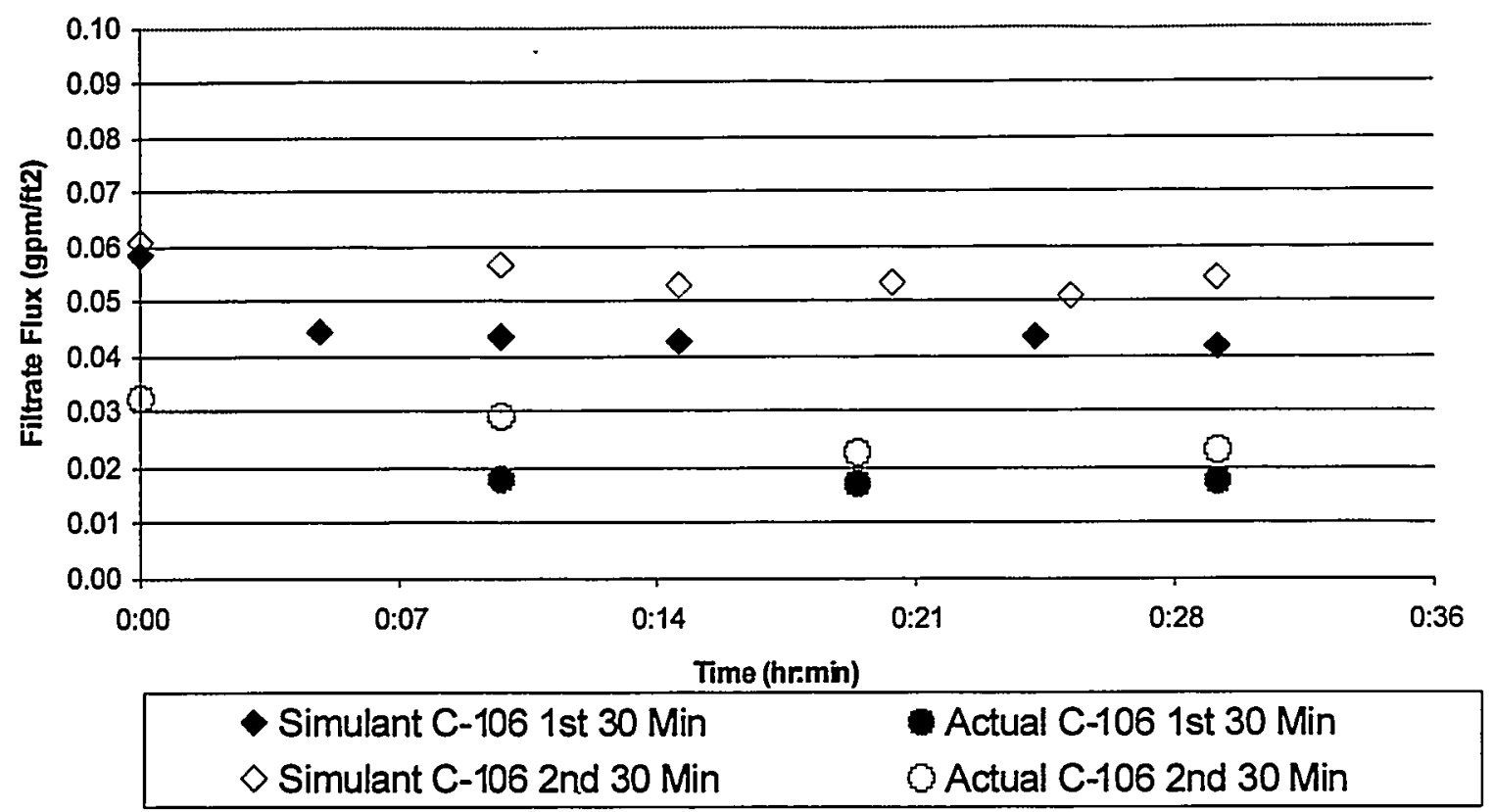

Figure 5.2. Filtrate Flux as a Function of Time for Actual and Simulated C-106 using a 0.5-Micron Mott Filter at $5 \mathrm{psig}, 6 \mathrm{ft} / \mathrm{s}$ and $8 \mathrm{wt} \%$ Solids (Condition 8) 


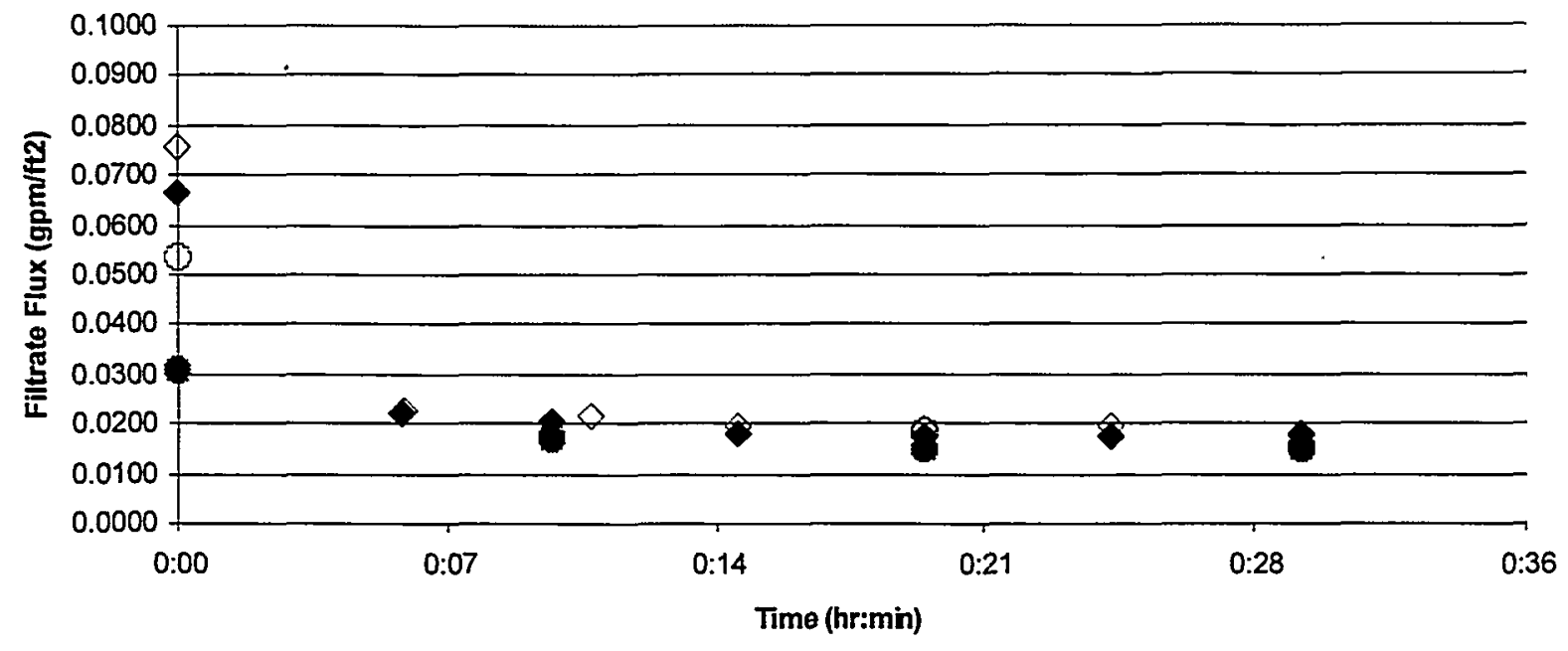

\begin{tabular}{|ll|}
\hline Simulant C-106 1st 30 Min & Actual C-106 1st 30 Min \\
$\diamond$ Simulant C-106 2nd 30 Min & OActual C-106 2nd 30 Min \\
\hline
\end{tabular}

Figure 5.3. Filtrate Flux as a Function of Time for Actual and Simulated C-106 using a 0.5-Micron Mott Filter at $20 \mathrm{psig}, 3 \mathrm{ft} / \mathrm{s}$ and $8 \mathrm{wt} \%$ Solids (Condition 9)

The C-106 simulant was also tested using the $0.1-\mu \mathrm{m}$ Mott liquid-service filter. In this case, a different matrix, developed by BNFL for actual waste testing, was performed (see Brooks et al. 2000a, $2000 \mathrm{~b}$ ). The test conditions and average filtrate flux for this matrix are shown in Table 5.2. This testing matrix contains much higher axial velocities and pressures than that performed by Geeting et al. (1997) and results in higher filtrate fluxes. The average, initial, and final filtrate flux values of these tests are shown in Figure 5.4. The curves showing filtrate flux as a function of time are presented in Appendix $C$.

Table 5.2. Test Conditions for the C-106 Simulant Slurry using a 0.1 Micron Mott Filter

\begin{tabular}{|c|c|c|c|}
\hline & $\begin{array}{c}\text { Target } \\
\text { Velocity } \\
\text { (ft/s) }\end{array}$ & $\begin{array}{c}\text { Target } \\
\text { Pressure }\end{array}$ & $\begin{array}{c}\text { Average } \\
\text { (psid) }\end{array}$ \\
\hline 1 & 12.2 & 50 & 0.071 \\
\hline 2 & 9.2 & 30 & 0.064 \\
\hline 3 & -11.3 & 70 & 0.115 \\
\hline 4 & 11.4 & 30 & 0.082 \\
\hline 5 & 9.1 & 70 & 0.096 \\
\hline 6 & 12.2 & 50 & 0.079 \\
\hline
\end{tabular}

The highest filtrate flux for the simulant occurred at the highest pressure and a high axial velocity. This result is to be expected in a regime where Darcy's Law applies-increased pressure results in increased filtrate flux. It is surprising, though, that Condition 4 with a trasmembrane pressure of 30 psid has a similar filtrate flux to Condition 6 with similar axial velocities at 50 psid pressure. This simulant 


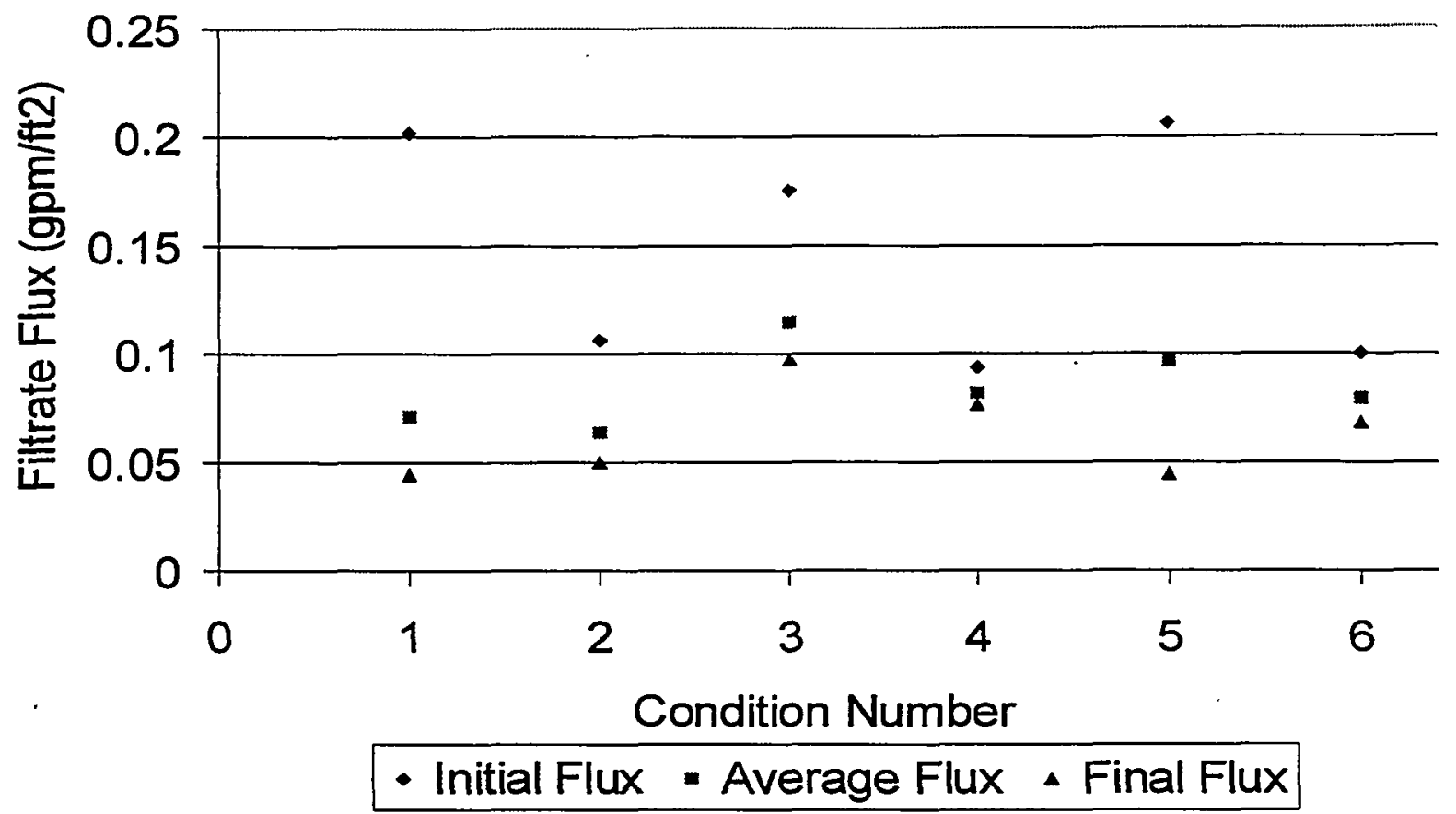

also shows an increase in filtrate flux in Condition 6 when compared to Condition 1. This result suggests little filter fouling or particle deagglomeration for this particular simulant over the course of the entire experiment.

\subsection{AZ-101/102 Simulant Slurry Crossflow Filtration}

The AZ-101/102 simulant developed during this effort was evaluated with the $0.1-\mu \mathrm{m}$ Mott filter. Although no actual waste AZ-101/102 CUF data were available during this work, efforts were made to create a simulant that would have a decreasing flux over time, similar to that seen in CUF testing of most actual waste samples. These results also provide a means of comparing the small-scale CUF tests to the Sellafield pilot-scale tests.

The testing matrix was performed with the simulant prepared at 5 and $15 \mathrm{wt} \%$ insoluble solids. Similar to the solids loading conditions performed with the actual AZ-102 waste sample (Brooks et al. $2000 \mathrm{~b}$ ). The target transmembrane pressure and axial velocity conditions along with the average filtrate flux are shown in Table 5.3. These conditions were the same as performed with the actual AZ-102 sample tested by Battelle with the hot CUF ultrafilter during January 2000 . Once the results of this upcoming study are published, they can be compared to the simulant results provided here.

Figure 5.4. Initial, Average, and Final Filtrate Flux for Each Test Condition with the C-106 Simulant using a 0.1-Micron Mott Filter and 8 wt\% Solids

The average filtrate flux results for both of these conditions are shown in Figure 5.5. The filtrate flux as a function of time for each condition are provided in Appendix C. Figure 5.5 shows that the filtrate flux 
obtained with the simulant with a $5 \mathrm{wt} \%$ solids loading is about $70 \%$ higher than the filtrate flux obtained with the simulant with a $15 \mathrm{wt} \%$ solids loading. This figure also shows that although for both solids concentrations, Conditions 1 and $6(\sim 9 \mathrm{ft} / \mathrm{s}$ and $50 \mathrm{psid})$ were nearly identical in velocity and pressure, Condition 1 has a higher filtrate flux. This indicates an overall decrease in filtrate flux over time, similar to what is seen in during actual waste testing due to 1) filter fouling and 2) agglomerate break-up due to the pump shear.

Table 5.3. Test Conditions and Average Filtrate Flux for the AZ-101/102 Simulant using a 0.1 -Micron Mott Filter at 5 and $15 \mathrm{wt} \%$ Solids

\begin{tabular}{|c|c|c|c|c|c|}
\hline \multirow{2}{*}{ 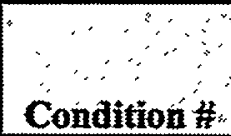 } & \multirow{2}{*}{$\begin{array}{l}\text { Yelocity } \\
5 \text { wt } \% \\
\text { (fts) }\end{array}$} & \multirow{2}{*}{$\begin{array}{l}\text { Velocity } \\
15 \text { wt } \% \\
\text { (tits) }\end{array}$} & \multirow{2}{*}{$\begin{array}{l}\text { Pressure } \\
\text { (psid) }\end{array}$} & \multicolumn{2}{|c|}{ Filtrate Flux (gpm/ft2) } \\
\hline & & & & $5 \times+\%$ & 15 w\% \\
\hline 1 & 9.4 & 7.8 & 50 & 0.198 & 0.092 \\
\hline 2 & 7.6 & 6.6 & 30 & 0.115 & 0.062 \\
\hline 3 & 7.2 & 5.9 & 70 & 0.124 & 0.062 \\
\hline 4 & 7.8 & 8.5 & 30 & 0.104 & 0.069 \\
\hline $6^{*}$ & 8.6 & 8.9 & 50 & 0.115 & 0.077 \\
\hline 7 & 13.1 & 11.5 & 30 & 0.104 & 0.072 \\
\hline
\end{tabular}

*Condition 5 in the actual waste testing was not performed. It was also not performed here for consistency.

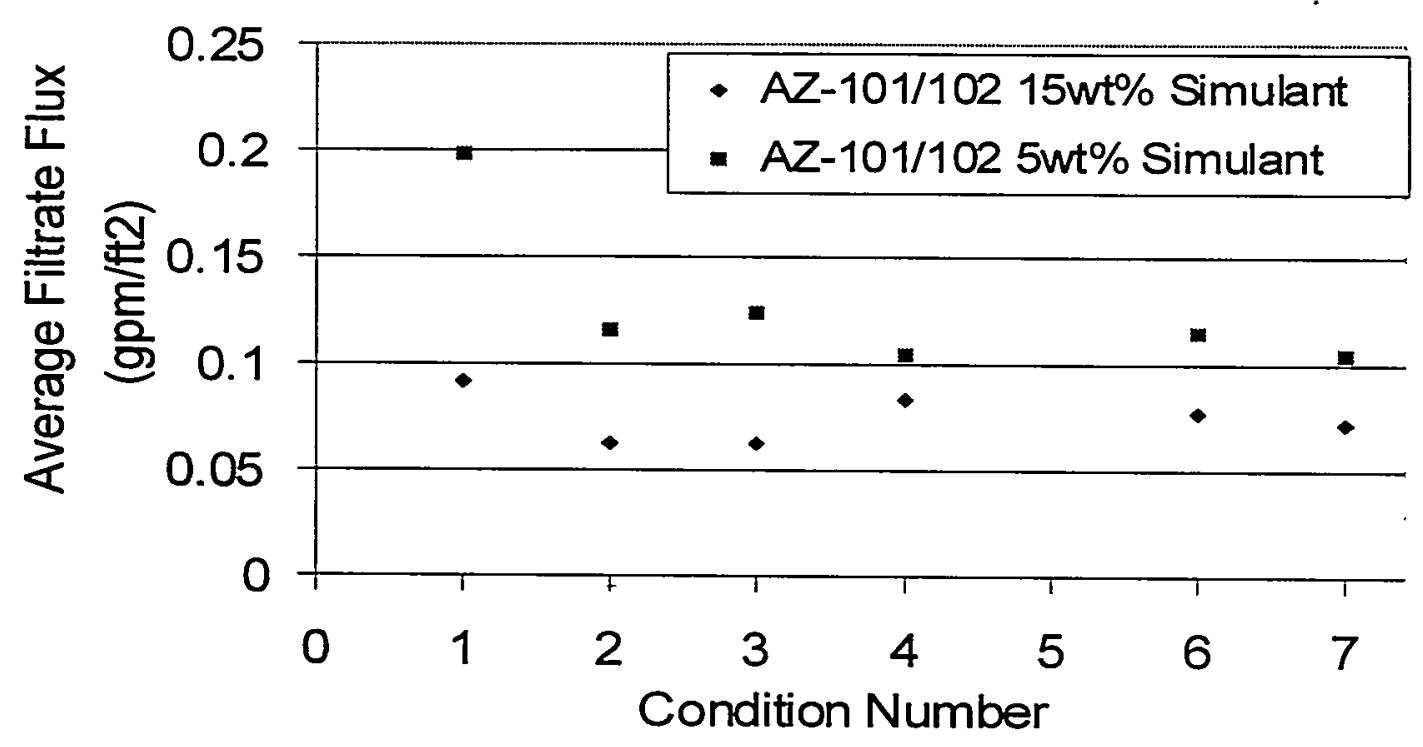

Figure 5.5 Average Filtrate Flux for Each Test Condition with the Simulated AZ-101/102 using a 0.1-Micron Mott Filter with 5 and $15 \mathrm{wt} \%$ Solids 


\subsection{Comparison to Other Simulant and Actual Waste Tests}

The decrease in filtrate flux of the AZ-101/102 simulant over the course of testing due to filter fouling and/or particle deagglomeration has not been seen in previous simulant studies, but is consistent with actual waste testing. Filtration simulants S-3 and S-103 were developed as part of Geeting et al. (1996). These simulants were meant to be used as general " $\mathrm{HLW}$ " filtration simulants. The S-3 simulant contained boehmite and gibbsite in a $0.1 \mathrm{M} \mathrm{NaOH}$ solution. The S-103 simulant was a mixture of precipitated ferric hydroxide, boehmite, gibbsite, silica, and calcium phosphate precipitated to a $\mathrm{pH}$ of 10 . These were tested with a $0.5-\mu \mathrm{m}$ Mott filter using the same conditions as described in Table 5.1. As with the work presented here, the first condition was at the same transmembrane pressure and axial velocity as the final condition, thus quantifying any decreases during the course of the test.

The initial and final filtrate fluxes are presented in Figure 5.6 below. Actual tank wastes S-107 and C-107 were also tested under similar conditions with a $0.5-\mu \mathrm{m}$ Mott filter. These are also shown in the Figure. Note that the filtrate fluxes obtained with simulants S-3 and S-103 do not decrease from the initial to the final condition using the same filter. In contrast, all of the actual wastes decrease. The actual C-106 test using a $0.5-\mu \mathrm{m}$ Mott filter shows the least decrease in filtrate flux. This is consistent with the C-106 simulant which had very little decrease in filtrate flux as well. In contrast, the AZ-101/102 simulant has a significant decrease in filtrate flux from the initial to the final condition, indicating it may better represent actual waste than previously developed simulants. The absolute value of the AZ-101/102 filtrate flux is considerably higher than for any of the other tests. This may be because it was performed with the much higher pressure and axial velocity test matrix using a $0.1-\mu \mathrm{m}$ Mott filter.

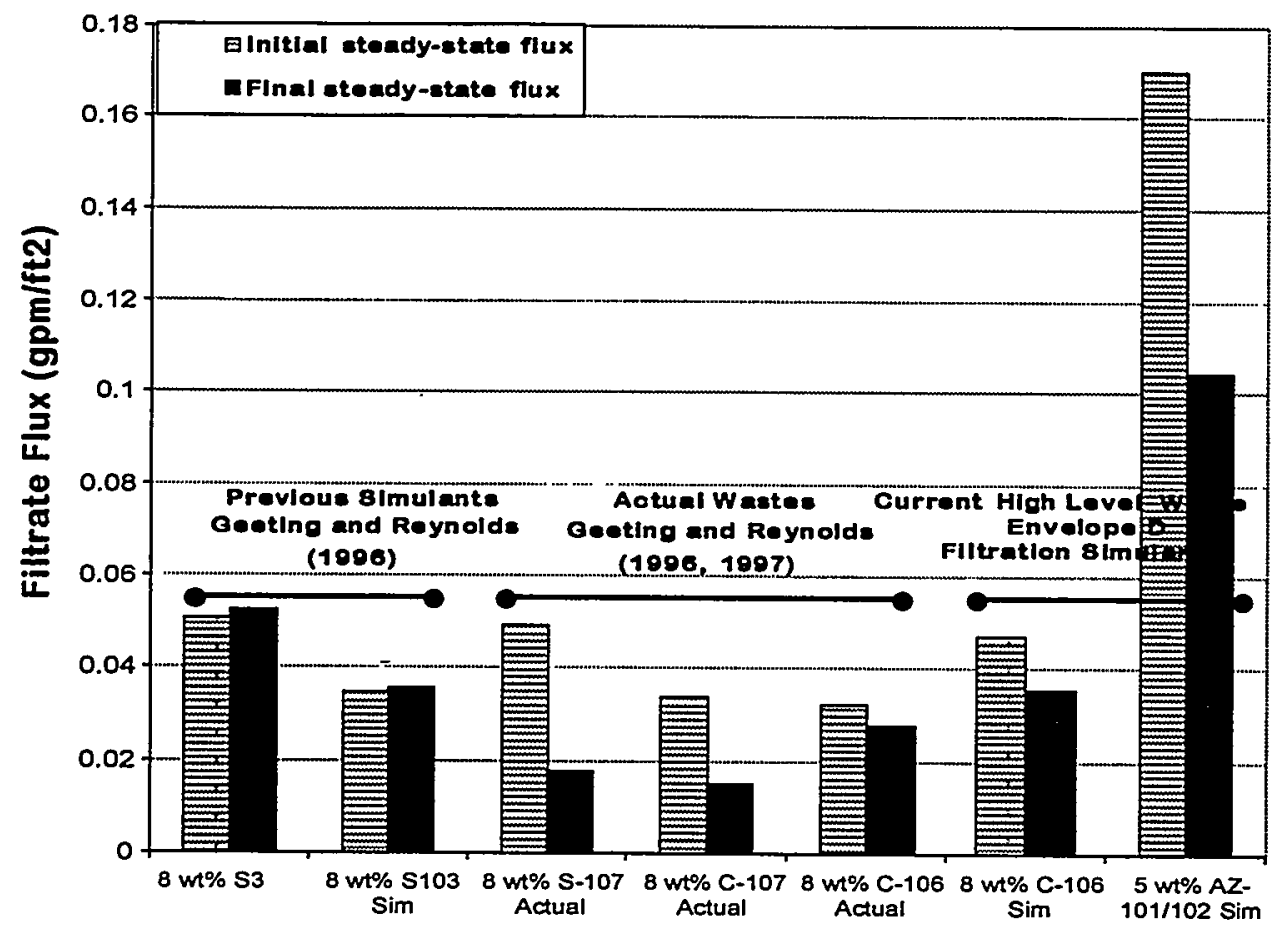

Figure 5.6. Comparison of Average Filtrate Flux for the Initial and Final Conditions of the CUF Filtration Matrix 


\subsection{Physical and Rheological Properties}

The PSD and rheological properties of the filtration simulant are presented in this section. These results were compared with the available actual waste results at the same solids loading and similar supernatant ionic strength. It should be noted that for the AZ-101/102 waste, the rheology of unwashed and unleached actual waste was compared with the filtration simulant.

\subsection{Rheology}

The rheological results of the radioactive NCAW were used in developing the AZ-101/102 crossflow filtration simulant. The viscosity profiles and the calculated power law models for

- the second core sample from Tank AZ-101 at 10 and $30 \mathrm{wt} \%$ undissolved solids concentration were described in Gary et al. (1990)

- the first core sample from Tank AZ-102 at 10 and $40 \mathrm{wt} \%$ undissolved solids concentration, reported in Gary et al. (1993),

were applied to mimic the NCAW slurry rheological characteristics. In Section 6.1.1, the experimental process for conducting simulant rheology is described in detail, and the rheological results of actual slurry and simulant slurry for AZ-101/102 waste types are compared in Section 6.1.2.

Unlike the NCAW waste, the available rheological results for actual C-106 sludge (Urie et al. 1997) were not applicable to the C-106 simulant developed under this task because the rheology of actual C-106 waste was conducted at too low of solids loading. As a result, the actual C-106 waste rheological data was not used for designing the C-106 filtration simulant. In Section 6.1.3, the rheological characteristics of the C-106 simulant slurry at various solids loading are presented only to document the rheological properties of this simulant.

\subsubsection{Experimental}

The rheological measurements of the AZ-101/102 and C-106 slurry simulants were conducted using a Haake rotational viscometer with a CV20 and an M-5 system. For both systems concentric cylinder geometries were used. The concentric cylinder geometry was used to replicate a steady-state shear flow in slurries. In these studies, shear stress as a function of shear rate (controlled rate experiments) were performed. A ME45 concentric cylinder geometry for the CV20 system and a MV1 for the M-5 system, both of which are suitable for medium viscous slurries, were used to measure the slurries. Ascending and descending curves were collected over a run period of 4 minutes for both systems ( 2 minutes in each direction). The ascending curve was obtained by increasing shear rate from 0 to 300 or $1000 \mathrm{~s}^{-1}$ and the descending curve was collected by decreasing the shear rate from 300 or $1000 \mathrm{~s}^{-1}$ to $0 \mathrm{~s}^{-1}$. The temperature of the system was kept at $25^{\circ} \mathrm{C}$ by a water bath.

The CV20 system with an ME45 geometry was used to capture the de-agglomeration of various agglomerates (both weak and compact) as the slurry samples were sheared. For the CV20 system, the shear stress was measured over the shear rate range of 0 to $300 \mathrm{~s}^{-1}$. The M-5 system with an MV1 geometry was used to measure the shear stress over the shear rate range of 0 to $1000 \mathrm{~s}^{-1}$ since the 
ranges of shear rates for flow in a pipe (similar to the crossflow filtration loop) is about 1 to $1000 \mathrm{~s}^{-1}$ (Barnes 1993). ${ }^{(a)}$

\subsubsection{Rheology of AZ-101/102 Slurries}

In this section, the results of the rheological measurements for the AZ-101/102 simulant slurries at known solids contents are discussed. Furthermore, the rheological characteristics of the AZ-101/102 simulant slurries are compared with the characteristics of radioactive slurries at similar solids loadings.

The instantaneous viscosity (or apparent viscosity) ${ }^{(b)}$ profile and experimental yield-stress values for the AZ-101/102 simulant slurry at various solids loadings were determined from the controlled shear-rate experiments. Figure 6.1 shows the viscosity as a function of shear rate for the $\mathrm{AZ}-101 / 102$ simulants at 10,30 , and $40 \mathrm{wt} \%$ undissolved solids concentrations in linear and logarithmic scale.

The plots of viscosity as a function of shear rate indicate that the viscosity for the AZ-101/102 simulants at all solids loadings drops to less than $30 \mathrm{mPa}$.s as the shear rate increases from about 0 to $300 \mathrm{~s}^{-1}$, representing a common shear-thinning behavior. The shear-thinning behavior indicates that the shearing action breaks the agglomerate structures. This behavior is desirable because it suggests that 1) the agglomerates are formed in the AZ-101/102 slurry simulant, and 2) the agglomerates break apart as a function of the shear rate over time. Similar behavior has been seen in the actual waste. It is expected that the AZ-101/102 simulant slurry exhibit a decreasing filtration flux over time as the agglomerates break during the crossflow filtration testing (see Section 5.3).

(a) Close attention to the range of shear rate is made because in a slurry system shear stresses are not linearly related to the shear rate and the slurry behaves as a "non-Newtonian" suspension. In a Newtonian fluid, the shear stress is linearly proportional to the shear rate by a constant viscosity factor. But, the addition of solid particles to a Newtonian fluid produces non-Newtonian behavior where the shear stress is a non-linear function of shear rate; and the viscosity of slurry depends on the shear rate. In dealing with non-Newtonian fluids the viscosities are expressed in terms of shear stress and shear rate at some instant in time.

(b) In this report, the term instantaneous viscosity or apparent viscosity is simply defined as the viscosity measured at one specific shear rate. 

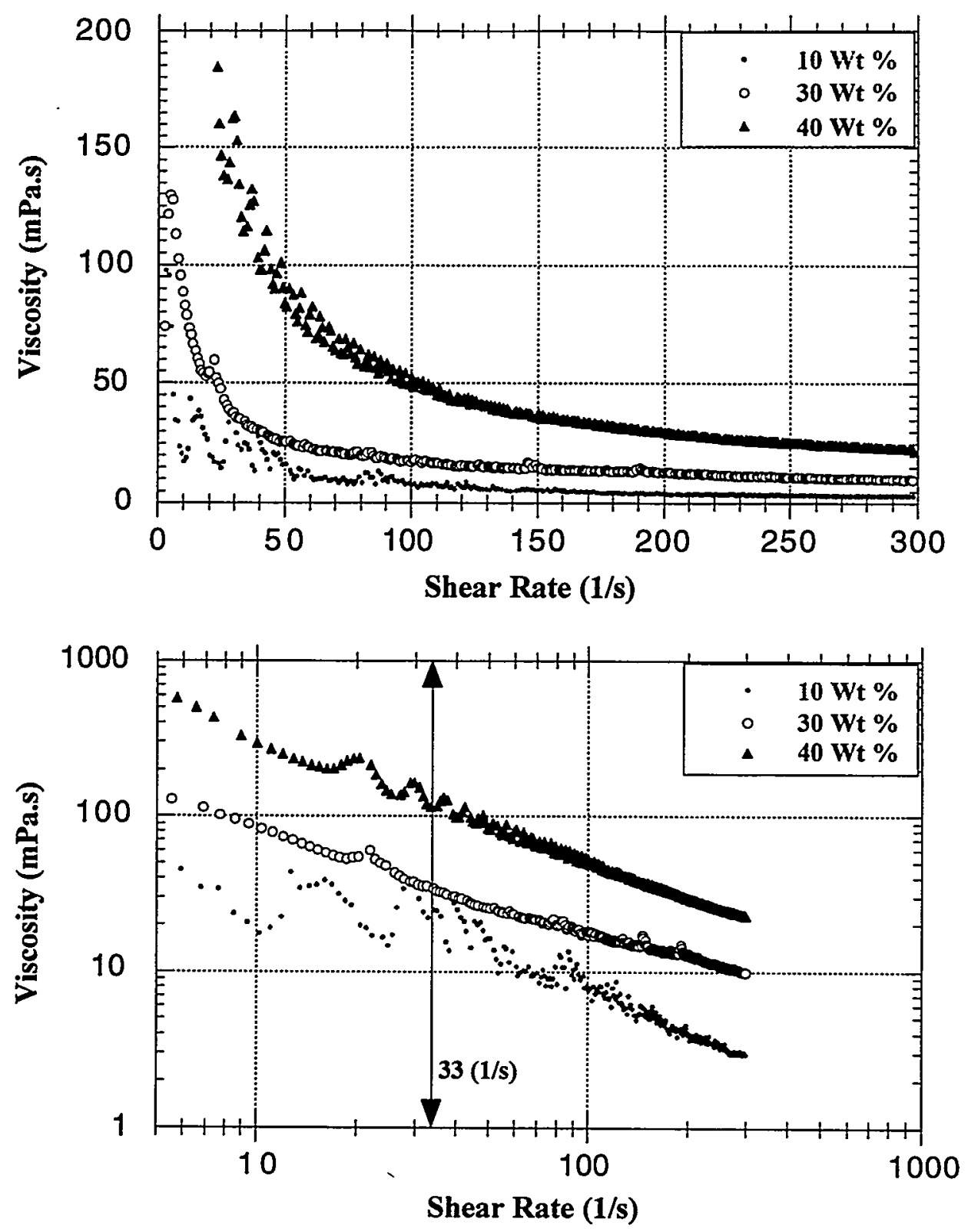

Figure 6.1. Viscosity as a Function of Shear Rate at $25^{\circ} \mathrm{C}$ for the AZ-101/102 Filtration Simulant 
Figure 6.2 shows the plots of shear stress as a function of shear rate for the AZ-101/102 simulant slurry at 10,30, and $40 \mathrm{wt} \%$ undissolved solids concentrations. The rheology of the AZ-101/102 simulant $(0$ to $300 \mathrm{~s}-1)$ at 30 and $40 \mathrm{wt} \%$ undissolved solids concentrations displays a yield stress of approximately 2.0 to $5.0 \mathrm{~Pa}$. The maximum yield stress at lower solids loading of $10 \mathrm{wt} \% \mathrm{un}$ dissolved solids concentration is below $1.0 \mathrm{~Pa}$. The yield stress was determined by extrapolating the linear portion of the measured shear stress in the direction of increasing shear rate ("up-curve") as a function of shear rate to shear rate $=0$.

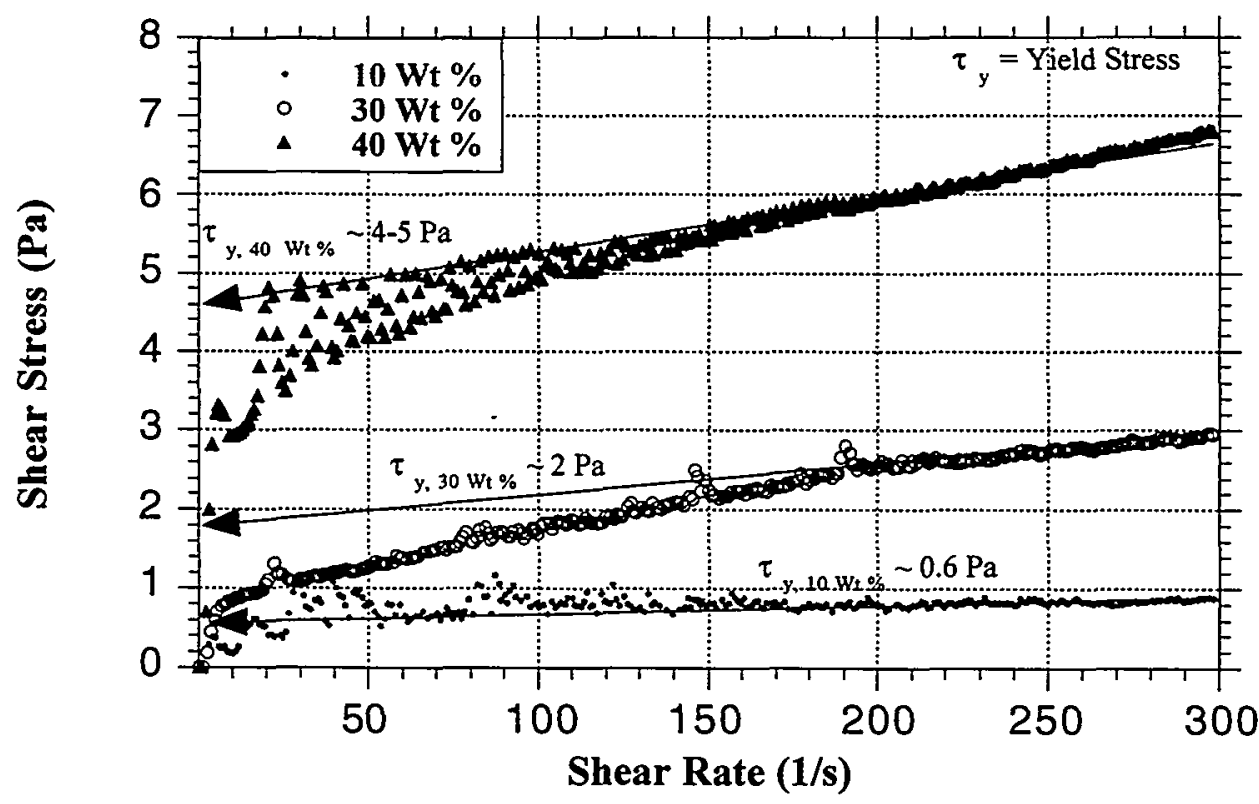

Figure 6.2. Shear Stress verses Shear Rate at $25^{\circ} \mathrm{C}$ for the $\mathrm{AZ}-101 / 102$ Filtration Simulant

In all cases, the rheology of the AZ-101/102 simulant slurries (at various solids loading) is mathematically modeled as the Bingham rheology, which is commonly used to describe suspensions that exhibit yield-Newtonian behavior. A yield-pseudoplastic characteristics was observed between 0 to $300 \mathrm{~s}^{-1}$, however, are observed because the rheogram was not measured at sufficiently high shear rates to detect the constant, high shear, Bingham viscosity. Mathematically, Bingham rheology differs from the yield pseudoplastic, but in practice, they are quite similar.

Furthermore as the solids content (wt\% undissolved solids concentration) increases, the simulant shows a higher time-dependent rheology evident from the observed thixotropy in the shear-stress plots. The thixotropy (the difference between the up-curve and down-curve) is caused by agglomerates being broken down as the slurry is sheared during the course of the test. As the solids loading increases from 10 to $40 \mathrm{wt} \%$, the slurry becomes highly agglomerated and this effect is more pronounced. In this case, as the shear rate increases at higher solids content, more of the structural 
configurations (agglomerates) break down, and the shear stress and measured viscosity decrease, which result in a higher thixotropic hystresis loop (see Figure 6.3). The increased thixotropy and shear thinning as a function of solids loading indicates that for the flow velocity in the crossflow filtration re-circulation line, the AZ-101/102 simulant slurries will flow as a pseudo-homogeneous suspension.

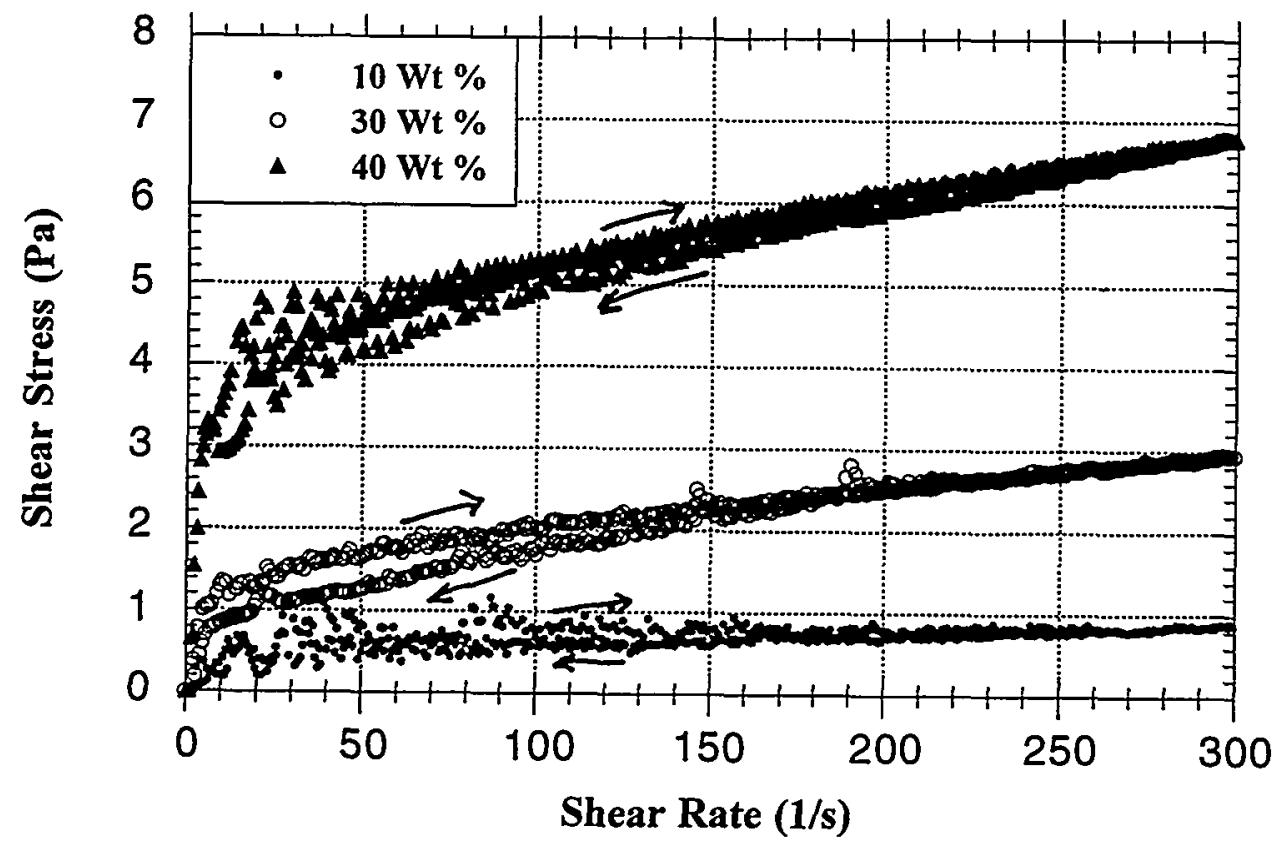

Figure 6.3. Shear Stress verses Shear Rate at $25^{\circ} \mathrm{C}$ for the $\mathrm{AZ}-101 / 102$ Filtration Simulant Ascending and Descending Profiles

The rheological properties of the AZ-101/102 simulant slurries were compared to actual AZ-101 and $A Z-102$ core samples at 10,30, and $40 \mathrm{wt} \%$ undissolved solids concentrations. The rheological measurements presented herein are for the radioactive and simulant slurries before any washing or caustic leaching pretreatment steps. Further, it should be noted that the rheograms of the actual waste data were not available. Instead, only the fitted parameters from the shear stress vs. shear rate curves were provided in the original source report. In these reports, the values listed in Table 6.1 were used to calculate shear stress as a function of shear rate using Equation (6.1) described below:

$$
\sigma=\alpha+\beta \gamma^{n}
$$

This equation is a nonlinear power law model fit where

$\sigma=$ Shear stress $(\mathrm{Pa})$

$\gamma=$ Shear Rate $\left(\mathrm{s}^{-1}\right)$

$\alpha=$ Yield stress $(\mathrm{Pa})$

$\beta, n=$ Empirical constants often referred to as the coefficients of rigidity in the flow index. 
Table 6.1. Results from the Fit to the Rheological Models for the NCAW Radioactive Slurries (Gary et al. 1990 and 1993)

\begin{tabular}{||l|c|c|c|c|c|c|c|c|c||}
\hline Wt\% & 40 & 40 & 10 & 10 & 30 & 30 & 10 & 10 & 10 \\
\hline Data Set & 1 & 2 & 1 & 2 & 1 & 2 & 1 & 2 & 3 \\
\hline$\beta$ & 2.02 & 2.12 & 0 & 0 & 1.26 & 1.29 & 0 & 0 & 0 \\
\hline $\mathbf{n}$ & 0.0284 & 0.0081 & 0.0015 & 0.0019 & 0.05 & 0.03 & 0.08 & 0.024 & 0.059 \\
\hline $\begin{array}{l}\text { Temperature } \\
(\mathbf{C})\end{array}$ & 0.7392 & 0.9554 & 0.9419 & 0.9306 & 0.7872 & 0.8664 & 0.5953 & 0.6856 & 0.6472 \\
\hline
\end{tabular}

* $\mathrm{NK}=$ The temperatures at which these data were taken were not provided in the report but appear to be somewhere close to ambient.

The shear stress as a function of shear rate were calculated for the core samples from equation 6.1 and the fitted parameters listed in Table 6.1 at 10,30, and $40 \mathrm{wt} \%$ solids. The actual waste shear stress profiles are shown in Figure 6.4.

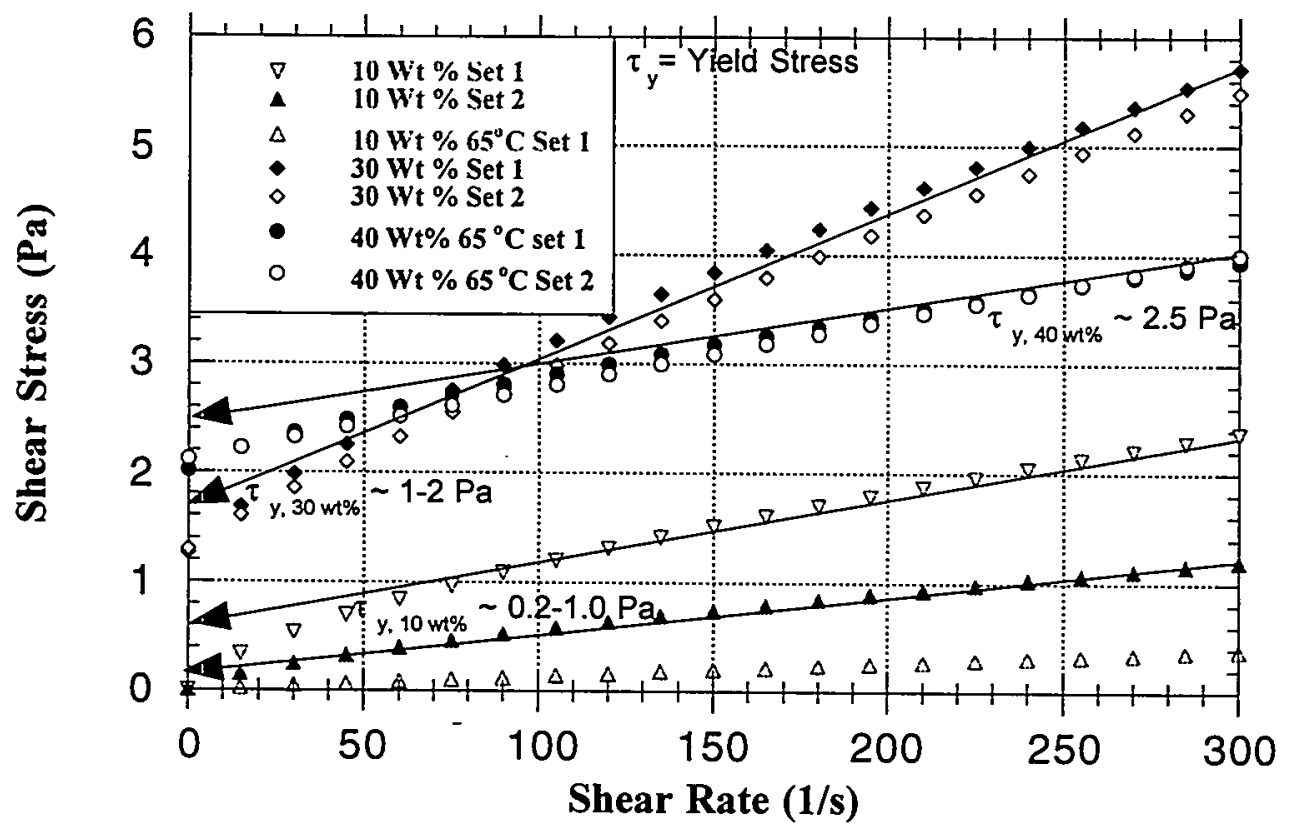

Figure 6.4. Shear Stress verses Shear Rate for the AZ-101/102 Actual Waste 
Once again, the yield stress for the core samples was determined by extrapolating the linear portion of the measured shear stress in the direction of increasing shear rate ("up-curve") as a function of shear rate to shear rate $=0$. The yield stress values for the core samples and the AZ-101/102 simulant slurries at similar solids contents are compared in Table 6.2. The yield stresses for the simulant slurries (see Figure 6.2) and the actual NCAW slurries are comparable. Although the yield stress values for the AZ-101/102 simulant slurries are higher than the radioactive slurries by a factor of 2 , the differences are considered insignificant in discriminating the flow and rheological behavior of the simulant and radioactive slurries.

Table 6.2. Yield Stress for the Actual NCAW and AZ-101/102 Filtration Simulant

\begin{tabular}{|c|c|c|}
\hline Wt\% & Actual Waste Yield Stress (Pa) & $\begin{array}{c}\text { AZlol/102 Filtration Simulant } \\
\text { Yleld Stress (Pa) }\end{array}$ \\
\hline 10 & $0.2-1$ & 0.6 \\
\hline 30 & $1-2$ & 2 \\
\hline 40 & $2.3-2.6$ & $4-5$ \\
\hline
\end{tabular}

Using equation 6.1 the instantaneous viscosities as a function of shear rate were calculated for the actual waste by dividing the shear rate by the shear stress. The instantaneous viscosity profiles (see Figure 6.5) indicate that the AZ-101/102 simulant slurries replicate the viscosity behavior of the radioactive NCAW waste (core samples from tanks AZ-101 and AZ-102 wastes) fairly well at 10, 30 and $40 \mathrm{wt} \%$ un-dissolved solids concentrations as a function of shear rate. At shear rates of less than $30 \mathrm{~s}^{-1}$, the instantaneous viscosity of the AZ-101/102 simulant slurries at all solids loading represent higher values, which desirably render the $A Z-101 / 102$ simulant slurries conservatively viscous. 

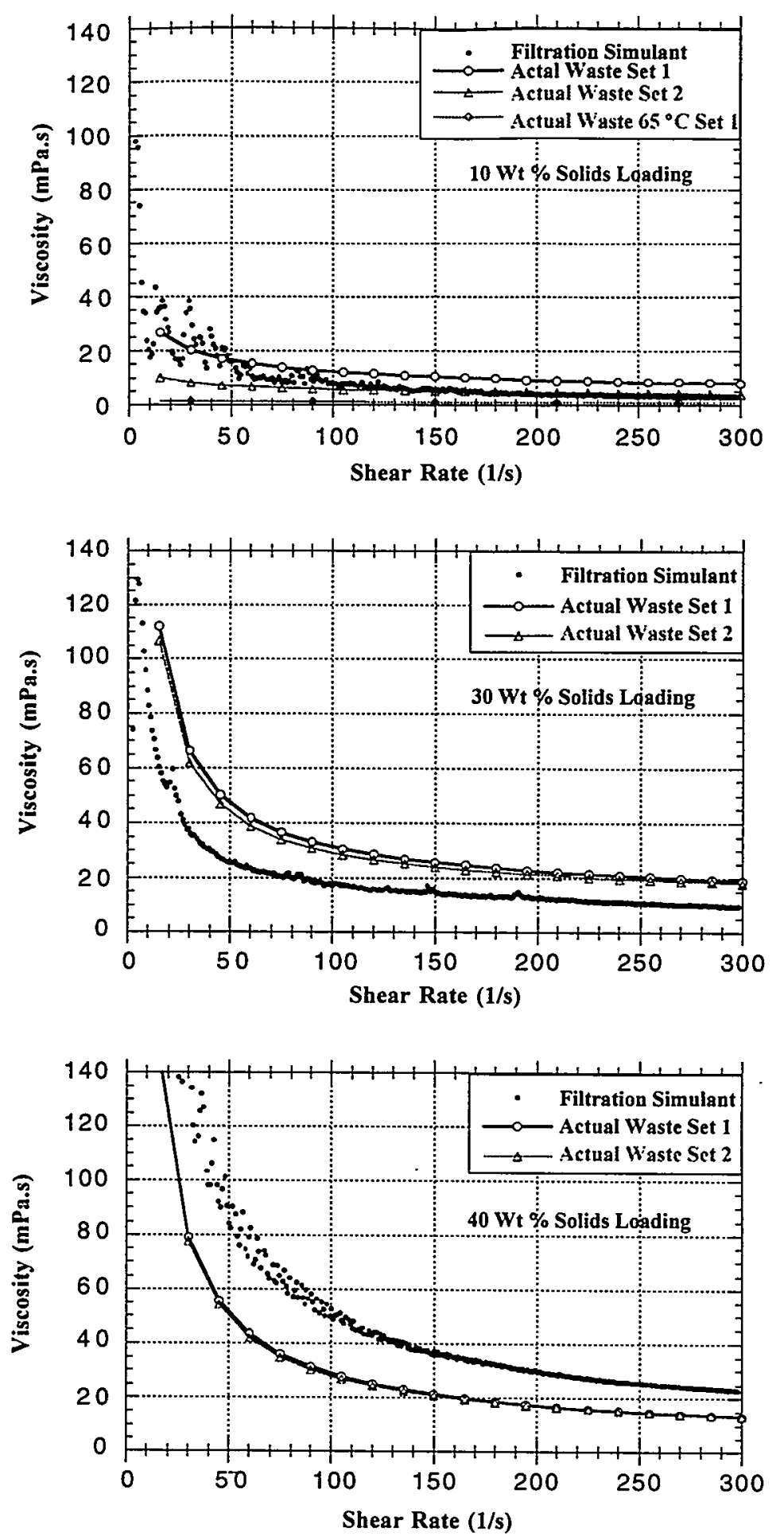

Figure 6.5 Viscosity as a Function of Shear Rate for the Actual AZ-101/102 waste and the AZ101/102 Filtration Simulant 


\subsubsection{Rheology of C-106 Slurries}

The plots of instantaneous viscosity and experimental yield stress values for the C-106 simulant slurry at various solids loadings were determined from the controlled shear-rate experiments. Figure 6.6 shows the viscosity as a function of shear rate for the C-106 simulants at 20,30 , and $40 \mathrm{wt} \%$ undissolved solids concentrations in a linear scale.

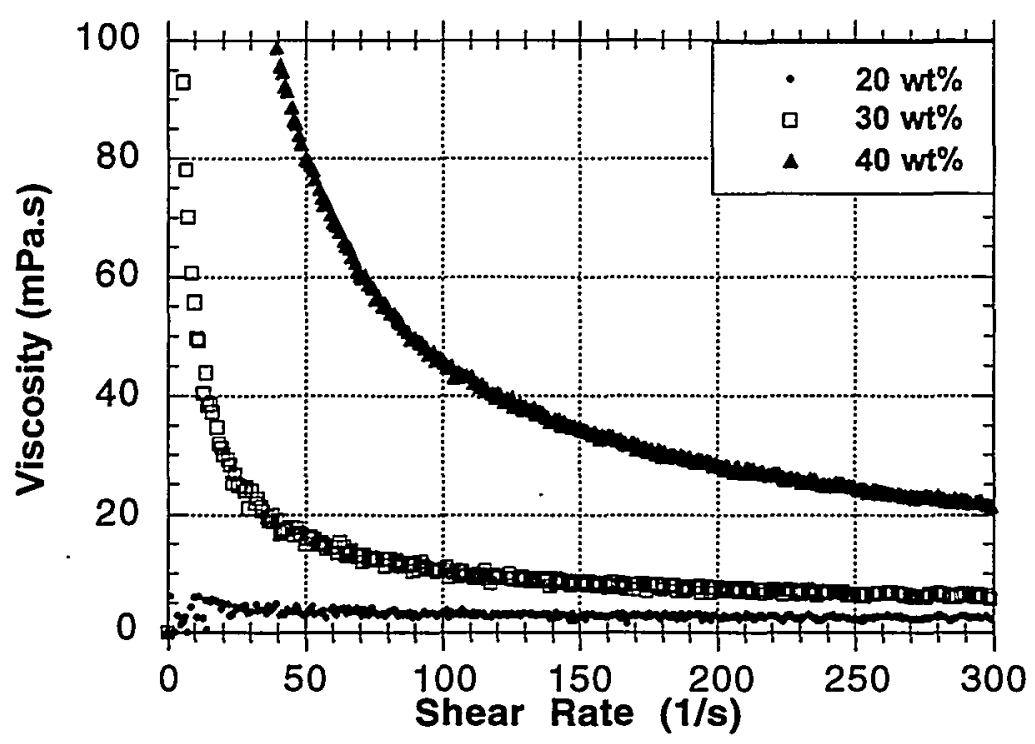

Figure 6.6 Viscosity as a Function of Shear Rate at $25^{\circ} \mathrm{C}$ for the C-106 Filtration Simulant

The plots of viscosity as a function of shear rate indicate that the viscosity for the C-106 simulants at all solids loadings drops to less than $25 \mathrm{mPa}$.s as the shear rate increases from about 0 to $300 \mathrm{~s}^{-1}$, representing a common shear-thinning behavior. Figure 6.7 shows the plots of shear stress as a function of shear rate for C-106 simulant slurry at 10,20,30, and $40 \mathrm{wt} \%$ undissolved solids concentrations. The rheology of the C-106 simulant ( 0 to $300 \mathrm{~s}-1)$ at 30 and $40 \mathrm{wt} \%$ undissolved solids concentration displays a yield stress of approximately 1.0 to $4.0 \mathrm{~Pa}$. The maximum yield stress at lower solids loadings of 10 and $20 \mathrm{wt} \%$ undissolved solids concentrations are below $1.0 \mathrm{~Pa}$. 


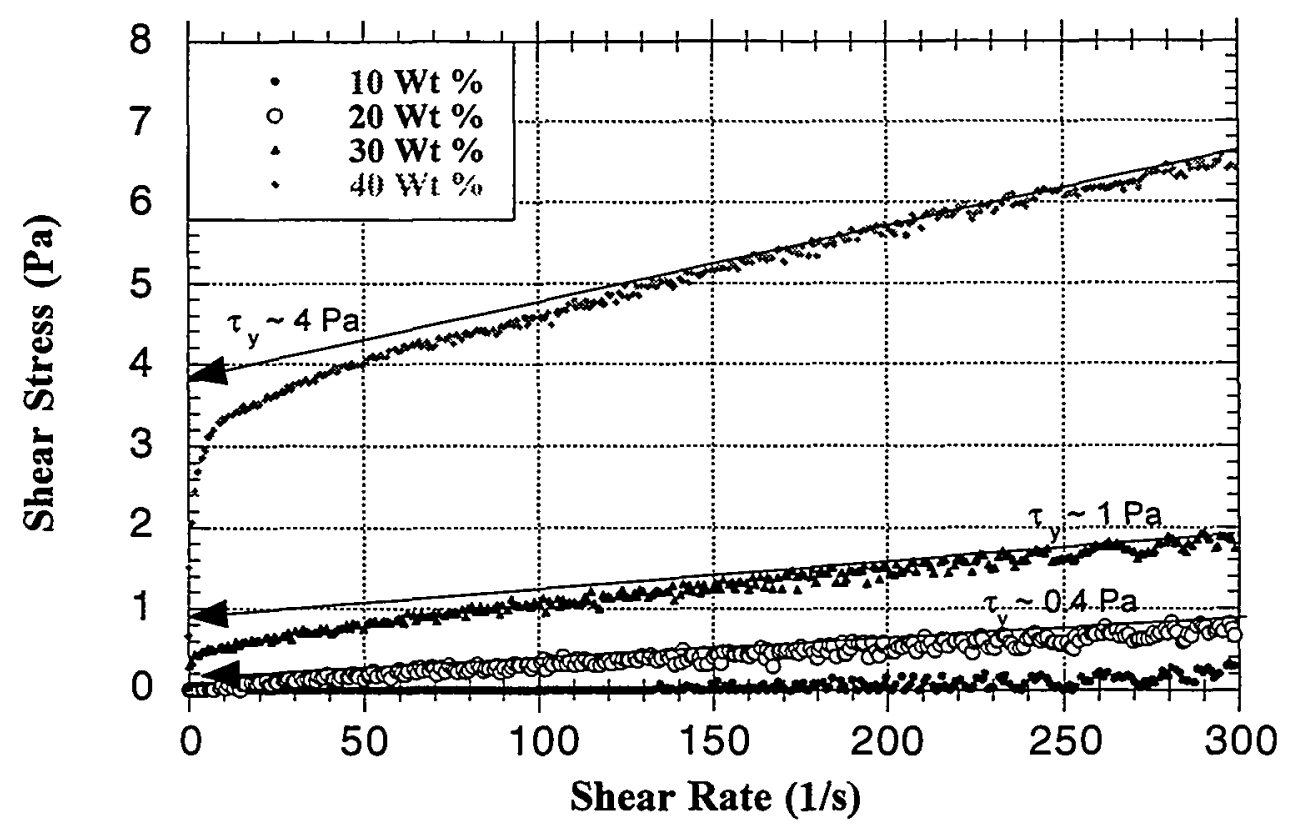

Figure 6.7 Shear Stress Verses Shear Rate at $25^{\circ} \mathrm{C}$ for the C-106 Filtration Simulant

\subsection{Particle Size Distribution}

The particle size distributions of the AZ-101/102 and C-106 filtration simulants are described below. The filtration simulant PSD was conducted for comparison with the particle size distribution of the actual waste. These measurements were conducted using the same instrument to produce actual waste data. The results for the actual waste particle size distributions are compared with the simulants. The criteria for developing a particle size distribution for the simulant were aimed at

- encompassing the particle size range observed in the actual waste

- achieving a poly-dispersed slurry system containing a broad range of sizes for selected solid phases

- representing a similar de-agglomeration trend as the actual waste when subjected to treatments of circulation and sonication in the particle-size analyzer flow loop

- modifying the PSD of simulants to attain a slurry that exhibit reduced filtrate flux over time comparable to the reduction seen with actual waste.

\subsubsection{Experimental}

A Microtrac X-100 Particle Analyzer was used to measure the PSD of these samples. The operation of the Mircotrac X-100 was checked against National Institute of Standards and Technology (NIST) traceable standards from Duke Scientific Corporation. The PSD results of NISTtraceable standards are documented in Appendix E. 
The Microtrac X-100 Particle Analyzer measures particle diameter by scattered light from a laser beam projected through a stream of the sample particles diluted in a suspending medium. The amount and direction of light scattered by the particles is measured by an optical detector array and then analyzed to determine the size distribution of the particles. This measurement is limited to particles with diameters between 0.12 and $700 \mu \mathrm{m}$.

The particle size distribution of the simulants was measured on the Microtrac X-100 after applying a variety of circulation times, circulation flow rates, and sonication treatments identical to the actual waste. The treatments in successive order included 1) circulation at $40 \mathrm{~mL} / \mathrm{s}, 2$ ) circulation at $60 \mathrm{~mL} / \mathrm{s}$, and 3) circulation at $60 \mathrm{~mL} / \mathrm{s}$ with $40 \mathrm{~W}$ sonication for $90 \mathrm{~s}$. A detailed comparison of the flow condition in the PSD analyzer and crossflow filtration is presented in Section 6.2.3. For each sample, the particle size distribution was measured three times and averaged. The PSD of the averaged data on a volume-weighted basis and on a number-weighted basis is reported. The suspending medium for these analyses was the surrogate supernatants specified in Section 3.0 so that the simulant PSD results can be related to the distribution of solids in the crossflow filtration loop. A $0.8 \mathrm{M} \mathrm{NaOH} / 1.0 \mathrm{M} \mathrm{NaNO}_{3}$ solution was used for measuring the PSD of the AZ-101/102 simulant, and a supernatant solution of $1.0 \mathrm{M} \mathrm{NaOH} / 1.0 \mathrm{M} \mathrm{NaNO}_{3}$ was used for the $\mathrm{C}-106$ simulant slurry.

In Appendix E, the PSD plots for the samples under all conditions measured are presented in volume-weighted distribution and number-weighted distribution form. The number-weighted PSD is computed by counting each particle and by weighting all of the particle diameters equally. The volume-weighted PSD, however, is weighted by the volume of each particle measured, which is proportional to the cube of the particle diameter. In this case, larger particles are treated as more important in the distribution than the smaller particles.

\subsubsection{Particle Size Distribution of AZ-101/102 Slurry}

The PSD of actual AZ-101/102 waste was measured by Rapko et al. (1997) in three supernatant solutions (1) deionized (DI) water, (2) $0.1 \mathrm{M} \mathrm{NaNO}_{3}$, and (3) $1.0 \mathrm{M} \mathrm{NaNO}_{3}$. In this report, in order to compare the simulant characteristics under similar ionic strength conditions, the PSD of the actual $\mathrm{AZ}-101 / 102$ waste obtained in a $1.0 \mathrm{M} \mathrm{NaNO}_{3}$ solution was used to compare with the $\mathrm{AZ}-101 / 102$ simulant PSD. Figure 6.8 shows a comparison of the cumulative undersize percentage as a function of the particle diameter for the actual waste and the simulant samples. Figure 6.9 illustrates the results as a volume-weighted distribution. It can be seen from Figures 6.8 and 6.9 that both the actual waste and the simulant exhibit a poly-dispersed behavior, and the simulant PSD range $(0.7$ to $74 \mu \mathrm{m})$ encompasses the spectrum of the particle sizes encountered in the actual waste $(0.4$ to $53 \mu \mathrm{m})$.

A close examination of the volume-weighted distribution plot (Figure 6.9) of the actual AZ-101/102 waste show a uniform distribution that can be approximated by three Gaussian distributions populated around $12.1,3.0$, and $1.0 \mu \mathrm{m}$. The simulant, on the other hand, exhibits more well-defined peaks at $18,6.5$, and $1.4 \mu \mathrm{m}$. Despite these slight differences in the distribution shape and the location of the peaks, the overall mean volume and number distribution of the actual waste compare very well with those measured with the simulant. For example, the mean volume and number distribution of the actual waste are $9.93 \mu \mathrm{m}$ and $0.63 \mu \mathrm{m}$, respectively, whereas those of the simulant are 9.32 and $0.77 \mu \mathrm{m}$, respectively. The major particle-size peak modes along with the relative volume or number percentage that each peak represents are summarized in Table 6.3. 


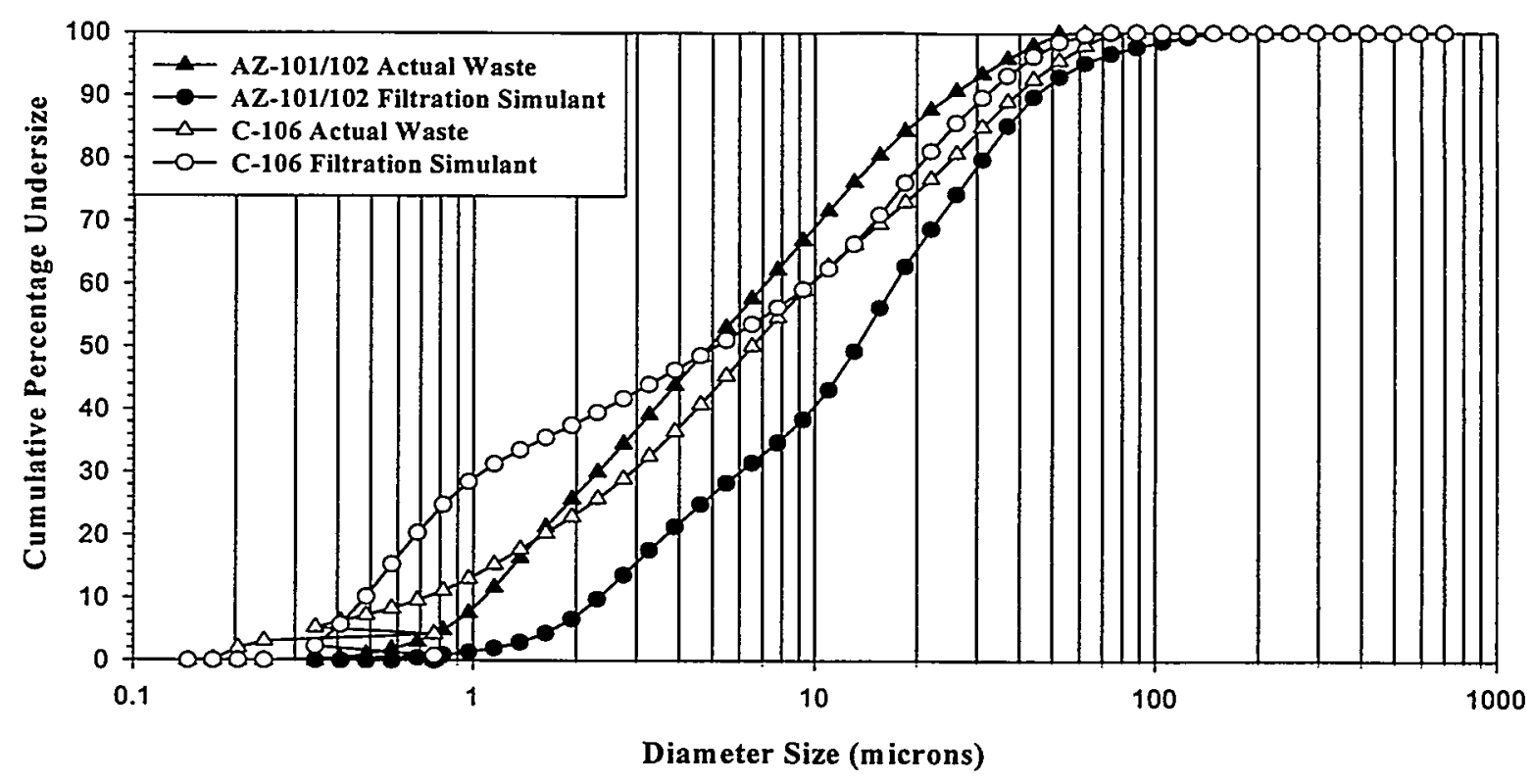

Figure 6.8. Cumulative Under-Size Percentage Distribution for Actual AZ-101/102 and C-106 Wastes Verses the AZ-101/102 and C-106 Filtration Simulant Slurries

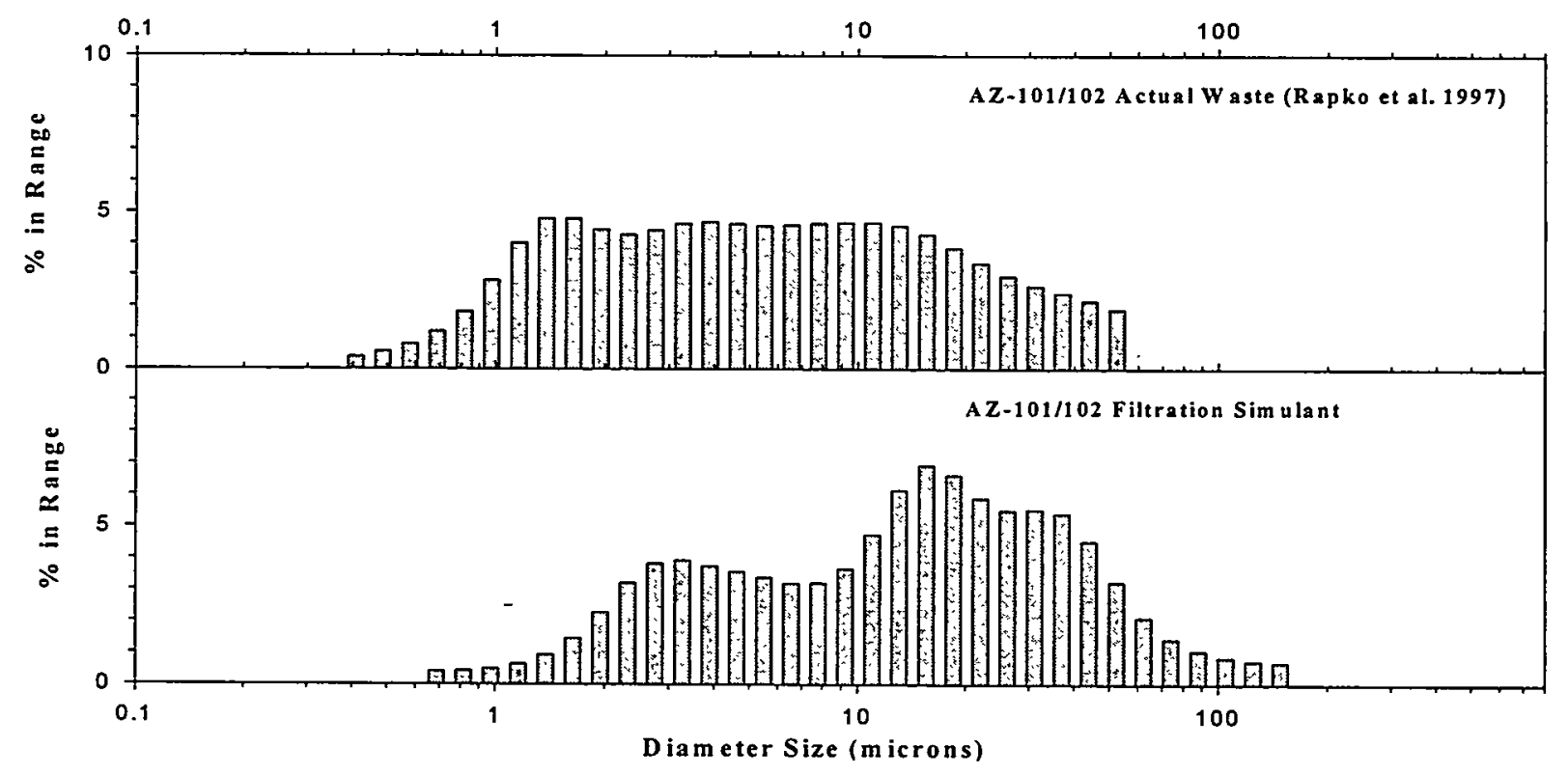

Figure 6.9. Volume-Weighted Distribution for AZ-101/102 Actual Waste and AZ-101/102 Filtration Simulant 
Table 6.3. Particle Size Distribution of AZ-101/102 Samples

\begin{tabular}{|c|c|c|c|c|c|c|}
\hline \multirow{2}{*}{ sample } & \multicolumn{3}{|c|}{ Yolume-Weighted Distribntion } & \multicolumn{3}{|c|}{ Number-Weighted Distribution } \\
\hline & $\begin{array}{l}\text { Mode Diameter } \\
(\mu \mathrm{m})\end{array}$ & Yol $\%$ & Width & $\begin{array}{c}\text { Mode Diameter } \\
(\boldsymbol{t u m})\end{array}$ & Num \% & Width \\
\hline \multirow{3}{*}{$\begin{array}{l}\text { AZ-101/102 Actual } \\
\text { waste }\end{array}$} & 12.1 & $52 \%$ & 21.5 & 0.6 & $100 \%$ & 0.7 \\
\hline & 3.0 & $23 \%$ & 1.8 & & & \\
\hline & 1.2 & $25 \%$ & 0.9 & & & \\
\hline \multirow{3}{*}{$\begin{array}{c}\mathrm{AZ}-101 / 102 \\
\text { Filtration Simulant }\end{array}$} & 17.9 & $31 \%$ & 17.8 & 0.4 & $100 \%$ & 0.6 \\
\hline & 6.4 & $40 \%$ & 5.2 & & & \\
\hline & 1.4 & $25 \%$ & 1.4 & & & \\
\hline \multirow{3}{*}{$\begin{array}{l}\text { AZ-101/102 Actual } \\
\text { Waste, Sonicated }\end{array}$} & 4.4 & $64 \%$ & 7.4 & 0.2 & $100 \%$ & 0.2 \\
\hline & 1.1 & $30 \%$ & 0.7 & & & \\
\hline & 0.3 & $6 \%$ & 0.1 & & & \\
\hline \multirow{4}{*}{$\begin{array}{c}\mathrm{AZ}-101 / 102 \\
\text { Filtration Simulant } \\
\text { Sonicated }\end{array}$} & 14.5 & $55 \%$ & 18.4 & 0.16 & $100 \%$ & 0.1 \\
\hline & 0.9 & $20 \%$ & 0.8 & & & \\
\hline & 0.3 & $18 \%$ & 0.2 & & & \\
\hline & 0.1 & $7 \%$ & 0.03 & & & \\
\hline
\end{tabular}

In crossflow filtration, a slight decrease in the filtrate flux is caused by the formation of a porous filter cake as the particles are deposited on the membrane surface. However, as small fine particles begin to plug the filter cake, the filtrate flux could decrease very rapidly and necessitate back flushing to regenerate the membrane. The shearing of the solids across the surface of the membrane/filter cake could produce fine particles which plug the membrane surface. Rapko et al. (1997) also measured the PSD of the actual waste after sonication. Although sonication does not represent the shear fields that are encountered in crossflow filtration, the data still provide some information regarding the breakup of the agglomerates.

Figure 6.10 shows a comparison of the volume-weighted distribution of the actual and simulated samples after sonication. It can be seen from Figure 6.10 that, although the simulant represented the PSD of the actual waste before sonication, the differences are much more pronounced after sonication. For example, $45 \%$ of the particles in the sonicated simulant sample are smaller than $1 \mu \mathrm{m}$ whereas the sonicated actual waste sample has only $25 \%$ of the particles of $<1 \mu \mathrm{m}$ in size. In other words, the de-agglomerating nature of the actual waste is conservatively replicated by the simulant. Filtration (CUF) data obtained with actual AZ-102 waste were not available during the development of the simulant. Thus, the performance of the AZ101/102 filtration simulant for the crossflow filtration testing was not verified. 

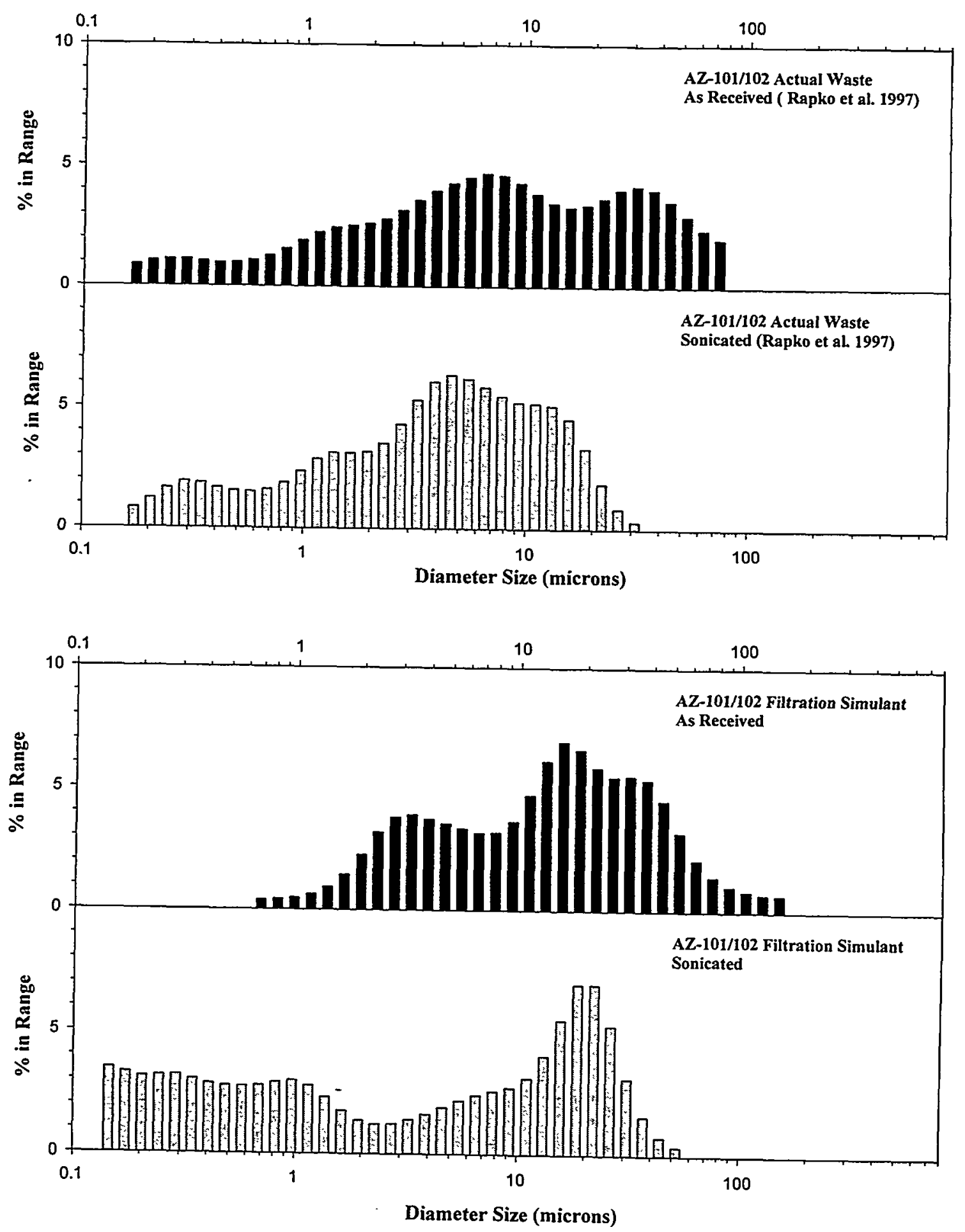

Figure 6.10. Volume-Weighted Distribution for AZ-101/102 Actual Waste and AZ-101/102 Filtration Simulant Before and After Sonication 


\subsubsection{Particle Size Distribution in Crossflow Filtration and X-100 Particle Analyzer}

Solid particles are expected to de-agglomerate in the crossflow filtration loop as a result of the shearing that occurs. Similarly, the solid particles are subjected to a shear field by circulation in the particle size analyzer at setup velocities ranging from $1.3-3.4 \mathrm{~m} / \mathrm{s}(40 \mathrm{~mL} / \mathrm{sec}$ and $60 \mathrm{~mL} / \mathrm{sec})$. In order to compare the PSD anticipated during crossflow filtration to the PSD data obtained using the particle analyzer, the Reynolds numbers for the flow condition in the CUF and PSD analyzer were calculated. It is postulated that by comparing the Reynolds numbers, one can conceptualize the order of magnitude of the shear field that solid particles experienced in the crossflow filtration and particle-size analyzer and therefore relate the information from the particle analyzer to the crossflow filtration unit.

The Reynolds numbers for the simulant slurry in the crossflow filtration re-circulation line were calculated using measured slurry viscosities (see Section 6.1.2) and densities. Solids loading of 10, 20, and $30 \mathrm{wt} \%$ were used in the Reynolds number calculation. The diameter of the filter unit itself and the average velocity were also used in this calculation.

The Reynolds numbers for the particle size analyzer were calculated assuming that material being pumped had the viscosity and density of water. Since the solids concentration is diluted to less than 2 volume percent in order to conduct the PSD analyses, the solids concentration did not impact the solution properties. The results of these calculations are summarized in Table 6.4.

It can be seen from Table 6.4 that the Reynolds numbers for the crossflow filtration and the Microtrac X-100 particle size analyzer are comparable. With the exception of $30 \mathrm{wt} \%$ solids loading, the flow is maintained in a turbulent regime for both the Microtrac particle size analyzer and the crossflow filtration re-circulation lines. Thus, it is speculated that in qualitative terms, the particles experience similar vigorous mixing and shearing in the particle analyzer and the crossflow filtration unit. It should be noted that this simple methodology does not account for the kinetics of de-agglomeration as a function of circulation time.

Table 6.4. Calculated Reynolds Number for the Crossflow Filtration and Particle Analyzer

\begin{tabular}{|c|c|c|c|c|c|}
\hline \multicolumn{6}{|c|}{ Crossflow Filtration System, 0,1-in Mott Filter with $3 / 8$ inch Inner Diameter } \\
\hline \multirow{2}{*}{$\begin{array}{l}\text { Solids Loading } \\
\text { (wt \%) }\end{array}$} & \multicolumn{2}{|c|}{ Velocity } & \multirow{2}{*}{$\begin{array}{l}\text { Slurry Viscosity } \\
\quad \text { (mPas) }\end{array}$} & \multirow{2}{*}{$\begin{array}{c}\text { Slurry Density } \\
\left(\mathrm{kg} / \mathrm{m}^{3}\right)\end{array}$} & \multirow{2}{*}{ Reynolds Number } \\
\hline & $(\mathrm{ft} / \mathrm{s})$ & $(\mathrm{m} / \mathrm{s})$ & & & \\
\hline 10 & \multirow{3}{*}{12.2} & \multirow{3}{*}{$\begin{array}{r}3.7 \\
-\end{array}$} & 2.17 & 1150 & 18760 \\
\hline 20 & & & 4.03 & 1240 & 10880 \\
\hline 30 & & & 9.90 & 1340 & 4800 \\
\hline \multicolumn{6}{|c|}{ Crossflow Filtration System; 0.5-1im Mott Filter with 0.5 inch Inner Diameter } \\
\hline \multirow{2}{*}{$\begin{array}{l}\text { Solids Loading } \\
\text { (wt \%) }\end{array}$} & \multicolumn{2}{|c|}{$\begin{array}{c}\text { Velocity } \\
\end{array}$} & Slumy Viscosity & Slumy Dénsity & Revinglds Number \\
\hline & $(\mathrm{ft} / \mathrm{s})$ & $(\mathrm{m} / \mathrm{s})$ & $\because($ mpass $)$ & Ant & $\therefore$ \\
\hline 10 & 12.2 & 3.7 & 2.17 & 1150 & 16700 \\
\hline
\end{tabular}


Table 6.4 Continued

\begin{tabular}{|c|c|c|c|c|c|}
\hline 20 & & & 4.03 & 1240 & 9670 \\
\hline 30 & & & 9.9 & 1340 & 4270 \\
\hline \multicolumn{6}{|c|}{ Microtrac X-100 Particle size anglezer } \\
\hline \multirow{2}{*}{$\begin{array}{l}\text { Tubing Diameter } \\
\text { (mm) }\end{array}$} & \multicolumn{2}{|c|}{$\begin{array}{l}\text { Flow Rate } \\
\text { Rate }\end{array}$} & \multirow{2}{*}{$\begin{array}{l}\text { Slumy Yiscosity } \\
\text { (mpass) }\end{array}$} & \multirow{2}{*}{$\begin{array}{l}\text { Slimy Density } \\
\left(\mathrm{kg} \mathrm{m}^{3}\right)^{2}\end{array}$} & \multirow{2}{*}{ Reynolds Number } \\
\hline & $(\mathrm{mil} / \mathrm{s})$ & $\left(\mathrm{m}^{\prime} / \mathrm{s}\right)$ & & & \\
\hline 4.8 & 40 & 2.25 & 1.00 & 1 & 10690 \\
\hline 6.3 & 40 & 1.26 & 1.00 & 1 & 8020 \\
\hline 4.8 & 60 & 3.37 & 1.00 & 1 & 16040 \\
\hline 6.3 & 60 & 1.90 & 1.00 & 1 & 12030 \\
\hline
\end{tabular}

\subsubsection{Particle Size Distribution of C-106 Slurry}

The PSD of actual C-106 waste was measured by Lumetta et al. (1996) in three supernatant solutions: 1) DI water, 2) $0.1 \mathrm{M} \mathrm{NaNO}_{3}$, and 3) $1.0 \mathrm{M} \mathrm{NaNO}_{3}$. Once again in this report, in order to compare the simulant characteristics under similar ionic strength conditions, the PSD of the actual C-106 waste was conducted in a $1.0 \mathrm{M} \mathrm{NaNO}_{3}$ solution. The cumulative undersize percentage data as a function of the particle diameter for the actual C-106 waste and the simulant samples are shown in Figure 6.8. Figure 6.11 illustrates the results as a volume-weighted distribution. It can be seen from Figure 6.11 that the simulant exhibits poly-dispersed behavior similar to actual waste. Further, the simulant PSD range $(0.3$ to $88 \mu \mathrm{m})$ encompasses the spectrum of the particle sizes encountered in the actual waste $(0.2$ to $62 \mu \mathrm{m})$.

A close examination of the volume-weighted distribution plot (Figure 6.11) of the actual C-106 waste shows a uniform distribution that can be approximated by three Gaussian distributions populated around $28.8,3.8$, and $0.2 \mu \mathrm{m}$. The simulant, on the other hand, exhibits two well-defined peaks at 22 and $0.6 \mu \mathrm{m}$. There are differences between the distribution shape and the location of the peaks. In the case of the C-106 simulant, a modal distribution that was centered around $0.6 \mu \mathrm{m}$ was deliberately introduced. This distribution was inserted into the simulant formulation as a compromise to achieve similar crossflow filtration fluxes as the actual C-106 waste (see Section 6.2). These small particles were also added to the simulant slurry to generate a C-106 filtration simulant that exhibits de-agglomeration and formation of small fine particles that begin to plug the filter cake. By deviating from the actual C-106 waste PSD, we were able to formulate a simulant that generated smaller agglomerates at comparable time scales as the actual C-106 waste under similar vigorous mixing and shearing of particles in the CUF. Earlier, C-106 simulant formulations, which replicated the PSD of actual waste very well, did not show a similar decline in the filtration flux as a function of re-circulation time.

The mean volume and number distribution of the actual waste are $13.7 \mu \mathrm{m}$ and $0.2 \mu \mathrm{m}$, respectively, whereas those of the simulant are 11.3 and $0.3 \mu \mathrm{m}$, respectively. The mean volume and number distribution of the actual waste compare fairly well with those measured with the simulant. The major particle-size peak modes along with the relative volume or number percentage that each peak represents are summarized in Table 6.5. 
AZ-101/102 Actual Waste and AZ-101/102 Filtration Simulant; As Received

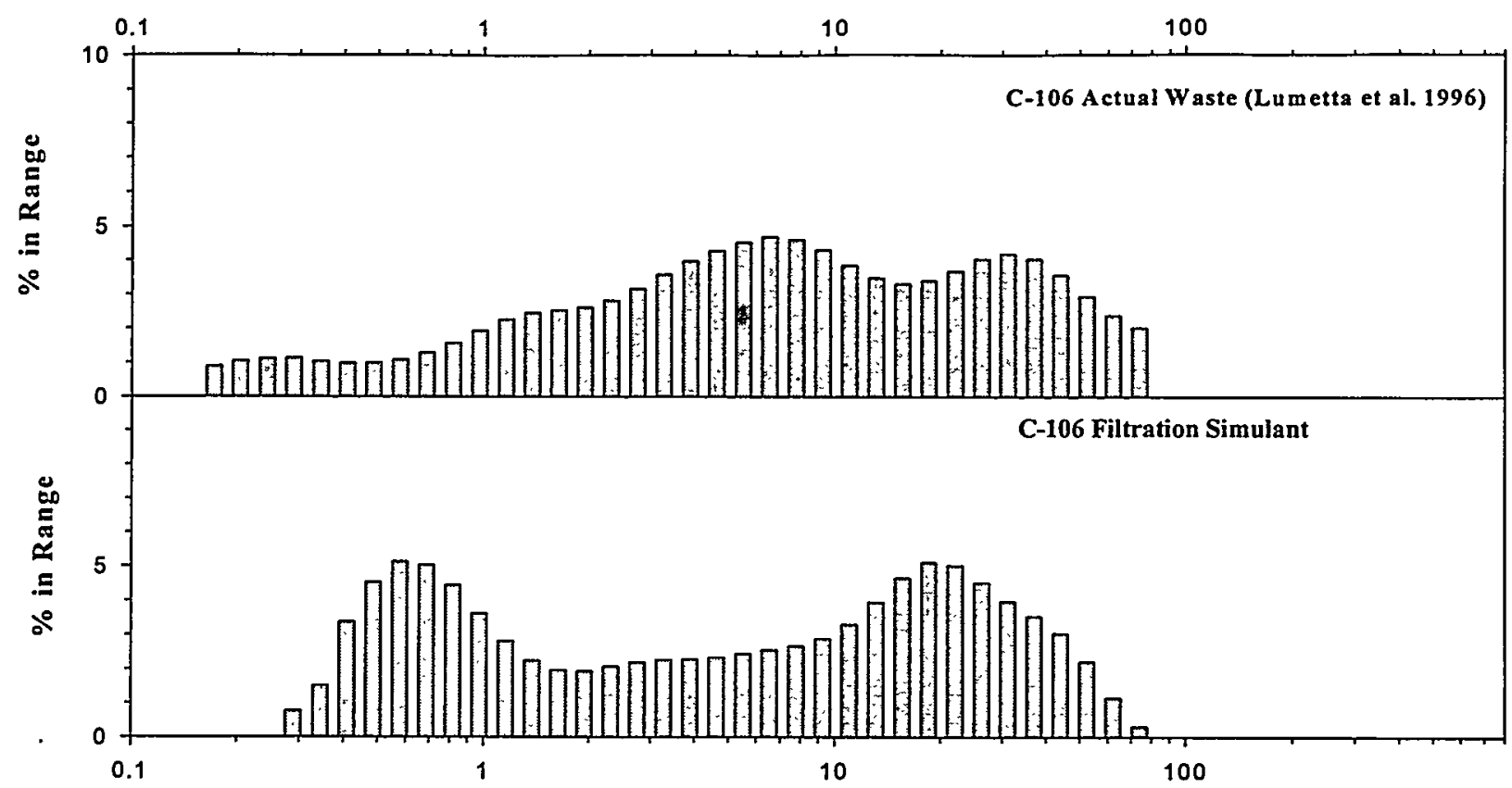

Figure 6.11. Volume-Weighted Distribution for C-106 Actual Waste and C-106 Filtration Simulant

Table 6.5. Particle Size Distribution of C-106 Samples

\begin{tabular}{|c|c|c|c|c|c|c|}
\hline \multirow[b]{2}{*}{ Sample } & \multicolumn{3}{|c|}{ Volume -Weighted Distribution } & \multicolumn{2}{|c|}{ Number-Weighted Distribution } & $\because \therefore \quad \therefore$ \\
\hline & $\begin{array}{l}\text { Mode Diameter } \\
(\mu \mathrm{m})\end{array}$ & Vol \% & Width & $\begin{array}{l}\text { Mode Diameter } \\
(\mu \mathrm{m})\end{array}$ & $\operatorname{Num} \%$ & Width \\
\hline \multirow{3}{*}{ C-106 Actual Waste } & 28.8 & $34 \%$ & 31.9 & 0.2 & $100 \%$ & 0.1 \\
\hline & 3.8 & $61 \%$ & 7.2 & & & \\
\hline & 0.2 & $5 \%$ & 0.1 & & & \\
\hline \multirow{3}{*}{$\begin{array}{l}\text { C-106 Filtration } \\
\text { Simulant }\end{array}$} & 22.0 & $59 \%$ & 16.0 & 0.3 & $100 \%$ & 0.1 \\
\hline & 6.5 & $12 \%$ & 0.7 & & & \\
\hline & 0.6 & $29 \%$ & 1.7 & & & \\
\hline \multirow{3}{*}{$\begin{array}{c}\text { C-106 Actual } \\
\text { Waste, Sonicated }\end{array}$} & 5.5 & $76 \%$ & 10.0 & 0.2 & $100 \%$ & 0.1 \\
\hline & 0.9 & $13 \%$ & 0.6 & & & \\
\hline & 0.3 & $11 \%$ & 0.2 & & & \\
\hline \multirow{3}{*}{$\begin{array}{c}\text { C-106 Filtration } \\
\text { Simulant, } \\
\text { Sonicated }\end{array}$} & 16.14 & $57 \%$ & 18.4 & 0.2 & 100 & 0.1 \\
\hline & 0.8 & $24 \%$ & 0.8 & & & \\
\hline & 0.2 & $19 \%$ & 0.2 & & & \\
\hline
\end{tabular}


Similar to AZ-102, the shearing of the solids across the membrane/filter cake surface could produce the fine particles to plug the membrane surface that may be simulated in the PSD analyzer with sonication. Although sonication does not represent the shear fields that are encountered in crossflow filtration, the data still provide some information regarding the breakup of the agglomerates. Lumetta et al. (1996) also measured the PSD of the actual waste after sonication.

Figure 6.12 shows a comparison of the volume-weighted distribution of the actual and simulated samples after sonication. It can be seen from Figures 6.12 and 6.13 that the differences are much more notable after sonication. For example, $43 \%$ of the particles in the sonicated simulant sample are smaller than $1 \mu \mathrm{m}$ whereas the sonicated actual waste sample has only $24 \%$ of the particles of $<1 \mu \mathrm{m}$ size. 

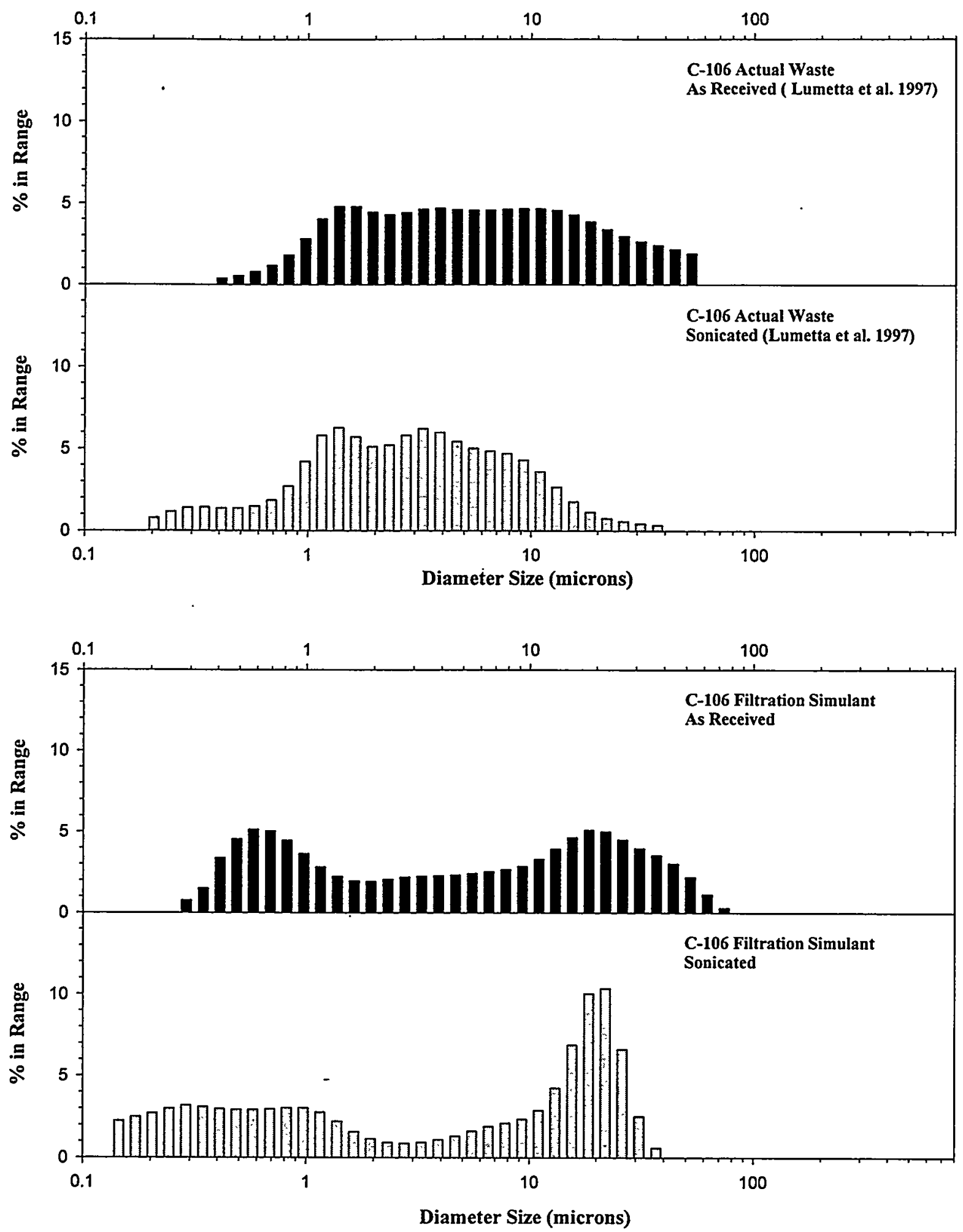

Figure 6.12. Volume-Weighted Distribution for C-106 Actual Waste and C-106 Filtration Simulant before and after Sonication 


\subsection{Conclusions and Recommendations}

Based on the testing and analysis performed on HLW AZ-101/102 and C-106 crossflow filtration simulants, the following conclusions and recommendations were obtained. They have been divided in two categories for clarity.

\section{Conclusions}

C-106

- The C-106 crossflow filtration simulant performance in the CUF suggested that the simulant accurately models the actual $\mathrm{C}-106$ waste in its filtration characteristics. The rheological properties of the C-106 simulant require verification with actual waste data because the available C-106 radioactive rheological data were not applicable for such evaluations. The rheology of actual C-106 waste was conducted at too low of solids loading.

\section{$N C A W$}

- The PSD and rheology of the actual NCAW slurry were emulated well by the AZ-101/102 filtration simulant. This simulant exhibited an overall decrease in filtrate flux over time, similar to what was seen in most CUF testing of other actual waste samples due to 1) filter fouling and 2) agglomerate break-up due to vigorous mixing and the pump shear in the CUF circulation line.

- The AZ-101/102 simulant crossflow filtration needs to be verified by comparing with actual NCAW results as a means to establish confidence in quantifying how closely the actual waste filtration performance is emulated by the simulant.

- Overall simulant properties, such as PSD and mineral composition, rheology, and filterability will vary from those listed in this report if alternative sources for simulant minerals and product brand name are used. Detailed simulant characterization and crossflow filtration performance testing are required if alternative commercial products are used. Such results should emulate the simulant properties documented in this report.

\section{Recommendations}

- Care should be taken in use of alternative commercial sources for simulants. The chemical and physical properties for each product description listed in Appendix A need to be matched in the case of choosing another commercial source.

- The applicability of these simulants for filtration studies of washed solids is uncertain and requires additional evaluation. These simulants have not been developed to mimic the chemical properties of the sludge, and their use for washing and caustic leaching experiments is not recommended.

- The application of these simulants for vitrification studies to make melter feeds for the purpose of preparing glass for waste form evaluation, final glass composition, or chemical durability, melt viscosity, etc. are not recommended. The elemental composition of all oxides, carbonates, and other salts with appropriate substitutions for radioisotopes significant to vitrification studies are not duplicated.

- Addition of the iron-bearing goethite $(\alpha-\mathrm{FeOOH})$ phase to the simulant formulation may improve the simulant performance in replicating the actual waste filtration behavior. Further testing is suggested to examine this hypothesis. If improvements resulted, an inexpensive acicular mineral source similar in properties to goethite needs to be identified and included in the formulation of the simulants. 


\subsection{References}

Barnes, H. A., J.F. Hutton, and K. Walters F. R. S. 1993. An Introduction to Rheology. Elsevier Science Publishers. Amsterdam, The Netherlands.

Brooks, K. P., P. R. Bredt, G. R. Golcar, S. A. Hartley, L. K. Jagoda, K. G. Rappe, and M.W. Urie. 2000a. Characterization, Washing, Leaching, and Filtration of C-104 Sludge, BNFL-RPT-030 Rev. 0, PNWD-3024, Battelle Northwest, Richland, Washington.

Brooks, K. P., P. R. Bredt, S. K. Cooley, G. R. Golcar, L. K. Jagoda, K. G. Rappe, and M.W. Urie. 2000b. Characterization, Washing, Leaching, and Filtration of AZ:102 Sludge, BNFL-RPT-038 Rev. 0, PNWD-3045, Battelle Northwest, Richland, Washington.

Geeting, J. G. H., and B. A. Reynolds. 1996. Bench-Scale Crossflow Filtration of Tank S-107 Sludge Slurries and Tank C-107 Supernatant, PNNL-11376. Pacific Northwest National Laboratory, Richland, Washington.

Geeting, J. G. H., and B. A. Reynolds. 1997. Bench-Scale Crossflow Filtration of Hanford Tank C-106, C-107, B-110, and U-110 Sludge Slurries, PNNL-11652. Pacific Northwest National Laboratory, Richland, Washington.

Golcar, G. R. N. G. Colton, J. G. Darab, H. D. Smith 2000. Hanford Tank Waste Simulants Specification and Their Applicability for Retrieval, Pretreatment, and Vitrification Processes, BNFL-RPT-012 Rev. 0, PNWD-2455, Battelle Northwest, Richland, Washington.

Golcar, G. R., J. R. Bontha, J. G. Darab, M. R. Powell, P. A. Smith, and J. Zhang. 1997. Retrieval Process Development and Enhancements Project Fiscal Year 1995 Simulant Development Technology Task Progress Report. PNNL-11103, Pacific Northwest National Laboratory, Richland, Washington.

Gray, W., M. E. Peterson, R. D. Scheele, and T. M. Tingy. 1990. Characterization of the First Core Sample of Neutralized Current Acid Waste from Double-Shell Tank 101-AZ, Pacific Northwest National Laboratory, Richland, Washington.

Gray, W., M. E. Peterson, R. D. Scheele, and T. M. Tingy. 1993. Characterization of the Second Core Sample of Neutralized Current Acid Waste from Double-Shell Tank 102-AZ, PNNL-13026. Pacific Northwest National Laboratory, Richland, Washington.

Hodgson, K. M. 1995. Tank Characterization Report for Double-Shell Tank 241-AZ-101, WHC-SDWM-ER-410, Westinghouse Hanford Company, Richland, Washington.

Kirkbride, R. A., G. K. Allen, R. M. Orme, R. S. Wittman. 1999. Tank Waste Remediation System Operation and Utilization Plan. HNF-SD-WM-SP-012, Rev. 1, Vol. I and II. Numatec Hanford Corporation, Richland, Washington.

LaFemina, J. P. (Task Leader), G. S. Anderson, D. L. Blanchard, P. J. Bruinsma, B. C. Bunker, N. G. Colton, S. D. Conradson, J. L. Cox, J. Craig Hutton, A. R. Felmy, R. L. Gordon, G. L. Graff, N. J. Hess, J. G. Hill, E. A. Jenne, M. M. Lamoureux, J. Liu, B. M. Rapko, D. R. Rector, P. A. Smith, L. Song, D. L. Syris, L. E. Thomas, A. J. Villegas, Y. Wang. 1995a. Tank Waste Treatment Science Task Quarterly Report for October - December 1994, PNL-10762, Pacific Northwest Laboratory, Richland, Washington. 
LaFemina, J. P. (Task Leader), G. S. Anderson, D. L. Blanchard, P. J. Bruinsma, B. C. Bunker, N. G. Colton, S. D. Conradson, J. L. Cox, J. Craig Hutton, A. R. Felmy, R. L. Gordon, G. L. Graff, N. J. Hess, J. G. Hill, E. A. Jenne, M. M. Lamoureux, J. Liu, B. M. Rapko, D. R. Rector, P. A. Smith, L. Song, D. L. Syris, L. E. Thomas, A. J. Villegas, Y. Wang. 1995b. Tank Waste Treatment Science Task Quarterly Report for January - March 1995, PNL-10763, Pacific Northwest Laboratory, Richland, Washington.

LaFemina, J. P. (Task Leader), G. S. Anderson, D. L. Blanchard, P. J. Bruinsma, B. C. Bunker, N. G. Colton, S. D. Conradson, J. L. Cox, J. Craig Hutton, A. R. Felmy, R. L. Gordon, G. L. Graff, N. J. Hess, J. G. Hill, E. A. Jenne, M. M. Lamoureux, J. Liu, B. M. Rapko, D. R. Rector, P. A. Smith, L. Song, D. L. Syris, L. E. Thomas, A. J. Villegas, Y. Wang. 1995c. Tank Waste Treatment Science Task Quarterly Report for April - May 1995, PNL-10764, Pacific Northwest Laboratory, Richland, Washington.

Lambert, S. L. 1998. Tank Characterization Report for Double-Shell Tank 241-AZ-102, WHC-SD-WMER-411, Rev. 0C, Westinghouse Hanford Company, Richland, Washington.

Lumetta, G. J., F. V. Hoopes, M. J. Wagner, and R. T. Steele. 1996. Washing and Caustic Leaching of Hanford Tank C-106 Sludge, PNNL-11381, Pacific Northwest National Laboratory, Richland, Washington.

Rapko, B. M., M. J. Wagner. 1997. Caustic Leaching of Composite AZ-101/102 Hanford Tank Sludge, PNNL-11580, Pacific Northwest National Laboratory, Richland, Washington.

Ryan, G. W. 1995. Tank Characterization Report for Double-Shell Tank 241-AZ-102, WHC-SD-WMER-411, Rev. 0, Westinghouse Hanford Company, Richland, Washington.

Schreiber, R. D., J. G. Douglas, R. D. Crmar, T. L. Welsh, B. C. Simpson. 1996. Tank Characterization Report forSingle-Shell Tank 241-C-106, WHC-SD-WM-ER-615, Westinghouse Hanford Company, Richland, Washington.

Urie, M. W. 1997. ACL Analytical Summary Report for Tank Waste Remediation System (TWRS) Privatization Contractor Samples, Waste Envelope D Material (241-C-106), Pacific Northwest National Laboratory, Richland, Washington. 


\section{Appendix A: Material Safety Data Sheets}




\section{Boehmite}


Original: July 1, 1996

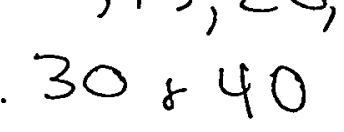

No. 272

Próduct Name: PSEUDOBOEHMITE ALUMINA

Alcoa Alumina \& Chemicals, LLC., 425 Sixth Avenue, Pittsburgh, PA 15219-1850 USA

Emergency Phone: 1-412-553-4001

\section{CHEMICAL PRODUCT AND COMPANY IDENTIFICATION}
Chemical Formula: $\mathrm{Al}_{2} \mathrm{O}_{3} \cdot \mathrm{H}_{2} \mathrm{O}$

\section{HIQ 10}

Product Use: Catalyst supports, binders, abrasives/polishing compounds, and viscosifiers.

Other Designations: Hydrated alumina, Aluminum oxide hydroxide, $\mathrm{HiQ}^{\circledR}-\mathrm{x}$ alumina, where $\mathrm{x}$ is a number or num:s:-
and letter(s) designating various products.

Manufacturer: Alcoa Pört Állen Works

USA Phones: Chemtrec: 1-800-424-9300; Health \& Safety: 1-412-553-4649; Product information: 1-504-382-3330

\section{COMPOSITION/INFORMATION ON INGREDIENTS}

Hazardous ingredients are listed if they comprise $\geq 1.0 \%$ by weight. "Special Hazardous Substances"

(Pennsylvania Right-to-Know Regulations) are listed if they comprise $\geq 0.01 \%$.by weight.

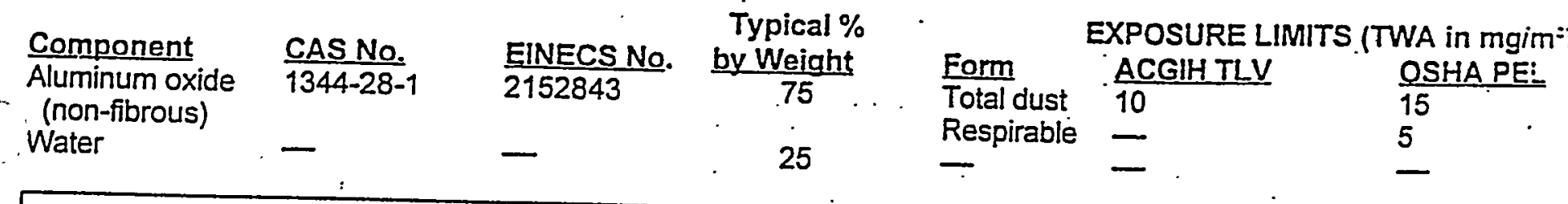

3. HAZARDS INFORMATION

\section{EMERGENCY OVERVIEW}

White crystalline powder, odorless; non-flammable, non-corrosive; not an explosion hazard. Can cause irritaticn

Potential Health Effects

EYES: Can cause mild irritation.

SKIN: Can cause mild irritation.

INHALATION: Can cause mild upper respiratory tract iritation.

INGESTION: May cause mild irritation.

Alumina is a low health risk by inhalation. Treat as a nuisance dust as specified by the ACGIH.

Medical conditions aggravated by exposure to the prodúct: Asthma, chronic lung disease. and skin rashes.

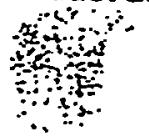

\section{FIRST AID MEASURES}

EYES: Flush eyes with plenty of water or saline for at least 15 minutes. Consult a physician if irritation persists.

SKIN: Wash with soap and water for at least 15 minutes. Consult a physician if irritation persists.

INHALATION: Remove to fresh air. Check for clear airway, breathing, and presence of pulse. Provide CPR for persons without pulse or resprrations Consult a physician

INGESTION: If swalluwed dilute by drinking large amounts of water Never give anything by mouth to a convilsing

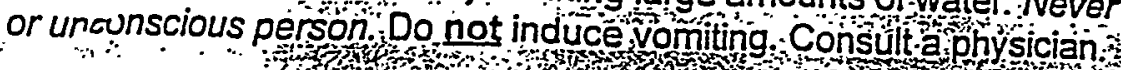


Product Name: RSEUDOBOEHMITE ALUMINA

\section{FIRE FIGHTING MEASURES}

FLAMMABLE PROPERTIES: Non-fiammable.

Flash Point: None.

Flammable Limits: Not applicable.

AUTO-IGNITION TEMPERATURE: Not applicable.

PRODUCTS OF DECOMPOSITION: None.

EXTINGUISHING MEDIA: Use extinguishing agent applicable to surrounding fire.

FIRE FIGHTING INSTRUCTIONS: Fire fighters should wear NIOSH approved. positive pressure. se!icontained breathing apparatus and full protective clothing when appropriate.

\section{ACCIDENTAL RELEASE MEASURES}

SMALLLARGE SPILL: Clean up using dry procedures; avoid dusting.

\section{HANDLING AND STORAGE}

HANDLING: Avoid dusting and contact with eyes and skin. Avoid inhaling dust.

STORAGE: Keep material dry.

\section{EXPOSURE CONTROLSIPERSONAL PROTECTION}

ENGINEERING CONTROLS: Use with adequate ventilation to meet exposure limits listed in Section 2.

RESPIRATORY PROTECTION: Use NIOSH-approved dust respirator if potential for overexposure exis!s.

EYE PROTECTION: 'Wear safety glasses to avoid eye contact.

SKIN PROTECTION: Wear appropriate gloves to avoid direct skin contact.

\section{PHYSICAL AND CHEMICAL PROPERTIES}

APPEARANCE: White crystalline powder

BOILING POINT: Not applicable

FREEZE-MELT POINT: Not determined

VAPOR PRESSURE (mm): Not applicable

VAPOR DENSITY (air = 1): Not applicable.

SOLUBILITY IN WATER: NII

SPECIFIC GRAVITY: See Density

DENSITY: Loose bulk: $37-50 \mathrm{lbift}^{3}\left(0.6-0.8 \mathrm{~g} / \mathrm{cm}^{3}\right)$

$\mathrm{pH}$ : Not determined

ODOR: None

ODOR THRESHOLD (ppm): Not applicable

COEFFICIENT OF WATER/OIL DISTRIBUTION: Not applicable

\section{STABILITY AND REACTIVITY}

rhenilcal Stability: Stable under normal conditions of use, storage, handling and transportation.

With heat: When exposed to fire or heat, hydrated alumina loses its waterof constallization begining at $392^{\circ} \mathrm{F}\left(200^{\circ} \mathrm{C}\right)$. 
Non-corrosive

\section{TOXICOLOGICAL INFORMATION}

$L D_{50}$ or $L C_{50}$ found for oral, dermal or inhalation routes of administration:

This product has not been specifically tested. Data for similar products are provided below:

Eyes: Rabbit eye irritation index: 6 (Max. score possible is 110); minimally irritating

Skin: Primary skin irritation index (rabbits): 0.0 (Max. score is 8.0); not a primary skin irritant.

Acute dermal $L D_{50}$ (rabbits): $>2 \mathrm{~g} / \mathrm{kg}$; practically non-toxic.

Inhalation: Inhalation of fine particles (6-8 microns diameter) for 4 hours by rats resulted in no signs oi
toxicity.

Rats survived exposure to a concentration of $83 \mathrm{mg} / \mathrm{l}$ for one hour

Ingestion: Acute oral $L D_{s o}$ (rat) - >5 g/kg; practically non-toxic.

\section{ECOLOGICAL INFORMATION}

ECOTOXICOLOGICALUCHEMICAL FATE INFORMATION: No information found.

\section{DISPOSAL CONSIDERATION}

Collect in containers, bags, or covered dumpster boxes. If reuse or recycling is not possible, material may be disposed of at an industrial landfill.

RCRA Hazardous Waste No.: Not federally regulated in the U.S.

\section{TRANSPORT INFORMATION}

\section{U.S.A. DOT: Not Regulated. - Enter the proper freight classification, "MSDS Number," and "Product Name" on the shipping paperwork.}

Canadian TDG Hazard Class \& PIN: Not regulated.

\section{REGULATORY INFORMATION}

\section{U.S. Federal Regulations}

TSCA STATUS: All components of this product are listed on the TSCA inventory.

CERCLA HAZARDOUS SUBSTANCES: None.

SARA TITLE III:

Section 311/312 Physical and Health Hazard Categories: Immediate (acute).

Section 313 Toxic Chemicals: None. In reference to Title VI of the Clean Air Act of 1990 , this material does not contain nor was it manufactured using
ozone-depleting chemicals.

International Regulations

CANADIAN DOMESTIC SUBSTANCES LIST: All components of this product are listed on the Canadian DSL. EUROPEAN COMMUNITY: All components of this product are listed on ECOIN, the European Core Inventory. AUSTRALIA: All components of this product are listed on the AlCS inventory. JAPAN: All components of this product are listed on MITT, the Ministry of International Trade Industry. 
ن.iginal: July 1.1996

Product Name: RSEUDOBOEHMITE ALUMINA

\section{OTHER INFORMATION}

MSDS STATUS: Original issue

PREPARED BY: Hazardous Materials Control Committee.

HAZMIN Number: 042402

- Guide to Occupational Exposure Values-1995, Compiled by the American Conference of Govemmental Industrial Hygienists (ACGIH).

- Documentation of the Threshold Limit Values and Biological Exposure Indices, Sixth Edition, 1991, Compilec :y the American Conference of Governmental Industrial Hygienists, Inc. (ACGIH).

- NIOSH Pocket Guide to Chemical Hazards, U.S. Department of Health and Human Services. June 1994.

- Dangerous Properties of Industrial Materials, Sax, N. Irving, Van Nostrand Reinhold Co., Inc., 1984.

- Patty's Industrial Hygiene and Toxicology: Volume II: Toxicology, 4th ed., 1994, Patty, F. A.; edited by Claytca. G. D. and Clayton, F. E.: New York: John Wiley \& Sons, Inc.

INFORMATION HEREIN IS GIVEN IN GOOD FAITH AS AUTHORITATIVE AND VALID; HOWEVER;
NO WARRANTY, EXPRESS OR IMPLIED, CAN BE MADE

\begin{tabular}{|c|c|}
\hline $\begin{array}{l}\text { ACGIH } \\
\text { AICS } \\
\text { CAS } \\
\text { CERCLA } \\
\text { CFR } \\
\text { DOT } \\
\text { DSL } \\
\text { ECOIN } \\
\text { EPA } \\
\text { LARC } \\
\text { LC }{ }_{50} \\
\text { LCLO } \\
\text { LDEO } \\
\text { LD'D } \\
\text { NFPA } \\
\text { NIOSH } \\
\text { NTP } \\
\text { OSHA } \\
\text { PEI } \\
\text { PIN } \\
\text { RCRA } \\
\text { SARA } \\
\text { STEL } \\
\text { TCLP } \\
\text { TLG } \\
\text { TLV } \\
\text { TSCA } \\
\text { TWA }\end{array}$ & $\begin{array}{l}\text { American Conference of Govemmental Industrial Hygienists . } \\
\text { Australian Inventory of Chemical Substances } \\
\text { Chemical Abstract Services } \\
\text { Comprehensive Environmental Response, Compensation, and Liability Act } \\
\text { Code of Federal Regulations } \\
\text { Department of Transportation } \\
\text { Domestic Substances List (Canada) } \\
\text { European Core Inventory } \\
\text { Environmental Protection Agency } \\
\text { Intemational Agency for Research on Cancer } \\
\text { Lethal concentration (50 percent kill) } \\
\text { Lowest published lethal concentration } \\
\text { Lethal dose (50 percent kill) } \\
\text { Lowest published lethal dose } \\
\text { National Fire Protection Association } \\
\text { National Institute for Occupational Safety and Health } \\
\text { National Toxicology Program } \\
\text { Occupational Safety and Health Administration } \\
\text { Permissible Exposure Limit } \\
\text { Product Identification Number } \\
\text { Resource Conservation and Recovery Act } \\
\text { Superfund Amendments and Reauthorization Act } \\
\text { Short Term Exposure Limit } \\
\text { Toxic Chemicals Leachate Program } \\
\text { Transportation of Dangerous Goods } \\
\text { Threshold Limit Value } \\
\text { Toxic Substances Control Act } \\
\text { Time Weighted Average }\end{array}$ \\
\hline
\end{tabular}

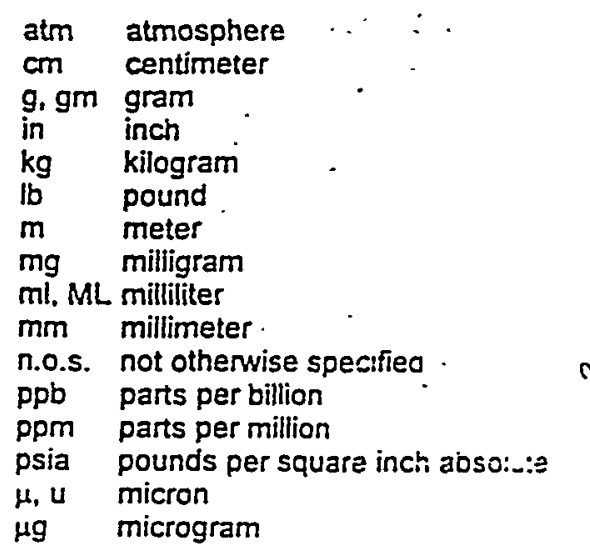




\section{Gibbsite}


1 CHEMICAL PRODUCT AND COMPANY IDENTIEICATION

- Product Name: Hydrared Aluminas/Rluminum Trihydroxide

- Other Designations:

Aluminum Trihydroxide ATH Series, Bayer Hydrated Alumina, Bayerite, BayGranire (TM). Bayer Scale Eines, $C-230, c-231, c-30, c-33 / 31, c-31 c$, $C-37 G, C-330, C-333 / 331, C-40, C-430, C-431, C-530, C-531, C-0 P S-1$, C-NEV-1, Coated ATH, CHSO-1, CV-3002, CV-3003, CV-3004, Flame Gard(R) Series, Hydral(R) Series, Hydral(R) 705, Hydral (R) 707, Hydral (R) 710, Hydral (R) 716, Hydral (R) 719, Hydral (R) Brite 100, Hydral (R) Coat 2, Hydral (R) Coat 5, Hydral (R) Coat 7, Hydral(R) PGA, Rydral (R) PGA SD, Hydrate 17LVE, Hydrogard C?, Hydrogard GP, Hydrogard HI, HyGraNite(TM) Series, KB-30, KB-308, KC-30, KH-30, LD-100, Lubral CSP, Onyx Classica Series, P-3, P-5, P-7, SpaceRite(TM) Series, SRP-A-:1, SRP-A-12, SRP-A-13, SRE-A-14, SRP-A-17, SRP-A-18, and SRE-A-89E.

(R) Registered Trademark of Aluminum Company of America

(TM) Trademark of Aluminum Company of America

- Manufacturer/Supplier:

Alcoa Alumina \& Chemicais, I.L.C.

PO Box 300 , Bauxite, AR 72011

Tel: $+1-501-776-4654$

$+1-800-860-3290$

Alcoa Point Comfort Operations

State Highway 35, Point Confort

Calhoun County, Tx 77978-0101

Tel: $+1-512-987-2631$

Dalton Alumina \& Chemicals Co., Inc.

PO BOX 1601

Dalton, GA 30722

$+1-706-278-4434$

Alcoa of Australia Led. - Kwinana Works

Po Box 161, Kwinana

Western Australia 6167 Australia

Tel. $\div 61-9-410-3111$

Alcoa Moerdijk B.V. - Alcoa Aluminio SA

Vlasweg 19

4782 PW Moerdijk

The Nerherlands

$+31-168-324865$

Rodovia Pocos/Andradas, Kn 10 37701-970 Pocos de Caldas KG Brazil

$+55-35-729-5000$

Emergency Information:

USA: Chemtrec: +1-703-527-3887 +1-800-424-9300 ALCOA: +1-412-553-4001

2 Composition/Data on components:

Components:

21645-51-2 Aluminum trihydroxide (non fibrous)

EINECS: $241-492-7$

Acditional information:

Less on ignition 


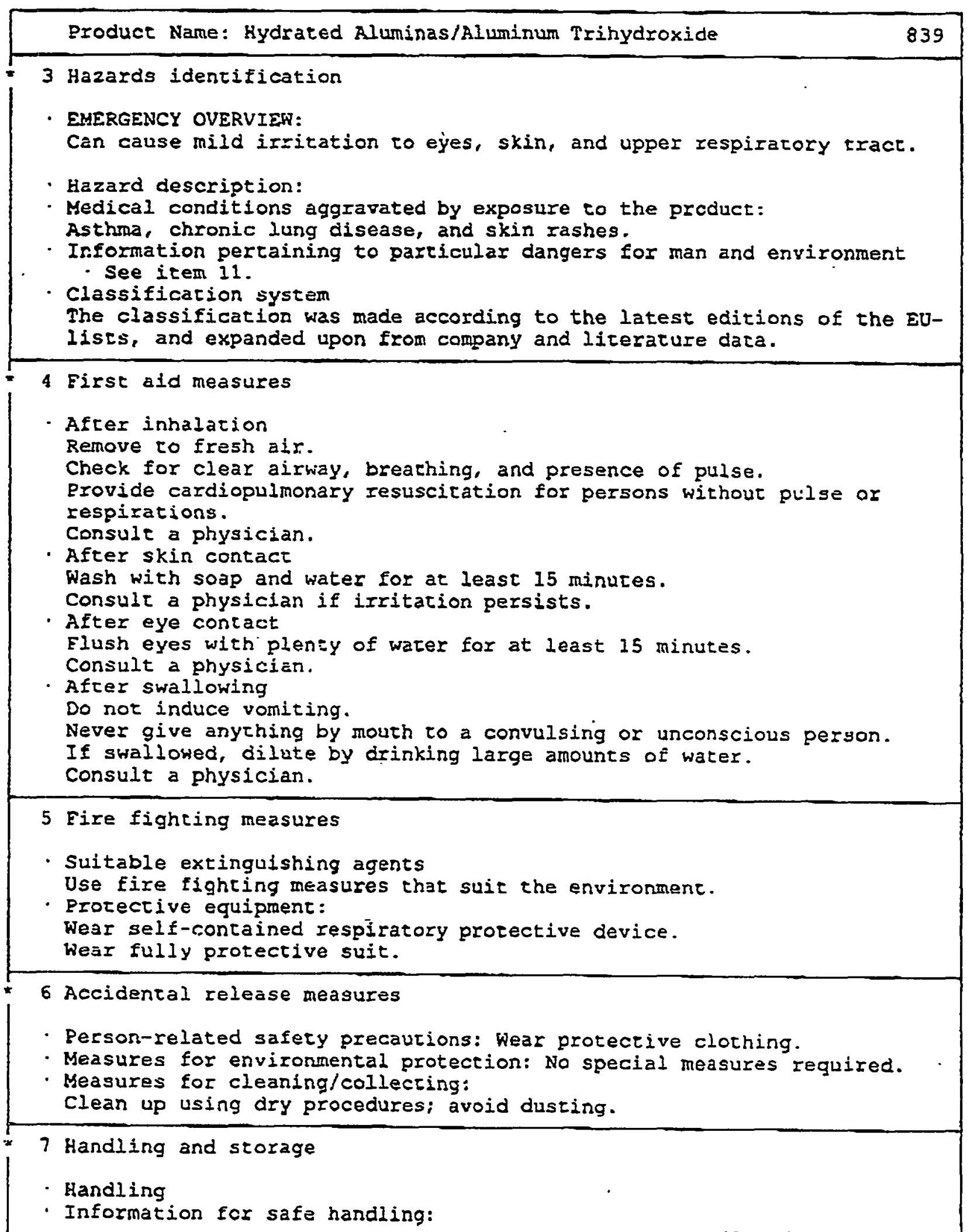



(Contd. from page 3 )

- Densiry:

- Bulk density:

Solubility in / Miscibility with

- Hater:

- pH-value:

- Solvent content:

- Organic solvents:

- Water:

- Solids content:
at $20 \cdot \mathrm{C}$
$2.4 \mathrm{~g} / \mathrm{cm} 3$

$0.15-1.3 \mathrm{~g} / \mathrm{cm} 3$

Insoluble

at $20 \cdot \mathrm{C}$

$8.5-10.2$

208 in $\mathrm{H} 2 \mathrm{O}$

\section{0 stability and reactivicy}

- Thermal decomposition / conditions to be avoided:

No decomposition if used according to specifications.

- Dangerous reactions:

When exposed to fire or heat, hydrated alumina loses its water of crystallization beginning at $200^{\circ} \mathrm{C}\left(390^{\circ} \mathrm{F}\right)$.

- Dangerous products of decomposition: No dangerous decomposition products known.

Coared ATH: Formaldehyde, carbon monoxide and carbon dioxide.

- Additional information: Non-corrosive.

11 Toxicological information

- Primary irritant effect:

- On the skin: Can cause mild irritation.

- On the eye: Can cause mild irritation, especially when wet.

- Inhalarion: Can cause mild upper respiratory tract irricarion.

- Ingestion: Can cause mild irritation.

- Additional coxicological information: The product is not subject to classification according to the Calcularion method of the General EU Classification Guidelines for Preparations as issued in the latest version:

12 Ecological information:

- General notes:

Water hazard class o (German Regularion) (Self-assessment): generally not hazardous for warer.

13 Disposal considerations

- Product:

- Recommendation

Collect in containers, bags, or covered dumpster boxes. If reuse or recycling is not possible, material may be disposed of at an industrial 
- European Community Waste disposal key: $160301 \quad 51308$

- Uncleaned packagirgs :

- Recomsendacion:

Disposal must be made according to official regulations.

14 Transport information

- DOT regulations:

- Remarks :

U.S.A. DOT: Not regulated - Enter the proper freight classification.

"MSDS Number," and "Frodict Name" on the shipping paperwork.

Canadian TDG Hazard Class \& PIN: Not regulated.

- Maritime transport IMDG:

- Marine polluzant:

No

\section{Regulations}

- U.S. Eederal Regulacions:

- tScA STATUS:

All componencs of this product are listed on the TSCA inventory.

- CERCLA REPORTABLE QUANTITY: None.

- SARA TITLE III:

Section 302 Extremely Hazardous Substances:

None.

- Section $311 / 312$ Hazardous Caregories: None.

- Section 313 Toxic Caregories: None.

- OTHER INEORMATION:

In reference to Title VI of the Clean Air Act of 1990, this material does not contain nor was it manufactured using ozone-deplering chemicals.

- Markings according to EU guidelines:

Observe the general safety regulations when handling chemicals.

The product is not subject to identification regulations under EU

Directives and the Ordinance on Hazardous Materials (Gefstoffu).

- National regulations

- Classification according to VoF: Void

- International Regularions:

- CANADIAN DOMESTIC SUBSTANCES IIST:

All components of this product are listed on the Canadian DSL.

- AUSTRALIAN INVENTORY OE CHEMICAI SUBSTANCES:

All components of this product are listed on the AICS.

- JARAN Ministry of International Trade Industry (MITI):

All components of this product are listed on MITI. 
16 orher informarion:

This information is based on our present knowledge. However, this shall not consticure a guarantee for any specific product features and shall not establish a legally valia contractual relationship.

- Department issuing MSDS:

Hazardous Materials Control Committee, Alcoa, Pittsburgh, RA 15219 USA 26.06.98 Supersedes 20.02 .98

- Alcoa MS * 134231

- Appendix:

- Guide to Occupational Exposure Values 1997, Compiled by the American Conference of Governmental Industrial Hygienists (ACGIH).

- Documentarion of the Threshold Limit Values and Biological Exposure Indices, Sixch Edition, 1991, Complled by the American Conference of Governmental Industrial Hygienists, Inc. (ACGIH).

- NIOSH Pocket Guide to Chemical Hazards, U.S. Department of Health and Human Services, June 1994.

- Dangerous Properties of Industrial Materials, Sax, N. Irving, Van Nostrand Reinhold Co.: Inc., 1984.

- Patty's Industrial Hygiene and Toxicology: Volume II: Toxicology, 1th ed., 1994, Patty, F. A.: edired by Claycon, G. D. and Clayton, F. E.: New York: John Wiley \& Sons, Inc.

- LEGEND:

ACGIH American Conference of Governmental Industrial Hygienists

CAS Chemical Abstract Services

CERCLA Comprehensive Environmental Response, Compensation, and Liability p.ce

CER Code of Federal Regulations

DOT Department of Transportation

DSI Domestic Substances list (Canada)

ECOIN European Core Inventory

EINECS European Inventory of Existing Commercial Chemical Substances

EWC European Waste Caralogue

EPA Enviromantal Protective Agency

IARC International Agency for Research on Cancer

IC Lethal Concentration

ID Lethal Dose

MAK Maximum Workplace Concentration (Germany)

"maximale Arbeitsplatz-Konzentration"

NDSL Non-Domestic Substances List (Canada)

NIOSH Narional Institute for Occupational Safery and Health

NTP National Toxicology Program

OEL Occuparional Exposure Limit

OSHA Occupational Safery and Health Administration

EIN Product Identification Number

RCRA. Resource Conservation and Recovery Act

SARA Superfund Amendments and Reauthorization Act

STEL Short Term Exposure Limit

TCLP Toxic Chemicals Leachate Program

TOG Transportation of Dangerous Goods

TLV Threshold Limic Value

ISCA Toxic Substances Control Act

THA Time Weighted Average

$m$ meter, $\mathrm{cm}$ centimeter, $\mathrm{mm}$ mildimeter, in inch,

g gram, kg kilogram, ib pound, $\mu g$ microgram, ppm pares per million 


\section{Hematite}




\section{Material Safety Data Sheet}

page 1a

\section{Substance Identification}

Identity:

Trade Names:

SYNTHETIC RED IRON OXIDE Cas\#:

1309-37-1

Manufacturer:

The Prince Manufacturing Co.

One Prince Plaza

Emergency: Chemtrec

Quincy, IL 62301

1-800-424-9300

217-222-8854

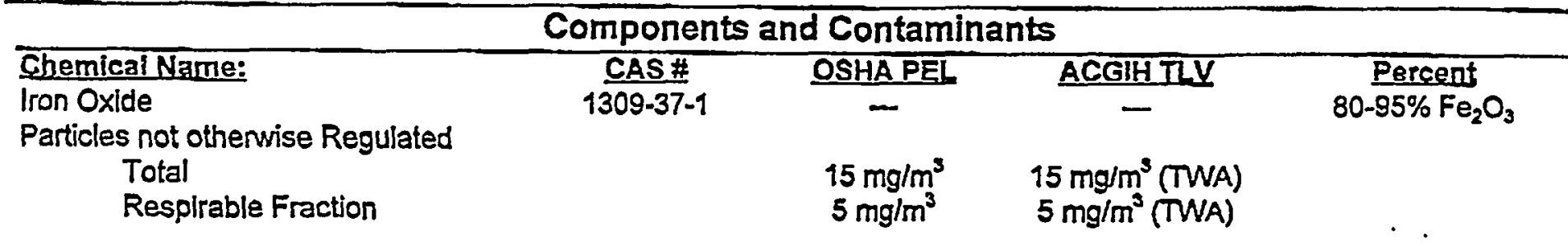

\begin{tabular}{llll}
\hline & & Physical Data & \\
\hline Bolling Point: & NA & Specific Gravity $\left(\mathrm{H}_{2} \mathrm{O}=1\right)$ : & $4.8-5.3$ \\
Vapor Pressure (mm/Hg): & NA & Melting Point: & $>1700^{\circ} \mathrm{C}$ \\
Vapor Density (Air=1): & NA & Evaporation Rate (Butyl Acetate=1): & NA \\
Solubility in Water: & insoluble & & \\
Appearance and Odor: & red to reddish-brown powder, no odor. &
\end{tabular}

Flash Point:

Flammable Limits:

Extinguishing Media:

Special Fire Fighting Procedures:

Unusual Fire and explosion hazards:

Stability:

Conditions to avoid:

Incompatibility (materials to avoid):

Hazardous Decomposition or Byproducts: Hazardous Polymerization:
Fire and Explosion Hazard Data

Not combustible $\cdot$
LEL NA

Foam, $\mathrm{CO}_{2 \mathrm{z}}$ dry chemical or water.

In the event of fire, wear full protective clothing and NIOSH-approved self-contained breathing apparatus with full face piece operated in the pressure demand or other positive pressure mode.

Not combustible.

\section{Reactivity Data}

Stable under ordinary conditions of use and storage.

None known.

Aluminum, Ethylene Oxide, Hydrazine, Calcium Hypochlorite,

Performic Acid, Bromine Pentaflouride.

None Known.

Will not occur.

\section{Health Hazard Data}

Route of Entry:

INHALATION: May cause irritation of mucous membraṇe if dust is inhaled over a prolonged period of time.

SKIN: No.

INGESTION: Ingestion of mineral compounds may cause abdominal pain and nausea. 


\begin{tabular}{|c|c|}
\hline & Health Hazard Data (cont) \\
\hline Health Hazards (Acute and Chronic): & $\begin{array}{l}\text { Respiratory disease may result from prolonged overexposurc. Can cause eye } \\
\text { irritation. }\end{array}$ \\
\hline $\begin{array}{l}\text { Carcinogenicity: } \\
\text { Signs and Symptoms of Exposurc: }\end{array}$ & $\begin{array}{l}\text { NIP: No IARCMonographs: Yes (Silica) } \\
\text { Excessive inhalation of dust may result in shortness of breath and reduced pul- } \\
\text { monary function. Symptoms of silicosis include impaired pulmonary function } \\
\text { and wheczing. }\end{array}$ \\
\hline Aggravation of Pre-existing Conditions: & $\begin{array}{l}\text { Persons with impaired respiratory function may be morc susceptible to the ef- } \\
\text { fect of this substance. }\end{array}$ \\
\hline Emergency and First Aid Procedures: & $\begin{array}{l}\text { IF WHALED, remove to fresh air and scek medical attention for any breathing } \\
\text { difficulty. } \\
\text { IN CASE OF SKNN CONTACT, wash with soap \& water. Scek medical atten- } \\
\text { tion if red \& irrirated } \\
\text { IN CASE OF EYE CONTACT, flush cyes immediately with water for at least } \\
\text { iS minutes. Seek medical attention if irritation persists. } \\
\text { If INGESTED, induce vomiting immediately by giving two glasses of water } \\
\text { and sticking finger down throat. Never give anything by mouth to an uncon- } \\
\text { scious person. Call a physician immediately. }\end{array}$ \\
\hline
\end{tabular}

\section{Precautions for Safe Handling and Use}

Material Relcase or Spill Precautions:

Should a spill. occur, ventilate area Clean-up personnel require respiratory protection. Recover uncontaminated material for usc. Vacuum or sweep remaining material, keeping dust to a minimum.

Waste Disposal Method:

Handling and Storing Precautions: Dispose of unreclaimable material in a RCRA-approved waste facility.

Other Precautions:

Protect confainers from damage and keep closed when not in use.

Observe good personal hygiene. Wash after handling.

\section{Control Measures}

Respiratory Protection:

Use NIOSH approved particulate respirator if dust generation occurs or is anticipated. OSHA standard 1910.134 or ANSI Z88.2-1980 specifications are recommended.

Ventilation:

A system of local and / or general exhaust is recommended to keep employec exposures below the Airborne Exposure Limits. Local exhaust is generally preferred because it can control the emissions of the contaminant at its source, preventing dispersion of it into the general work area. Please refer to the ACGIH document, "Industrial Ventilation, A Manual of Recommended Practiees", most recent edition, for details.

Yes

Protective Gloves:

Eye Protection:

Safely goggles are recommended.

Other Protective Clothing or Equipment: Use other protective equipment when necessary in order to avoid prolonged

Work and Hygicnic Practices: exposure to skin.

Observe good personal hygienc. Wash after handling.

\section{SARA Title III Section 313 Supplier Notification}

This product contains the following toxic chemicals subject to the reporting requirementis of section 313 of the Emergency Planning and Community Right-Io Know Act of 1986 and of 40 CFR 372.45:

Component

Chromium (III) Compounds
CAS\#

$7440-47-3$
\% by Weight $10-16 \% \mathrm{Cr}$

This information must be included in all MSDS's that are copied and distributed for this material. 


\section{Substance Identification}

\begin{tabular}{llll}
$\begin{array}{l}\text { Identity: } \\
\text { Item Numbers: }\end{array}$ & $\begin{array}{l}\text { IRON OXIDE } \\
\text { O4-5113, 04-5114 }\end{array}$ & CAS \#: & 1309-37-1 \\
\hline Manufacturer: & $\begin{array}{l}\text { The Prince ManuPacturing Company } \\
\text { One Prince Plaza } \\
\text { Quincy, II 62301 } \\
\text { 217-222-8854 }\end{array}$ & Emergency: & $\begin{array}{l}\text { Chemtrec } \\
1-800-424-9300\end{array}$ \\
\end{tabular}

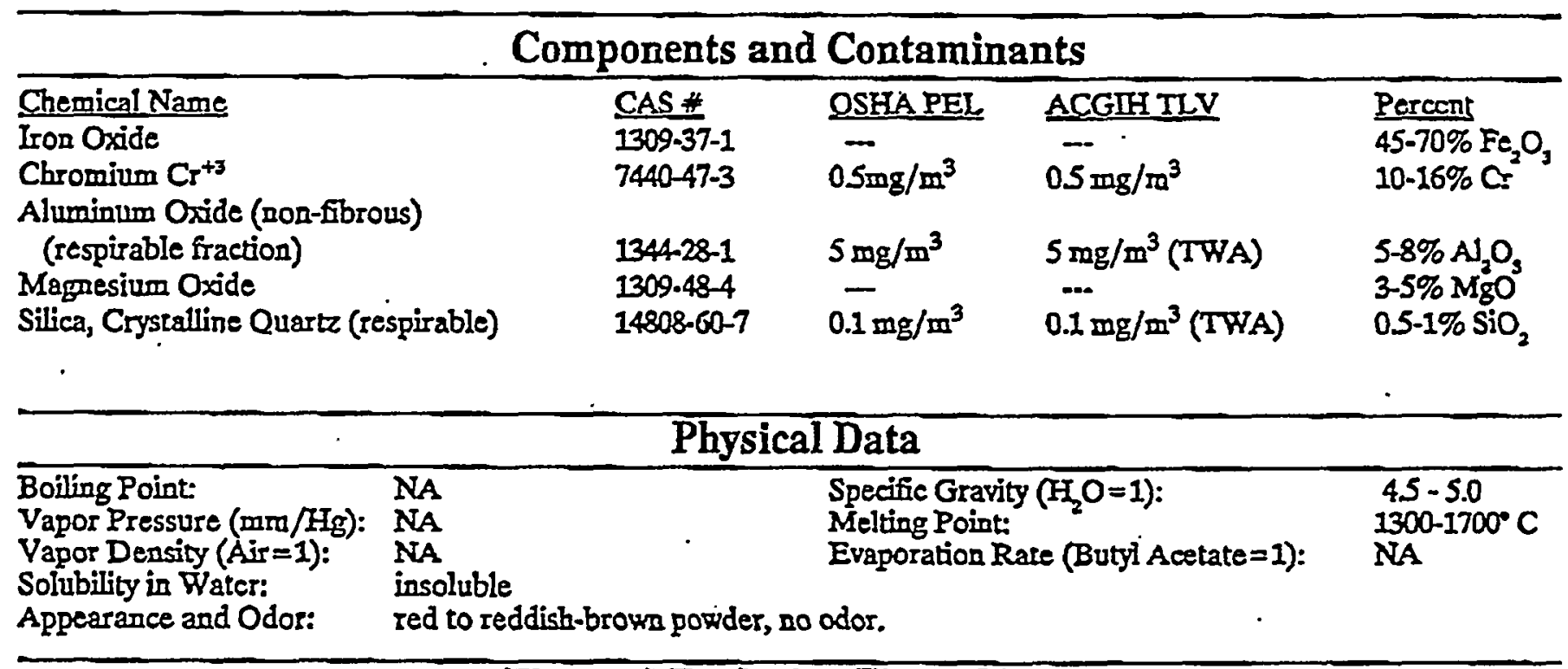

\section{Fire and Explosion Hazard Data}

Flash Point:

Flammable Limits:

Extinguishing Media:

Special Fire Fighting Procedures:

Unusual Fire and explosion hazards:

\section{Not combustible}

IEL NA

Foam, $\mathrm{CO}_{2}$, or dry chemical or water.

In the event of fire, wear full protective clothing and NIOSH-approved selfcontained breathing apparatus with full face piece operated in the pressure demand or other positive pressure mode.

Not combustible.

\section{Reactivity Data}

Stability:

Corditions to avoid:

Incompatibility (materials to avoid):

Hazardous Decomposition or Byproduc

Hazardous Polymerization:
Stable under ordinary condicions of use and storage.

-None Known

Aluminum, Ethylene Oxide, $\mathrm{Ca}(\mathrm{OCl})_{2}, \mathrm{~N}_{2} \mathrm{H}_{4}$.

None Krown.

Will not occurs.

\section{Health Hazard Data}

Route of Entry:

INHALATION: May cause irritation of mucous membrane or delayed respiratory disease if dust is inhaled over a prolonged period of time.

SKIN: No.

INGESTION: Ingestion of mineral compounds may cause abdominal pain and nausea 


\begin{tabular}{ll}
\hline & Health Hazard Data (cont.) \\
\hline Health Hazards (Acute and Chronic): & Can cause eye irritation. Injury to skin may occur by direct mechanical \\
Carcinogenicity: & action. \\
Signs and Symptoms of Exposure: & Excessive inhalation of dust may result in shortness of breath and reduced \\
& pulmonary function. Iron oxide fume has been linked to siderosis which is \\
& considered to be a benign pneumoconiosis that exhibits no adverse health \\
& .effects. To the best of our knowledge, this condition has not been observed \\
& after prolonged exposure to iron oxide pigments. \\
Aggravation of Pre-existing Conditions: & None Known. \\
Emergency and First Aid Procedures: & IF INHALED, remove to fresh air and seek medical attention for any \\
& breathing difficulty. \\
& IN CASE OF SKIN CONTACT, wash with soap \& water. Seek medical \\
& attention if red \& imitated. \\
& IN CASE OF EYE CONTACT, flush eyes immediately with water for at least \\
& 15 minutes. Seek medical attention if irritation persists. \\
& IF INGESTED, induce vomiting immediately by giving two glasses of water \\
& and sticking finger down throat. Never give anything by mouth to an \\
& Unconscious person. Call a physician immediately.
\end{tabular}

\section{Precautions for Safe Handling and Use}

Material Release or Spill Precautions:

Should a spill occur, yentilate area. Clean-up personnel require respiratory.

protection. Recover uncontaminated material for use. Vacuum or sweep -

remaining material, keeping dust to a minimum.

Waste Disposal Method:

Handling and Storing Precautions:

Other Precautions:

Dispose of unreclaimable material in a RCRA-approved waste facility.

Protect containers from damage and keep closed when not in use.

Observe good personal hyggiene. Wash after handling.

\section{Control Measures}

Respiratory Protection:

Use NIOSH approved particulate respirator if dust generation occurs or is anticlpated. OSHA standard 1910.134 or ANSI Z88.2-1980 specifications are recommended.

Ventilation: $A$ system of local and/or general exhaust is recommended to keep employee exposures below the Airborne Exposure Limits. Local exhaust is generally preferred because it can control the emissions of the contaminant at its source, preventing dispersion of it into the general work area. Please refer to the ACGIH document, "Industrial Ventilation, A Manual of Recommended Practices", most recent edition, for detalls.

Protective Gloves: Eye Protection:

Other Protective Clothing or Equipment:

Work and Hygienic Practices:
Yes

Safety goggles are recommended.

Use other protective equipment when necessary in order to avoid prolonged exposure to skin.

Observe good personal hygiene. Wash after handling.

\section{SARA Title III Section 313 Supplier Notification}

This product does not contain chemicals subject to the reporting requirements of section 313 of the Emergency Planning and Community Right-to-Know Act of 1986 and of 40 CFR 372.45:

This information must be included in all MSDS's that are copied and distributed for this material. 


\section{Nepheline}


DIIMIR CORPORATION 258 Ein street sew Canaan, CI 06840

Date Prepared: October 1998
Energency Telephore Number (203) $956-8890$

Ielephone Nunber for Inforinarion (203) 966-8880

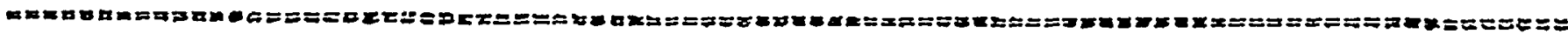

\section{SECTION 1, IDENTIEICATION}

PRODUCT NAME: Nepheline syenite - various grades'.

SYNONXMS: Anhydrous oodium gocassium alumino silicate, Inorganic feldspathic mineral

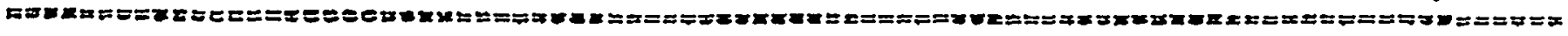

\section{EECTION 2: COKPOAREATS}

CAS\# Component
Percentage Sxposure Iinits

37248-96-5 Nepheline syenite $100 \frac{3}{2}$

QEL- $5 \mathrm{mg} / \mathrm{m}^{2}$ TWA (respirable fraction) ILV- $10 \mathrm{mg} / \mathrm{m}^{2}$ TWA (inisiable fraction) MSFA- 5 . $\mathrm{NG} / \mathrm{m}$ ) IWA (respizable fraction)

PEL means OSHA Pexmissible Exposure Limit.

IUV means American Conference of Govermental Industrial fygienises (ACGIH) Threshold limit Value.

MFHA means Mine Safety and Health Administration Exposure Limit.

TWA means 8 hour rime weighted average.

Note: The Fermissible Exposure Limirs (PEL) reported zbove are the pre-2989 dimits trat weze refnotated by ostin June 30,2993 following a decision by the 31 th circlite Courc of Appea2s. These pers are now being enforced by Federal osta. se aware that more restrictive exposure limits ray be enforced by some states, agezeies or othér authorities.

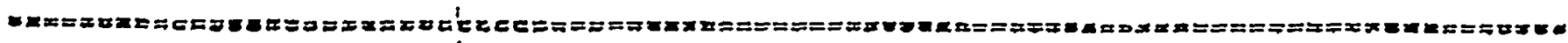

\section{SBCTION 3: HAZARDS IDERTEEICATION-}

\section{EMERGENCY OVERYJEW}

Thia product is a chemically inert, non-combustible mineral. Excessive inhaiarior of dust may cause lung injury with symptoms of shortoess of breath ard reduced pilmonary Iuncelos.

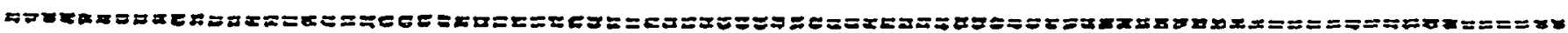

Page 2 of 5 Pages

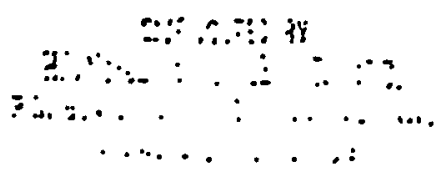




\section{HEALTH ILZARDS:}

Inhalation: Inhalation of dust may cause irritation of the nose, throat and zespiratory passages.

Sxin Contact: No adverse effects expected.

Eye Contact: Contact roy cause mechanical irrisation and possible injury.

Ingestion: No zơverse effects expected for normal, incidental ingestion.

Chronic yealth EFEerts: Prolonged overexposure to any nuizance durt may cause lung injury. Symptons include cough, shortness of breztb, and reduced pulmonary function.

Cancer status:; Wore of the components of this product are listed as carcinogeris or suspected carcinogens by IARC. NTP OI OSHA.

Hedical Conditions Aggravated by Exposure: Individuals with respiratory disenso.

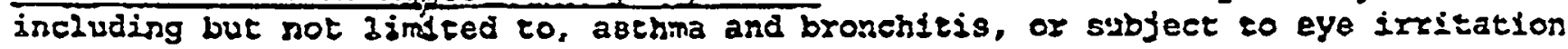
should be excluded from exposure.

Signs nnd symptoms of Exposure: overexposure to nuigance buste may cause mucous membrane and resplratery irritation, cough, so:e throat, nasal congegtion, sreezirg and ehortness of brearh.

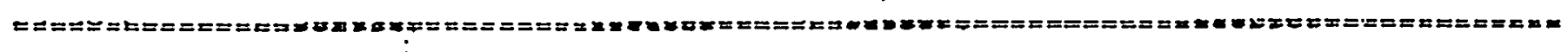

\section{BgCTION A: PIREI XID.}

Grose Inhalation: Rersove vicein to fresh air. If breathing has stopped, perform artigiclal respiration. If breathing is difzicule have onsibified personsel administer • oxygen. Get prompt medical attention.

Skin Contact: wo Ejrst aid should be needed aince this produet does not affect the skin. Wach exposed skin with sosp and water before breaks and at the end of the shiet.

Eye Colntact: Flust the eyes immediztely with large amounts of runoing water, lifting the upper and lower lids occasionally. If irfitation persists or for Inbedded forelgn body, get immodiate nedical attention.

Ingestion: If large amourts are swillowed, get imnediate medical attertion.

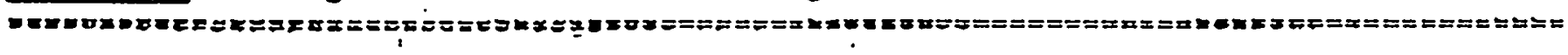

\section{SECITOA 5: FIRE AND EXPLOSIOX DATX}

Elagh point (Metrod Used): Rilly oxidized, will not burd. Autoignition Teme: Wili not burn.

Flammable Limits: LEL: Not applicable UEL: Not applicable 
Excingulghing Media: This product.will not bum but is compatible with all - extingliting media. Use any media that is appropriate for the surcounding fize.

ipecial Fire Fjohting Erocedures: None reguired wịth respect to this product. firestghters should always wear self-contained brepthing apparatus for Eires indoors or in confined sreas.

Onusual Fire and Explosion Hazarós: None.

Hazardous Combuscion Producta: None.

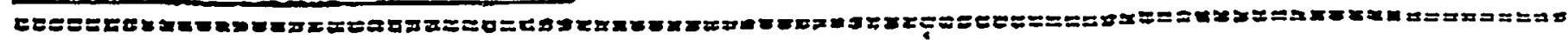

\section{SBCILOA 6: ACCIDESTAZ REZBASE MEASURES}

If uncontaminated, collect uging dustless metbod (Hapa vacuum or wet method) and place in appropriate container Eoi use. If contaminated, use appropriate method for the najure of contaminarion. Consjier possible toxic or fire bazizds. Wear agpropriate protective equiprant. Collect for disposal.

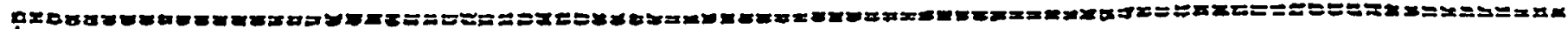

\section{SECTIOA 7, RANDLINE ARD STORAGS}

Avoid breathing dust. Use nosmal precautions against bag brezkage of spilis of bulk motcrial. Avodd ereation of respirable dust. Use good housekeeping in stozage and use areas to prevent accumulation of dust in work area.

- Dse adequate vontilation and dust collection. Maintain aed use proper, clean cuspiratory equipment (Sẹe section 8). Launder clokhing that has become dusty. Hark ud TRAiN employees in accordance with orace and federal regulasions.

WRRN YOUR EMPLOYEES (AND YOUR CUSTOMERS - USERS IN CASE OF RESALES 'BY EOSZING RND OTHER MEANS OF THE YHZARDS AND OSHA PNECAUTIONS TO BE DSEO. PZOUIDE TRAININE FOR YOUR EMRZOYEES ABOUT OSHR PRECAUTIONS.

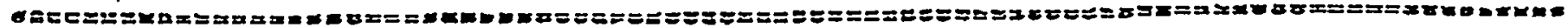
i

\section{ECTION 8: EXPOSURE CONTROLS/R8RSONAL PROTECTIOH}

Ventilarion: Uge local exhsust as required to maintain exposures below applicable occupational exposure Iinles. See also ACGIH "Industrial Vertilation - A Manual for Recommended practice". (current edition).

Respizatory protection: Use appropriate respizatory protection for respizable particulates based on consideration of airborne workplace ceneentraticns and duration of exposure. Refer to the mose recent standard's of ANSI (288.2) OSpa (29 CFR 2930.231), MSHA (30 CER Parts 56 and 57) and NIOSR Respirator Desislon Logic.

Gloves: Protecrive gloves recommasded.

Eye Protection: Safety glasbes or goggles recoumended.

other protective Equipment/Clothing: As appropriate for the vork envizonment. Dusty clothing should be laurdered before reuse.

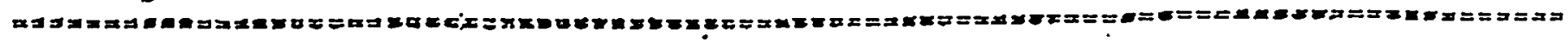

Page 3 of 5 Bages 
- 9. PHYSICAR UND CHEHICAL RROPERIIES

Appearance and Odor: White powder, odorless.

pH: Not applicuble

Boiling point: Not applicable Meleing goint : $2223^{\circ} \mathrm{C} / 2233^{\circ} \mathrm{F}$ Solubllity in Water: Kegligible Eercent Vojatile: of
Specific Gravity (sater=1): 2.61

Vapor Pressure: Not applicable Vapor Density: Not spplicable Evaporation Rate: Not applicable

\section{SECIION 10: STMBIZIJY ANO REACIIVITY}

Stability: stable

Conditions to Avotd: None

Incompatibility: None known.

Hazardous Decomposjejon Products: Hone

Hazardous Polymerizaeson: Will not occur.

Conditions to Avoid: None

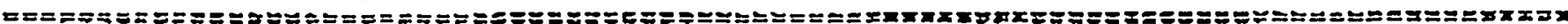

\section{SECTION 12: IOXICOZOGFCRL INFORMATION}

No acute toxiciey data is available for product or components. Reter to Section 3 for healeh hazard information.

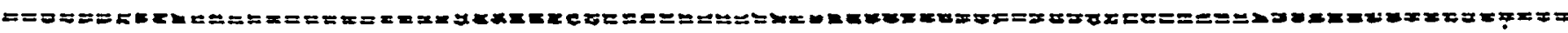

SBCTIOA 12: ECOLOGICAR IRTORMATIOX

No ecoraxicity data is available. This product is not expected to prosent an environmental hazard.

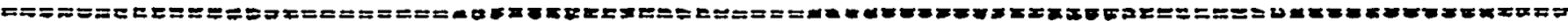

\section{SECTIOY 23: DISPOSAL}

Waste Dibposal Methodi if uncontaminared, dispose as an inert, non-metallie mineral. If contaminated, dispase in accordance with all applisable local, state/proviacial and federal regulatioric.

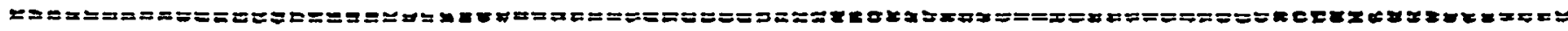

\section{SECTIOA IS: TRETSPORTATION DAIA}

U.S. DOT HAZARD CLASSIFICATION

Proper Shipping Name: Not Regulated

Techrical Name: N/A.

UN Number; $\$ / A$

Hazard Class/Facking Group: N/A

inbels Required: Nors

DOT Packaging Requirements: N/A

Page 1 of 5 eages

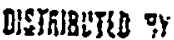

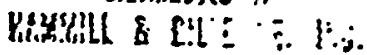

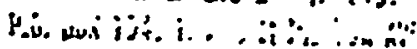




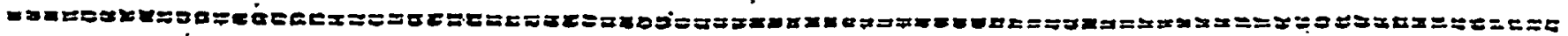
.

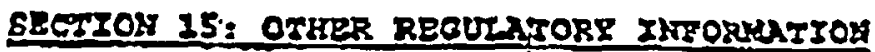

5ARA 311/322: Hazard Categories for SARA seetion $331 / 312$ Reporting: Not Appli cable

sarr 313 Ihis groduct contains the following Chemicals subject to arnual Release Reporting Requirements Under the sart seetion 323 (180 CFR 372): None

SERCLA Section 103 Reportable Quanejey: Nore

Califonta progogition 65: This pzoduct does not contain substances zegulated under Calieorria Proposition 65. $\therefore$

Canodiah MHIS Classification: Not a cantrolled product.

טm:

16: OTERR ERTORMATION

Europan Community Lubeling Classificarion: N/A

Europear Community Risk and Safety Phrases: Nore

- HFPa Hazaza Rating: Heazth: 0 Fire: 0 Reaerivity: 0

Hors yazard Ratirg: Ifalth: 0 Fize: 0 Reacejvity: 0

Leterences:

Registry for toxic iftects of chemical substances (RTECs), 1998

Patry'a Industrial Hygiere and Toxicosogy

NIP Seventh Arnual Report on Carcinogens, 2994

liawley's Condensed chemical Dicrionary, tweltith edleior

Toxine Database, Nzy, 1998

Reybion Sumnary: Revise exposure limits (section z)

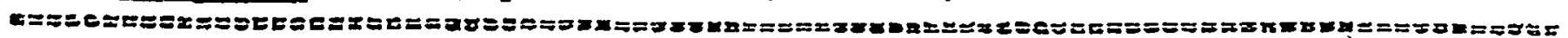

The data in this Material Satety Data sheet relates only to the specilis matcíal designaced herein and does not relate to use in combination with any other material or in any prosess. The information set forth herein is bases on tachnical data the Unimin Corporation believes reliablo. It is intended for vee by pezsons having technieal skill and at their om diseretion and risk. since conditions of uso are outside the control of unimin Corporation, no warranties, erpressed or implied, are made and no liabslity is assumed in consection with any uge of thio information. Any use of ehese data and inforaneion must be determined by the user to bo in accordance with federal, state and local lawg and regulations.

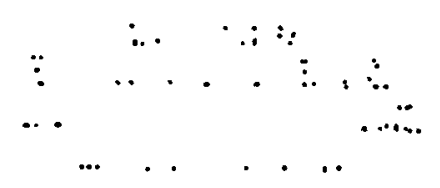




\section{Zirconium Hydroxide}




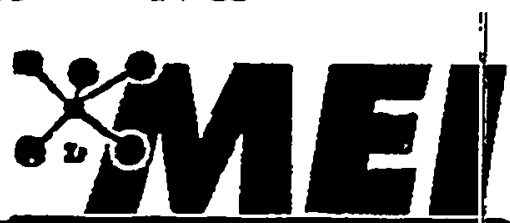

\section{MATERIAL SAFETY DATA SHEET}

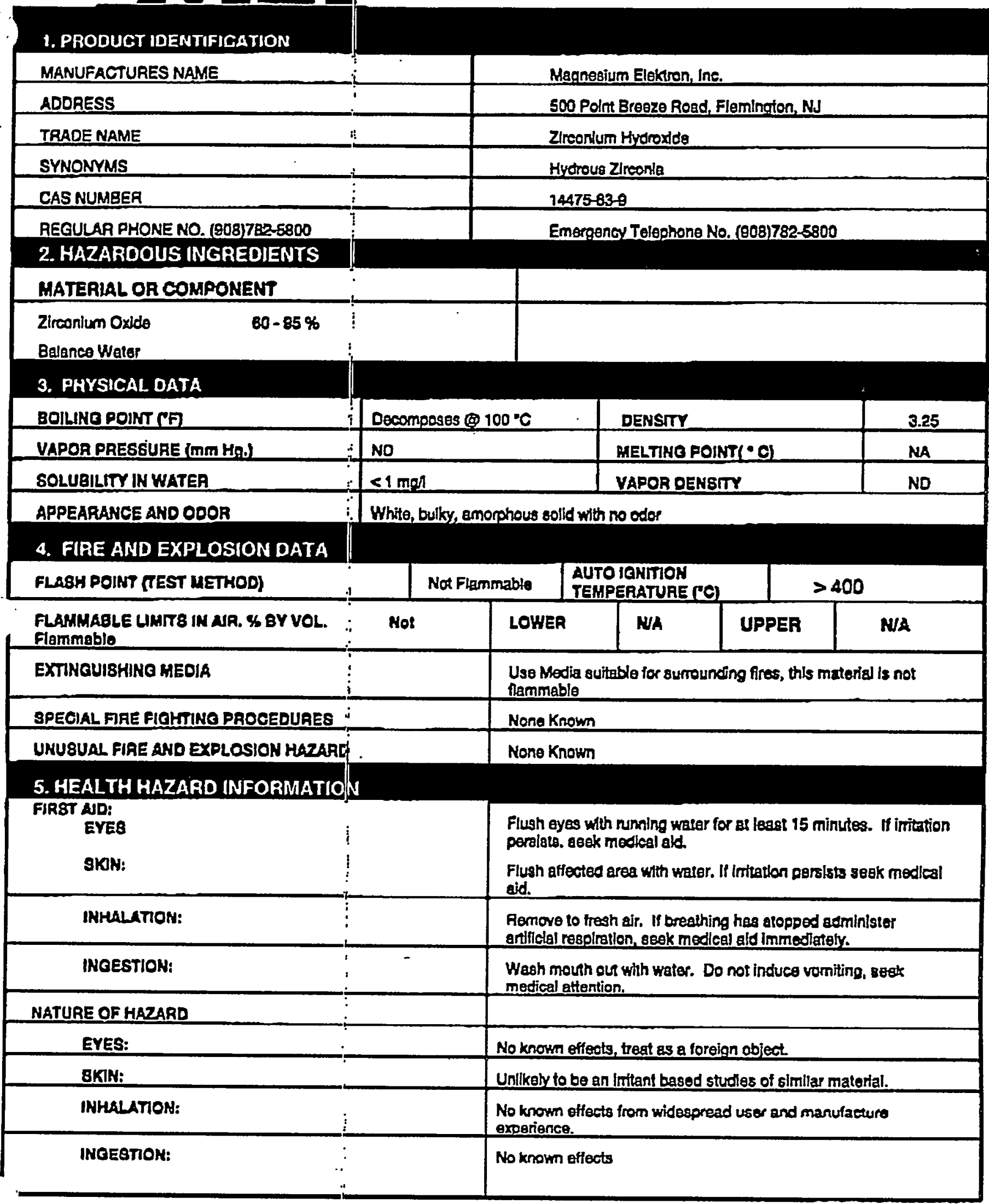




\section{Appendix B: Mineral Product Specifications}




\section{Boehmite}


Alcoa Industrial Chemicals

HiQ® Alumina Product Line: Boehmite Phase

$H i Q \otimes-10, H i Q \circledast-20, H i Q \circledast-30, H i Q \otimes-40$

Powders for Catalysts and Abrasives

MAY 1998

CHEMICALS PRODUCT DATA

\section{Product Information}

Alcoa markets high purity boehmite worldwide under the HiQ® - Alumina trade name. The manufacturing process for this product begins with primary aluminum to produce an alumina of extraordinary purity. This is unlike other processes that start with trihydrate and yield aluminas which are subject to common purities such as sodium, iron, or silica. High purity denotes very low levels (less than 0.01 $w t \%)$ of such impurities.

\section{Description}

HIQ@ aluminas are available as white, free-flowing, spray-dried powders. These aluminas consist of small boehmite crystals, often referred to as pseudoboehmite. The crystalline character of each alumina is controlled in order to tailor their chemical and physical properties. HiQ@-10 alumina exhibits the smallest crystallite size and is mainly used for making extruded catalysts. HiQ@(-20 alumina is the general-purpose grade of alumina that is easy to mull and extrude. HiQ@-30 is typically used as the binder for extruded oxide blends. Additionally, supports made from HiQ@-30 have very narrow micro/meso pore distributions. HiQ@-40 alumina offers the largest crystallite size and is well suited for applications requiring exceptionally high acid dispersibility or binding ability.

\section{Applications}

HiQ@ Alumina is a specialty product but its applications are quite diverse: specialty chemical catalysts; automotive washcoat catalysts; catalyst binders and supports; sol-gel abrasives; polishing compounds; viscosifiers; and anti-skid agents.
Typical Physical Properties

\begin{tabular}{|c|c|c|c|c|}
\hline & $H i Q \otimes-10$ & HIQQ-20 & $H I Q \otimes-30$ & HIQ@- -40 \\
\hline Surface Area $\left(\mathrm{m}^{2} / \mathrm{g}\right)$ & 290 & 280 & 280 & 250 \\
\hline Pore Volume (cc/g) & 0.45 & 0.48 & 0.48 & 0.5 \\
\hline Acid Dispersibility (wt\%) & 80 & 88 & 89 & 94 \\
\hline Loose Bulk Density $(\mathrm{g} / \mathrm{l})$ & 730 & 730 & 730 & 730 \\
\hline NAG (minutes) & 60 & 10 & 4 & $<1$ \\
\hline \multicolumn{5}{|l|}{ Crystallite Size (A) } \\
\hline 020 peak & 26 & 30 & 33 & 47 \\
\hline 021 & 41 & 43 & 50 & 72 \\
\hline
\end{tabular}

Particle Size, wt\% (HiQ Product Line)

\begin{tabular}{cccc}
\hline$d_{50}(\mu \mathrm{m})$ & $<125 \mu \mathrm{m}$ & $<88 \mu \mathrm{m}$ & $<44 \mu \mathrm{m}$ \\
50 & 95 & 95 & 80
\end{tabular}

Typical Chemical Properties (HiQ Product Line)

\begin{tabular}{ccccc}
\hline $\mathrm{Al}_{2} \mathrm{O}_{3}(w 1 \%)$ & Carbon (wt\%) & $\mathrm{SiO}_{2}(\mathrm{ppm})$ & $\mathrm{Fe}_{2} \mathrm{O}_{3}(\mathrm{ppm})$ & $\mathrm{Na}_{2} \mathrm{O}(\mathrm{ppm})$ \\
72 & $<0.3$ & $<100$ & $<50$ & $<10$
\end{tabular}

HiQ@ Aluminas-Typical Properties

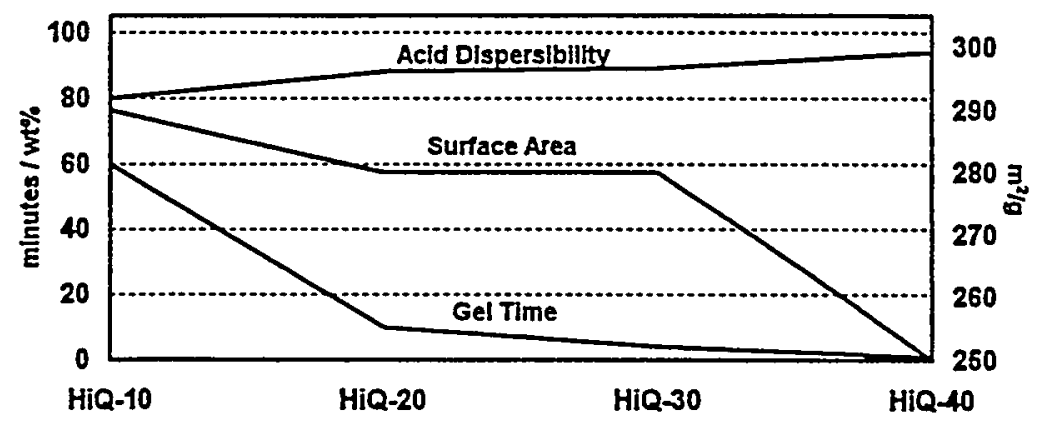

For recommendations on your specific application, call Alcoa's Applications Manager, (504) 382-3353. For price and shipment information contact your Alcoa Sales Representative or Sales Service Unit at (800) 533-4511.

Information presented herein is believed to be accurate and reliable but does not imply any guaranteo or warranty by Alcoa. Nothing herein shall bo construed as an imitation to use processes covered by patents without proper amangements with individuals or companies owning these patents.
Alcoa Industrial Chemicals

Adsorbents and Catalysts Division 16010 Barker's Point Lane, Suite 250

Houston TX 77079 
PRODUCT:

LOT NUMBER:

Analysis Property

${ }^{*} \mathrm{Al}_{2} \mathrm{O}_{3}$ Content, wt\%:

.. **Surface Area, sq M/g.:

**Pore Volume (pores $<1000 \mathrm{~A}$ dia), cc/g:

Loose Bulk Density, g/:

Carbon Content, wt\%:

$<44$ microns

$>88$ microns
Particle Size Distribution, wt\%:

$\mathrm{HiQ}^{(\mathrm{R})} 10$ Alumina

8K30-1

$\underline{\text { Value }}$

73.7

281

0.61

747

0.49

52.7

12.7

Impurities, wt. \%:

$\mathrm{SiO}_{2}$

0.007

$\mathrm{Fe}_{2} \mathrm{O}_{3}$

0.006

$\mathrm{Na}_{2} \mathrm{O}$

0.01 


\section{Gibbsite}



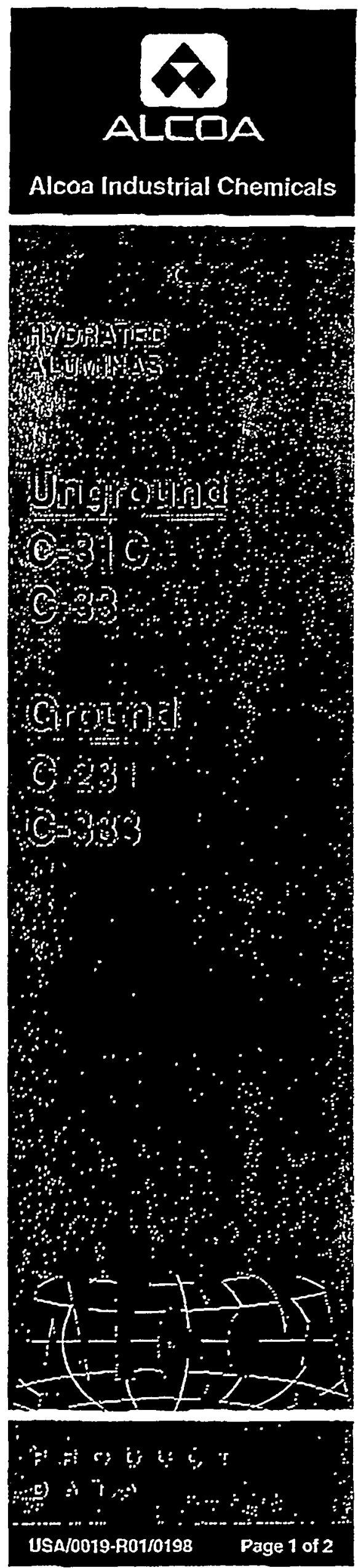

\section{Exceptionally pure white hydrates}

\section{Product Information}

Alcoa white hydrated alumina, is aluminum trihydroxide, $\mathrm{Al}(\mathrm{OH})_{3}$, that is produced through special processing of alumina-bearing feedstocks and stringent process control systems. The result is an alumina trihydroxide of exceptional purity and whiteness. Although hydrated alumina is a dry powder, it contains a high proportion, approximately 35 percent by weight, of chemically combined water. The hydrate is a nonabrasive, low-density material with a Mohs' hardness index of $2.5-3.5$ and a specific gravity of $2.42 \mathrm{~g} / \mathrm{cc}$. White hydrates are used primarily in applications where color and the absence of impurities are critical. They are halogen-free making them excellent nontoxic flame retardant/smoke suppressant fillers for plastic compounds.

\section{Product Description}

Alcoa precipitates a highly pure gibbsite phase of alpha alumina trihydrate. The Alcoa proprietary white stream process is designed, through chemical and recrystallization processes, to achieve near 100 percent photovolt brightness and relatively uniform particles.

\section{C-33 and C-31C (coarse)}

The precipitation process is controlled to produce two median particle sizes, Grades C-33 (50 microns) and C-31C (85 microns). Both grades have free-flowing properties.

\section{C-231 and C-333 Ground White} Hydrates

Intermediate and fine size grades are produced by grinding the precipitated grades to form C-231

(14 microns) and C-333

(7 microns).

\section{Applications}

Grades C-33 and C-31C hydrates are used in the manufacture of glass, chemicals, catalysts, vitreous enamels and ceramic whitewares, and as additives in high quality pigments. These products are also used as additives and fillers in polymer systems such as electrical wire insulation and high quality cultured marble and solid countertop surfacing material. Hydrated aluminas are preferred because of their good arc and track resistance, aesthetic properties, reinforcing characteristics and performance as nontoxic smoke suppressants and flame retardants.

Grades $\mathrm{C} .231$ and $\mathrm{C.333}$ are ground versions of Grade C-33. They are used in polymer formulations, toothpastes, adhesives, coatings, paper, cosmetics, waxes and polishes. 


\section{Typlcal Properties of Alcoa White Serles Alumina Trihydrates}

\begin{tabular}{lcccc}
\hline Chemical Analysls & $\mathrm{C}-33$ & $\mathrm{C}-31 \mathrm{C}$ & $\mathrm{C}-231$ & $\mathrm{C}-333$ \\
\hline $\mathrm{Al}(\mathrm{OH})_{3}(\%)$ & 99.6 & 99.6 & 99.6 & 99.6 \\
\hline $\mathrm{LOl}(\%)$ & 34.6 & 34.6 & 34.6 & 34.6 \\
\hline $\mathrm{Al}_{2} \mathrm{O}_{3}(\%)$ & 65.0 & 65.0 & 65.0 & 65.0 \\
\hline $\mathrm{SiO}_{2}(\%)$ & 0.003 & 0.003 & 0.003 & 0.003 \\
\hline $\mathrm{Fe}_{2} \mathrm{O}_{3}(\%)$ & 0.009 & 0.009 & 0.009 & 0.009 \\
\hline $\mathrm{Na}_{2} \mathrm{O}(\%$ Total) & 0.17 & 0.26 & 0.17 & 0.17 \\
\hline $\mathrm{Na}_{2} \mathrm{O}(\%$ Soluble) & 0.010 & 0.010 & 0.023 & 0.022 \\
\hline Moisture $(\%)$ & 0.05 & 0.06 & 0.15 & 0.15 \\
\hline
\end{tabular}

Physical Analysis

\begin{tabular}{lllll}
\hline Loose Bulk Density $\left(\mathrm{g} / \mathrm{cm}^{3}\right)$ & 1.17 & 1.15 & 0.8 & 0.6 \\
\hline Packed Bulk Density $\left(\mathrm{g} / \mathrm{cm}^{3}\right)$ & 1.38 & 1.33 & - & - \\
\hline Surface Area $\left(\mathrm{m}^{2} / \mathrm{g}\right)$ & - & - & 2.5 & 3.0 \\
\hline
\end{tabular}

Particle Size Analysis

\begin{tabular}{lcccc}
\hline$\%$ on 100 Tyler Mesh & 0 & 3 & - & 0 \\
\hline$\%$ on 200 Tyler Mesh & 10 & 60 & 3 & 0 \\
\hline$\%$ on 325 Tyler Mesh & 55 & 90 & 20 & 2 \\
\hline$\%$ through 325 Tyler Mesh & 45 & 10 & 80 & 98 \\
\hline Median Micron (D50) & 50 & 85 & 14 & 7 \\
\hline
\end{tabular}

\section{Physical Constants}

Refractive Index

Denshy (g/an')

Mohs' Hardness

Color

\subsection{7}

2.42

2.5-3.5

White

\section{Test Methods}

$\mathrm{Al}(\mathrm{OH})_{3}$ and $\mathrm{Al}_{2} \mathrm{O}_{3}$ - by difference

LOI(Loss On Ignition) - from $110^{\circ}$ to $1100^{\circ}$ Centigreds

$81 \mathrm{O}_{2}$ - by DC ArC Optical Emission Spectrometry

$\mathrm{Fo}_{2} \mathrm{O}_{3}$ - by DC Arc Optical Emission Spectromety

Total Soda - by DC Arc Optical Emission Spectrometry

Soluble Soda - by Flame Emission Photometry

Moisture by Mlcrowave
Loose Bulk Density - Modified ASTM B212-89 Packed Bulk Density - Modified ASTM B527-85

Surface area measured by Brunaver-Emmer Color Teller method of nitrogen atborption $\%$ through Tyler 325 Mesh-by wet sereen Median Mleren (D50) - Microtrac (C-33/31C) Medlan Micron (D50) - Sedigraph 5100 (C-231/333)

Information presented herein is believed to be accurate and reliable but is not intended to meet any specification and does not Imply any guarantee or wartanty by Alcoa.

MSDS Number-839

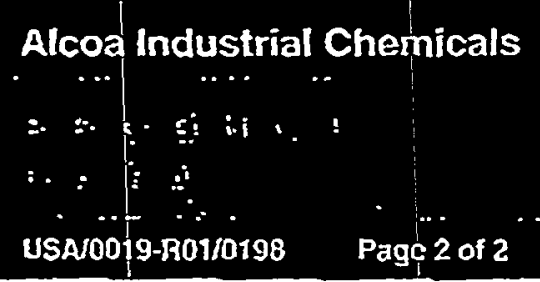

United States of America \& Latin America Alcoa Industrial Chemicals

P.O. Box 300, 4701 Alcoa Road, Beuxte AR 72011, USA

Phone: 800-860-3290, FAX: 800-483-7328

E-mail address: baucc01.alcoa03 ssw.alcoa.com.

For calls from outside of the Unlied States - Phone: 501-776-4760, Fax: 501-776-4762

South Amstica Săo Pauto, Brazll • Europe Frankfunt, Germany - Asia Booragoon, Wertern Australia 

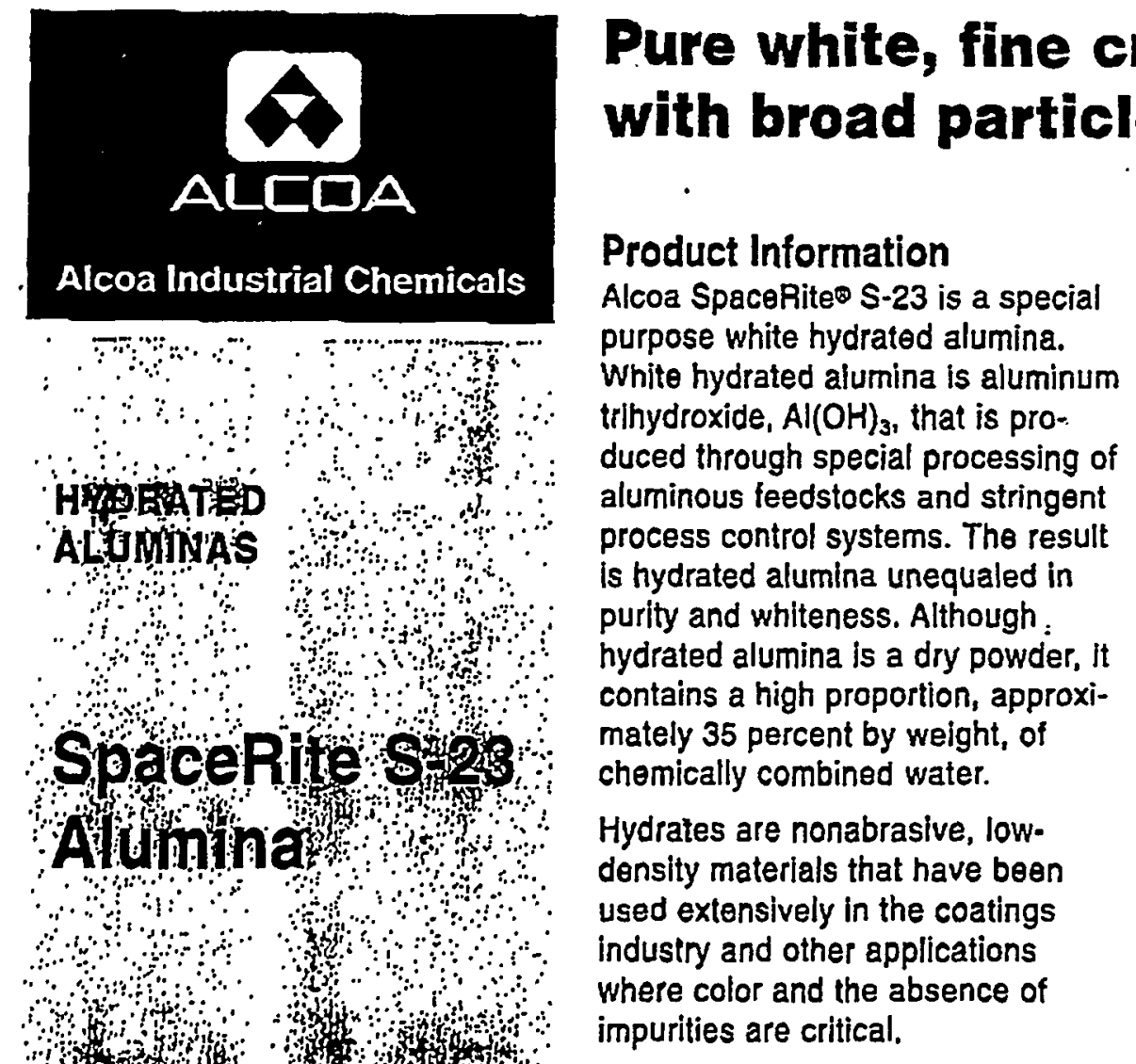

SpaceRite aluminas meet FDA specification 175.300. MSDS Section IX, Regulatory Information, states: "For purposes of SARA III reporting, this substance contains no ingredients listed on the Extremely Hazardous, CERCLA, or Section III lists."

\section{Applleations}

Architectural coatings

\section{Properties}
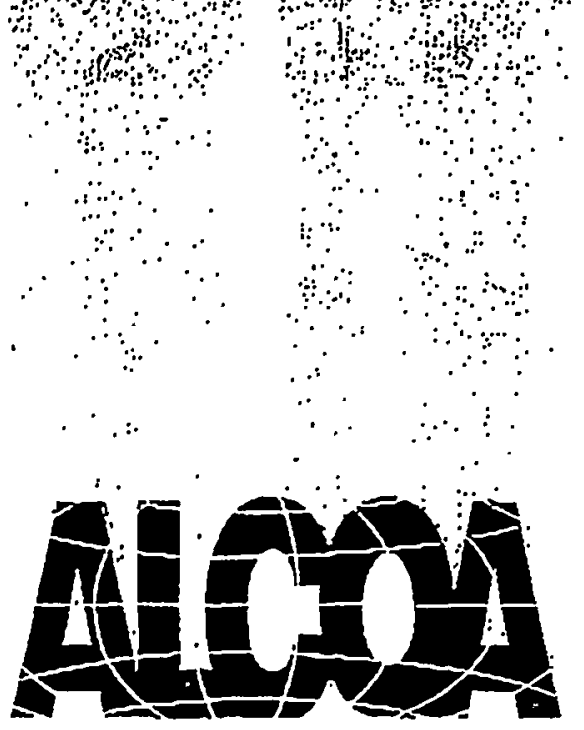

High solidshow VOC coatings capability, •Reduces yellowing in alkyds. "Easily dispersed (5+ Hegman). $\bullet$ Can be used in wide range of colors (no impact on colors). color. -Easily dispersed (5+ Hegman). -Weathor resistant. - Inert.

Features

- Broad particle size distribution

(7.5 microns median)

- Low oll absorption

- High brightness

- Clean white color

- Low specific gravity

- Nonabrasive

- Excellent dispersion characteristics

- Chemically inert

- UV transparent
UV coatings

-RMC reduction (formulation extender). •Improves photoinitiator efficiency. $\cdot$ Will not adversely alfecl speed or depth of cure (UV Iransparent). Easily dispersed.

Organic colored pigments $5 \%$ ). - Inert. Excellent weatherability, Low oil absorption. -Will not impact hue. Easily dispersed (5+ Hegmar).
$P R O D U C T$
D. A T A

USA/0027-R0010796

Page 1 of 2 


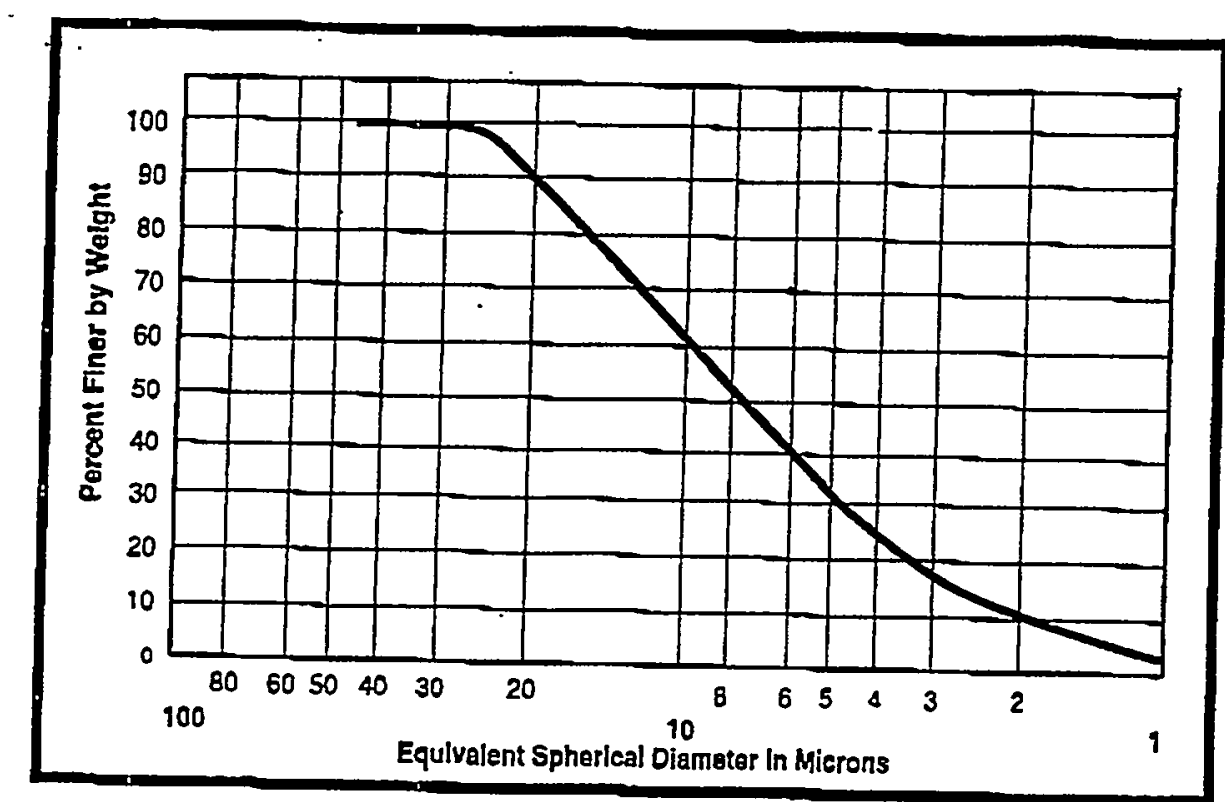

SpaceRite S-23 Alumina Typical Particle-Size Analysis by Sedigraph

Typical Properties of SpaceRite S-23 Alumina

Chemical Composition

Al $(\mathrm{OH})_{3}(\%$ minimum $) \quad 98.0$

\begin{tabular}{ll} 
Moisture conteni (\%) & $0.01-0.5$ \\
\hline $\mathrm{Na}_{2} \mathrm{O}$ (\% soluble) & $0.0-0.04$ \\
\hline
\end{tabular}

Physical Properties

Specific gravity 2.42

Moh's hardness $\quad 2.5-3.5$

Pounds per gallon 20.20

\begin{tabular}{ll}
\hline Gallons per pound $\quad 0.0495$ \\
\hline
\end{tabular}

Median particle size, $\mu \mathrm{m}$

Oil absorption, $\mathrm{g} / 100 \mathrm{~g}-18-20$

$\mathrm{pH}^{*}$ (ASTM 1208)

Refraceive index

1.57
Information presented herein is believed to be sccurate and reliable but is not intended to meet
any speciflcation and does not imply any guaranteo or warranty by Alcoa.

\begin{tabular}{|c|c|}
\hline Brightness $-Z$ percent ${ }^{* *}$ & 98.0 \\
\hline Color & white \\
\hline Bulk density, loose, $\mathrm{g} / \mathrm{cm}^{3}$ & 1.52 \\
\hline Bulk density, packed, $\mathrm{g} / \mathrm{cm}^{3}$ & 2.65 \\
\hline
\end{tabular}

MSDS Number-839

- Not a buHer

- $Z$ percent brighinass la the $Z$ valus of the XYZ tilstimulus divided by 1,1810 s

\section{Alcoa Industrial Chemicals}

$P R O D \cup C T$

D A T A

USAV0ól $27-80010796$
Page 2 of 2
United States of America \& Latin America Alcoa Industrial Chemicals

P.O. Box 300. 4701 Alcoa Road, Bauxite AR 72011. USA

Phone: 800-860-3290, FAX: 800.493-7329

E.mail address: baucc01.alc02030ssw.alcoa.com.

For calls from ouiside of the Unitcd Stales - Phone: 501-776-4760, Fax: 501.776.4762

South America Sàd Paulo, Brazil • Europe Frankfun, Germany - Asia Booragoon. Westem Australia 

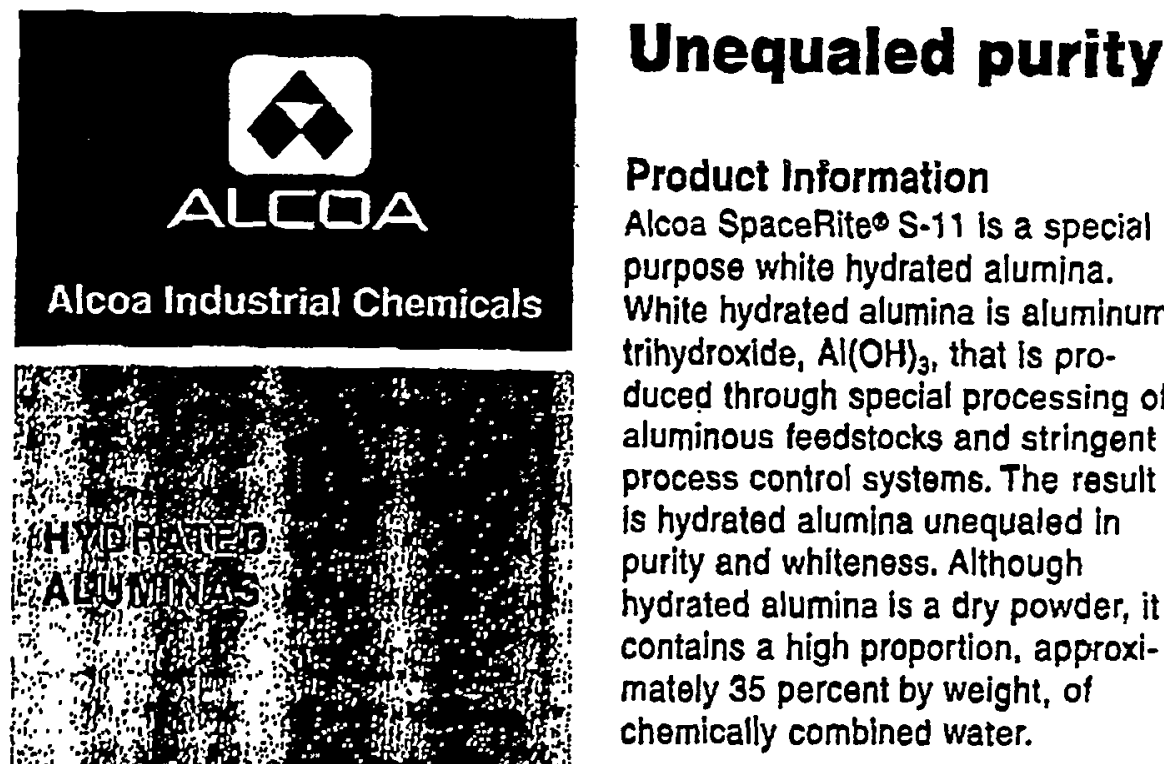

Hydrates are nonabrasive, lowdensity materials that have been used extensively in the coatings industry and other applications where color and purity are critical.

SpaceRite aluminas meet FDA specification 175.300. MSDS Section IX, Regulatory Information, states: "For purposes of SARA III reporting. this substance contains no ingredients listed on the Extremely Hazardous, CERCLA, or Section III lists."

\section{Product Description}

SpaceRite S.11 is a fine crystalline aluminum trihydroxide with uniform particles averaging $1 / 4$ micron in diameter. It is an organic-free, pure white powder that has been further processed to function in coatings and adhesives.

\section{Features}

- Narrow particle size distribution (0.25 micron median)

- Low oil absorption

- High brightness

- Clean white color

- Low specific gravity

- Nonabrasive

- Excellent dispersion characteristics

- Chemically inert

- UV transparent

\begin{tabular}{|c|c|}
\hline Applications & Properties \\
\hline Architectural coatings & $\begin{array}{l}\text { - } \mathrm{TIO}_{2} \text { replacement. -Will not reduce gloss. } \\
\text {-Excellent gloss retention. •Will not Impact } \\
\text { color. •Easily dispersed ( } 7+\text { Hegman). } \\
\text {-Weather resistant. •Iner. }\end{array}$ \\
\hline High solids/low VOC coatings & $\begin{array}{l}\text { - Highly inert. - Low oll absorption and high } \\
\text { loading capability. } \cdot \text { Will not reduce gloss. } \\
\text {-Excellent gloss retention. } \cdot \text { Reduces } \\
\text { yellowing in alkyds. } \cdot \text { Easily dispersed }(7+ \\
\text { Hegman). } \cdot \text { Can be used in wide range of } \\
\text { colors (no impact on colors). }\end{array}$ \\
\hline UV coatings & $\begin{array}{l}\text {-RMC reduction (formulation extender). } \\
\text {-Improves photoinitiator efficiency. -Will not } \\
\text { adversely affect speed or depth of cure } \\
\text { (UV transparent). EEasily dispersed. }\end{array}$ \\
\hline Organic colored pigments & $\begin{array}{l}\text {-Ideal pigment extender (invisible at levels } \\
\text { up to } 5 \% \text { ). Inent. Excellent weatherability. } \\
\text {-Low oil absorption. -Will not impact hue. } \\
\text {-Easily dispersed (7+ Hegman). }\end{array}$ \\
\hline
\end{tabular}




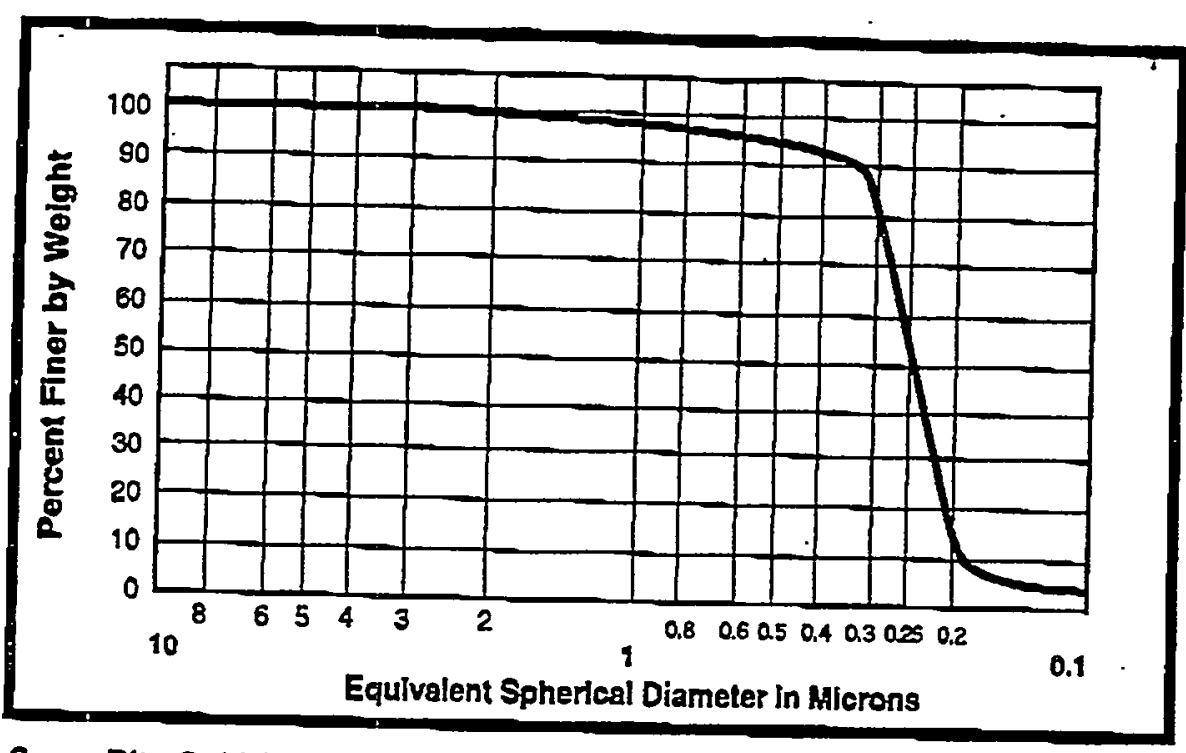

SpaceRite $S .11$ is a fine crystalline aluminum trihydroxide with uniform particles averaging $1 / 4$ micron in diameler. (This typlcal particle size analysis is by Sedigraph.)

Intormation presented hereln is believed to be accurate and reliable but is not intended to meat any speciflcation and does not imply any guarantes or warranty by Alcoa.

\section{MSDS Number-839}

Typical Properties of

SpaceRIte S-11 Alumina

Chemical Composition

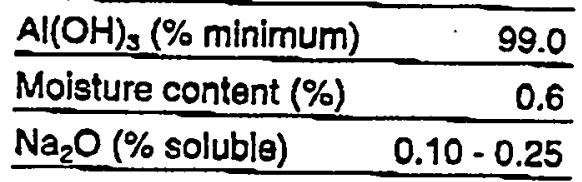

Physical Propertles

Specific gravity 2.42

Moh's hardness $2.5 \cdot 3.5$

Pounds per gallon $\quad 20.20$

Median particle size, $\mu \mathrm{m} \quad 0.25-0.30$

Oil absorption, g/100g $24-28$

\begin{tabular}{ll}
\hline $\mathrm{pH}^{*}$ (ASTM 1208) & 9.8 \\
\hline
\end{tabular}

\begin{tabular}{ll} 
Refractive index & 9.57 \\
\hline
\end{tabular}

\begin{tabular}{ll}
\hline Brightness - Z percent"• $\quad 98.0$ \\
\hline
\end{tabular}

Color white

Bulk density, loose, g/cm3 $0.13-0.24$

Bulk density, packed, g/cm3 $0.26-0.45$

- Not a outfer

- Z porcont ughenos le the $z$ value of the $x$ z oistimulus onded by 3.18103

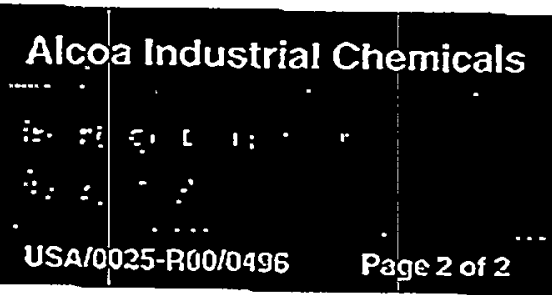

United States of Amerlea \& Lotin Amerlea Alcoa Industrial Chemleals

P.O. Box 300, 470 i Alcoz Road, BauxitB AR 72011, USA

Phono: 800-880-3290, FAX: 800-493-7328

E-mail address: baucc01.alcoso3@ssw.alcoa,com.

For calls from outside of the United States - Phone: 501-776-4760, Fax: 501-776-4762

South America Sáo Paula Braz') - Eurepe Frankfurt, Germany - Asia Booragoon, Westem Australia 


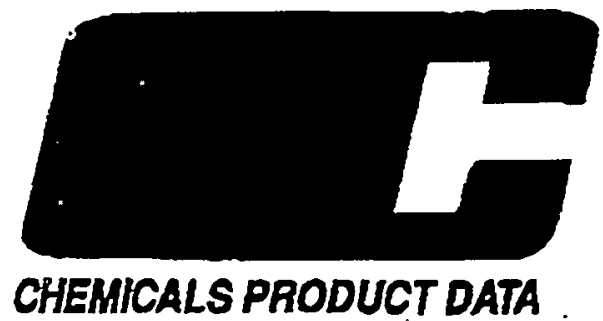

Product Information

Alcon Spaceriteo se3 ls a spectal purpase white hydrated alumina. Whito hydratod alumine is aluminum trihydroxide, Al(OH)s, that Is produced through apecial processing of aluminaus foedstocks and stringent procasa control systems. Tho result is hydratod alumina unequaled in purlty and whiteness. Although hydrated alumina ls a diry powder, it contalns a high proportlon, approxImately 35 percent by welght, of chemically combined water.

Hydrates are nonabrastve, lowdensity materials that havi been used oxtensively in the coatings industy and other applleattons where color and the absence of impurtites are. . crileal.

SpaceRlte aluminas meet FDA spaclficatlon 175.300. MSDS Section IX, Regulatory Information, states: "For purpases of SARA III repording, thls substance contains no Ingredients llsted on the Extramely Hazardous, CERCLA, or Secilon III lisfs."

\title{
SpaceRite S-3 Alumina
}

\author{
Hydrated Aluminas
}

\section{Product Description}

Spacerite $\mathrm{S}-3$ is a fine crystalline, aluminum irihydroxkde with uniform partlcles averaging about one micron in dlameter: It is an organlc-free, pure white powder produced by a proprietary precipitation process that closely controls particle-size dlstributions. SpaceRite S-3 can also replace other extenders providing enhanced performance and benefits in coatings and adhesives.

\section{Product Features}

- Narrow particle size distribution

(1.0 micron median)

- Low oil absorption

- High brightness

- Clean white color

- Low spectfic gravity

- Nonabrasive

- Excelleni dispersion characteristics

- Chemically Iner

- UV transparent

\section{Typical Properties of SpaceRite S-3 Alumina}

Chemleal Composition

$\mathrm{Al}(\mathrm{OH})_{3}$ (\% minimum)

88.0

Moisture content ( $\%$ maximum)

0.7

$\mathrm{Na} 2 \mathrm{O}$ (\% soluble)

0.08

Physleal Propertes

Specilic gravity

Moh's hardness

Pounds per gallon

Gallons per pound

Median particle size, $\mu \mathrm{m}$

Oll absorption, g/100g

$\mathrm{pH}^{*}$ (ASTM 1208)

Refractive index

Brightness - Z percent"*

Color

Bulk density, loose, g/cm $\mathrm{cm}^{3}$

Bulk density, packed, g/cm3

$2.5 \cdot 3.5$

20.20

0.0485

98.0

whitte

0.22

0.37

- Nol a bufles

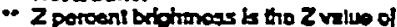
the Xve inistinutus diriod by 1,18100
Applications Properties

Architectural coatings

- $\mathrm{TO}_{2}$ replacement. -WIII not reduce gloss. - Excellent gloss retention. -Will not impact color. - Easily dispersed (7+ Hegman). -Weather reslstant. Inert.

High solidshow VOC coatings

- Highly inert. Low oil absorption and high loading capability. -Will not reduce gloss. • Excellent gloss retention. Reduces yellowing in alkyds. - Easily dispersed (7+ Hegman). - Can be used in wide range of cotors (no impact on colors).

UV coatings

- RMC reduction (formulation extender). -Improves photolnitiator efficiency. -Will not adversely affect speed or depth of cure (UV transparent). Easily dispersed.

Organic colored pigments
-Ideal plgment extender (Invisible at levels up to $5 \%)$. Inert. Excellent weatherability. Low oil absorption. owill not impact hue. Easily disporsod (7+ Hegman). 


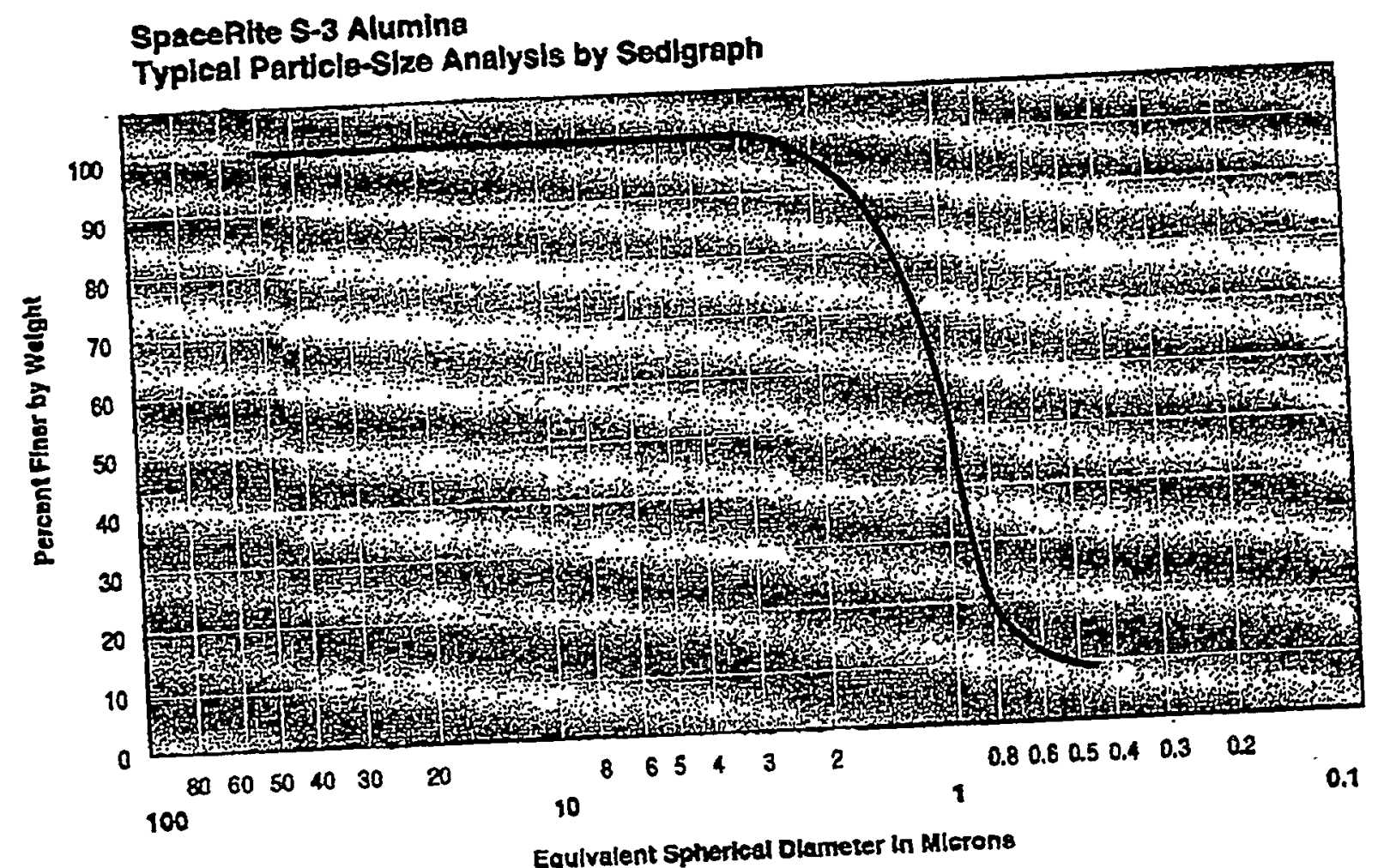

Inforitition presented herein is belleved to bo

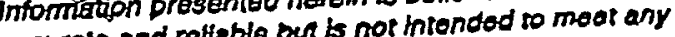
specification and does not imply any guaranteo or wamenty by Aloos. 


\section{Hematite}




\title{
The Prince Manufacturing Company Established 1858
}

\author{
Data Sheet
}

Iron Oxide 5001

$\mathrm{Fe}_{2} \mathrm{O}_{3}$

Item Number: 07-5001

\section{Typical Chemical Analysis}

Fe

$67.8 \%$

$\mathrm{Fe}_{2} \mathrm{O}_{3}$

$97.0 \%$

$\mathrm{Al}_{2} \mathrm{O}_{3}$

$1.50 \%$

$\mathrm{SiO}_{2}$

$1.35 \%$

$P$

$0.115 \%$

$\mathrm{MgO}$

$0.10 \%$

$\mathrm{Mn}$

$0.09 \%$

$\mathrm{CaO}$

$0.04 \%$

$\mathbf{S}$

$0.032 \%$

\section{Physical Description}

Color rouge

Fineness. $.99 \%$ thru 325 Mesh

Apparent Bulk Density

Loose............................................................................................. $70 \mathrm{lb} / \mathrm{ft}^{3}$

Compacted $170 \mathrm{lb} / \mathrm{tt}^{3}$

Package $50 \mathrm{lb} 3$ ply paper bag $\$ 320 / 2000 \mathrm{lbs}$

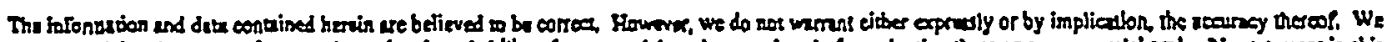

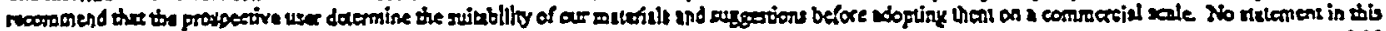

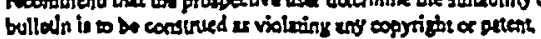




\begin{tabular}{|c|c|c|c|c|c|c|c|c|}
\hline \multicolumn{2}{|c|}{$\begin{array}{l}\text { COLLECT DISPLAY } \quad \text { - MICI } \\
\text { Fe203 Samplë̈: } \\
\text { in DI } \\
\text { GRG }\end{array}$} & & & & \multicolumn{4}{|c|}{ Ver 3.0} \\
\hline \multicolumn{9}{|c|}{ 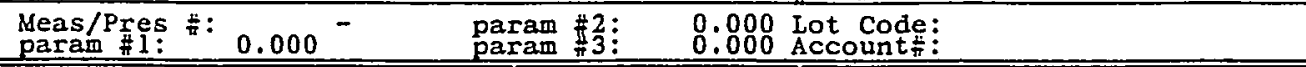 } \\
\hline \multicolumn{2}{|c|}{ 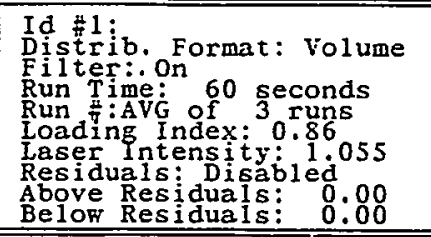 } & & 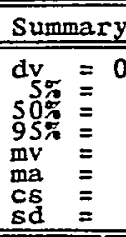 & $\begin{array}{l}\text { Data } \\
0.1205 \\
0.72 \\
21: 07 \\
44: 58 \\
21.71 \\
4.81 \\
1.247 \\
13.63 \\
\end{array}$ & 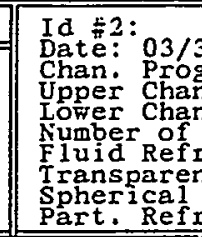 & 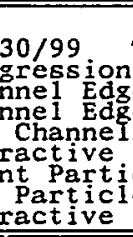 & 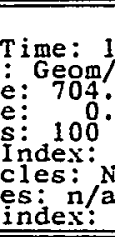 & \\
\hline 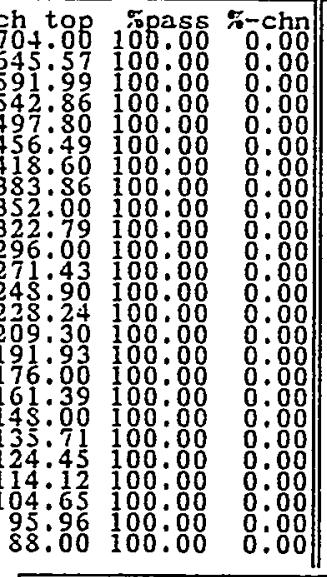 & 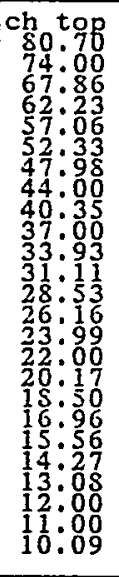 & 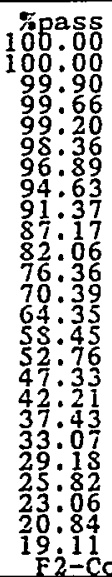 & 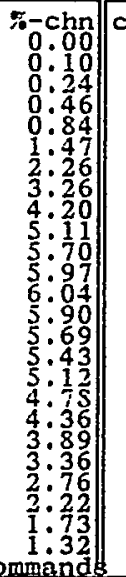 & 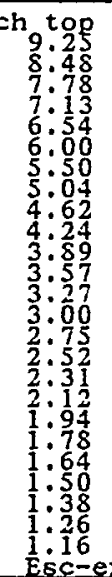 & 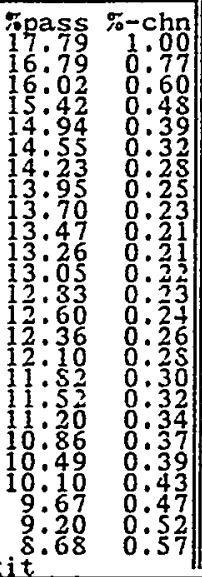 & $\begin{array}{c}\mathrm{ch}_{1} \text { top } \\
1: 00 \\
0: 97 \\
0: 89 \\
0: 82 \\
0: 75 \\
0: 69 \\
0: 63 \\
0: 58 \\
0: 53 \\
0: 49 \\
0: 45 \\
0: 11 \\
0: 37 \\
0: 34 \\
0: 32 \\
0: 29 \\
0: 27 \\
0: 24 \\
0: 22 \\
0: 19 \\
0: 17 \\
0: 16 \\
0: 14 \\
0: 13\end{array}$ & 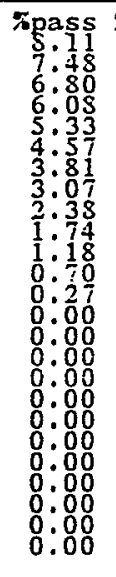 & $\begin{array}{l}7-c h n \\
00: 63 \\
0: 68 \\
0: 72 \\
0: 75 \\
0: 76 \\
0: 76 \\
0: 77 \\
0: 69 \\
0: 64 \\
0: 56 \\
0: 48 \\
0: 43 \\
0: 27 \\
0: 00 \\
0: 00 \\
0: 00 \\
0: 00 \\
0: 00 \\
0: 00 \\
0: 00 \\
0: 00 \\
0: 00 \\
0: 00 \\
0: 00\end{array}$ \\
\hline
\end{tabular}

Record Number: 0

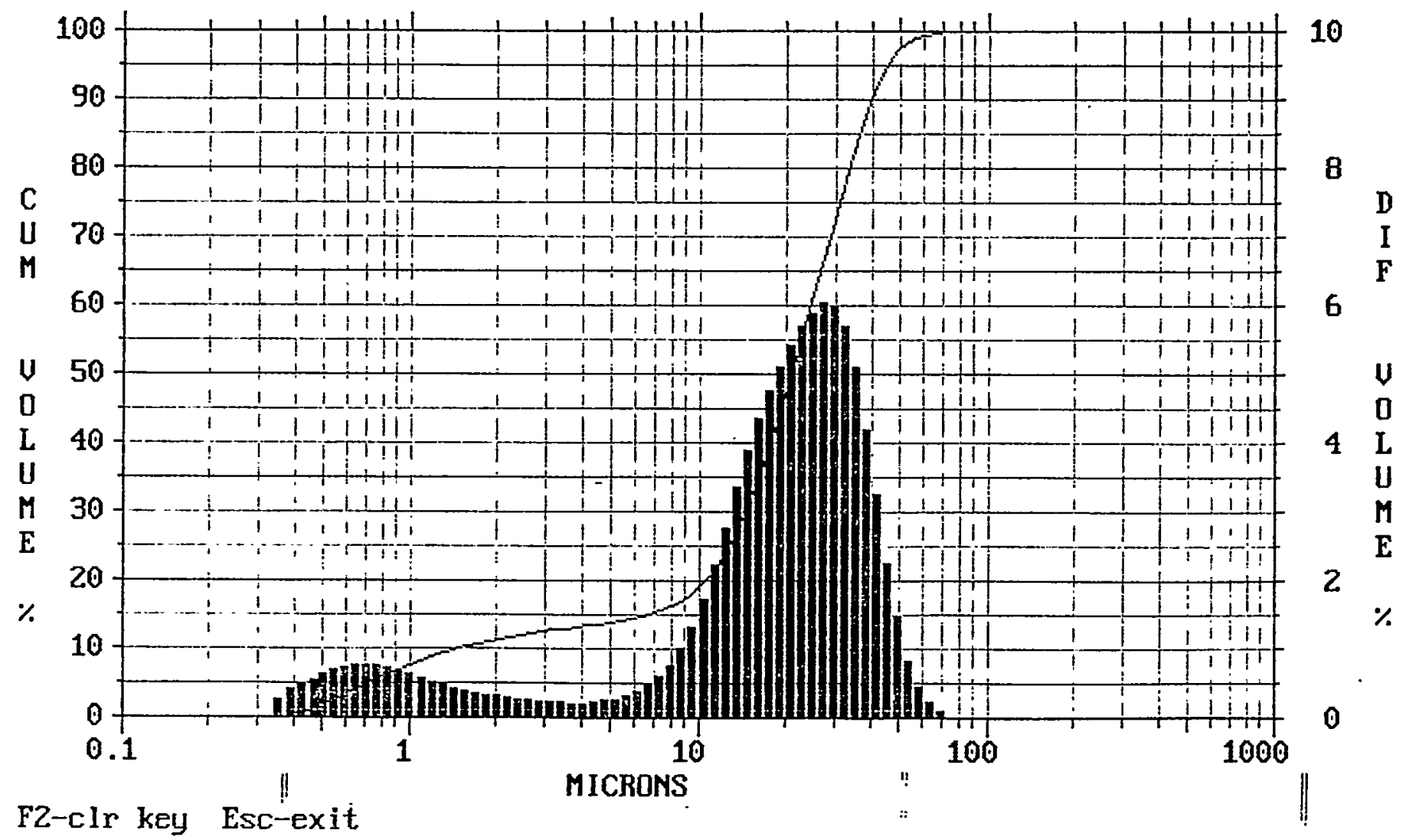




\title{
The Prince Manufacturing Company \\ Established 1858
}

\author{
Data Sheet
}

\author{
Red Iron Oxide 3752 * \\ $\mathrm{Fe}_{2} \mathrm{O}_{3}$ \\ Item Number: 07-3752
}

\section{Typical Chemical Analysis}

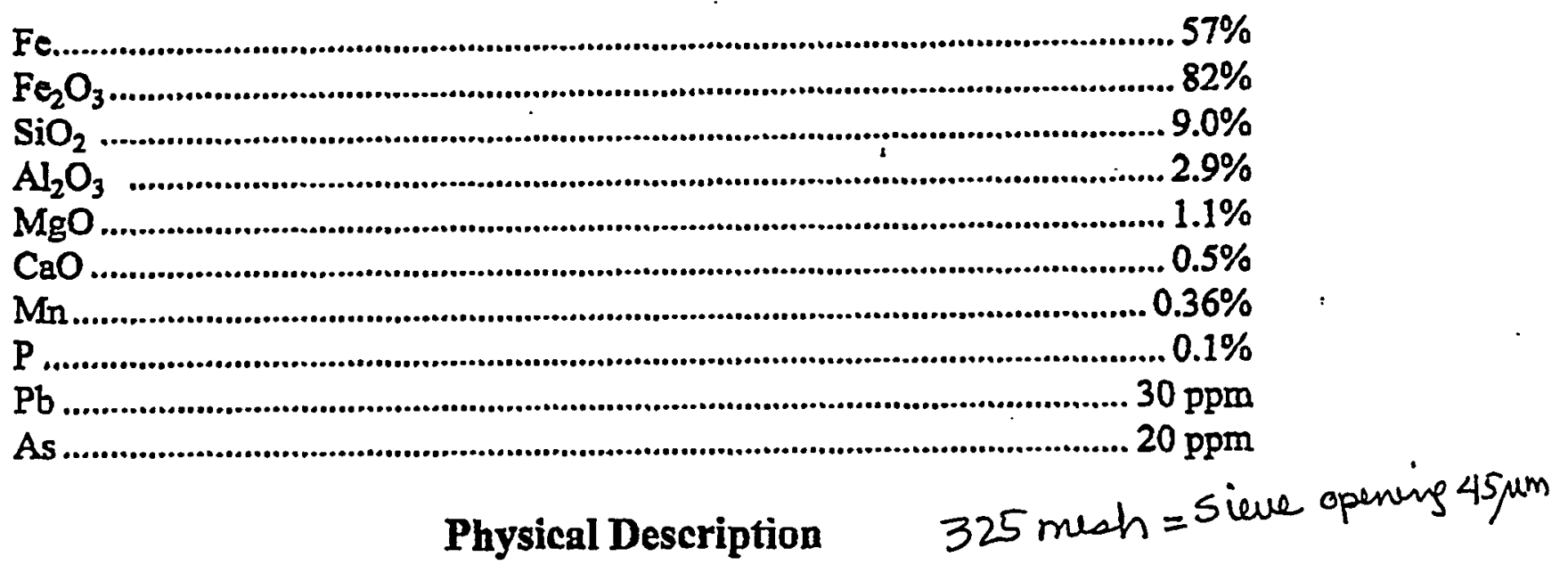

Color red

Fineness. $99.9 \%$ thru 325 Mesh

Average Particle Size 2 microns Apparent Bulk Density

Loose. $24 \mathrm{lb} / \mathrm{ft}^{3}$

Compacted $81 \mathrm{lb} / \mathrm{ft}^{3}$ Package $50 \mathrm{lb} \cdot 3$ ply paper bag 2000 lb SuperSack<smiles>C1CCC(C2CCCC2)C1</smiles>

The information and datn contained herein are believed to be correct. However, we do not wamant either expressly or by implication, the accuracy thereof. We recommend that the prospective usee determine the suitability of our materials and suggestions before adopting them on a commercial scale. No statement in this bulletin is to be construed as violating any copyright or parent. 


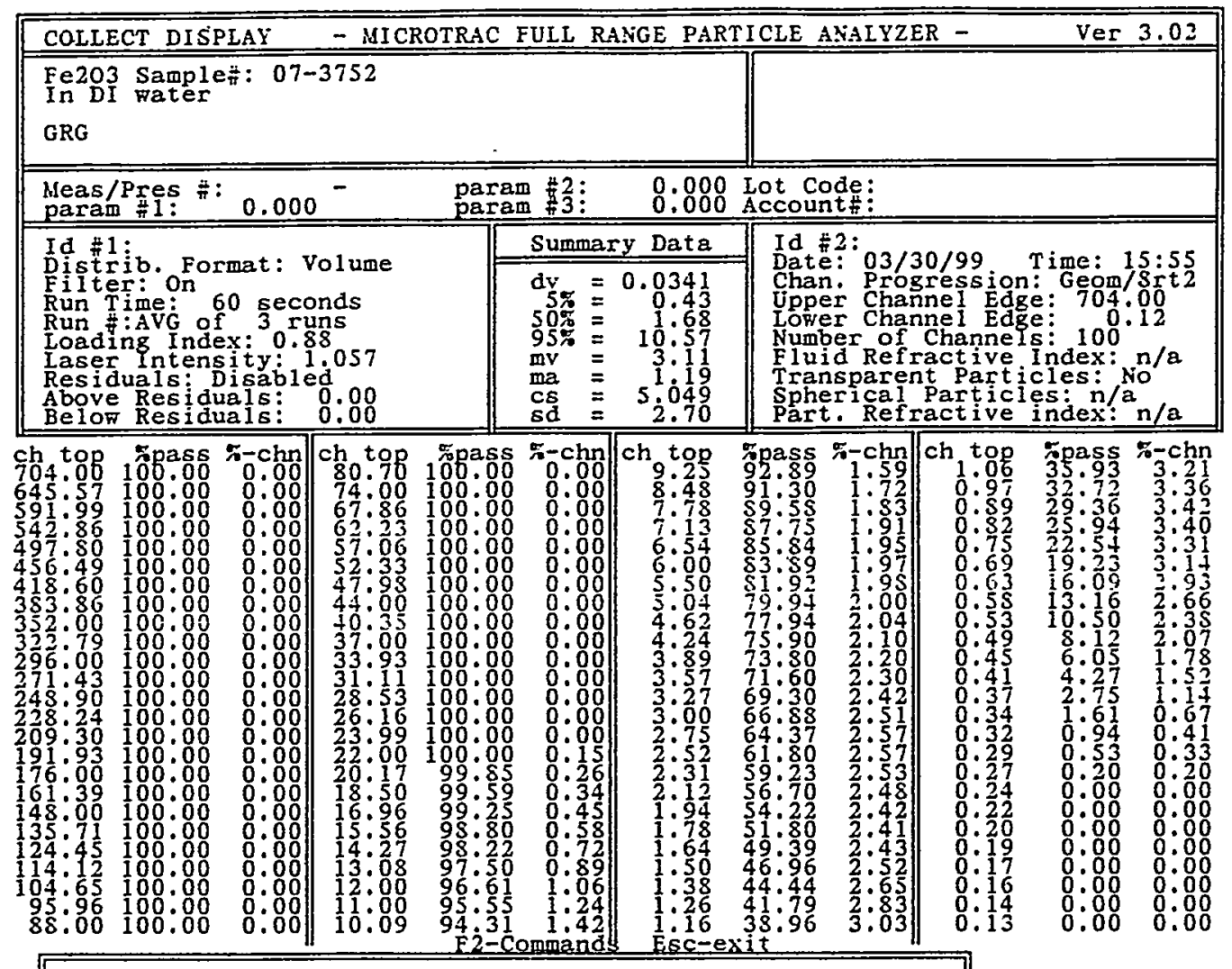

Record Number: 0

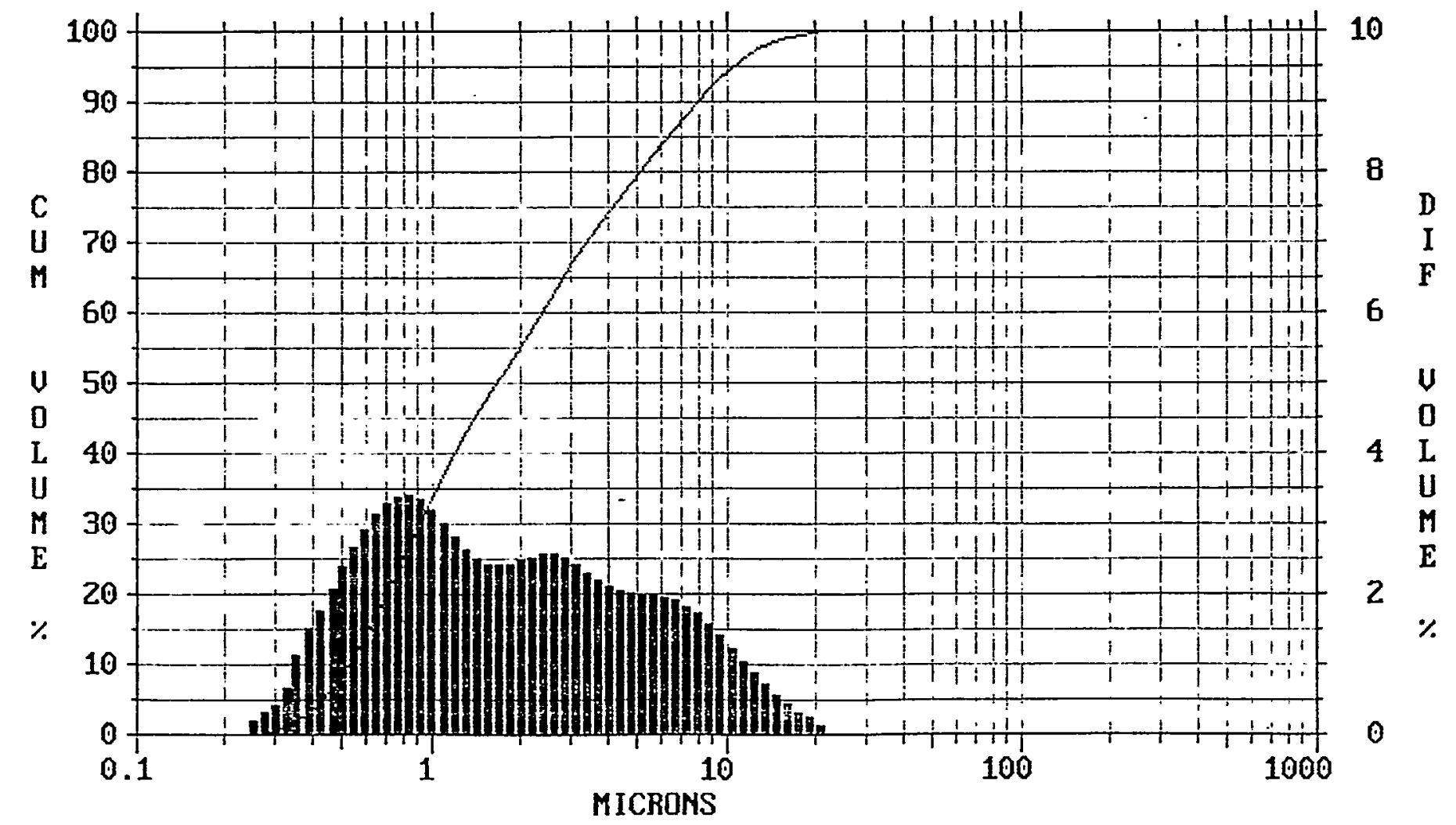

\section{F2-clr key Esc-exit}




\title{
The Prince Manufacturing Company Established 1858
}

\author{
Data Sheet
}

\section{Synthetic Red 2568 .}

. $\mathrm{Fe}_{2} \mathrm{O}_{3}$

Item Number: 07-2568

\section{Typical Chemical Analysis}

Fe.

$67.5 \%$

$\mathrm{Fe}_{2} \mathrm{O}_{3}$

$96.5 \%$

$\mathrm{Al}_{2} \mathrm{O}_{3} \& \mathrm{SiO}_{2}$

$3.0 \%$

Oil Absorption .26

Total Water Solubles. $0.3 \%$

Soluble Sulfates $0.3 \%$

Loss on Ignition $0.5 \%$

$\mathrm{pH}$ .6

\section{Physical Description}

Color red

Fineness. $.99 .9 \%$ thru 325 Mesh

Tap Density $68.7 \mathrm{lb} / \mathrm{At}^{3}$

Specific Gravity .5 .0

Package $.50 \mathrm{lb} 3$ ply paper bag $114 / 16 s$

The information and data contained herein are believed to be correct. However. we do not warrant either expressly or by implicution, the accuracy thereof. We recommend that the prospective urer determine the suitability of our materials and suggestions before odopting thern on a commercial seale. No statement in this bulletin is to be construed as violating any copyright or patent. 


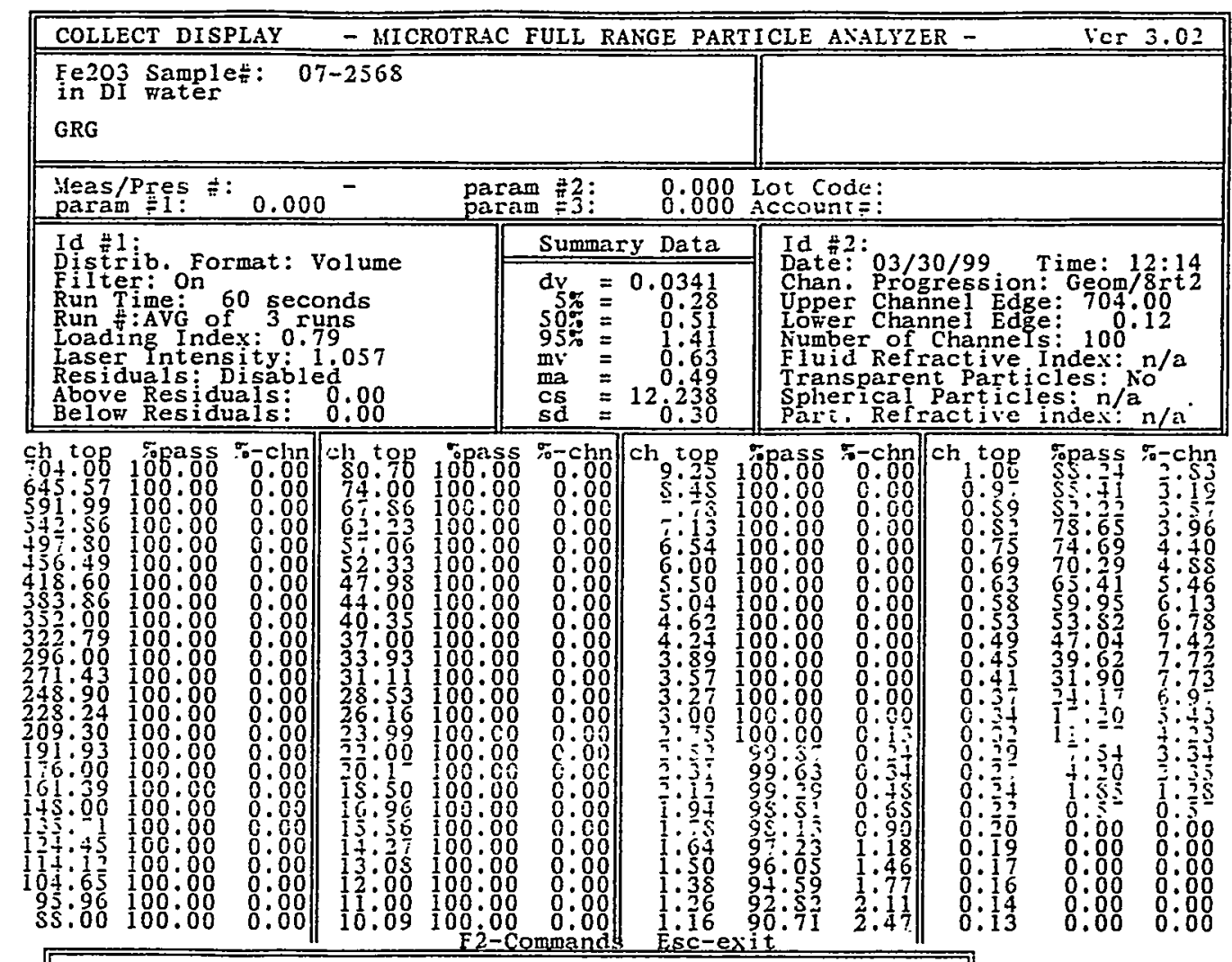

Record Number: 0

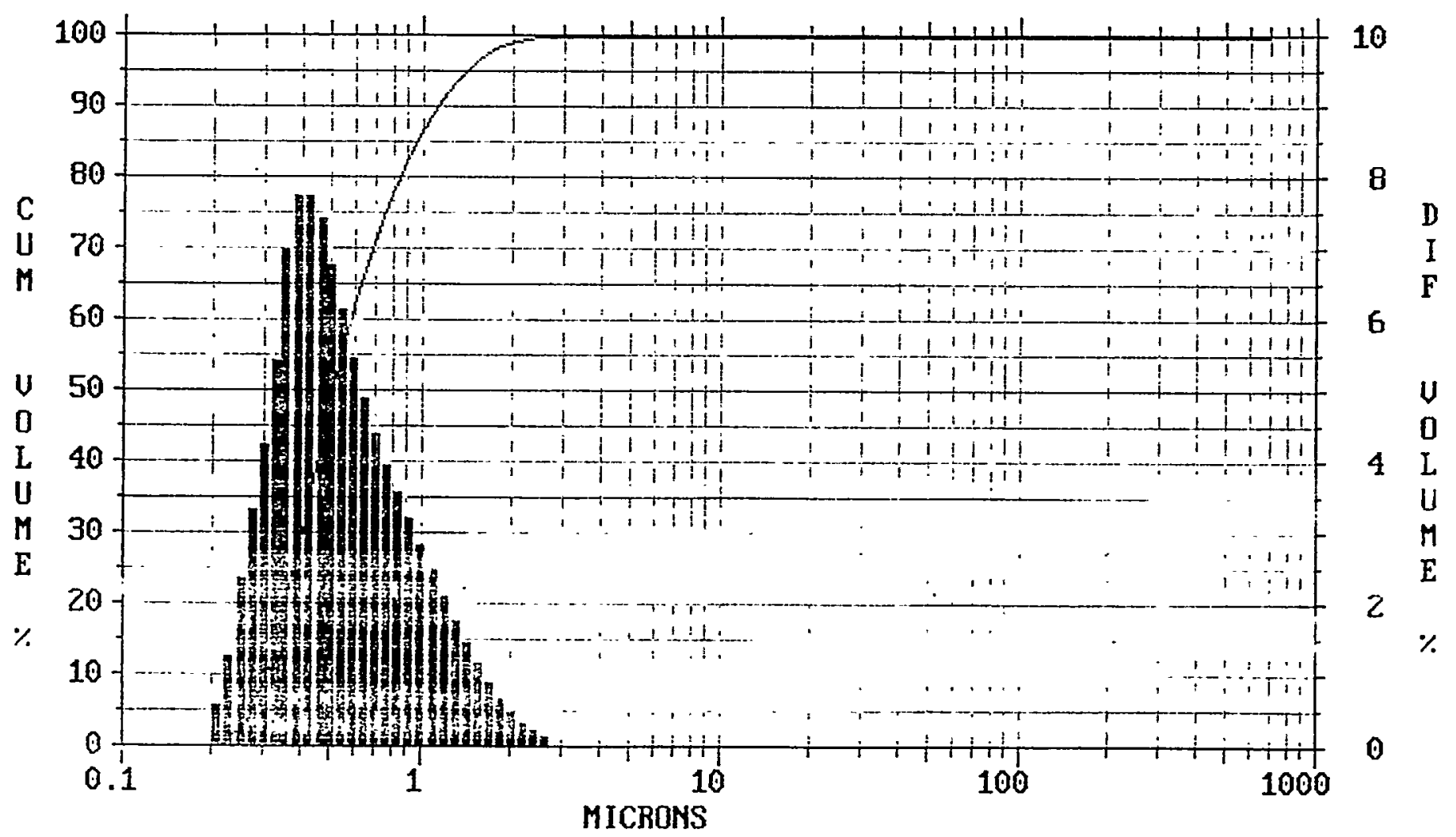

F2-clr key Esc-exit 


\section{Nepheline}




\author{
- Chemistry: (Na, K)AlSiO4, Sodium Potassium Aluminum Silicate. \\ - Class: Silicates \\ - Subclass: Tectosilicates \\ - Group: Feldspathoid. \\ - Uses: As mineral specimens and as raw material for special kinds of glass and ceramics. \\ - Specimens
}

Nepheline is a major rock forming mineral that is not often sold in rock shops due to a lack of good crystals or attractive specimens. It is a major component of several igneous rocks called nepheline syenite, nepheline monzonite and nephelinite. The basic difference between these is in the amount and types of feldspars present. In nepheline syenite potassium feldspars or $\mathrm{K}$-spars are the predominant feldspar. In the nepheline monzonite rocks both $\mathrm{k}$-spars and plagioclase feldspars are present in near equal proportions. And finally in the nephelinites there is little of any of the feldspars present and the rock is mostly nepheline.

The formula of nepheline in some sources will list it as NaAlSiO4. There are very few natural nephelines that have this "pure" chemistry although it produces a stable structure and it is manufactured for use in ceramics and glass production. Potassium is always present in some amounts and often the chemical analysis of nepheline will approach Na3K(AlSiO4)4. This result reflects the fact that the alkali sites for the sodiums and potassiums have an interesting difference in the amount of space within the nepheline structure. There is actually one site out of four that is larger than the other three sites. This larger site is a more comfortable fit for the larger potassium ion.

Nepheline is a member of the feldspathoid group of minerals. Minerals whose chemistries are close to that of the alkali feldspars but are poor in silica (SiO2) content, are called feldspathoids. As a result or more correctly as a function of the fact, they are found in silica poor rocks containing other silica poor minerals and no quartz. If quartz were present when the melt was crystallizing, it would react with any feldspathoids and form a feldspar. Localities that have feldspathoids are lew.

Nepheline is reactive to acids although it does not bubble like many of the carbonates. If powdered it will dissolve in hydrochloric acid and if clear specimens are dipped in acid they will become cloudy or frosted. This could be helpful in distinguishing nepheline from some similar looking feldspars, scapolite and cryolite.

The greasy luster of nepheline also is diagnostic. Massive nepheline with a greasy luster is given the variety name "eleolite" which is derived from the greek word for oil. Nepheline is derived from the greek word for cloud in allusion to its cloudy or translucent crystals and masses.

\title{
PHYSICAL CHARACTERISTICS:
}

- Color is usually off white to gray or brown and occasionally other tints.

- Luster is mostly greasy to dull in weathered specimens.

- Transparency: Crystals are translucent to more rarely transparent.

- Crystal System: Hexagonal; 6

- Crystal Habits: Usually massive or granular. Some prismatic to columnar crystals are found with a simple hexagonal cross section.

- Cleavage is poor, in three directions, prismatic, but rarely seen.

- Fracture is conchoidal to uneven.

- Hardness is $5.5-6$

- Specific Gravity is $2.6+$ (average)

- Streak is white.

- Other Characteristics: Application of acids onto the surface of nepheline will cause a cloudy frosting and powdered nepheline will dissolve in hydrochloric acid.

- Associated Minerals include calcite, feldspars such as albite, apatite, biotite, hornblende, cancrinite, sodalite and other feldspathoids.

- Notable Occurrences include Kola Pennisula, Russia; Mt. Vesuvius, Italy; Bancroft area, Ontario, Canada and Kennebec Co., Maine, USA.

- Best Field Indicators luster, associations, reaction to acids, locality and hardness. 


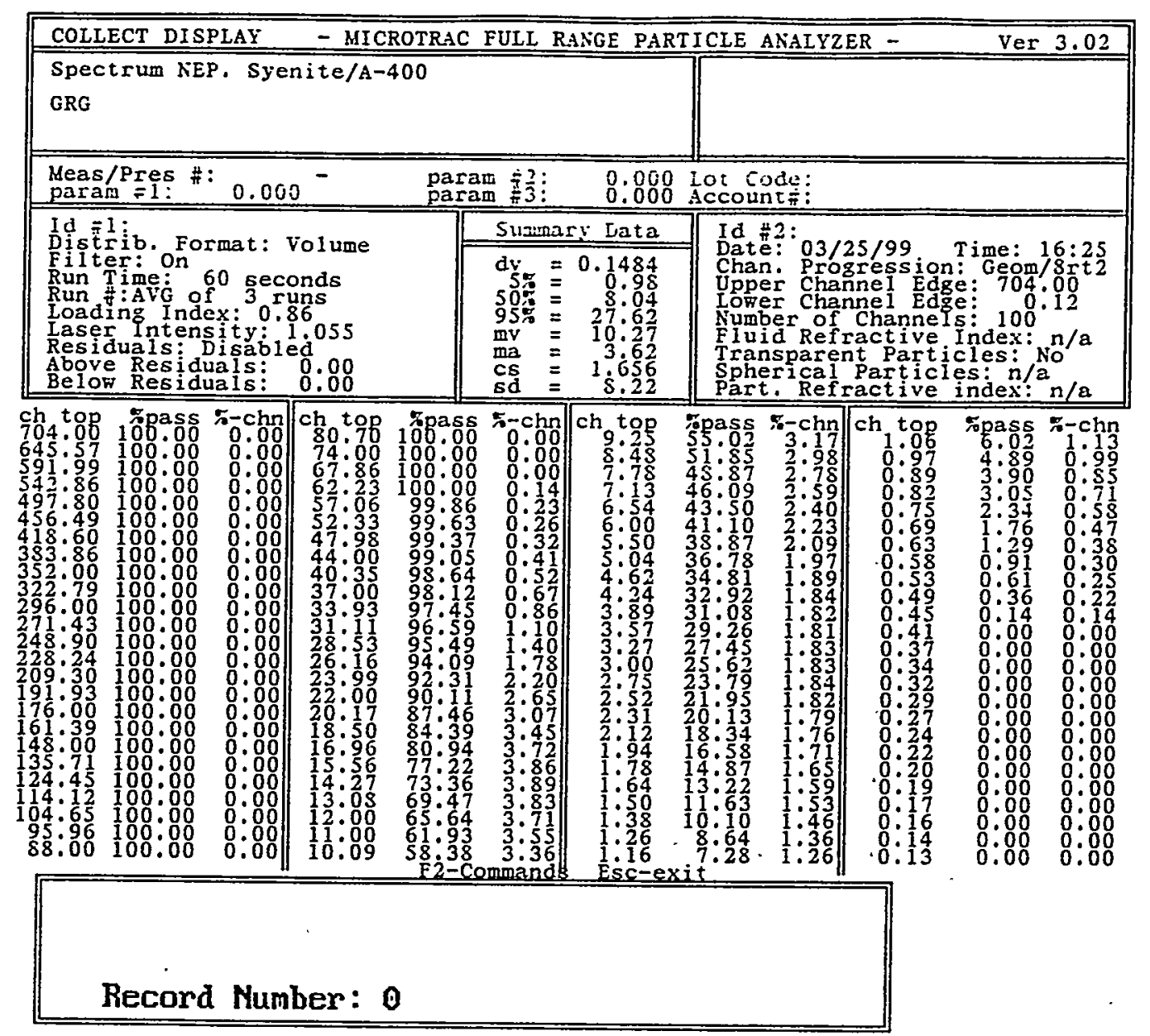

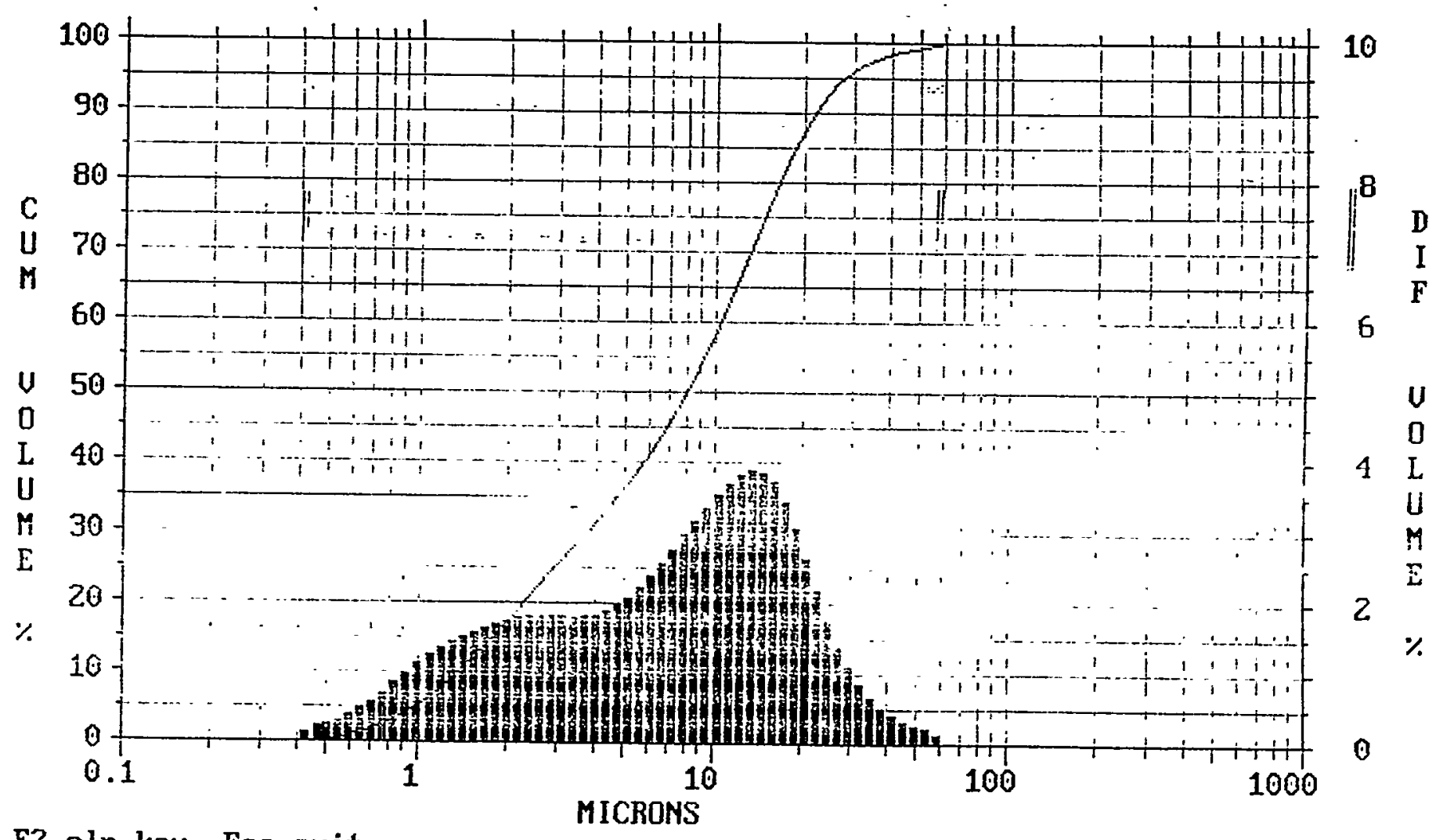

\section{F2-clr key Esc-exit}




\section{Zirconium Hydroxide}


ZIRCONIUM HYDROXIDE

DRY POWDER GRADES PRODUCT DETAILS

MEI supplies pure zirconium hydroxide grades produced by chemical precipitation processes.

These grades have controlled purity and morphology.

PRODUCT DATA FOR ZIRCONIUM HYDROXIDE DRY POWDER GRADES

\begin{tabular}{ll}
\hline Product & $\begin{array}{l}\text { General } \\
\text { Description }\end{array}$ \\
\hline FZO922/01 & $\begin{array}{l}\text { Dry, coarse } \\
\text { hydroxide }\end{array}$ \\
FZO935/01 & $\begin{array}{l}\text { Dry, fine } \\
\text { hydroxide }\end{array}$ \\
\hline
\end{tabular}

Customised variations can be made available on request.
FZO 922 SERIES

PRODUET CODE - FZO922/01

ZIRCONIUM HYDROXIDE

Typical $\mathrm{ZrO}_{2}$ content range: $65-75 \%$

TYPICAL IMPURITIES

$\mathrm{Na} \quad 0.02 \%$

$\mathrm{Cl} \quad 0.02 \%$

$\mathrm{SiO}_{2} \quad .0 .1 \%$

$\mathrm{SO}_{3} \quad 0.1 \%$

L.O.I. $\left(1000^{\circ} \mathrm{C}\right) \quad 30 \%$

PARTICLE SIZE

$\mathrm{d}_{50} \quad 15-20 \mu \mathrm{m}$

Surface area

as received $\left(\mathrm{m}^{2} \mathrm{~g}^{-1}\right)^{(\mathrm{a})} \quad 300-400$

\section{POROSITY}

Pore Volume

$0.2 \mathrm{~cm}^{3} \mathrm{~g}^{-1(\mathrm{a})}$
$0.3 \mathrm{~cm}^{3} \mathrm{~g}^{-1(\mathrm{~b})}$

(a) After degassing at $260^{\circ} \mathrm{C}$

B) After degassing at $80^{\circ} \mathrm{C}$
FZO 935 SERIES

PRODUCT CODE - FZ0935/01

ZIRCONIUM HYDROXIDE

Typical $\mathrm{ZrO}_{2}$ content range: $55-65 \%$

TYPICAL IMPURITIES

$\begin{array}{ll}\mathrm{Na} & 0.02 \% \\ \mathrm{Cl} & 0.02 \% \\ \mathrm{SiO}_{2} & 0.1 \% \\ \mathrm{SO}_{3} & 0.1 \% \\ \text { L.O.I. }\left(1000^{\circ} \mathrm{C}\right) & 40 \%\end{array}$

PARTICLE SIZE

$\mathrm{d}_{50} \quad 1-2 \mu \mathrm{m}$

Surface area

as received $\left(m^{2} \mathrm{~g}^{-1}\right)^{(a)} \quad 300-400$

POROSITY

Pore Volume

$0.2 \mathrm{~cm}^{3} \mathrm{~g}^{-1(a)}$

\section{ZIRCONIUM HYDROXIDE PASTE GRADE PRODUCT DETAILS}

MEl supplies pure zirconium hydroxide grades produced by chemical precipitation processes.

These grades have controlled purity and morphology and are available as white paste.

Customised variations can be made available on request.

\section{HCP}

ZIRCONIUM HYDROXIDE PASTE

Typical $\mathrm{ZrO}_{2}$ content range: $45-55 \%$

\begin{tabular}{ll}
\hline TYPICAL IMPURITIES & \\
$\mathrm{Na}$ & $0.01 \%$ \\
$\mathrm{Cl}$ & $0.01 \%$ \\
$\mathrm{SiO}_{2}$ & $0.05 \%$ \\
$\mathrm{SO}_{3}$ & $<0.1 \%$ \\
$\mathrm{TiO}_{2}$ & $0.2 \%$ \\
$\mathrm{Fe}$ & $0.001 \%$ \\
\hline PARTICLE SIZE & \\
$\mathrm{d}_{50}$ & $20-30 \mu \mathrm{m}$ \\
\hline Surface area against calcination temperature \\
Temp. ( \\
$\left.400^{-} \mathrm{C}\right)$ & Surface Area $\left(\mathrm{m}^{2} \mathrm{~g}^{-1}\right)$ \\
700 & 100 \\
\hline
\end{tabular}




\section{Appendix C: Crossflow Filtration Raw Data}




\section{C-106 Slurry CUF Testing Using 0.1 $\mu \mathrm{m}$ Graver Filter}

Same sequence of run condition as actual waste 
BNFL AZ102 testing--AZ-102

Using 0.1 Micron Mott filter-3/8 inch ID Run \# $\quad \mathrm{V}(\mathrm{ft} / \mathrm{s}) \quad \mathrm{V}(\mathrm{m} / \mathrm{s}) \quad$ GPM

1.0 .2

1.0 .3

1.1

1.2

1.3

1.4

1.5

1.6
$12.2 \quad 3.2$

12.2

12.2

12.2

9.1

15.2

15.2

9.1

12.2
3.72

3.72

3.72

2.77

4.63

4.63

2.77

3.72

4.20

4.20

4.20

4.20

3.13

5.23

5.23

3.13

4.20
J.G.H. Geeting et al, PNNL-11652 Sept. 1997

Using 0.5 Micron Mott filter-0.5 inch ID

Psid Run\# $V(\mathrm{ft} / \mathrm{s}) \quad \mathrm{V}(\mathrm{m} / \mathrm{s}) \quad$ GPM Psid

$\begin{array}{rrrrrr}10 & 1 & 6.1 & 1.86 & 3.73 & 20 \\ 20 & 2 & 4.5 & 1.37 & 275 & 125\end{array}$

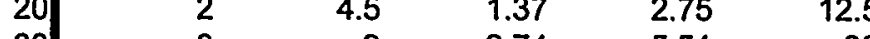

50

30

70

30

70

50

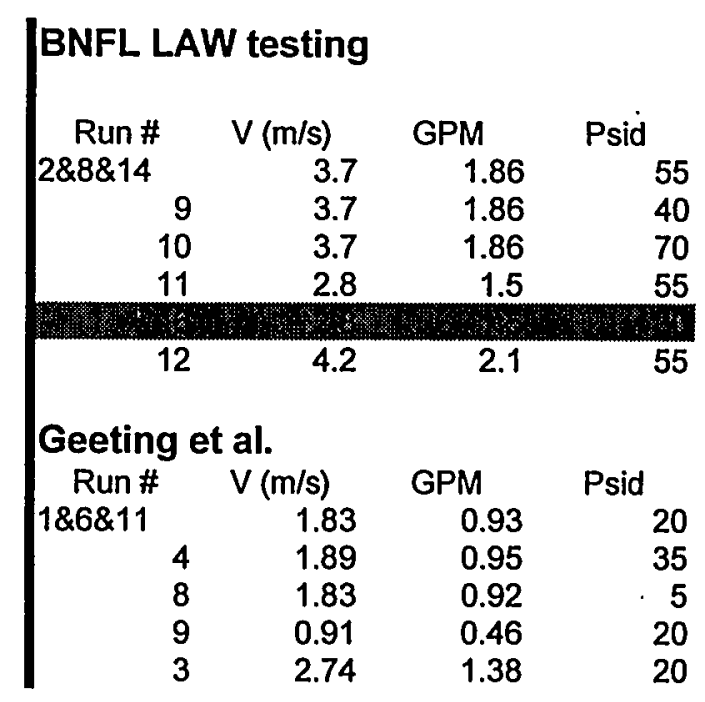

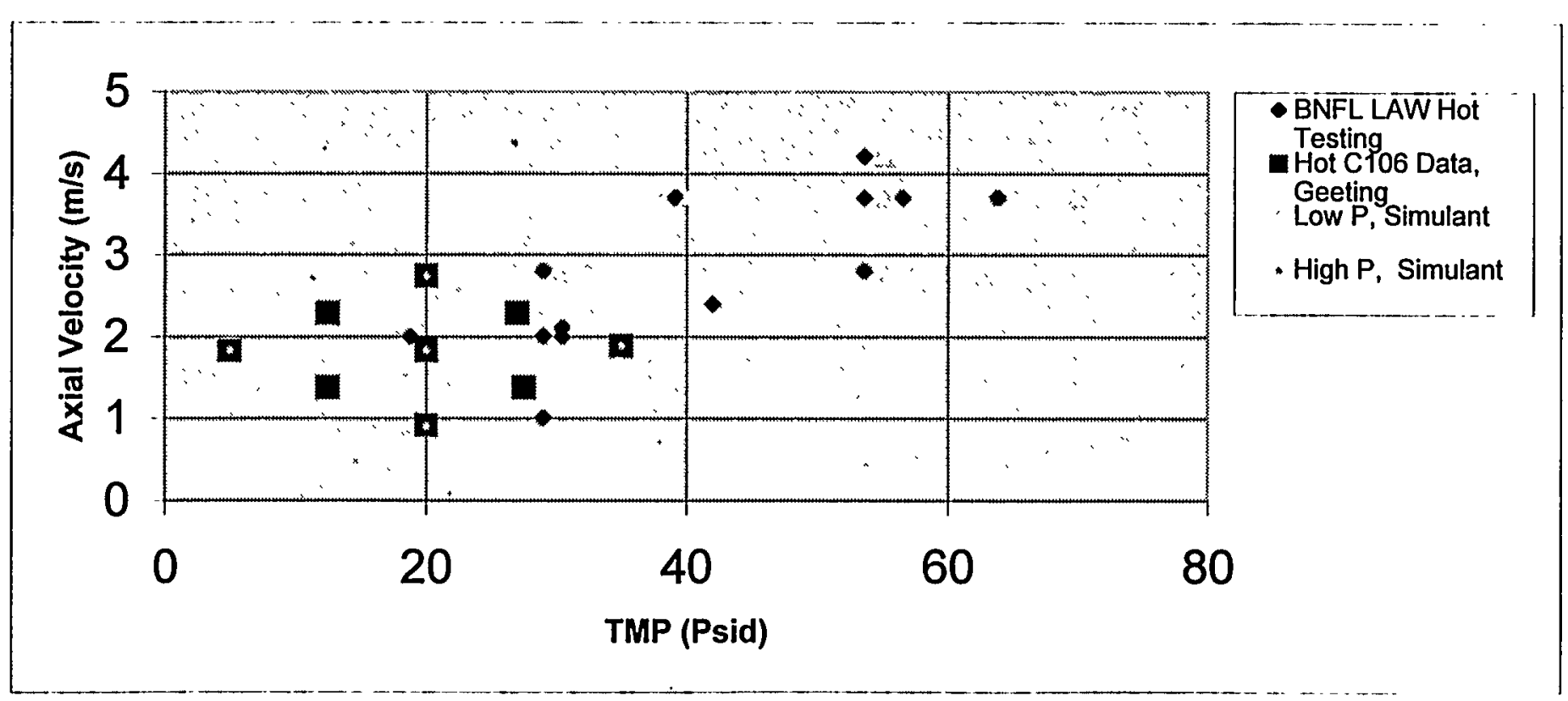




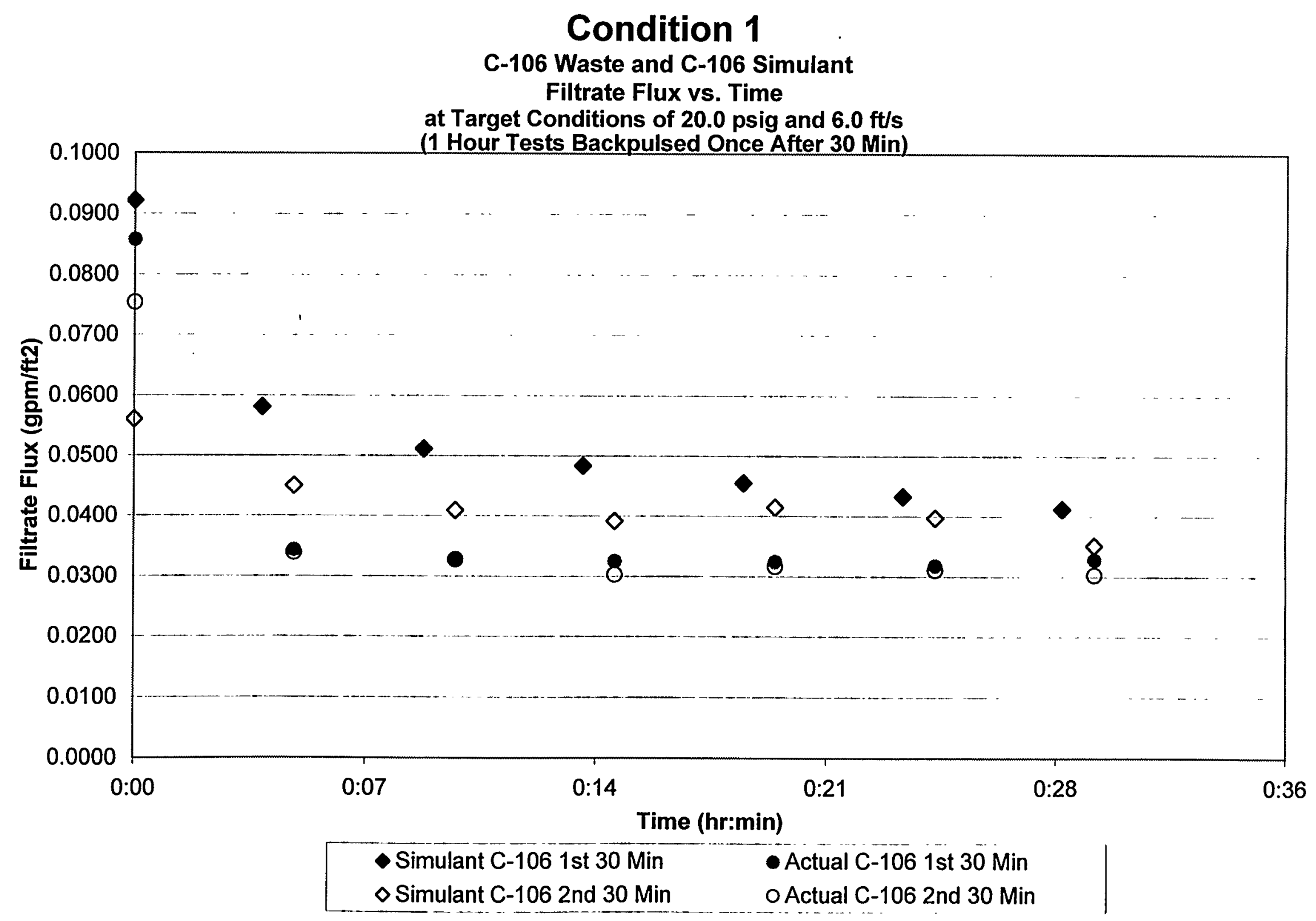




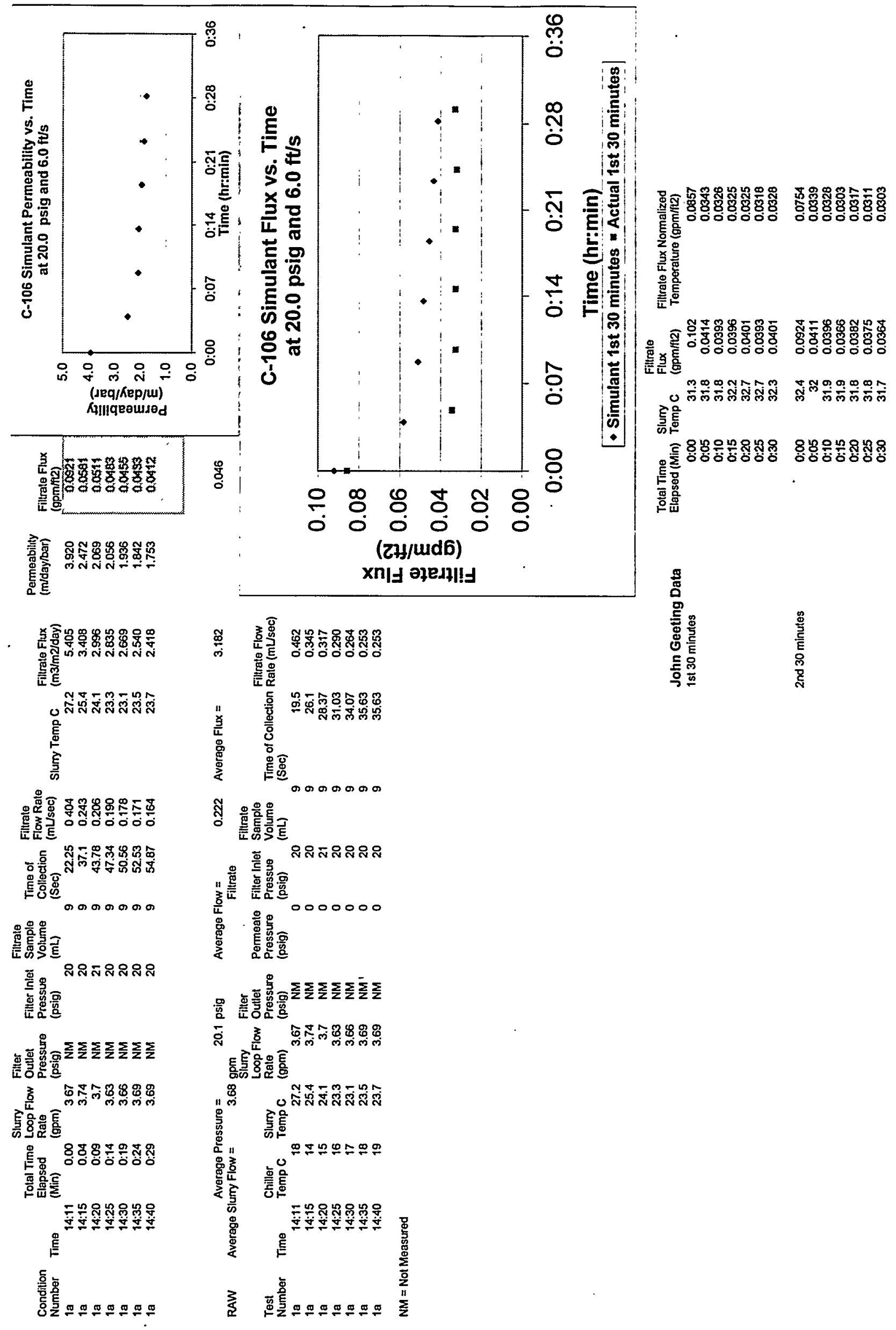




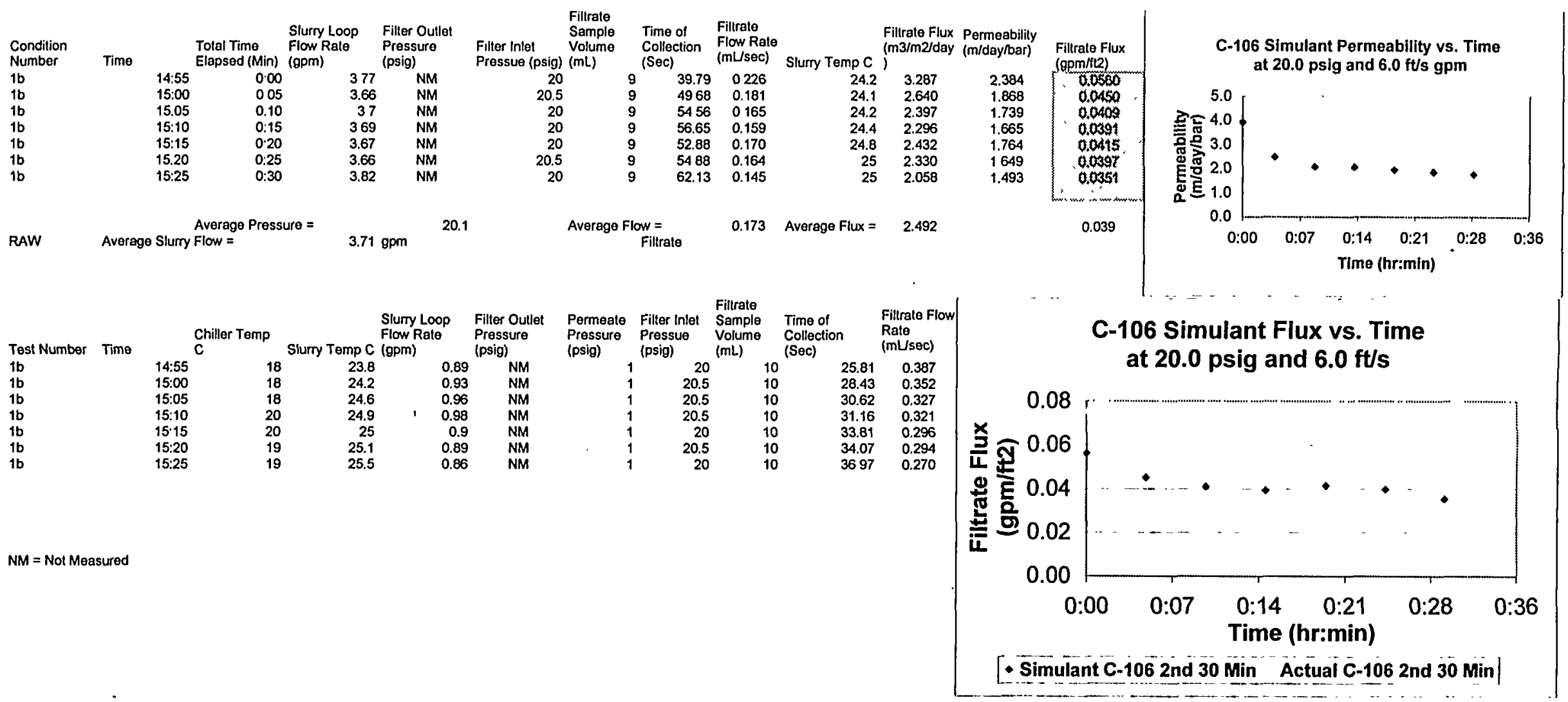

\begin{tabular}{|c|c|c|c|c|}
\hline John Geeting Data & $\begin{array}{l}\text { Total Time } \\
\text { Elapsed (Min) }\end{array}$ & $\begin{array}{l}\text { Slurry } \\
\text { Temp C }\end{array}$ & $\begin{array}{l}\text { Filirale Flux } \\
\text { (gpm/ft2) }\end{array}$ & $\begin{array}{l}\text { Filtrate Flux Normalized } \\
\text { Temperafure (gpm/tt2) }\end{array}$ \\
\hline 1st 30 minutes & $\begin{array}{l}0: 00 \\
0: 05 \\
0: 10 \\
0: 15 \\
0: 20 \\
0: 25 \\
0: 30\end{array}$ & $\begin{array}{l}31.3 \\
31.8 \\
31.8 \\
32.2 \\
32.7 \\
32.7 \\
32.3\end{array}$ & $\begin{array}{r}0.102 \\
0.0414 \\
0.0393 \\
0.0396 \\
0.0401 \\
0.0393 \\
0.0401\end{array}$ & $\begin{array}{l}0.0857 \\
0.0343 \\
0.0326 \\
0.0325 \\
0.0325 \\
0.0318 \\
0.0328\end{array}$ \\
\hline 2nd 30 minutes & $\begin{array}{l}0: 00 \\
0: 05 \\
0: 10 \\
0: 15 \\
0: 20 \\
0: 25 \\
0: 30\end{array}$ & $\begin{array}{r}32.4 \\
32 \\
31.9 \\
31.9 \\
31.8 \\
31.8 \\
31.7\end{array}$ & $\begin{array}{l}0.0924 \\
0.0411 \\
0.0396 \\
0.0366 \\
0.0382 \\
0.0375 \\
0.0364\end{array}$ & $\begin{array}{l}0.0754 \\
0.0039 \\
0.0328 \\
0.0003 \\
0.0317 \\
0.0311 \\
0.0303\end{array}$ \\
\hline
\end{tabular}


Condition 2

C-106 Waste and C-106 Simulant

Filtrate Flux vs. Time

at Target Conditions of $12.5 \mathrm{psig}$ and $4.5 \mathrm{ft} / \mathrm{s}$

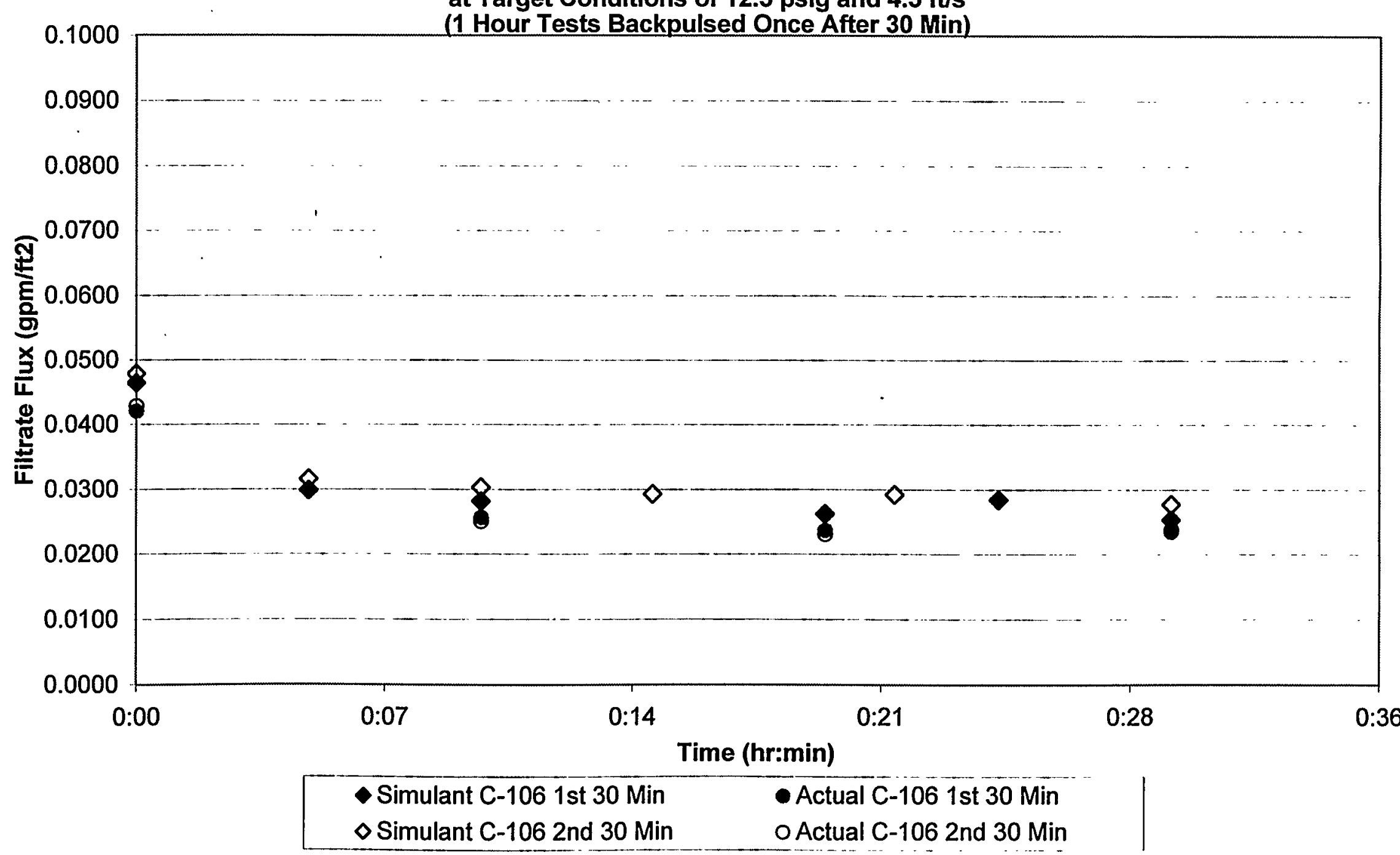




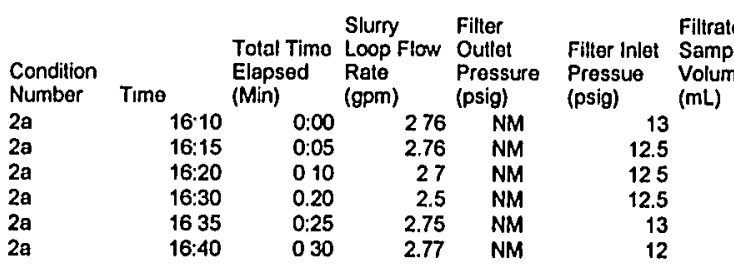

Time of Filtrale

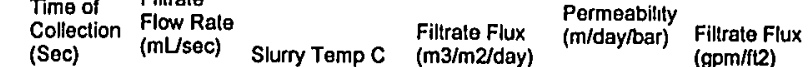

$\begin{array}{lrrrr}15 & 7384 & 0.203 & 271 & 2.722\end{array}$

$\begin{array}{lll}69.97 & 0129 \\ 7484 & 0.120\end{array}$

$\begin{array}{ll}7484 & 0.120 \\ 81.22 & 0.111\end{array}$

$74.56 \quad 0.121$

$81.5 \quad 0.110$

Average Flow $=$

0.132 Average Flux $=$
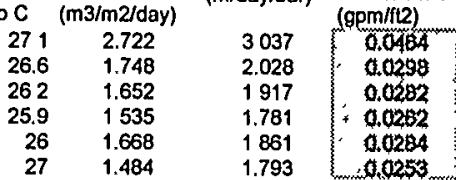

Average Pressure $=$
RAW Average Slury Flow $=\quad 2.71 \mathrm{gpm}$

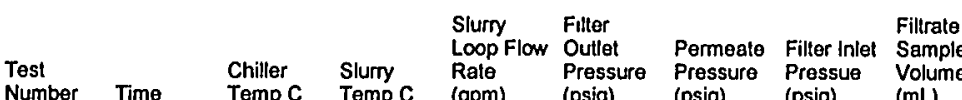

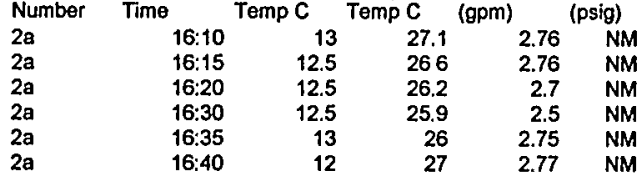

$\mathrm{NM}=$ Not Measured
81.5
13
12.5
12.5
12.5
13
12
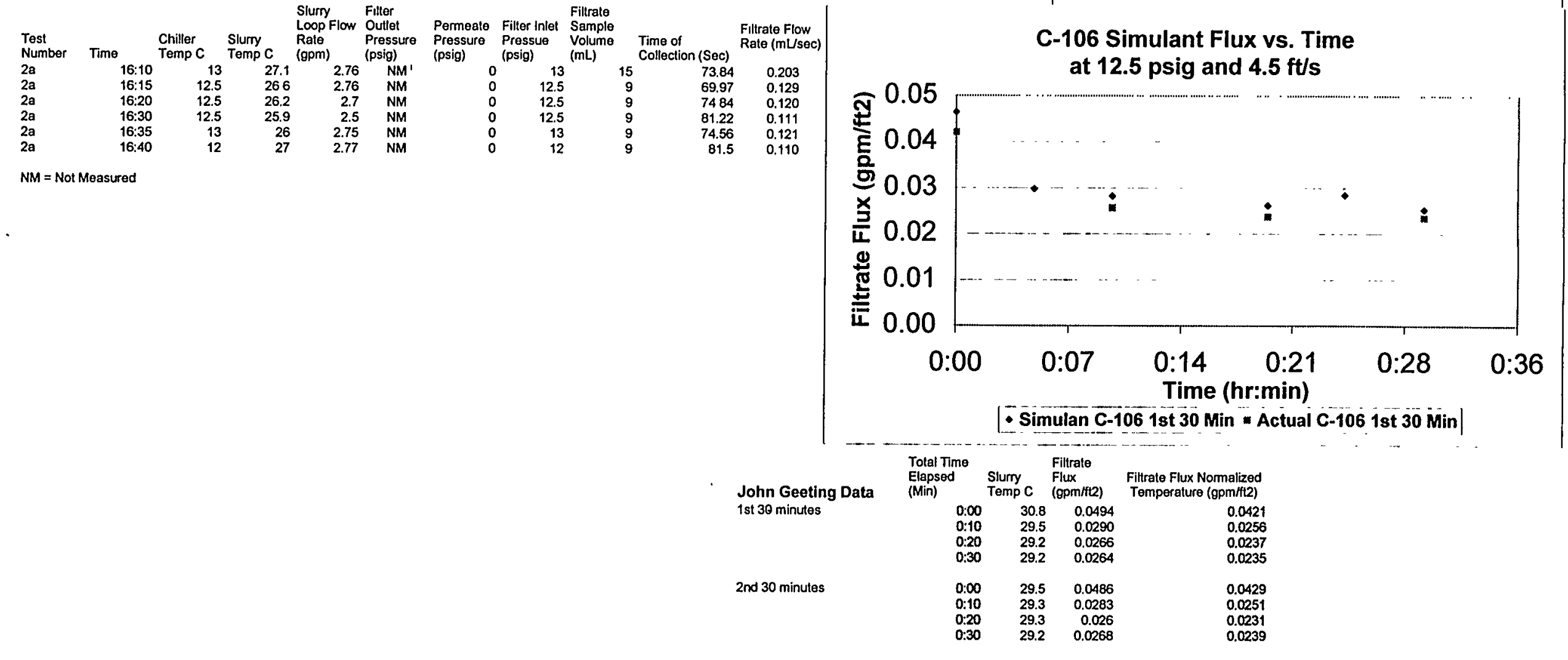

.

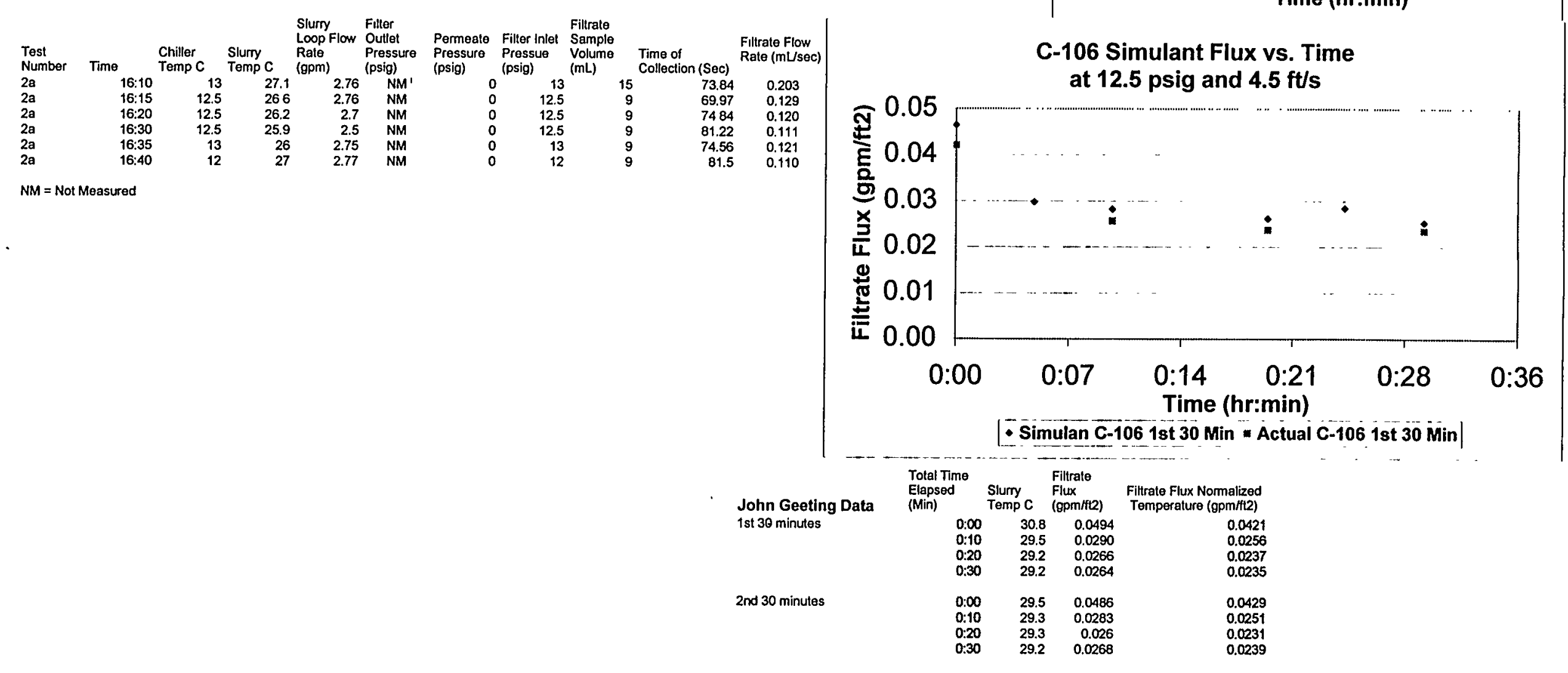

John Geeting Data

Total Time John Geeting
1 st 30 minutes

(Min)

$\begin{array}{lll}\text { Temp C } & \begin{array}{l}\text { Flux } \\ \text { (gpm/ft2) }\end{array} & \begin{array}{c}\text { Filtrate Flux Normalized } \\ \text { Temperature (gpm/fit) }\end{array}\end{array}$

1 st 30 minutes

$0: 00$
$0: 10$
$0: 20$
$0: 30$

2nd 30 minutes

$\begin{array}{llll}0: \infty 0 & 30.8 & 0.0494 & 0.0421 \\ 0: 10 & 29.5 & 0.0290 & 0.0256 \\ 0: 20 & 29.2 & 0.0266 & 0.0237 \\ 0: 30 & 29.2 & 0.0264 & 0.0235 \\ 0: 00 & 29.5 & 0.0486 & \\ 0: 10 & 29.3 & 0.0283 & 0.0429 \\ 0: 20 & 29.3 & 0.026 & 0.0251 \\ 0: 30 & 29.2 & 0.0268 & 0.0231 \\ & & & 0.0239\end{array}$

C-106 Simulant Permeability vs. Time

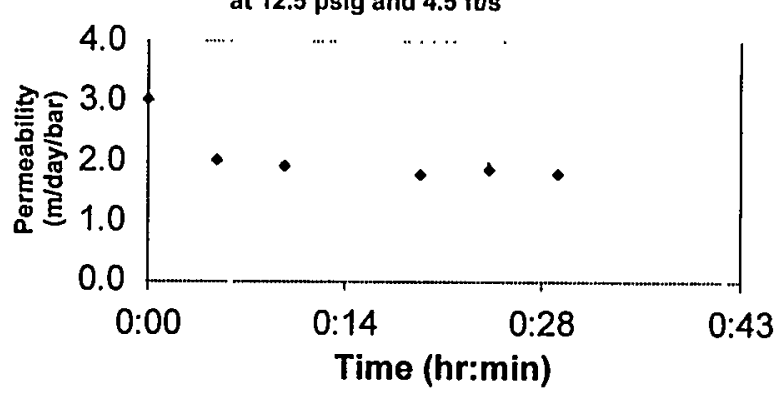

Flux vs. Tim 


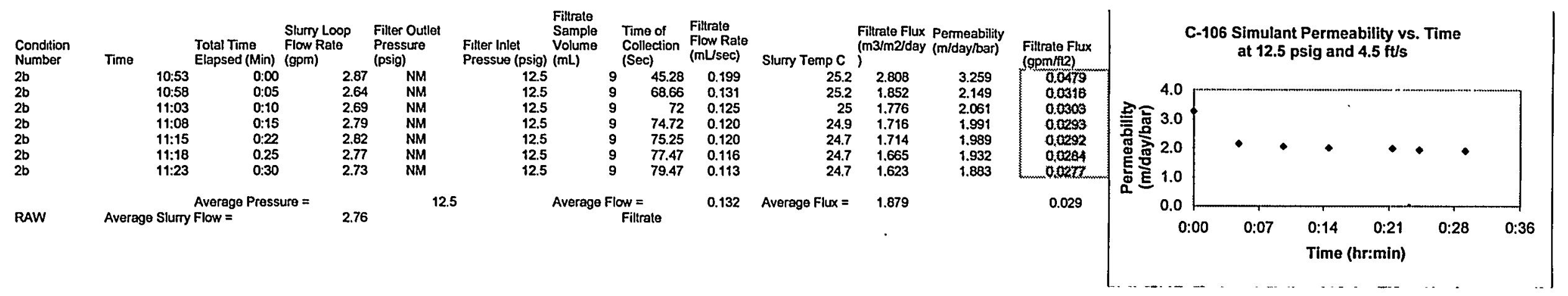

\begin{tabular}{|c|c|c|c|c|c|c|}
\hline & & & $\begin{array}{l}\text { Chiller Temp } \\
\text { C }\end{array}$ & & $\begin{array}{l}\text { Slurry Loop } \\
\text { Flow Rate } \\
\text { (gpm) }\end{array}$ & $\begin{array}{l}\text { Filter Outlet } \\
\text { Pressure } \\
\text { (psig) }\end{array}$ \\
\hline $2 b$ & tinto & 10:53 & 19 & 25.2 & 2.87 & \\
\hline & & 10:58 & 17 & 25.2 & 2.64 & NM \\
\hline & & $11: 03$ & 18 & 25 & 2.69 & NM \\
\hline $2 b$ & & 11:08 & 17 & 24.9 & 2.79 & NM \\
\hline $2 b$ & & 11:15 & 18 & 24.7 & 2.82 & NM \\
\hline 2b & & 11:18 & 18 & 24.7 & 2.77 & NM \\
\hline 2b & & 11:23 & 18 & 24.7 & 2.73 & NM \\
\hline
\end{tabular}

\begin{tabular}{|c|c|c|c|}
\hline $\begin{array}{l}\text { Permeate } \\
\text { Pressure } \\
\text { (psig) }\end{array}$ & & $\begin{array}{l}\text { Inlet } \\
\text { ue }\end{array}$ & $\begin{array}{l}\text { Filt } \\
\text { San } \\
\text { Vol } \\
\text { (ml }\end{array}$ \\
\hline & 0 & 12.5 & \\
\hline & & 12.5 & \\
\hline & & 12.5 & \\
\hline & 0 & 12.5 & \\
\hline & 0 & 12.5 & \\
\hline & 0 & 12.5 & \\
\hline & 0 & 12.5 & \\
\hline
\end{tabular}

$N M=$ Nol Measured
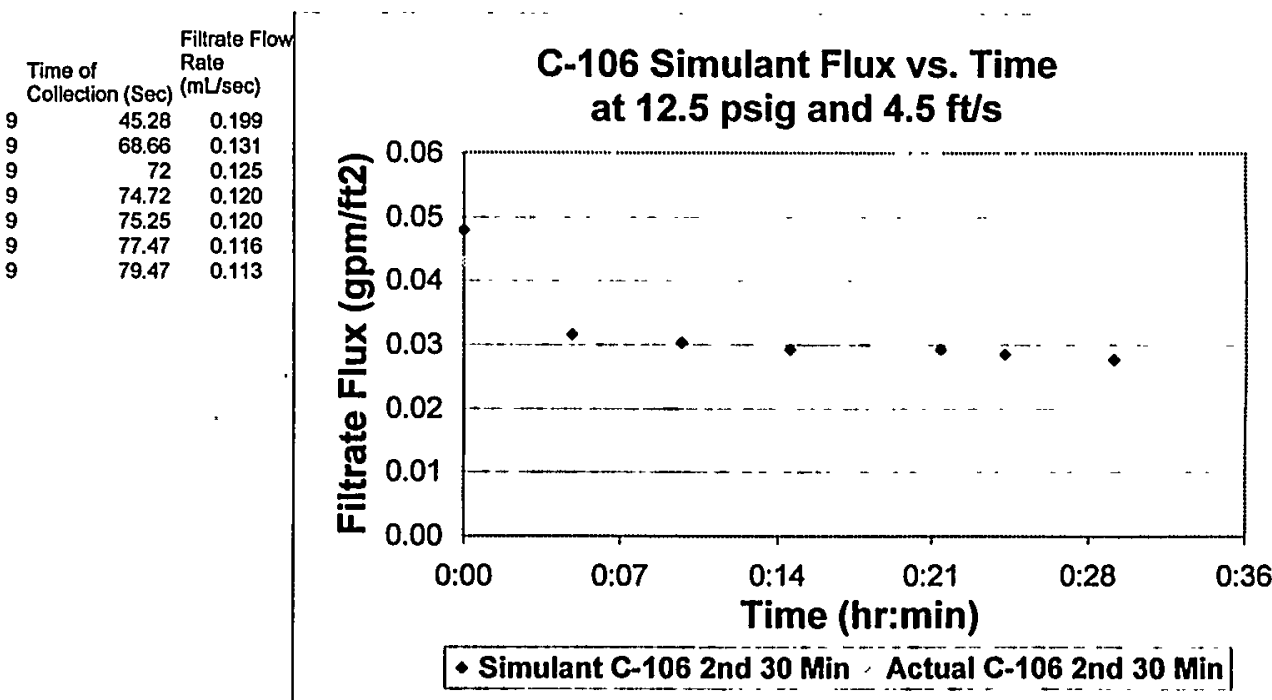

John Geeting $1 s t 30$ minutes

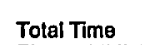

2nd 30 minutes

$\begin{array}{llll}0: 00 & 30.8 & 0.0494 & 0.0421 \\ 0: 10 & 29.5 & 0.0290 & 0.0256 \\ 0: 20 & 29.2 & 0.0266 & 0.0237 \\ 0: 30 & 29.2 & 0.0264 . & 0.0235 \\ & & & \\ 0.00 & 29.5 & 0.0486 & 0.0429 \\ 0: 10 & 29.3 & 0.0283 & 0.0251 \\ 0: 20 & 29.3 & 0.026 & 0.0231 \\ 0: 30 & 29.2 & 0.0268 & 0.0239\end{array}$




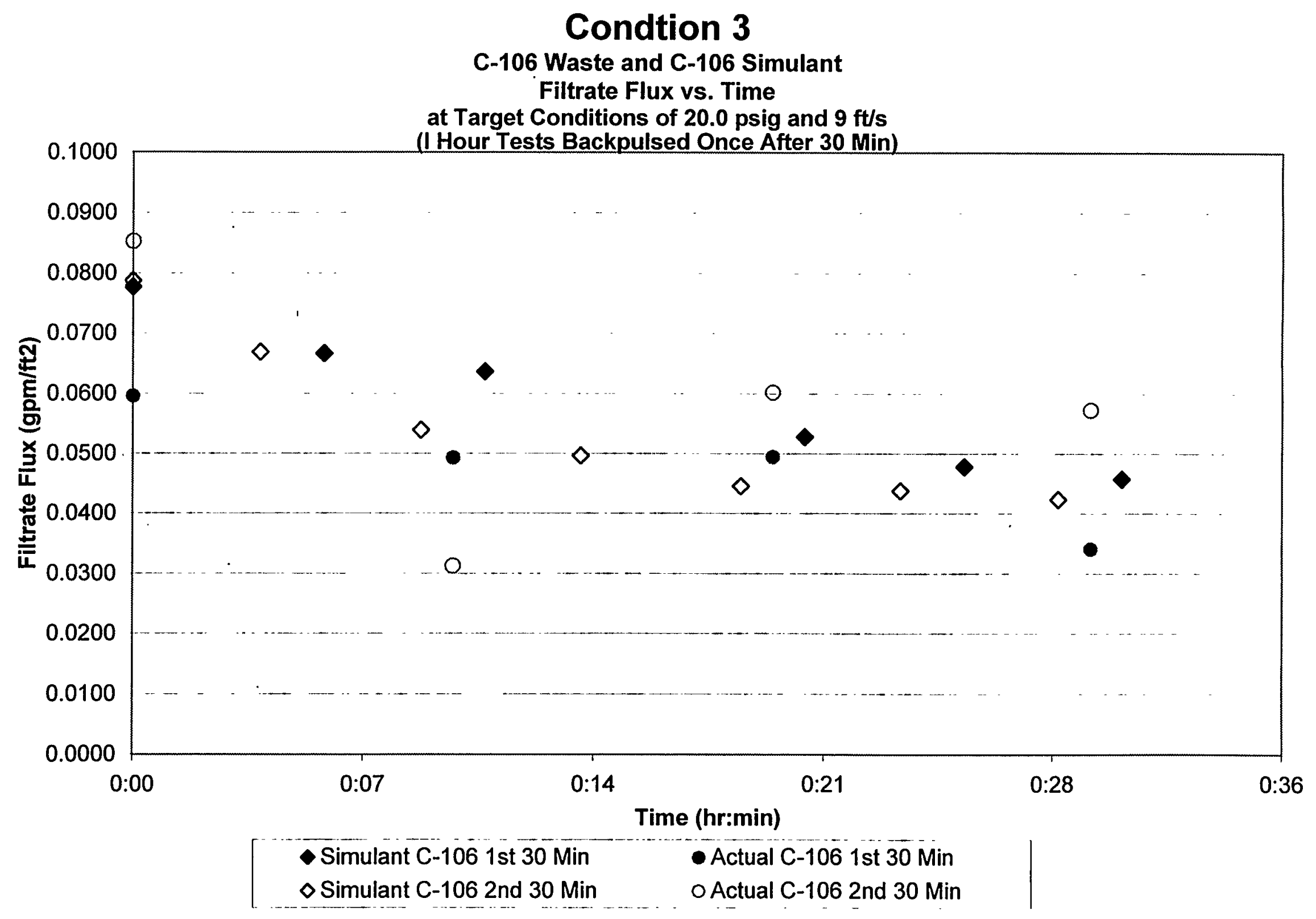




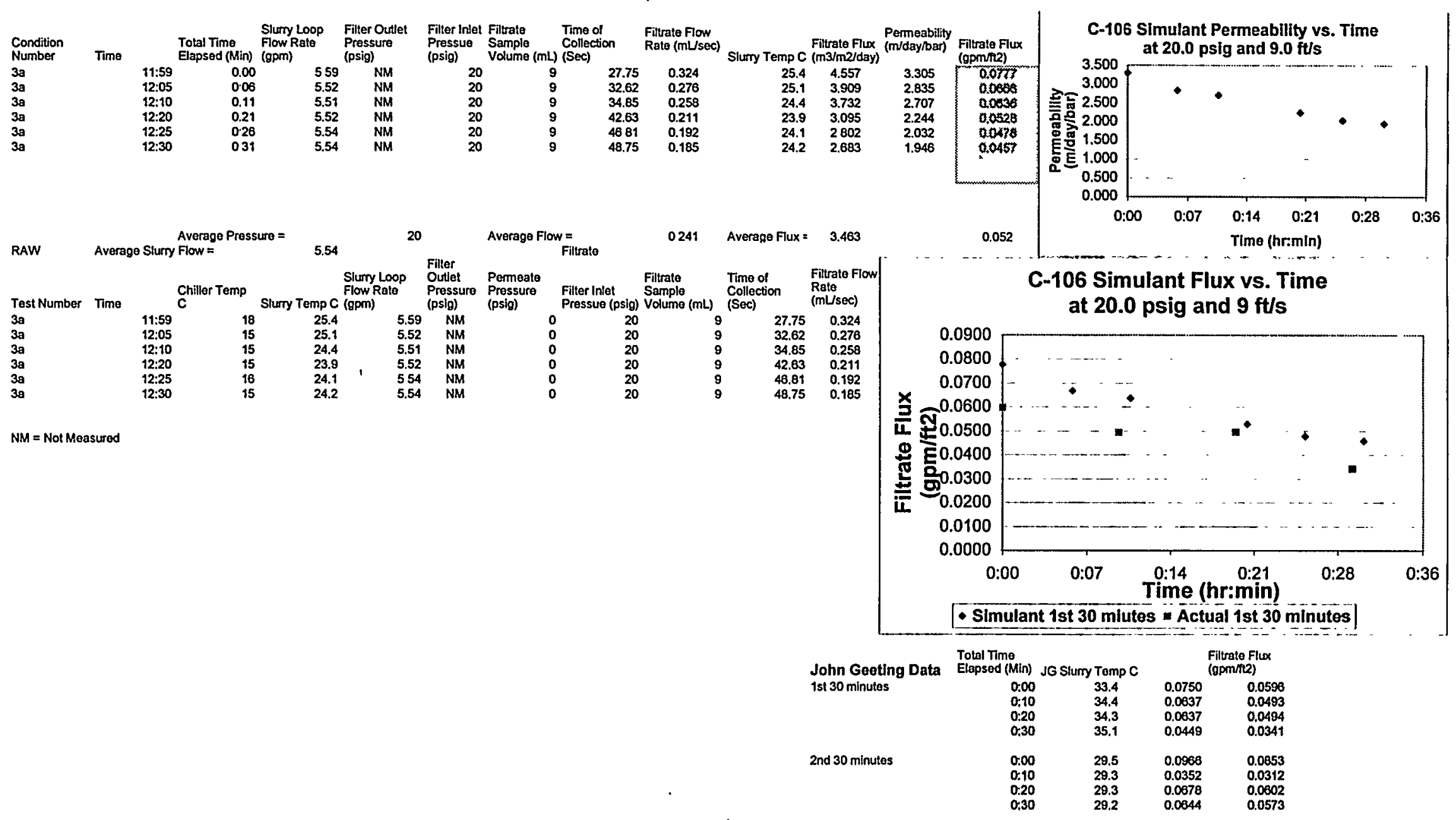




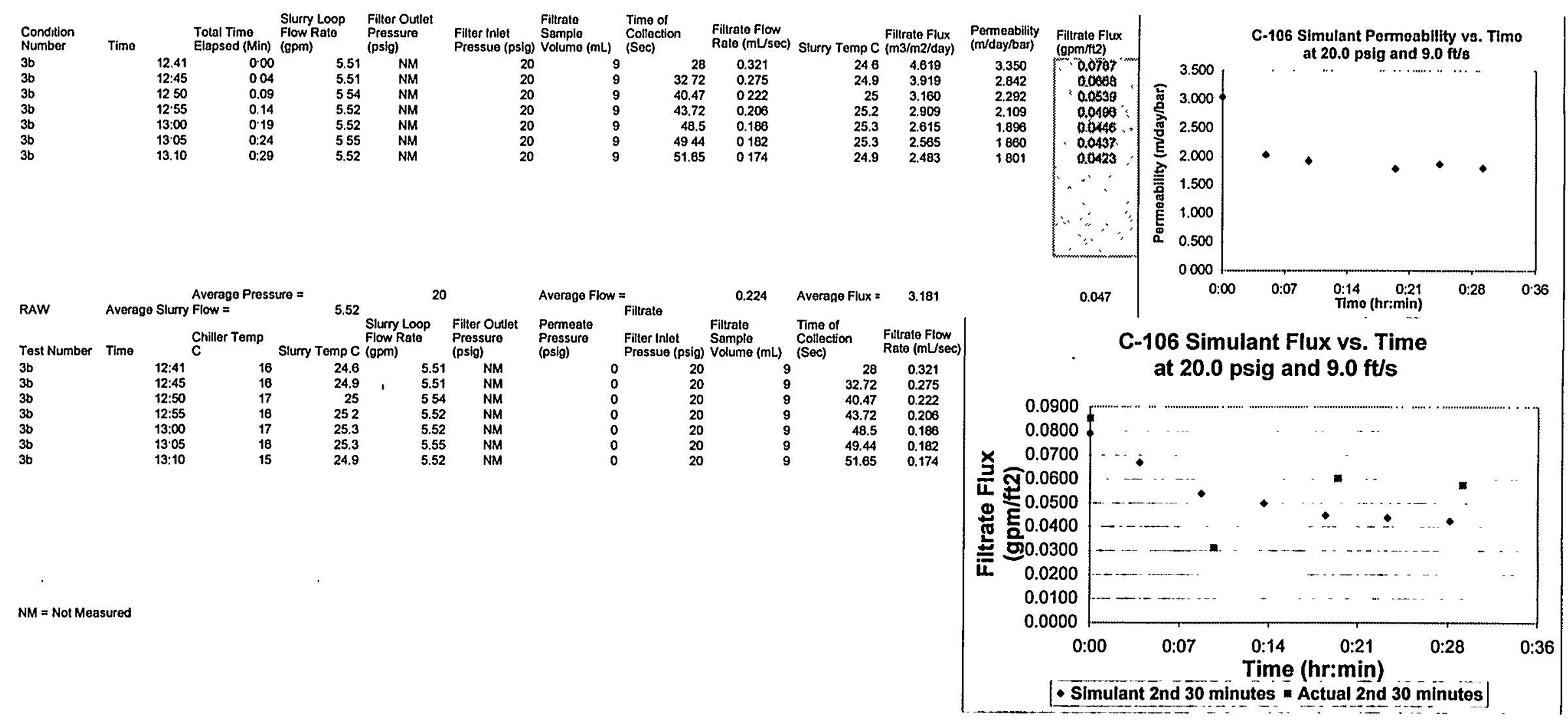

\begin{tabular}{|c|c|c|c|c|}
\hline \multirow{2}{*}{$\begin{array}{l}\text { John Geeting Data } \\
\text { 1st } 30 \text { minutios }\end{array}$} & \multicolumn{2}{|c|}{$\begin{array}{l}\text { Total Time } \\
\text { Elapsed (Min) JG Slurry Temp C }\end{array}$} & \multicolumn{2}{|c|}{$\begin{array}{l}\text { Filkrate Flux } \\
\text { (gpmitiz) }\end{array}$} \\
\hline & $\begin{array}{l}0: 00 \\
0: 10 \\
0: 20 \\
0: 30\end{array}$ & $\begin{array}{l}33.4 \\
34.4 \\
34.3 \\
35.1\end{array}$ & $\begin{array}{l}0.0750 \\
0.0837 \\
0.0837 \\
0.0449\end{array}$ & $\begin{array}{l}0.0596 \\
0.0493 \\
0.0494 \\
0.0341\end{array}$ \\
\hline 2nd 30 minutes & $\begin{array}{l}0: 00 \\
0: 10 \\
0: 20 \\
0: 30\end{array}$ & $\begin{array}{l}29.5 \\
29.3 \\
29.3 \\
29.2\end{array}$ & $\begin{array}{l}0.0986 \\
0.0352 \\
0.0878 \\
0.0644\end{array}$ & $\begin{array}{l}0.0853 \\
0.0312 \\
0.0802 \\
0.0573\end{array}$ \\
\hline
\end{tabular}




\section{Condition 4}

\section{C-106 Waste and C-106 Simulant}

Filtrate Flux vs. Time

at Target Conditions of $35.0 \mathrm{psig}$ and $6 \mathrm{ft} / \mathrm{s}$

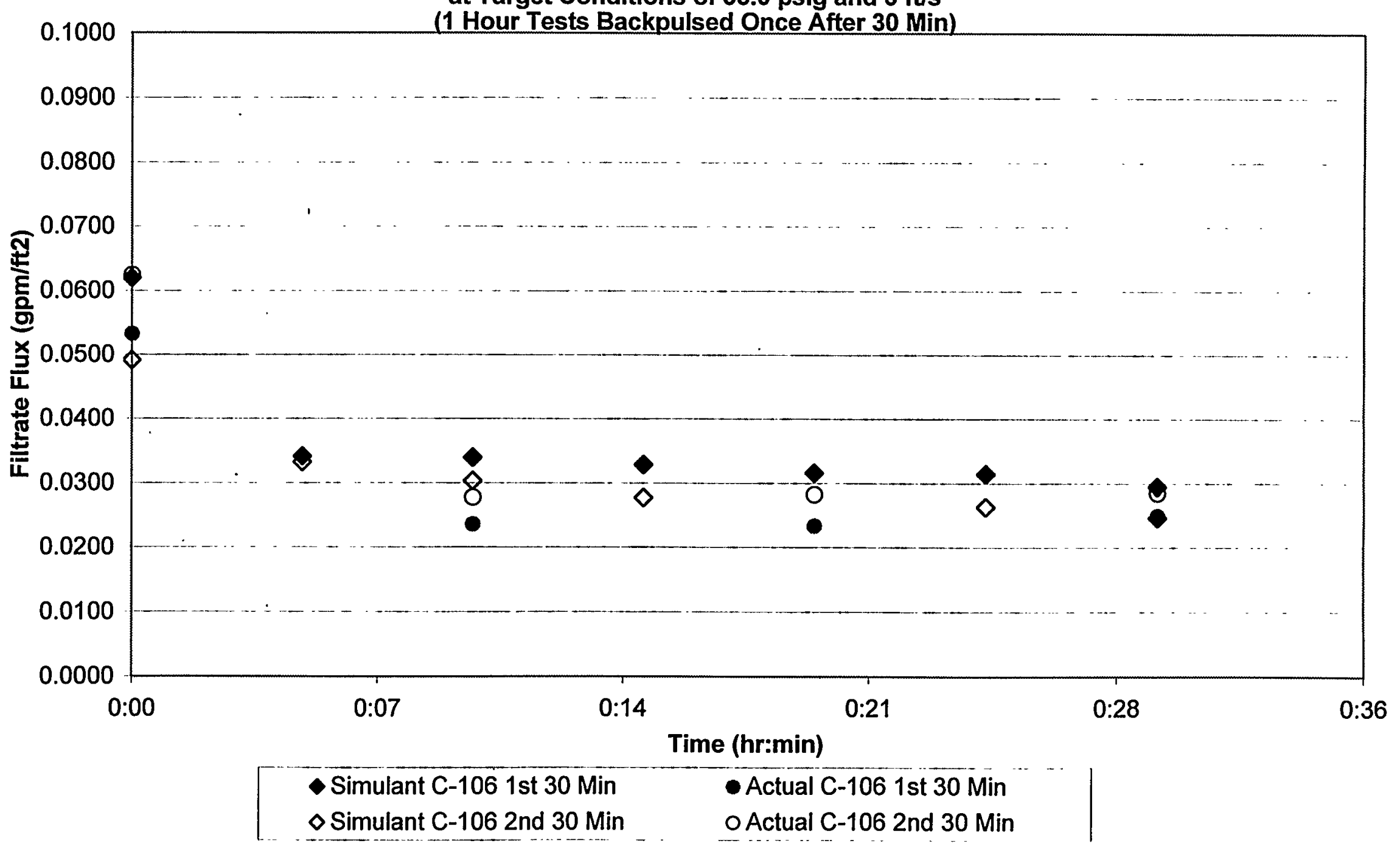




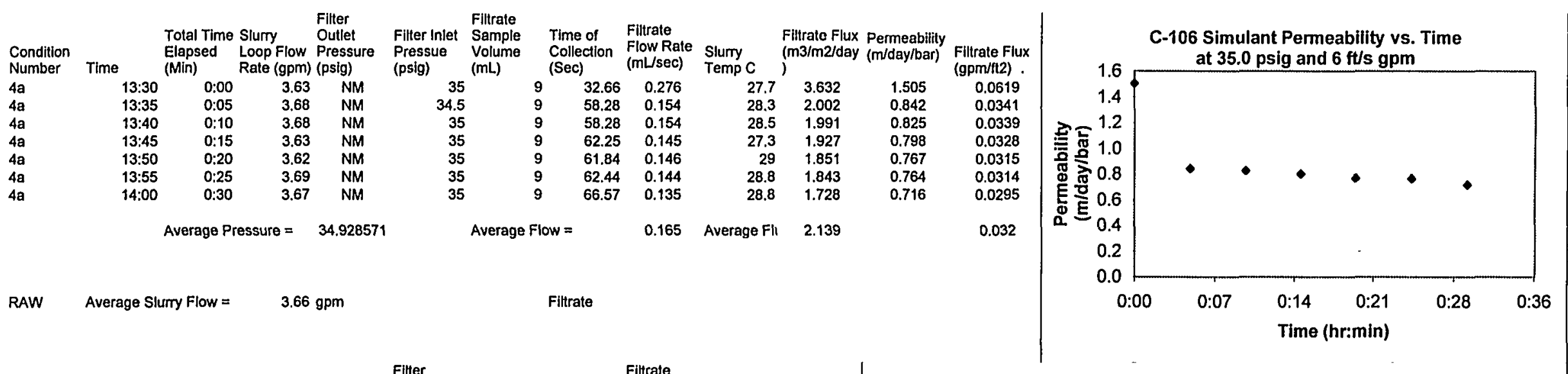

\begin{tabular}{|c|c|c|c|c|c|c|c|c|c|c|c|}
\hline $\begin{array}{l}\text { Test } \\
\text { Number }\end{array}$ & Time & $\begin{array}{l}\text { Chiller } \\
\text { Temp C }\end{array}$ & $\begin{array}{l}\text { Slurry } \\
\text { Temp C }\end{array}$ & $\begin{array}{l}\text { Slurry } \\
\text { Loop Flow } \\
\text { Rate (gpm) }\end{array}$ & $\begin{array}{l}\text { Filter } \\
\text { Outlet } \\
\text { Pressure } \\
\text { (psig) }\end{array}$ & $\begin{array}{l}\text { Permeate } \\
\text { Pressure } \\
\text { (psig) }\end{array}$ & $\begin{array}{l}\text { Filter Inlet } \\
\text { Pressue } \\
\text { (psig) }\end{array}$ & $\begin{array}{l}\text { Filtrate } \\
\text { Sample } \\
\text { Volume } \\
\text { (mL) }\end{array}$ & & $\begin{array}{l}\text { e of } \\
\text { ection } \\
\text { c) }\end{array}$ & $\begin{array}{l}\text { Filtrate F } \\
\text { Rate } \\
\text { (mL/sec) }\end{array}$ \\
\hline $4 a$ & $13: 30$ & 1 & ; $\quad 27.7$ & 3.63 & NM & c & 35 & & 9 & 32.66 & 0.27 \\
\hline ta & 13:35 & 1 & 28.3 & 3.68 & NM & c & 34.5 & & 9 & 58.28 & \\
\hline $4 a$ & $13: 40$ & 1 & 28.5 & 3.68 & NM & c & 35 & & 9 & 58.28 & 0.1 \\
\hline & $13: 45$ & 1 & 27.3 & 3.63 & NM & c & 35 & & 9 & 62.25 & \\
\hline a & $13: 50$ & 1 & 29 & 3.62 & NM & $\mathrm{c}$ & 35 & & 9 & 61.84 & \\
\hline & $13: 55$ & 1 & 28.8 & 3.69 & NM & c & 35 & & 9 & 62.44 & \\
\hline & $14: 00$ & 1 & 28.8 & 3.67 & NM & c & 35 & & 9 & 66.57 & \\
\hline
\end{tabular}

$\mathrm{NM}=$ Not Measured

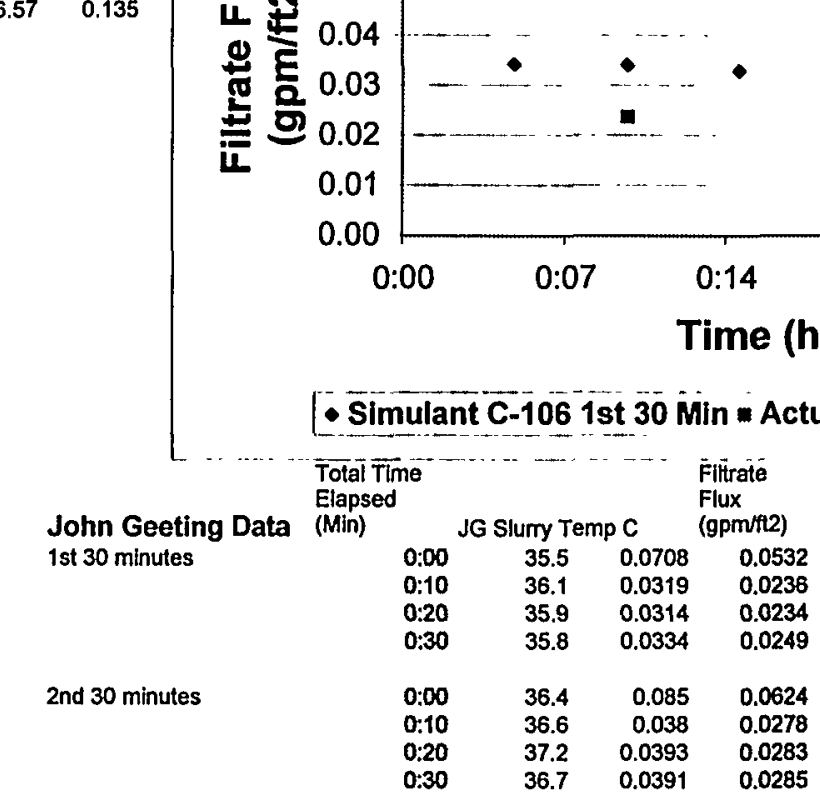




\begin{tabular}{|c|c|c|c|c|}
\hline $\begin{array}{l}\text { Condition } \\
\text { Number }\end{array}$ & Time & $\begin{array}{l}\text { Total Time } \\
\text { Elapsed } \\
\text { (Min) }\end{array}$ & $\begin{array}{l}\text { Slurry } \\
\text { Loop Flow } \\
\text { Rate (gpm) }\end{array}$ & $\begin{array}{l}\text { Filter } \\
\text { Outlet } \\
\text { Pressure } \\
\text { (psig) }\end{array}$ \\
\hline $4 b$ & 14:15 & ; $\quad 0: 00$ & $\quad 3.69$ & $\mathrm{NM}$ \\
\hline $4 b$ & $14: 20$ & $0: 05$ & 3.67 & NM \\
\hline $4 b$ & 14:25 & $0: 10$ & 3.63 & NM \\
\hline $4 b$ & $14: 30$ & $0: 15$ & 3.64 & NM \\
\hline $4 b$ & $14: 40$ & 0.25 & 3.69 & NM \\
\hline $4 b$ & $14: 45$ & $0: 30$ & 3.67 & NM \\
\hline
\end{tabular}

RAW Average Slumy Flow $=$

Filter Inle
Pressue
(psig)

Filtrate

Sample Time of Filtrate

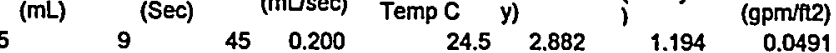

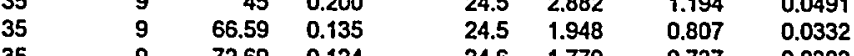
$\begin{array}{lll}9 & 72.69 & 0.124\end{array}$ $\begin{array}{llll}35 & 9 & 79.85 & 0.113\end{array}$ $\begin{array}{llll}35 & 9 & 83.9 & 0.107\end{array}$ (n) Average Flow $=$ $89.31 \quad 0.101$ Filtrate

$24.5 \quad 1.624$

0.0277

$\begin{array}{llll}24.7 & 1.444 & 0.598 & 0.0246\end{array}$

\begin{tabular}{|c|c|c|c|c|c|c|c|c|c|c|}
\hline $\begin{array}{l}\text { Test } \\
\text { Number }\end{array}$ & Time & $\begin{array}{l}\text { Chiller } \\
\text { Temp C }\end{array}$ & $\begin{array}{l}\text { Slumy } \\
\text { Temp C }\end{array}$ & $\begin{array}{l}\text { Slumy } \\
\text { Loop Flow } \\
\text { Rate (gpm) }\end{array}$ & $\begin{array}{l}\text { Fitter } \\
\text { Outlet } \\
\text { Pressure } \\
\text { (psig) }\end{array}$ & $\begin{array}{l}\text { Filler Inlet } \\
\text { Pressue } \\
\text { (psig) }\end{array}$ & $\begin{array}{l}\text { Filtrate } \\
\text { Sample } \\
\text { Volume } \\
\text { (mL) }\end{array}$ & & $\begin{array}{l}\text { Time of } \\
\text { Collection } \\
\text { (Sec) }\end{array}$ & $\begin{array}{l}\text { Fillrate } \\
\text { Flow Rate } \\
\text { (mL/sec) }\end{array}$ \\
\hline $4 b$ & 14:15 & 16 & 24.5 & 3.69 & NM & 35 & & 9 & 45 & 0.200 \\
\hline $4 b$ & $14: 20$ & 16 & 24.5 & 3.67 & NM & 35 & & 9 & 66.59 & 0.135 \\
\hline $4 b$ & $14: 25$ & 16 & 24.6 & 3.63 & NM & 35 & & 9 & 72.69 & 0.124 \\
\hline 4b & $14: 30$ & 16 & 24.5 & 3.64 & NM & 35 & & 9 & 79.85 & 0.113 \\
\hline 4b & $14: 40$ & 16 & 24.6 & 3.69 & NM & 35 & & 9 & 83.9 & 0.107 \\
\hline $4 b$ & $14: 45$ & 17 & 24.7 & 3.67 & NM & 35 & & 9 & 89.31 & 0.101 \\
\hline
\end{tabular}

$\mathrm{NM}=$ Not Measured 


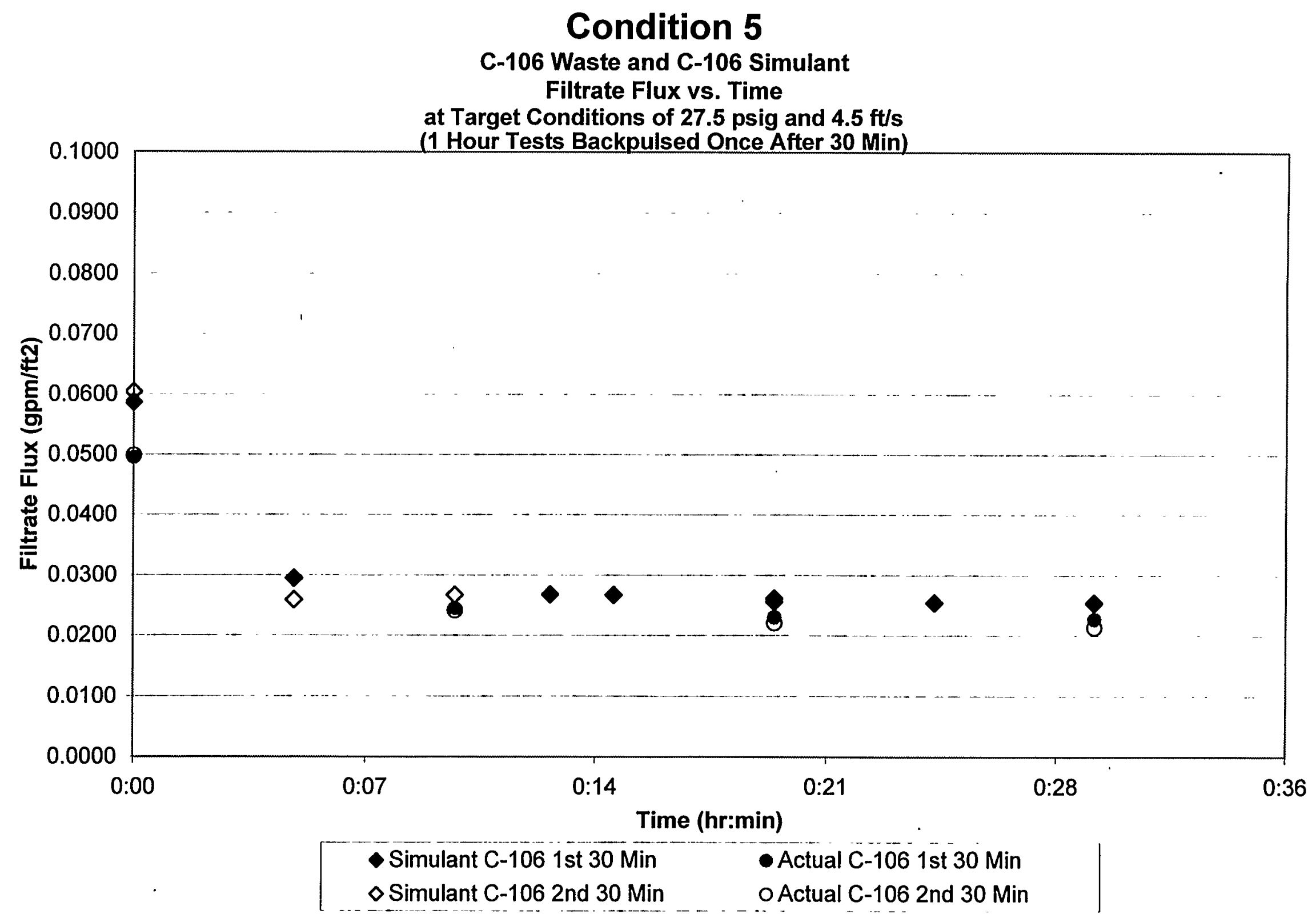



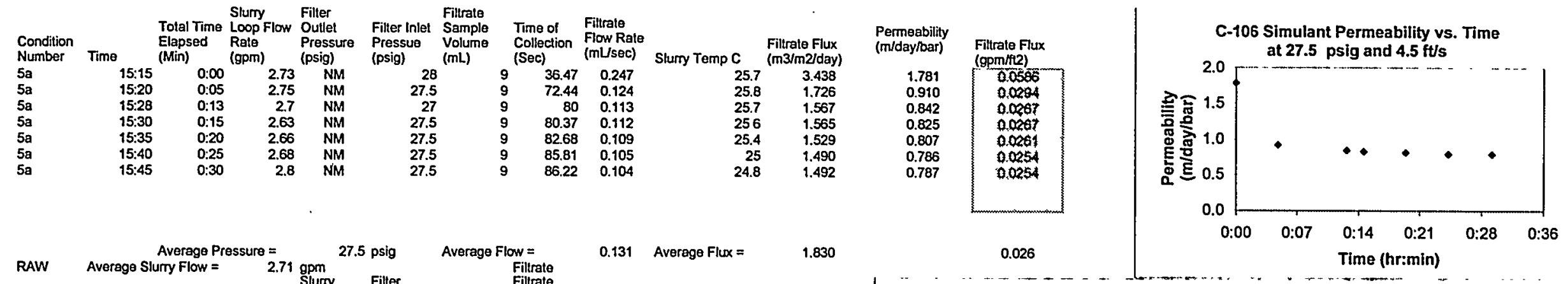

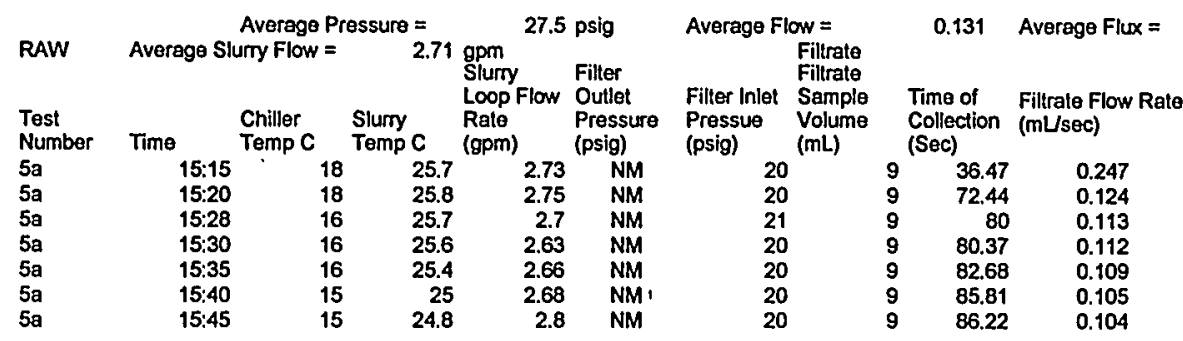

1.830

NM $=$ Not Measured

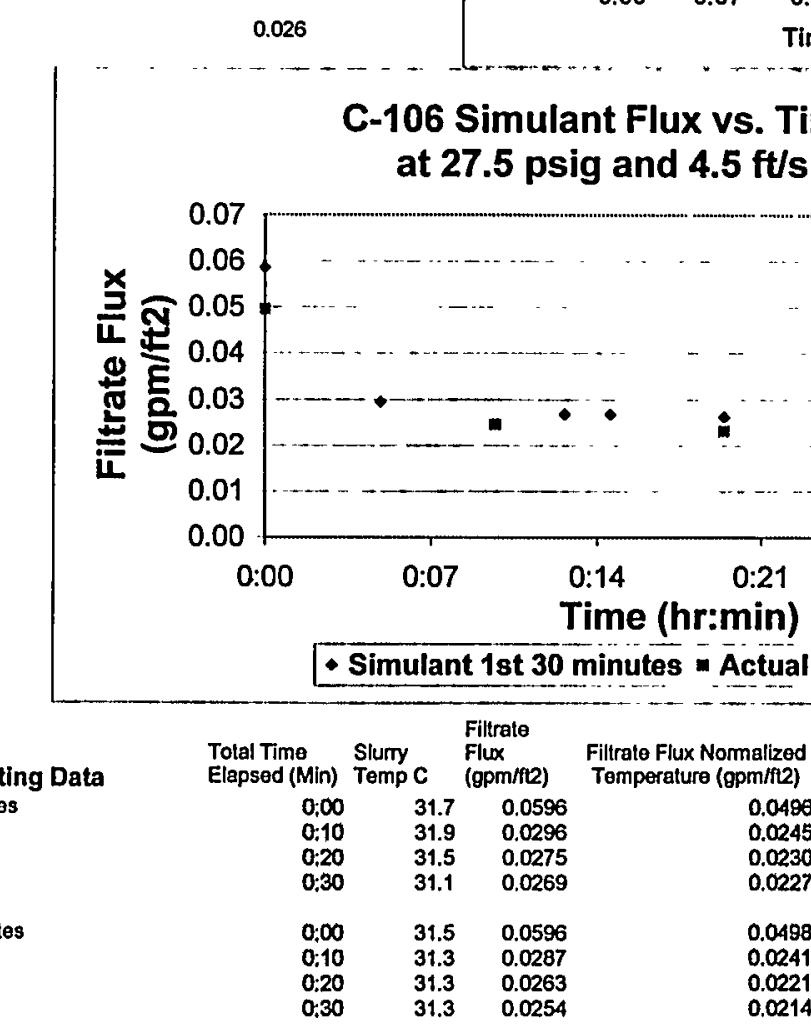




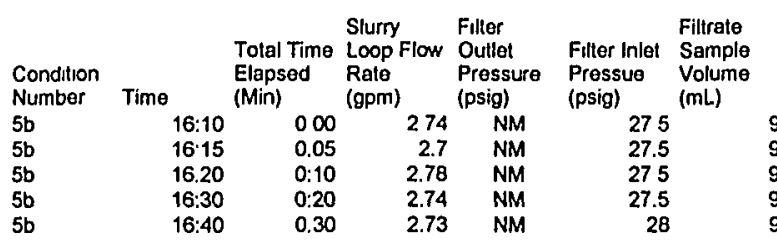

Tume of Filtrate Collection Flow Rate $\begin{array}{lll}9 & 36.22 & 0.248 \\ 9 & 8459 & 0.106 \\ 9 & 8232 & 0.109\end{array}$ $\begin{array}{rr}8232 & 0.109 \\ 86 & 0.105 \\ 86.85 & 0.104\end{array}$ \begin{tabular}{rr}
86.85 & 0.104 \\
\hline
\end{tabular}

Slury Temp C $\begin{aligned} & \text { Fillrate Flux } \\ & \text { (m3/m2/day) }\end{aligned}$ $\begin{array}{lr}\text { C } & (\mathrm{m} 3 / \mathrm{m} 2 / \text { day } \\ 249 & 3541 \\ 249 & 1516 \\ 248 & 1.562 \\ 24.7 & 1.500 \\ 24.7 & 1485\end{array}$ Permeability
(m/daylbar)

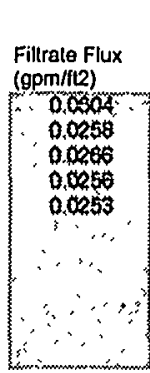

Average Pressure $=$

\section{6 psig}

Average Flow $=$
Filtra

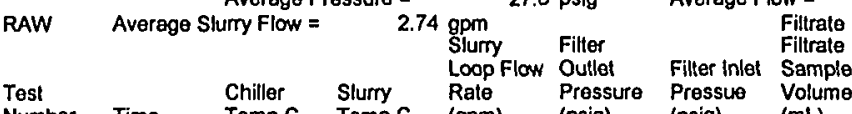

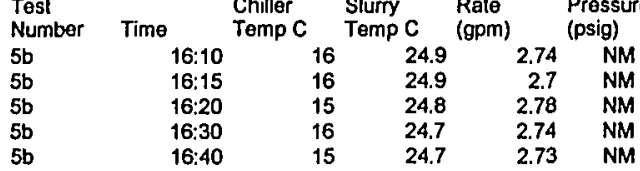

(psig) $(\mathrm{mL})$

NM

27.5
27.5

27.5
27.5
28

0.134 Average Flux $=$

Time of Fittrate Flow Rate Collection (mLsec)
(Sec)

$5 \mathrm{~b}$ 73 NM

NM $=$ Not Measured
1.921

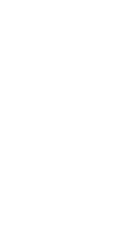

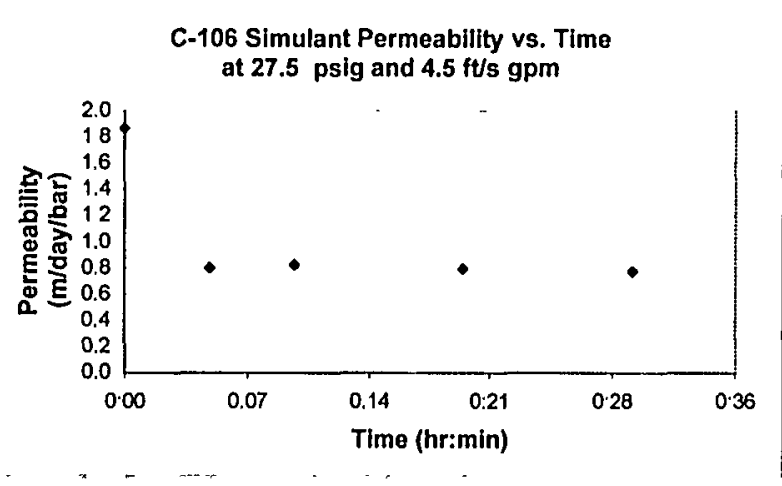

John Geeting Data 1st 30 minutes

2nd 30 minutes
C-106 Simulant Flux vs. Time at $27.5 \mathrm{psig}$ and $4.5 \mathrm{ft} / \mathrm{s}$

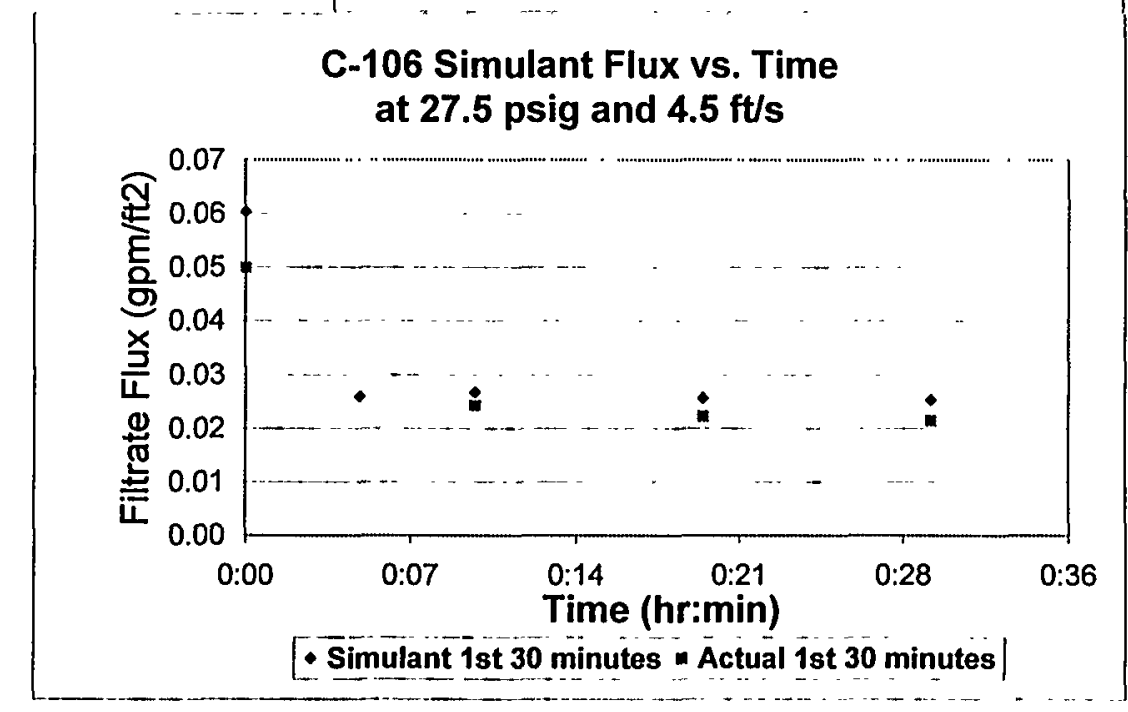

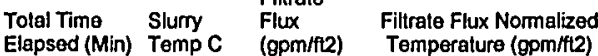

$\begin{array}{llll}0: 00 & 31.7 & 0.0596 & 0.0496 \\ 0: 10 & 31.9 & 0.0296 & 0.0245 \\ 0: 20 & 31.5 & 0.0275 & 0.0230\end{array}$

$\begin{array}{llll}0: 00 & 31.5 & 0.0596 & 0.0498\end{array}$

$\begin{array}{llll}0: 00 & 31.5 & 0.0596 & 0.0498 \\ 0: 10 & 313 & 0.0287 & 0.0241\end{array}$

$\begin{array}{llll}0: 10 & 313 & 0.0287 & 0.0241 \\ 0: 20 & 31.3 & 0.0263 & 0.0221\end{array}$ 


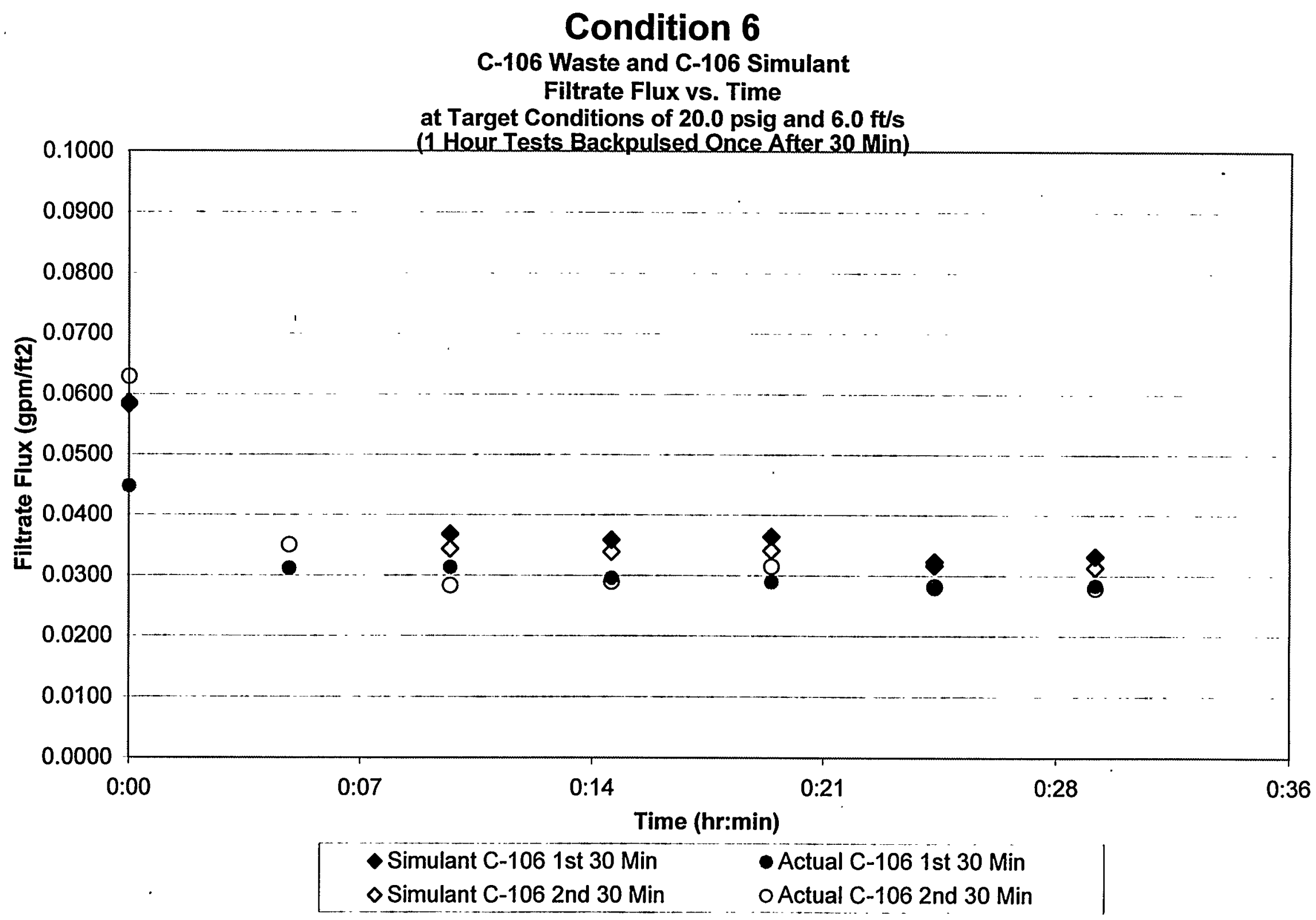




\begin{tabular}{|c|c|c|c|c|c|c|c|c|c|c|}
\hline $\begin{array}{l}\text { Condition } \\
\text { Vumber }\end{array}$ & Time & $\begin{array}{l}\text { Tolal Time } \\
\text { Elapsed } \\
\text { (Min) }\end{array}$ & $\begin{array}{l}\text { Slurry } \\
\text { Loop Flow } \\
\text { Rate } \\
\text { (gpm) }\end{array}$ & $\begin{array}{l}\text { Filter } \\
\text { Outlel } \\
\text { Pressure } \\
\text { (psig) }\end{array}$ & $\begin{array}{l}\text { Filler Inlet } \\
\text { Prossue } \\
\text { (psig) }\end{array}$ & $\begin{array}{l}\text { Filluate } \\
\text { Sample } \\
\text { Volume } \\
\text { (mL) }\end{array}$ & $\begin{array}{l}\text { Time of } \\
\text { Collection } \\
\text { (Sec) }\end{array}$ & $\begin{array}{l}\text { Filtrate } \\
\text { Flow Rate } \\
\text { (mL/soc) }\end{array}$ & Slurry Temp C & $\begin{array}{l}\text { Filtrate Flux } \\
\text { (m3/m2/day) }\end{array}$ \\
\hline & 18:40 & 000 & 35 & NM & 20 & & $9 \quad 35.62$ & 0.253 & 26.6 & $\quad 3.433$ \\
\hline & $18: 50$ & 010 & 364 & NM & 20 & & 61.72 & 0146 & 23.6 & \\
\hline & $18: 55$ & 0.15 & 3.67 & NM & 20 & & 64 & 0.14 & & 211 \\
\hline & $19 . C$ & $0: 20$ & 367 & NM & 20 & & 6325 & & 23.1 & 2,134 \\
\hline $6 \mathrm{a}$ & 19:05 & 0.25 & 363 & NM & 20 & & 70.94 & 012 & 23.3 & 1.892 \\
\hline 6a & 19:10 & 030 & 3.64 & NM & 20 & & 6906 & 0.130 & 23.3 & 1.943 \\
\hline
\end{tabular}

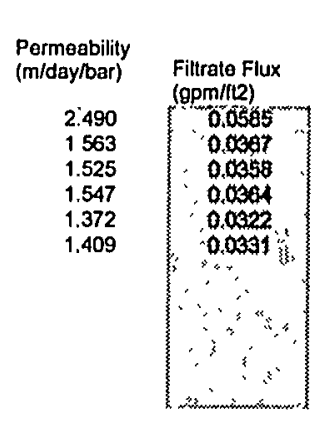

C-106 Simulant Permeability vs. Time at $20.0 \mathrm{psig}$ and $6.0 \mathrm{ft} / \mathrm{s}$

0.034

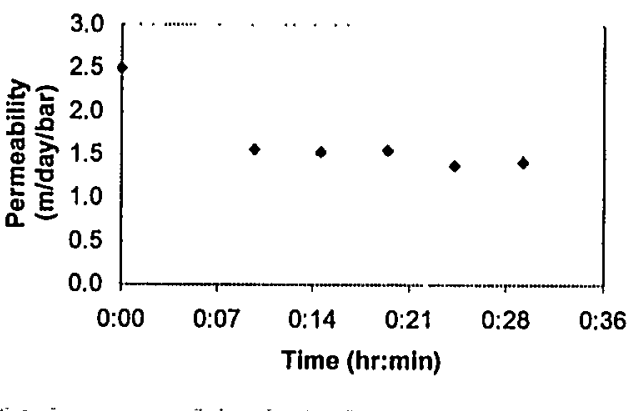

\begin{tabular}{|c|c|c|c|c|c|c|}
\hline \multirow{3}{*}{ RAW } & \multicolumn{3}{|c|}{ Average Pressure $=$} & & \multicolumn{2}{|c|}{$20.0 \mathrm{psig}$} \\
\hline & Average Sil & urry Flow = & & & & \\
\hline & & & & & iumy & Fither \\
\hline $\begin{array}{l}\text { Test } \\
\text { Number }\end{array}$ & Time & $\begin{array}{l}\text { Chiller } \\
\text { Temp C }\end{array}$ & $\begin{array}{l}\text { Sluriy } \\
\text { Temp c }\end{array}$ & & ate & $\begin{array}{l}\text { Pressu } \\
\text { (psiag) }\end{array}$ \\
\hline & $18: 40$ & 16 & & & 3. & \\
\hline & 18:50 & 14 & & & 3.6 & \\
\hline & 18:55 & 14 & & & 3.6 & \\
\hline & 19.00 & 15 & & & 3.6 & \\
\hline & 19:05 & 15 & & & 36 & \\
\hline & 19:10 & 16 & & & 3.6 & \\
\hline
\end{tabular}

Average Flow $=$
Filtrate

Filtrate

Permeate Filter Inlet Sample Filltrate Flow Pressure Pressue Volume Time of Collection Rate (mL/sec) Time of Collection Rate (mL/sec)
(Sec) $\begin{array}{lll}0 & 20 \\ 0 & 20\end{array}$ NM

NM $=$ Not Measured

$\begin{array}{rr}61.72 & 0.146 \\ 64 & 0.141 \\ 63.25 & 0142 \\ 70.94 & 0.127 \\ 69.06 & 0.130\end{array}$

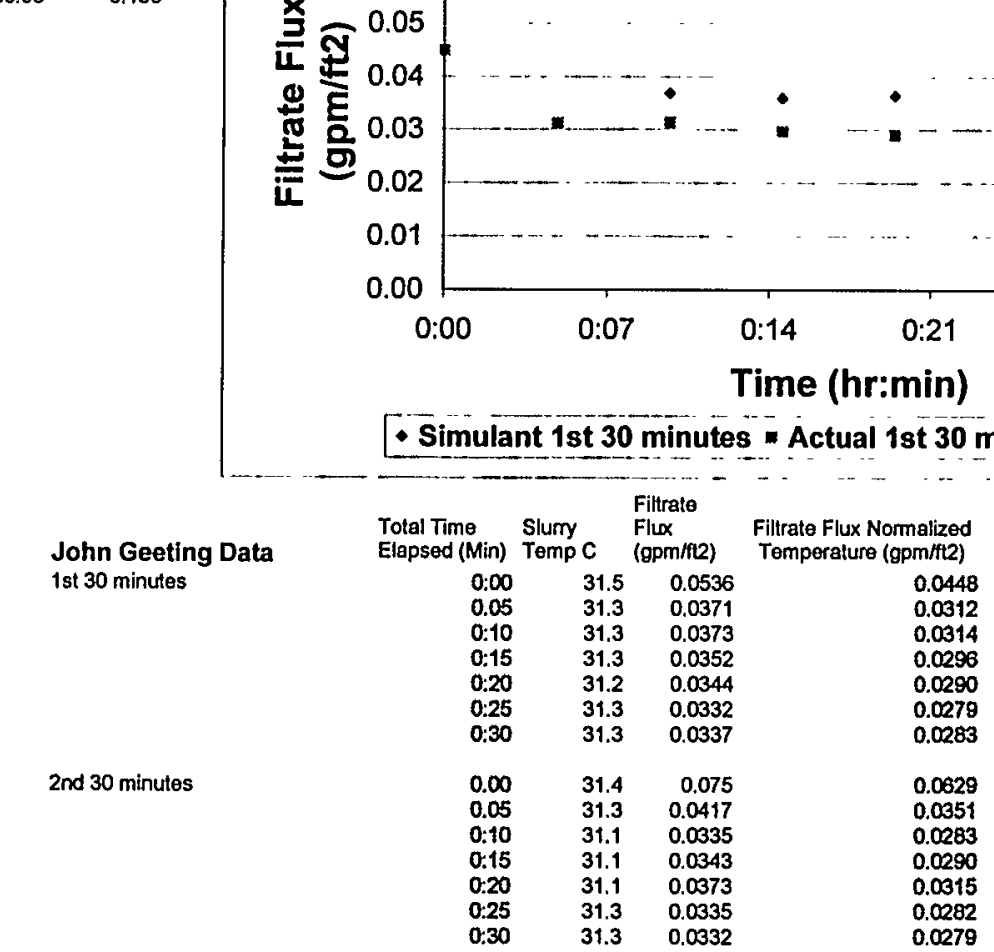



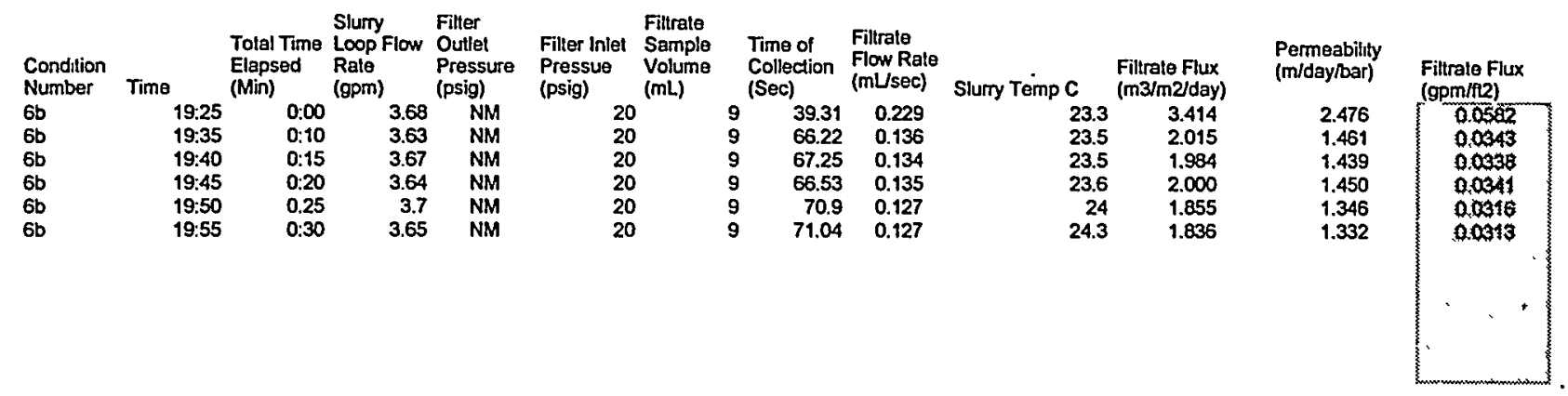

C-106 Simulant Permeability vs. Time at $20.0 \mathrm{psig}$ and $6.0 \mathrm{ft} / \mathrm{s}$

\begin{tabular}{|c|c|c|c|c|c|c|c|c|c|c|}
\hline \multirow[b]{2}{*}{ RAW } & \multirow{2}{*}{ Average $\mathrm{S}$} & \multicolumn{2}{|c|}{ Average Pressure $=$} & \multicolumn{2}{|c|}{$20.0 \mathrm{psig}$} & \multirow{2}{*}{\multicolumn{2}{|c|}{$\begin{array}{c}\text { Average Flow }= \\
\text { Filtrate }\end{array}$}} & \multirow{3}{*}{$\begin{array}{l}0.148 \\
\text { Filtrate } \\
\text { Sample } \\
\text { Volume } \\
\text { (mL) }\end{array}$} & \multirow[t]{2}{*}{ Average Flux = } & \multirow[t]{2}{*}{2.184} \\
\hline & & urry Flow = & 3.66 & & & & & & & \\
\hline $\mathrm{mb}$ & Time & $\begin{array}{l}\text { Chiller } \\
\text { Temp C }\end{array}$ & $\begin{array}{l}\text { Slurny } \\
\text { Temp C }\end{array}$ & $\begin{array}{l}\text { Loop flow } \\
\text { Late } \\
\text { (gpm) }\end{array}$ & $\begin{array}{l}\text { - liter } \\
\text { Outlet } \\
\text { Pressure } \\
\text { (psig) }\end{array}$ & $\begin{array}{l}\text { Permeate } \\
\text { Pressure } \\
\text { (psig) }\end{array}$ & $\begin{array}{l}\text { Filter Inlet } \\
\text { Pressue } \\
\text { (psig) }\end{array}$ & & $\begin{array}{l}\text { Time of Collec } \\
(\mathrm{Sec})\end{array}$ & $\begin{array}{l}\text { Filtrate Flow } \\
\text { Rate (m Usec }\end{array}$ \\
\hline & 19:25 & 15 & $\quad 23.3$ & 3.68 & NM & 0 & 20 & & 9 & \\
\hline & 19:35 & 15 & 23.5 & 3.63 & NM & 0 & 20 & & & \\
\hline & 19.40 & 16 & 23.5 & 3. & Na & 0 & 20 & & & \\
\hline & 19:45 & 15 & 23.6 & 3.64 & NM & 0 & & & 66. & \\
\hline & 19.50 & 16 & 24 & 3.7 & & $\mathbf{0}$ & & & 7 & \\
\hline & 19:55 & 16 & 24.3 & 3.65 & NM & 0 & 20 & & 71.04 & 0.127 \\
\hline
\end{tabular}

NM $=$ Not Measured

$\begin{array}{llll}0.00 & 31.5 & 0.0536 & 0.0448 \\ 0: 05 & 31.3 & 0.0371 & 0.03912 \\ 0.10 & 31.3 & 0.0373 & 0.0314 \\ 0: 15 & 31.3 & 0.0352 & 0.0296 \\ 0: 20 & 31.2 & 0.0344 & 0.0290 \\ 0: 25 & 31.3 & 0.0332 & 0.0279 \\ 0: 30 & 31.3 & 0.0337 & 0.0283 \\ 0.00 & 31.4 & 0.075 & 0.0629 \\ 0.05 & 31.3 & 0.0417 & 0.0351 \\ 0.10 & 31.1 & 0.0335 & 0.0283 \\ 0: 15 & 31.1 & 0.0343 & 0.0290 \\ 0.20 & 31.1 & 0.0373 & 0.0315 \\ 0.25 & 31.3 & 0.0335 & 0.0282 \\ 0: 30 & 31.3 & 0.0332 & 0.0279\end{array}$

0.033

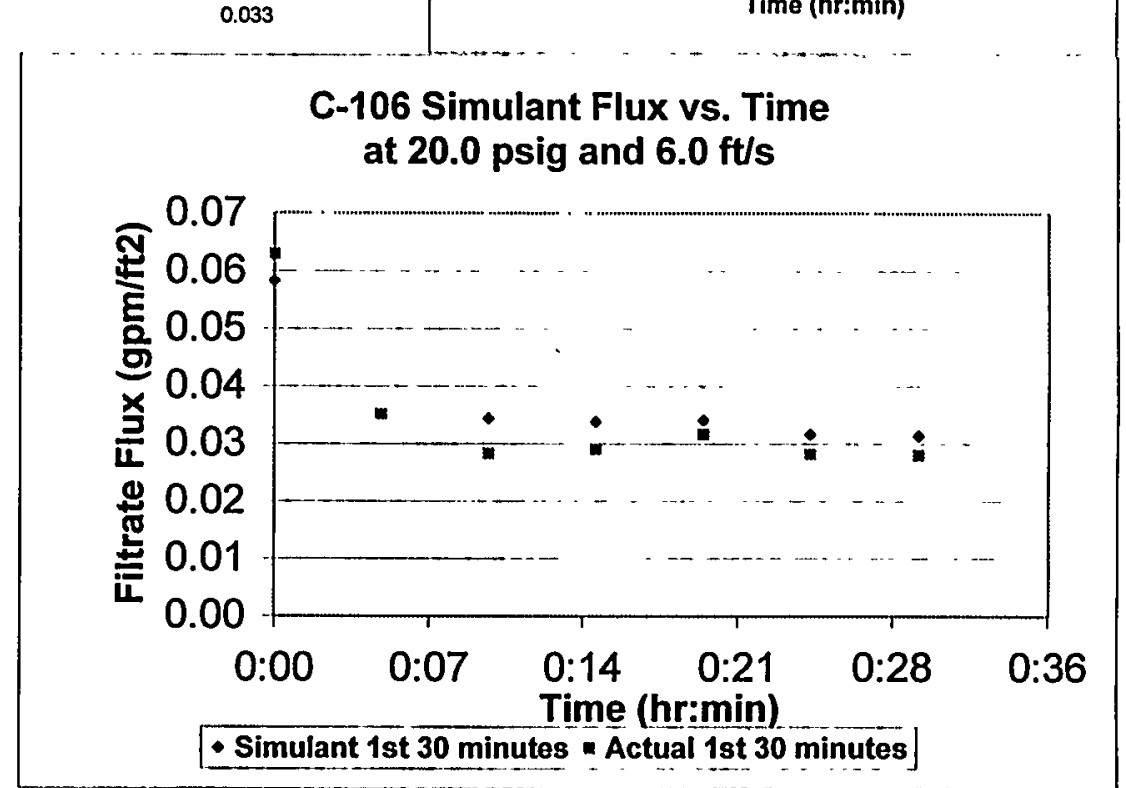

John Geeting Data Total Time Slurry Filtux

Filtrate Flux Normalized Ist 30 minutes

Elapsed (Min) Temp C (gpm/fi2) Temperature (gom/fit2)

2nd 30 minutes

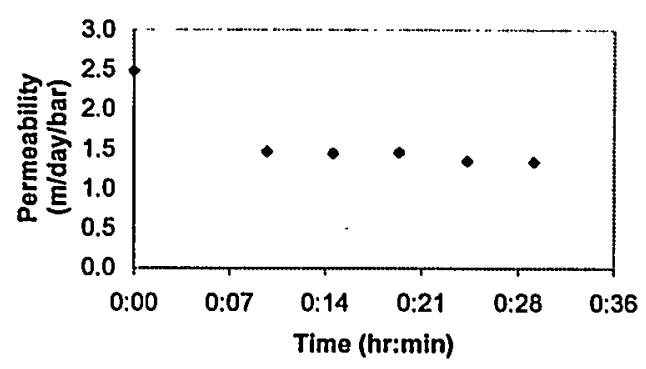

-106 Simulant Flux vs. Time

0312

0.0096

0.0283

2nd
0.035

0.0290

0.0315
0.0282
0.0279 


\section{Condition 7}

C-106 Waste and C-106 Simulant

Filtrate Flux vs. Time

at Target Conditions of $12.0 \mathrm{psig}$ and $7.5 \mathrm{ft} / \mathrm{s}$

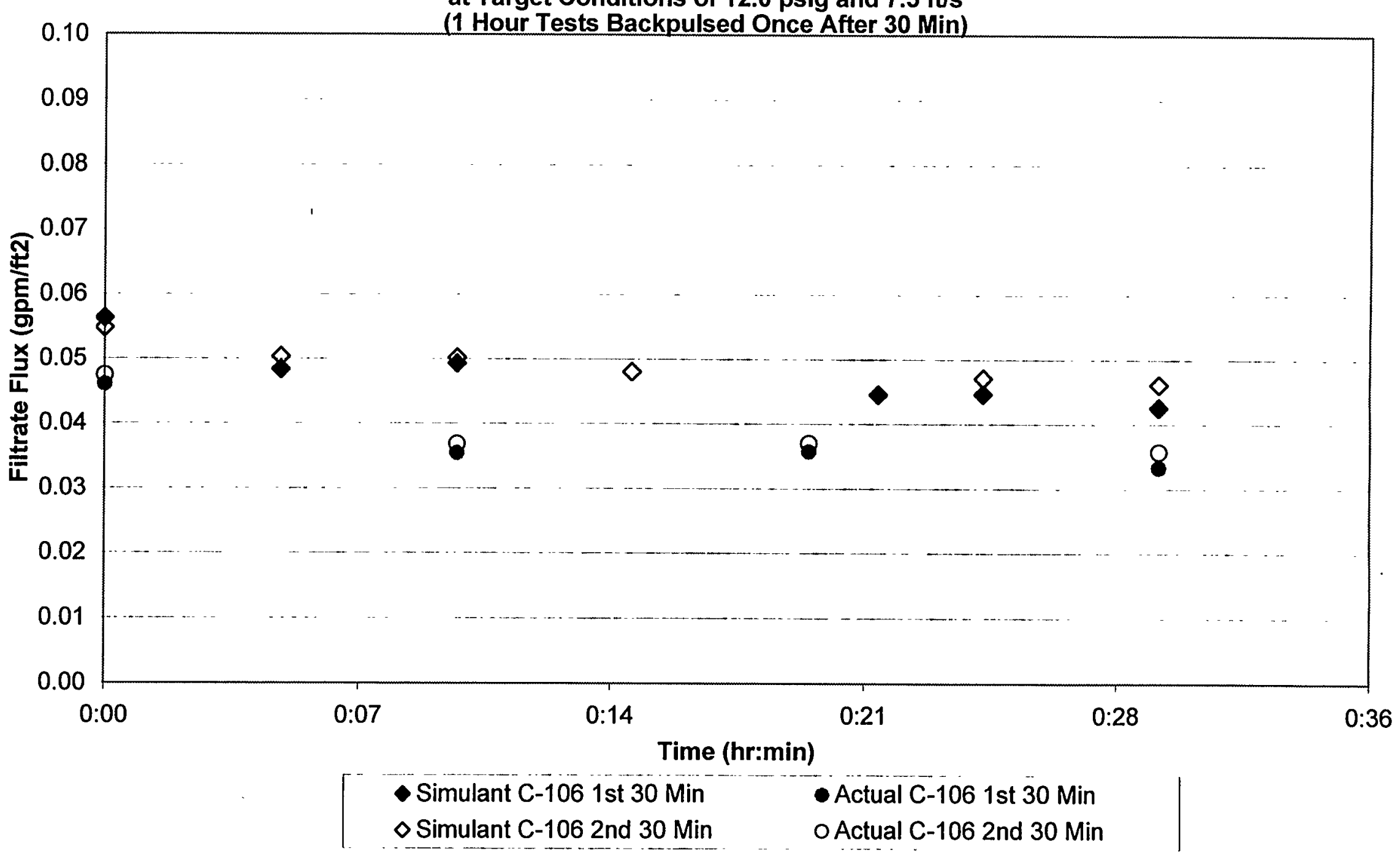



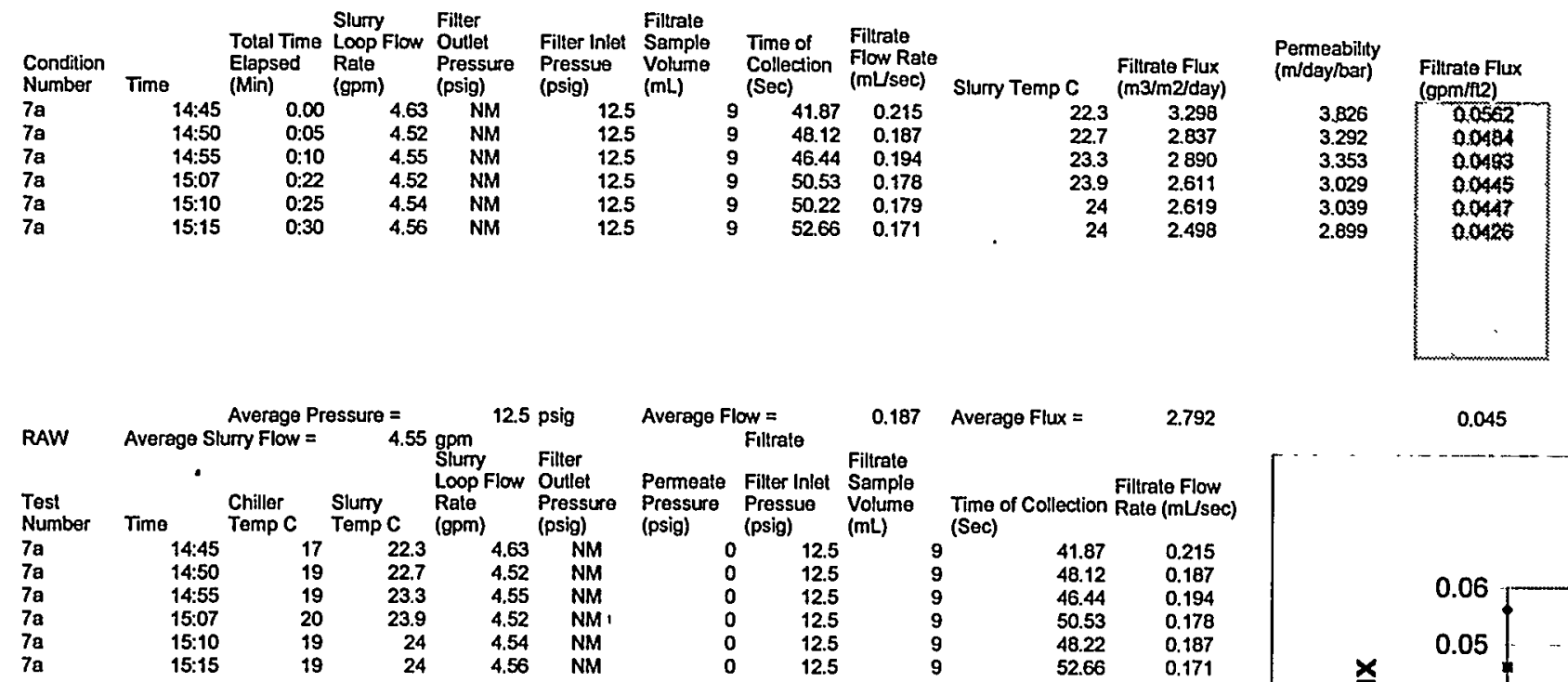

Average Flow $=$
Filtrate

0.187 Average Flux $=\quad 2.792$ Permeate Filter Inlet Sample

Filtrate Flow (psig) (psig) Volutr Filtrate Flow
Time of Collection Rate (mLsec) (Sec)

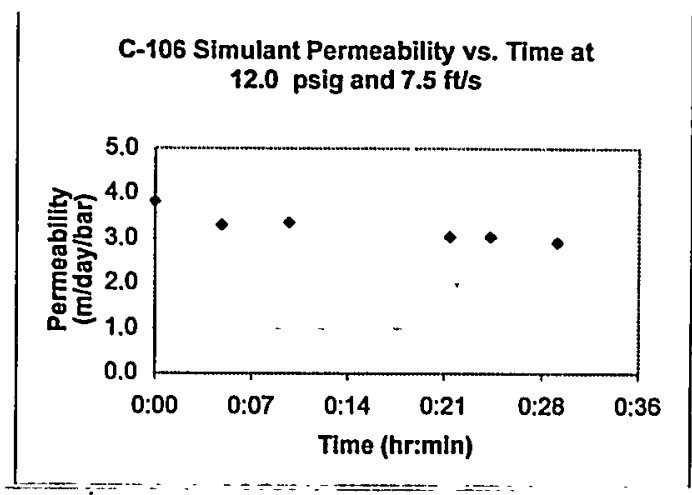

NM $=$ Not Measured

$\begin{array}{ll}0 & 12.5 \\ 0 & 12.5 \\ 0 & 12.5 \\ 0 & 12.5 \\ 0 & 12.5 \\ 0 & 12.5\end{array}$

$\begin{array}{ll}41.87 & 0.215 \\ 48.12 & 0.187 \\ 46.44 & 0.194 \\ 50.53 & 0.178 \\ 48.22 & 0.187 \\ 52.66 & 0.171\end{array}$

$\begin{array}{ll}9 & 48.22 \\ 9 & 52.66\end{array}$

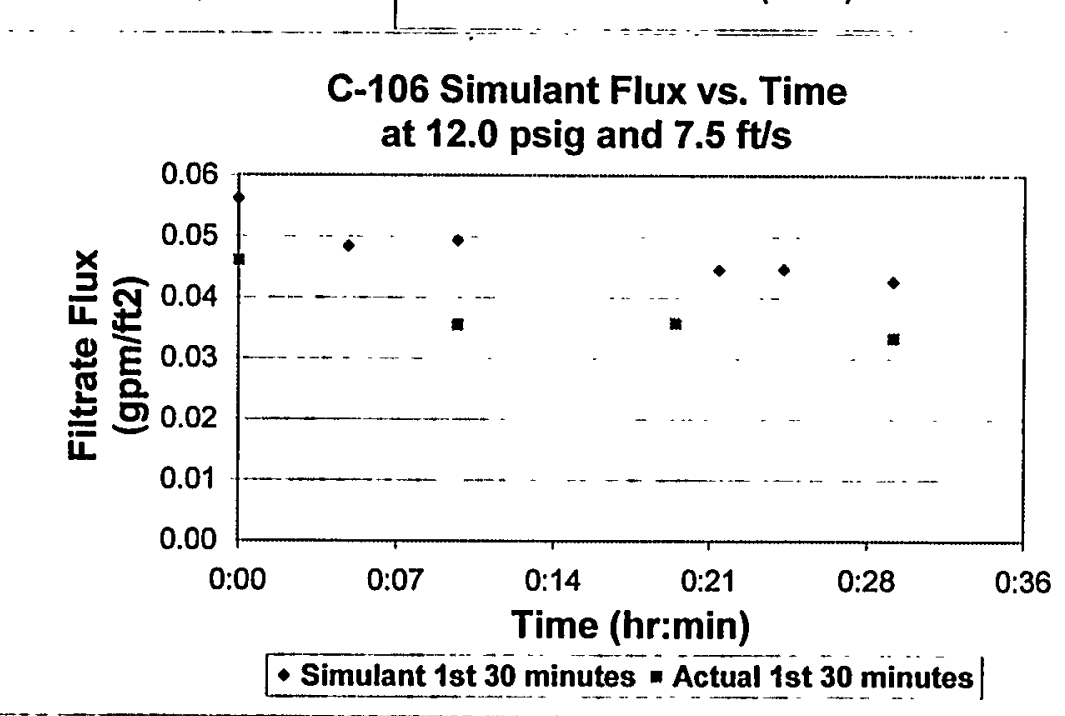

John Geeting Data

Total Time Slurry Filux

1st 30 minutes

\begin{tabular}{|c|c|c|c|}
\hline $\begin{array}{l}0: 00 \\
0: 10 \\
0: 20 \\
0: 30\end{array}$ & $\begin{array}{r}30.8 \\
30.6 \\
31 \\
31\end{array}$ & $\begin{array}{l}0.054 \\
0.0414 \\
0.0422 \\
0.0393\end{array}$ & $\begin{array}{l}0.0460 \\
0.0355 \\
0.0358 \\
0.0333\end{array}$ \\
\hline $\begin{array}{l}0.00 \\
0: 10 \\
0: 20 \\
0.30\end{array}$ & $\begin{array}{l}31.6 \\
31.7 \\
31.8\end{array}$ & $\begin{array}{l}0.0569 \\
0.0443 \\
0.0446\end{array}$ & $\begin{array}{l}0.0474 \\
0.0368 \\
0.0370 \\
0.0250\end{array}$ \\
\hline
\end{tabular}

2nd 30 minutes

0.0358 
Filter Inlet $\begin{gathered}\text { Filtrate } \\ \text { Sample }\end{gathered}$ Prosto Time of Filtrate

\begin{tabular}{|c|c|c|c|c|}
\hline $\begin{array}{l}\text { Condtion } \\
\text { Number }\end{array}$ & $\operatorname{Tim} \theta$ & $\begin{array}{l}\text { Total Time } \\
\text { Elapsed } \\
\text { (Min) }\end{array}$ & $\begin{array}{l}\text { Slurry } \\
\text { Loop Flow } \\
\text { Rate } \\
\text { (gpm) }\end{array}$ & $\begin{array}{l}\text { Filler } \\
\text { Outlet } \\
\text { Pressur } \\
\text { (psig) }\end{array}$ \\
\hline & 1530 & 0.00 & 457 & \\
\hline & $15: 35$ & & 4.59 & \\
\hline $7 \mathrm{~b}$ & & & 4.6 & \\
\hline $7 \mathrm{~b}$ & 15: & 015 & 46 & \\
\hline & 15 & $0: 25$ & 4.59 & \\
\hline & $16: 00$ & 0.30 & 4.56 & \\
\hline
\end{tabular}
Collection Flow Rate Filtrate Flux

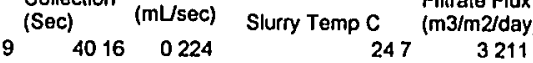
\begin{tabular}{|ll|}
4016 & 0224 \\
43.44 & 0.207 \\
\hline
\end{tabular} $\begin{array}{lll}436 & 0206\end{array}$ $45.4 \quad 0.198$ $4635 \quad 0.194$ $47.63 \quad 0189$

$\begin{array}{rr}247 & 3211 \\ 249 & 2.952 \\ 24.9 & 2941 \\ 25 & 2.817 \\ 25 & 2.759 \\ 24.7 & 2708\end{array}$

Permoability

(m/dayibar)

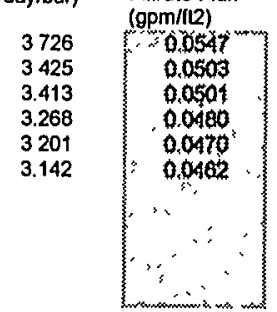

Average Pressure $=$
RAW Average Slumy Flow $=\quad 4.59 \mathrm{gpm}$

$\begin{array}{lll}2.5 \mathrm{psig} & \text { Average Flow }= & 0.203 \quad \text { Average Flux }=\quad 2.898\end{array}$

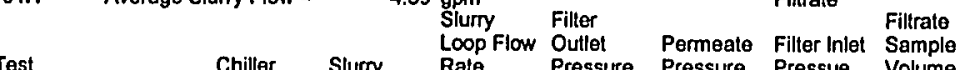
Number Time Temp C Temp C Rate Pressure Pressure Proster Volume Time of Collection Filtrate Flow

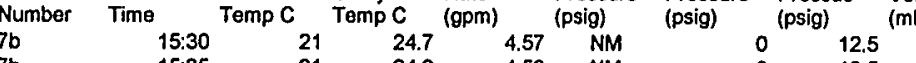

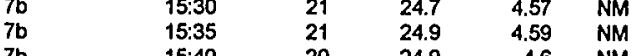

$7 \mathrm{~b}$

$7 \mathrm{~b}$

$15: 40$

$15: 45$

16.00

$\begin{array}{lrrr}21 & 24.9 & 4.6 & \text { NM } \\ 1 & 25 & 4.6 & \text { NM I }\end{array}$

$\mathrm{NM}=$ Nol Measured

\begin{tabular}{|c|c|c|}
\hline \multicolumn{3}{|c|}{$\begin{array}{l}\text { Filtrate Flow } \\
\text { Time of Collection Rate (mLsec) } \\
\text { (Sec) }\end{array}$} \\
\hline & 40.16 & \\
\hline & 43.44 & 0.207 \\
\hline & 43.6 & 0.206 \\
\hline 9 & 45.4 & 0.198 \\
\hline & 46.35 & 0.194 \\
\hline 9 & 47.63 & 0.189 \\
\hline
\end{tabular}

0.048

... . .

$$
\mid
$$

\section{C-106 Simulant Flux vs. Time} at $12.0 \mathrm{psig}$ and $7.5 \mathrm{ft} / \mathrm{s}$

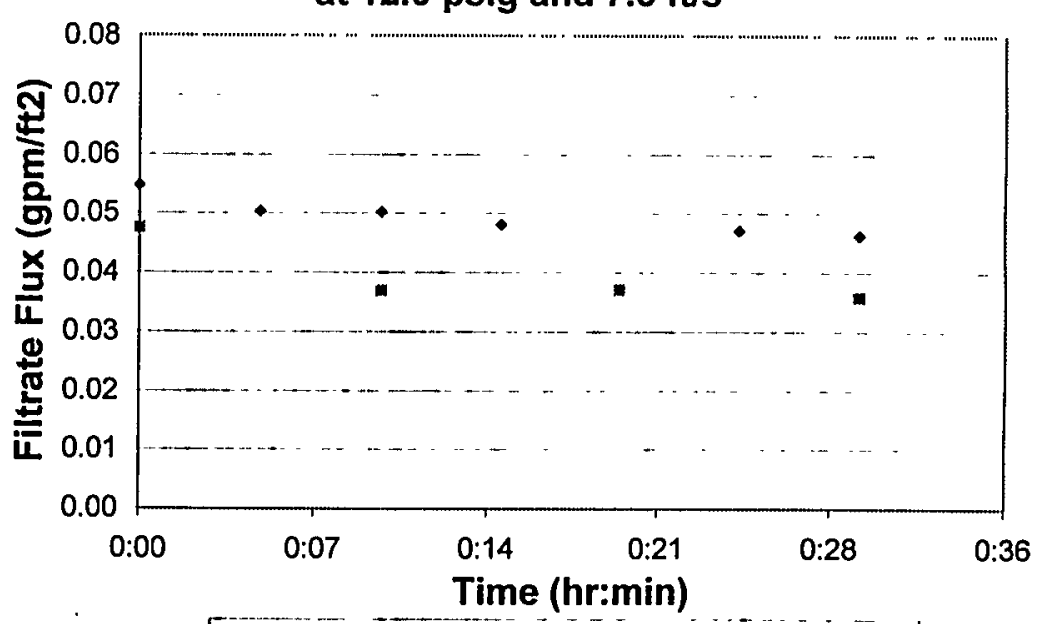

- Simulant 1 st 30 minutes Actual 1 st 30 minutes

\begin{tabular}{|c|c|c|c|c|}
\hline John Geeting Data & $\begin{array}{l}\text { Total Time } \\
\text { Elapsed (Min) }\end{array}$ & $\begin{array}{l}\text { Slumy } \\
\text { Temp C }\end{array}$ & $\begin{array}{l}\text { Fittrate } \\
\text { Flux } \\
\text { (gpm } / f(t 2)\end{array}$ & $\begin{array}{l}\text { Filtrate Flux Normalized } \\
\text { Temperature (gpm/ft2) }\end{array}$ \\
\hline $1 s 130$ minutes & $\begin{array}{l}0: 00 \\
0: 10 \\
0: 20 \\
0: 30\end{array}$ & $\begin{array}{r}30.8 \\
30.6 \\
31 \\
31\end{array}$ & $\begin{array}{r}0.054 \\
0.0414 \\
0.0422 \\
0.0393\end{array}$ & $\begin{array}{l}0.0460 \\
0.0355 \\
0.0358 \\
0.0333\end{array}$ \\
\hline 2 nd 30 minutes & $\begin{array}{l}0: 00 \\
0: 10 \\
0: 20 \\
0: 30\end{array}$ & $\begin{array}{r}31.6 \\
31.7 \\
31.8 \\
32\end{array}$ & $\begin{array}{l}0.0569 \\
0.0443 \\
0.0446 \\
0.0434\end{array}$ & $\begin{array}{l}0.0474 \\
0.0368 \\
0.0370 \\
0.0358\end{array}$ \\
\hline
\end{tabular}




\section{Condition 8}

C-106 Waste and C-106 Simulant

Filtrate Flux vs. Time

at Target Conditions of 5 psig and $6 \mathrm{ft} / \mathrm{s}$

(1 Hour Tests Backpulsed Once After 30 Min)

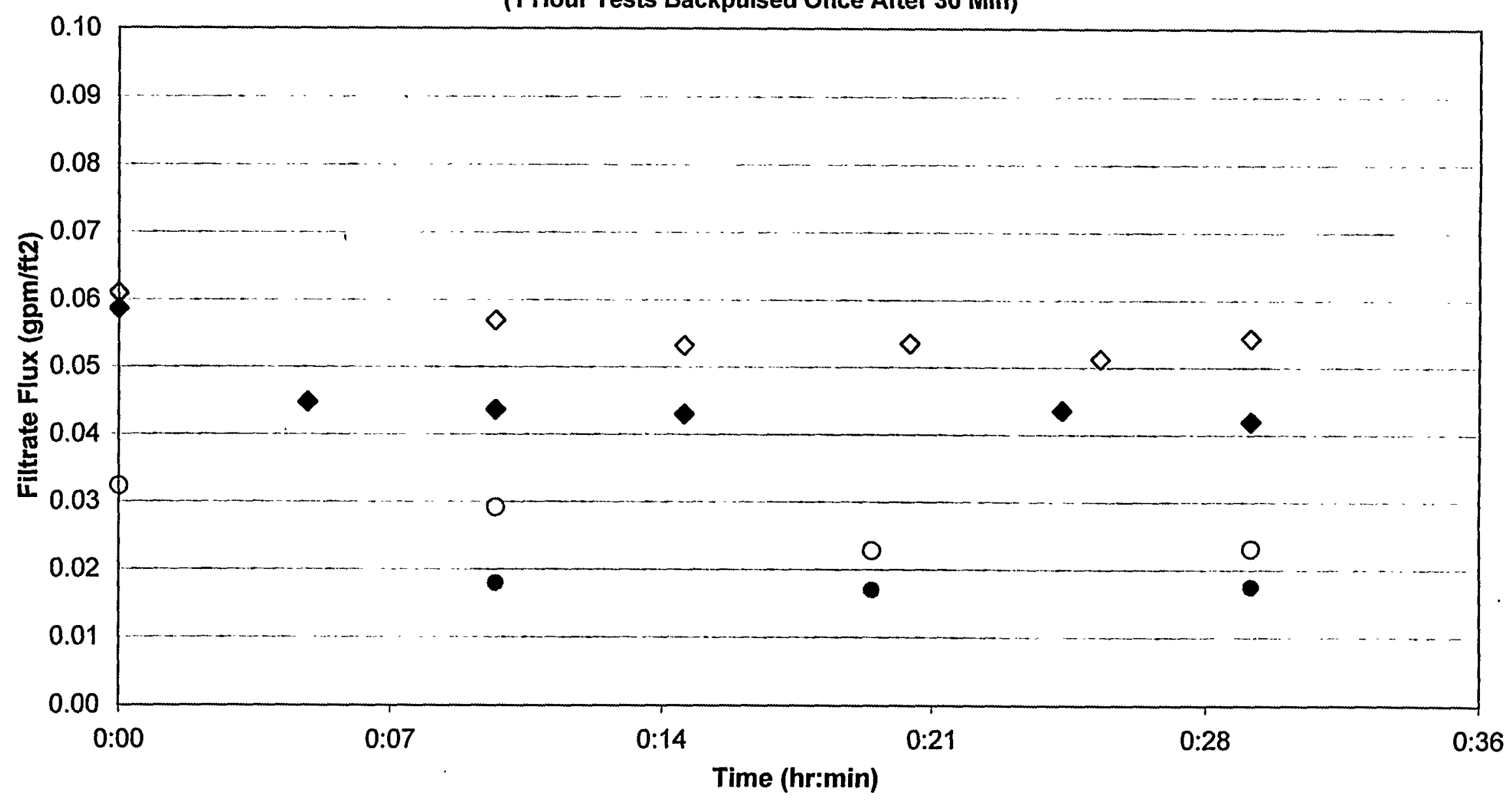

- Simulant C-106 1st $30 \mathrm{Min} \quad-$ Actual C-106 1st $30 \mathrm{Min}$

๑ Simulant C-106 2nd 30 Min OActual C-106 2nd 30 Min 


\begin{tabular}{|c|c|c|c|c|c|c|c|c|c|}
\hline $\begin{array}{l}\text { Sondition } \\
\text { Jumber }\end{array}$ & Time & $\begin{array}{l}\text { Total Time } \\
\text { Elapsed } \\
\text { (Min) }\end{array}$ & $\begin{array}{l}\text { Slury } \\
\text { Loop Flow } \\
\text { Rate } \\
\text { (gpm) }\end{array}$ & $\begin{array}{l}\text { Filter } \\
\text { Outlet } \\
\text { Pressure } \\
\text { (psig) }\end{array}$ & $\begin{array}{l}\text { Filler Inlet } \\
\text { Pressue } \\
\text { (psig) }\end{array}$ & $\begin{array}{l}\text { Filtrate } \\
\text { Sample } \\
\text { Volume } \\
\text { (mL) }\end{array}$ & & $\begin{array}{l}\text { e of } \\
\text { ection } \\
\text { y) }\end{array}$ & $\begin{array}{l}\text { Filltrate } \\
\text { Flow R } \\
\text { fmLsed }\end{array}$ \\
\hline & $16: 30$ & 000 & 367 & $\mathrm{NM}$ & e & & 9 & 37.75 & \\
\hline & & 0.05 & 369 & NM & 5 & & 9 & 49.32 & \\
\hline & & & 364 & NM & 5 & & & 49. & \\
\hline & & $0: 15$ & 3.69 & NM & & & & & \\
\hline & $16: 55$ & 0.25 & 3.71 & NM & 5 & 5 & & 49.85 & \\
\hline & $17 \cdot 00$ & 0.30 & 37 & NM & 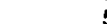 & 5 & 9 & 51,75 & \\
\hline
\end{tabular}

\begin{tabular}{|rr} 
& \\
Slury Temp C & $\begin{array}{c}\text { Filtrate Flux } \\
\text { (m3/m2/day) }\end{array}$ \\
24.5 & 3.436 \\
245 & 2.630 \\
25 & 2561 \\
25.2 & 2523 \\
25.1 & 2.558 \\
251 & 2.464
\end{tabular}

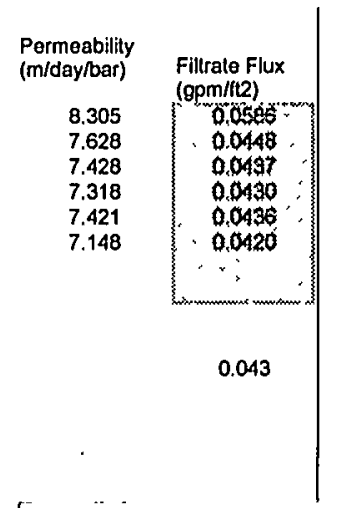

C-106 Simulant Permeability vs. Time at $5 \mathrm{psig}$ and $6.0 \mathrm{ft} / \mathrm{s}$

\begin{tabular}{|c|c|c|c|c|c|c|c|c|c|c|c|}
\hline \multirow{3}{*}{$\begin{array}{l}\text { RAW } \\
\text { Test } \\
\text { Number }\end{array}$} & \multirow[b]{2}{*}{ Average SI } & \multirow{2}{*}{\multicolumn{2}{|c|}{ Average Pressure $=$}} & \multicolumn{2}{|c|}{$5.2 \mathrm{psig}$} & \multirow{2}{*}{\multicolumn{2}{|c|}{$\begin{array}{l}\text { Average Flow }= \\
\text { Fillrale }\end{array}$}} & \multirow{3}{*}{$\begin{array}{l}\quad 0.189 \\
\text { Filtrate } \\
\text { Sample } \\
\text { Volume } \\
\text { (mL) }\end{array}$} & \multirow{2}{*}{\multicolumn{2}{|c|}{ Average Flux = }} & \multirow{3}{*}{$\begin{array}{l}\quad 2.695 \\
\text { Filtrate Flow } \\
\text { Rate (mL/sec) }\end{array}$} \\
\hline & & & 368 & & & & & & & & \\
\hline & Time & $\begin{array}{l}\text { Chiller } \\
\text { Temp C }\end{array}$ & $\begin{array}{l}\text { Slunry } \\
\text { Temp C }\end{array}$ & $\begin{array}{l}\text { Slurry } \\
\text { Loop Flow } \\
\text { Rate } \\
\text { (gpm) }\end{array}$ & $\begin{array}{l}\text { Filler } \\
\text { Outlet } \\
\text { Pressure } \\
\text { (psig) }\end{array}$ & $\begin{array}{l}\text { Permeate } \\
\text { Pressure } \\
\text { (psig) }\end{array}$ & $\begin{array}{l}\text { Filler Inlet } \\
\text { Pressue } \\
\text { (psig) }\end{array}$ & & $\begin{array}{l}\text { Time of } \\
\text { (Sec) }\end{array}$ & Sollection & \\
\hline & $16: 30$ & 20 & 24.5 & 3.67 & NM & 0 & $0 \quad 6$ & & 9 & 37.75 & \\
\hline & & 20 & 24.5 & 3.69 & NM & 0 & 5 & & 9 & & \\
\hline & $16: 40$ & 22 & 25 & 3. & & 0 & 5 & & & & \\
\hline & 16: & 22 & 25.2 & & NI & 0 & 5 & & 9 & & \\
\hline & $16: 55$ & 20 & 25.1 & 3.71 & NM & 0 & 0 & & 9 & & 0.181 \\
\hline & 17.00 & 21 & 25.1 & 3.7 & NM & 0 & 0 & & 9 & 51.75 & 0.174 \\
\hline
\end{tabular}

$\mathrm{NM}=$ Not Measured

$51.75 \quad 0.174$

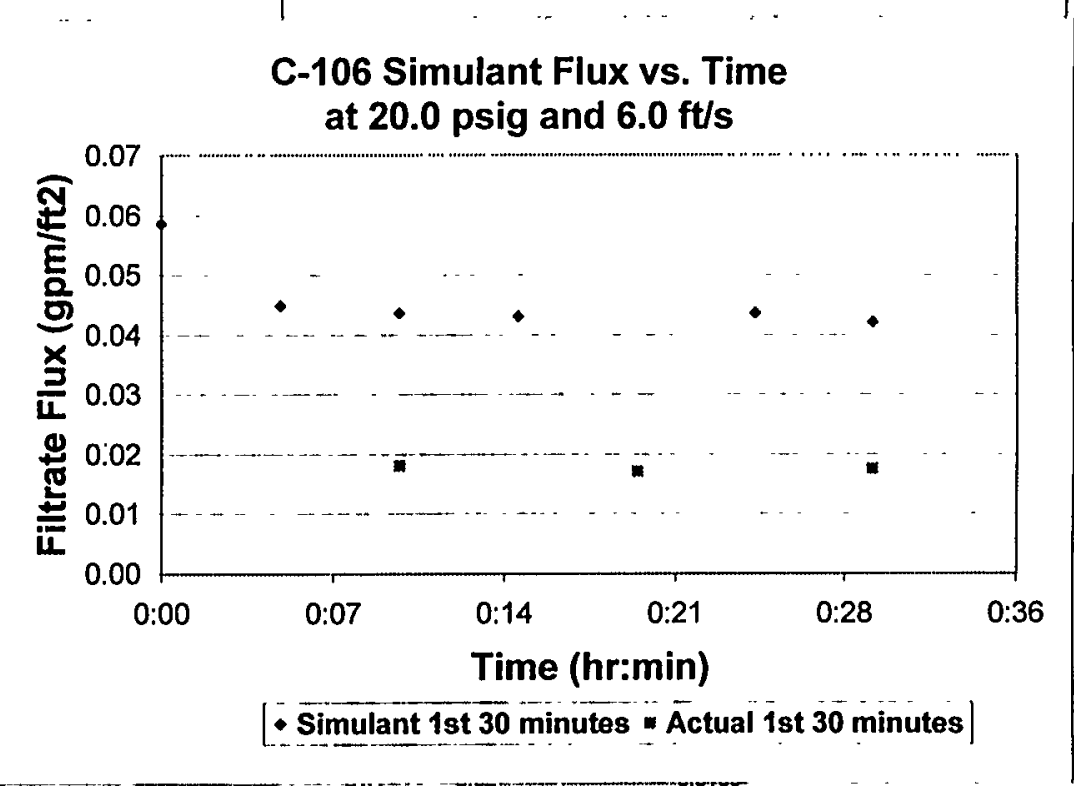

John Geeting 1st 30 minutes

$\begin{array}{llll}0: 10 & 29.9 & 0.0206 & 0.0180 \\ 0: 20 & 29.4 & 0.0192 & 0.0170 \\ 0: 30 & 29.1 & 0.0196 & 0.0175 \\ & & & \\ 0: 00 & 29.4 & 0.0366 & 0.0324 \\ 0: 10 & 29.2 & 0.0328 & 0.0282 \\ 0: 20 & 29.1 & 0.0256 & 0.0228 \\ 0: 30 & 29.1 & 0.026 & 0.0232\end{array}$




\begin{tabular}{|c|c|c|c|c|c|}
\hline $\begin{array}{l}\text { Condition } \\
\text { Number }\end{array}$ & Time & & $\begin{array}{l}\text { Total Time } \\
\text { Elapsed (Min) }\end{array}$ & $\begin{array}{l}\text { Sluryy Loop } \\
\text { Flow Rate } \\
\text { (gpm) }\end{array}$ & $\begin{array}{l}\text { Filter Ou } \\
\text { Pressure } \\
\text { (psig) }\end{array}$ \\
\hline $8 b$ & & 12.30 & $0: 00$ & 3.75 & \\
\hline 80 & & 12.40 & $0: 10$ & 3.64 & \\
\hline 列 & & $12: 45$ & $0: 15$ & 3.65 & \\
\hline $8 b$ & & $12: 51$ & $0: 21$ & 3.65 & \\
\hline $8 b$ & & $12: 56$ & $0: 26$ & 3.64 & \\
\hline$B D$ & & 13.00 & $0: 30$ & 3.65 & \\
\hline
\end{tabular}

\begin{tabular}{|c|c|c|c|c|c|c|c|}
\hline Fitter Inlet & $\begin{array}{l}\text { Fillate } \\
\text { Sample } \\
\text { Volume }\end{array}$ & & of & $\begin{array}{l}\text { Filtrate } \\
\text { Flow Rate } \\
\text { (mUsec) }\end{array}$ & Stume & $\begin{array}{l}\text { Filtrate Flux } \\
\text { (m3/m2/day }\end{array}$ & $\begin{array}{l}\text { Permeabi } \\
\text { (m/day/ba }\end{array}$ \\
\hline & & 9 & 36.5 & 0.247 & 24.3 & 3.574 & \\
\hline 5 & & 9 & 38.53 & 0.234 & 24.8 & 3.338 & \\
\hline 5 & & 9 & 41 & 0.220 & 25 & 3.119 & \\
\hline 5 & & 9 & 40.54 & 0.222 & 25.2 & 3.137 & \\
\hline 5 & & 9 & 42.43 & 0.212 & 25.1 & 3.006 & \\
\hline 5 & & 9 & 39.94 & 0.225 & 25.2 & 3.184 & \\
\hline
\end{tabular}

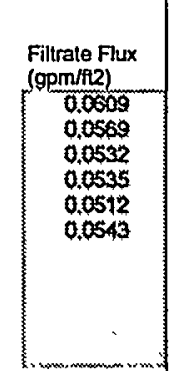

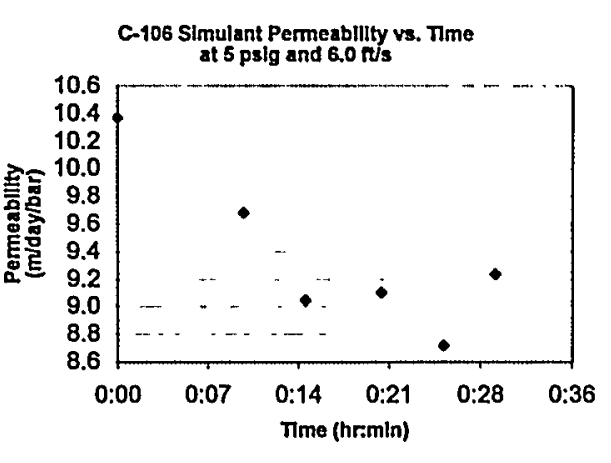

\begin{tabular}{|c|c|c|c|c|c|c|c|}
\hline \multirow[t]{2}{*}{ RAW } & \multicolumn{3}{|c|}{$\begin{array}{l}\text { Average Pressure } \\
\text { Average Stury Flow = }\end{array}$} & ure $=$ & $\mathrm{gpm}$ & \multicolumn{2}{|c|}{5.0 psig } \\
\hline & & & Chiller Temp & & $\begin{array}{l}\text { Slury Loo } \\
\text { Flow Rate }\end{array}$ & & $\begin{array}{l}\text { Filker Outt } \\
\text { Pressurb }\end{array}$ \\
\hline est Number & Time & & & Slurry Temp C & & & \\
\hline & & $12: 30$ & 22 & 24.3 & & 3.75 & NM \\
\hline & & $12: 40$ & 22 & 24.8 & & 3. & NM \\
\hline & & $12: 4$ & 21 & 25 & $'$ & 3. & \\
\hline & & $12:$ & 22 & 25.2 & & 3.65 & NM \\
\hline & & & & & & 3.64 & \\
\hline & & 13:00 & 21 & 25.2 & & 3.65 & NR \\
\hline
\end{tabular}

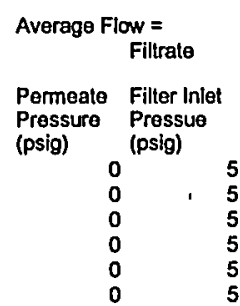

0.227

0.054

\section{C-106 Simulant Flux vs. Time} at 5 psig and $6.0 \mathrm{ft} / \mathrm{s}$

NM $=$ Not Measured

\begin{tabular}{lr}
\multicolumn{2}{l}{ Time of } \\
Collection \\
(Sec) \\
9 & 36.5 \\
9 & 38.53 \\
9 & 41 \\
9 & 40.54 \\
9 & 42.49 \\
9 & 39.9
\end{tabular}

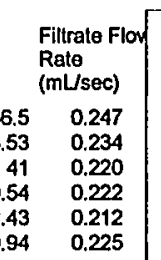

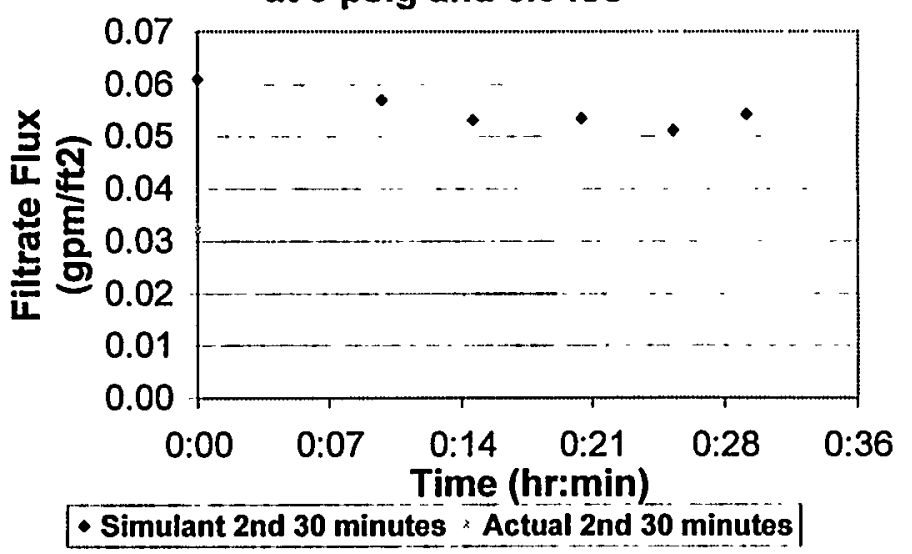

John Geeting Data $\begin{array}{ll}\text { Total Time } & \text { Slurry } \\ \text { Elapsed (Min) } & \text { Temp C }\end{array}$ 1st 30 minutes

$\begin{array}{ll}0: 00 & 31.1 \\ 0: 10 & 29.9 \\ 0: 20 & 29.4 \\ 0: 30 & 29.1 \\ 0: 00 & 29.4 \\ 0: 10 & 29.2 \\ 0: 20 & 29.1 \\ 0: 30 & 29.1\end{array}$

Filtrate Flax
(gpm/ft2)

Filtrate Fiux Normalized $1^{0.02}$ remperalure (gpm/fit2)

0.0169
0.0480

2nd 30 minutes

$\begin{array}{ll}29.4 & 0.0366 \\ 29.2 & 0.0328\end{array}$




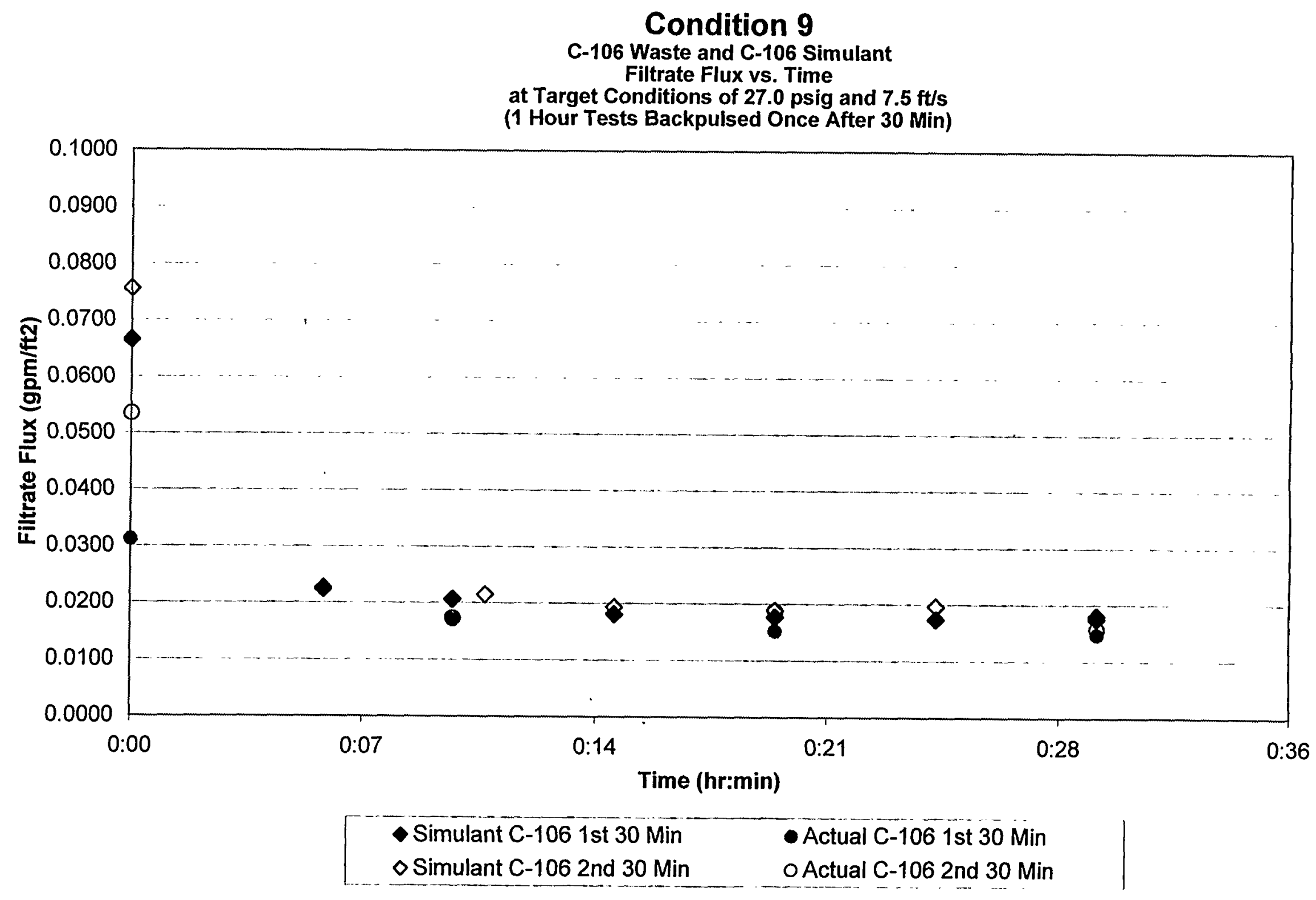




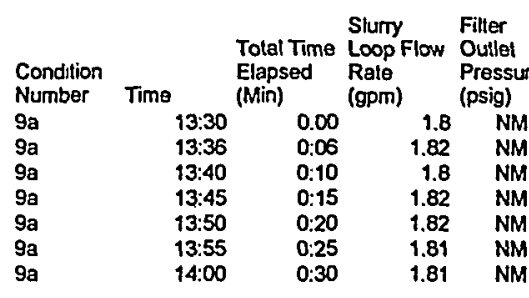

$\begin{array}{ll}\text { Filter Iniet } & \text { Filtrate } \\ \text { Pample } \\ \text { Pressue }\end{array}$

Time of Filtrate

Collection Flow Rate Filrate Flux (Sec) (mLsec)

Slurry Temp C $\quad \begin{aligned} & \text { Filtrate Flux } \\ & \text { (m3/m2/day) }\end{aligned}$

$\begin{gathered}\text { Permeability } \\ \text { (m/day/bar) }\end{gathered}$
2.827
0.953
0.835
0.770
0.752
0.738
0.764

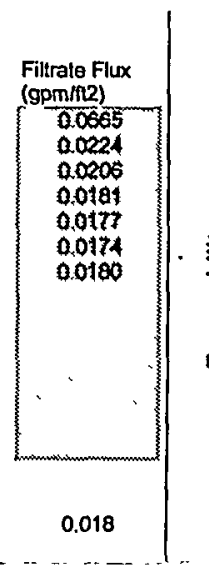

C-106 Simulant Permeability vs. Time at $\begin{array}{llrl}20 & 9 & 32.53 & 0.277 \\ 20 & 9 & 96.53 & 0.093 \\ 21 & 9 & 104.84 & 0086 \\ 20 & 9 & 119.47 & 0.075 \\ 20 & 9 & 123 & 0.073 \\ 20 & 9 & 125.63 & 0.072 \\ 20 & 5 & 67.44 & 0.074\end{array}$ $\begin{array}{rr}25.3 & 3.898 \\ 25.3 & 1.314 \\ 25.3 & 1.210 \\ 25.3 & 1.061 \\ 25.1 & 1.037 \\ 25 & 1.018 \\ 25 & 1.053\end{array}$ 20.0 psig and $3.0 \mathrm{ft} / \mathrm{s}$

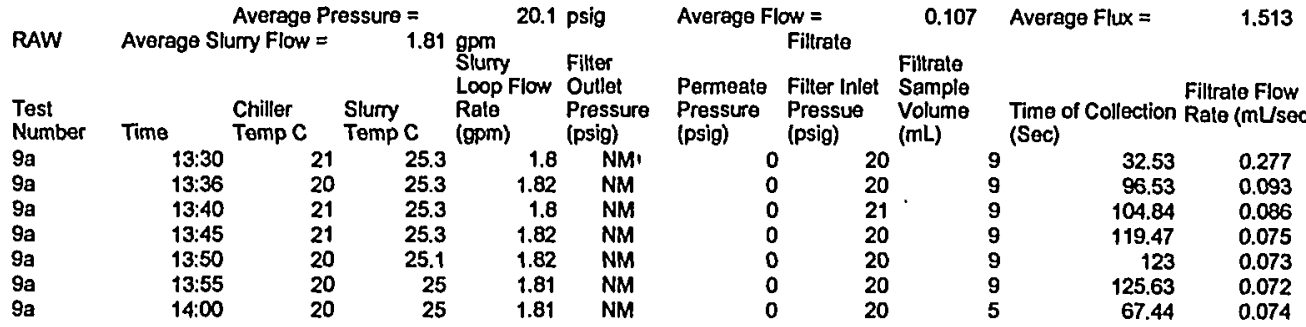

NM $=$ Not Measured

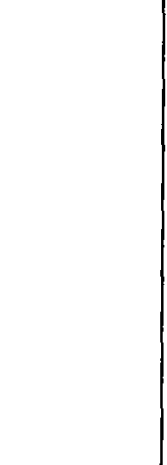

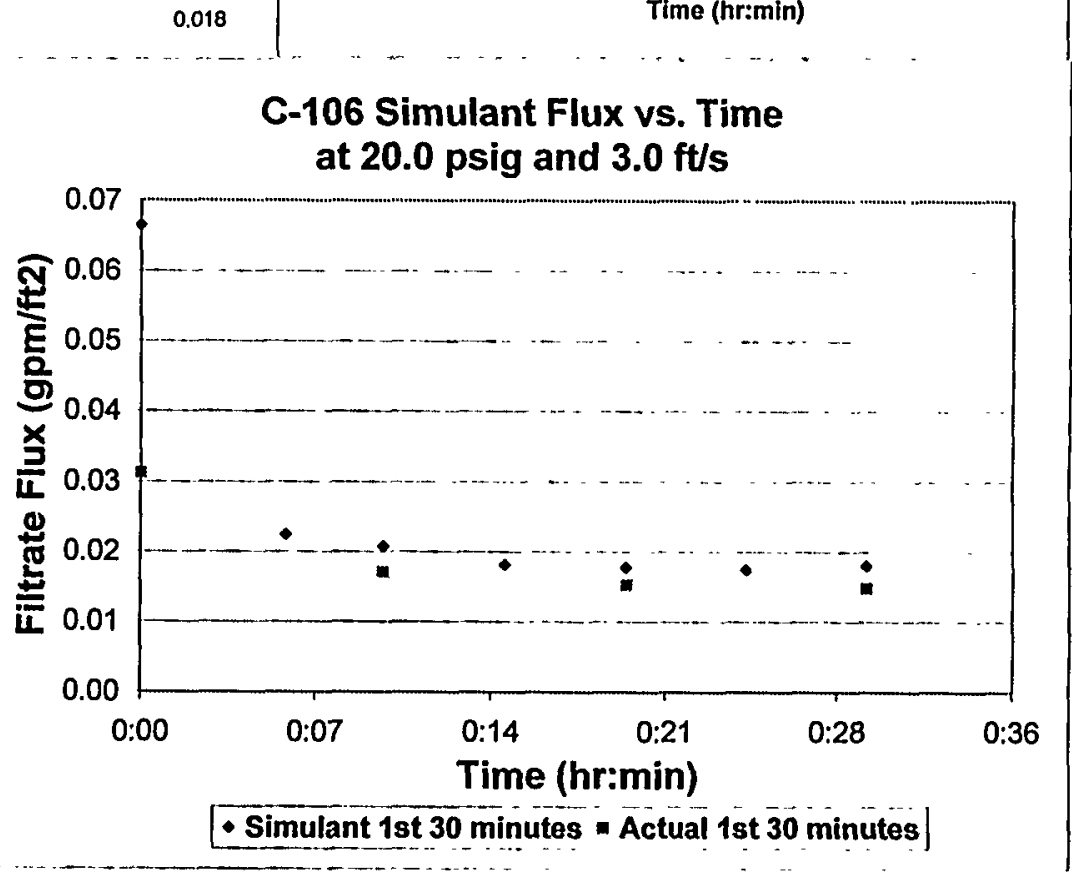

\begin{tabular}{|c|c|c|c|c|c|}
\hline John Geeting Data & $\begin{array}{l}\text { Tolal Time } \\
\text { Elapsed (Min) }\end{array}$ & $\begin{array}{l}\text { Slurry } \\
\text { Temp C }\end{array}$ & $\begin{array}{l}\text { Flifrate } \\
\text { Flux } \\
\text { (gpm/ftz) }\end{array}$ & $\begin{array}{l}\text { Filtrate Flux Normalized } \\
\text { Temperature (gpm/tit2) }\end{array}$ & \\
\hline 1st 30 minutes & $\begin{array}{l}0.0 \\
0: 10 \\
0.20 \\
0: 30\end{array}$ & $\begin{array}{l}29.6 \\
29.3 \\
29.3 \\
29.3\end{array}$ & $\begin{array}{l}0.0354 \\
0.0192 \\
0.0171 \\
0.0166\end{array}$ & $\begin{array}{l}0.0312 \\
0.0170 \\
0.0152 \\
0.0147\end{array}$ & 0.0156 \\
\hline 2nd 30 minutes & $\begin{array}{l}0: 0 \\
0: 10 \\
0: 20 \\
0: 30\end{array}$ & $\begin{array}{l}29.6 \\
29.6 \\
29.3 \\
29.3\end{array}$ & $\begin{array}{l}0.0607 \\
0.0197 \\
0.0211 \\
0.0177\end{array}$ & $\begin{array}{l}0.0534 \\
0.0175 \\
0.0187 \\
0.0382\end{array}$ & 0.0248 \\
\hline
\end{tabular}




\begin{tabular}{|c|c|c|c|c|}
\hline $\begin{array}{l}\text { Condition } \\
\text { Number }\end{array}$ & Time & $\begin{array}{l}\text { Total Time } \\
\text { Elepsed } \\
\text { (Min) }\end{array}$ & $\begin{array}{l}\text { Slurry } \\
\text { Loop Flow } \\
\text { Rate } \\
\text { (gpm) }\end{array}$ & $\begin{array}{l}\text { Filler } \\
\text { Oullet } \\
\text { Press } \\
\text { (psig) }\end{array}$ \\
\hline $9 b$ & $22: 05$ & 0.00 & 1.81 & \\
\hline $9 b$ & $22: 11$ & 006 & 18 & \\
\hline $9 \mathrm{~b}$ & $22 \cdot 16$ & $0: 11$ & 1.86 & \\
\hline $9 \mathrm{~b}$ & $22: 20$ & 0.15 & 183 & \\
\hline $9 \mathrm{~b}$ & $22: 25$ & $0: 20$ & 1.81 & \\
\hline $9 b$ & $22 \cdot 30$ & 0.25 & 1.82 & \\
\hline $9 b$ & $22: 35$ & 0.30 & 1.81 & \\
\hline
\end{tabular}

Filler Inlet $\begin{gathered}\text { Filtrate } \\ \text { Sample }\end{gathered}$ Time of Fittrale Pressue Volume Collection Flow Rate $\begin{array}{ll}21 & (\mathrm{~mL}) \\ 20 & 9 \\ 21 & 9 \\ 20 & 5 \\ 20 & 5 \\ 20 & 5 \\ 20 & 5 \\ & \end{array}$ (Sec) (mL/sec) $\begin{array}{ll}28.22 & 0.319 \\ 95.22 & 0.095\end{array}$ $\begin{array}{ll}95.22 & 0.095 \\ 56.09 & 0.089\end{array}$ $\begin{array}{ll}56.09 & 0.089 \\ 62.07 & 0.081\end{array}$ $\begin{array}{ll}62.07 & 0.081 \\ 64.82 & 0.077\end{array}$ $\begin{array}{ll}64.82 & 0.077 \\ 63.03 & 0.079\end{array}$ $\begin{array}{ll}7078 & 0.071\end{array}$

Slurry Temp C Filltrate Flux

$\begin{array}{lc} & \begin{array}{c}\text { Filtrate Flux } \\ \text { C } \\ \text { (m3/m2/day) }\end{array} \\ 258 & 4431 \\ 256 & 1.321 \\ 25.3 & 1.256 \\ 25.3 & 1.135 \\ 24.7 & 1.105 \\ 24.3 & 1.150 \\ 24.2 & 1027\end{array}$
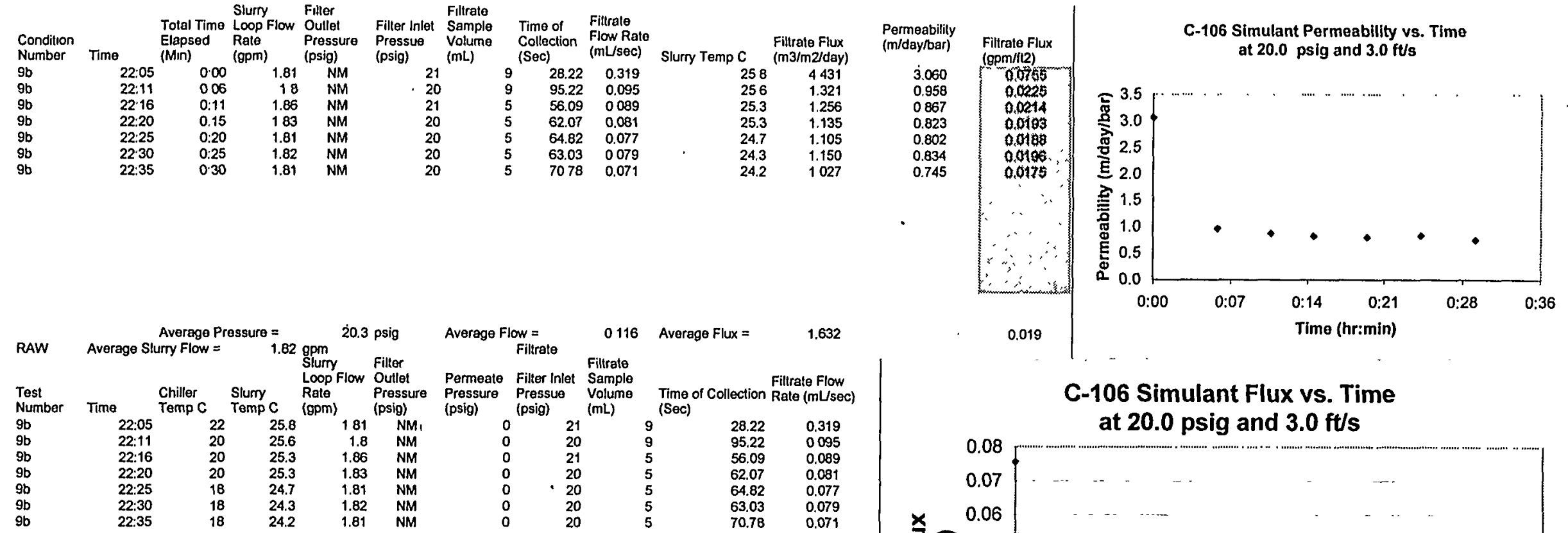

Average Flow $=$
Filtrate

0116 Average Flux =

1.632 Permeate Filter Inlet Filtrate Pressure Pressue Volume Time of Collection Rate $(\mathrm{mL} / \mathrm{sec})$

\begin{tabular}{lllll}
\multicolumn{2}{c}{$\begin{array}{l}\text { Pressue } \\
\text { (psig) }\end{array}$} & $\begin{array}{l}\text { Volume } \\
\text { (mL) }\end{array}$ & \multicolumn{3}{c}{$\begin{array}{l}\text { Time of Collection Rate (mLsec) } \\
\text { (Sec) }\end{array}$} \\
0 & 21 & 9 & 28.22 & 0.319 \\
0 & 20 & 9 & 95.22 & 0.095 \\
0 & 21 & 5 & 56.09 & 0.089 \\
0 & 20 & 5 & 62.07 & 0.081 \\
0 & 20 & 5 & 64.82 & 0.077 \\
0 & 20 & 5 & 63.03 & 0.079 \\
0 & 20 & 5 & 70.78 & 0.071
\end{tabular}

NM $=$ Not Measured

\begin{tabular}{|c|c|c|}
\hline & $\langle\mathrm{gpm}\rangle$ & \\
\hline 25.8 & 181 & \\
\hline 25.6 & 1.8 & \\
\hline 25.3 & 1.86 & \\
\hline 25.3 & 1.83 & \\
\hline & 1.81 & \\
\hline 24.3 & 1.82 & \\
\hline 24.2 & 1.81 & \\
\hline
\end{tabular}

70.78
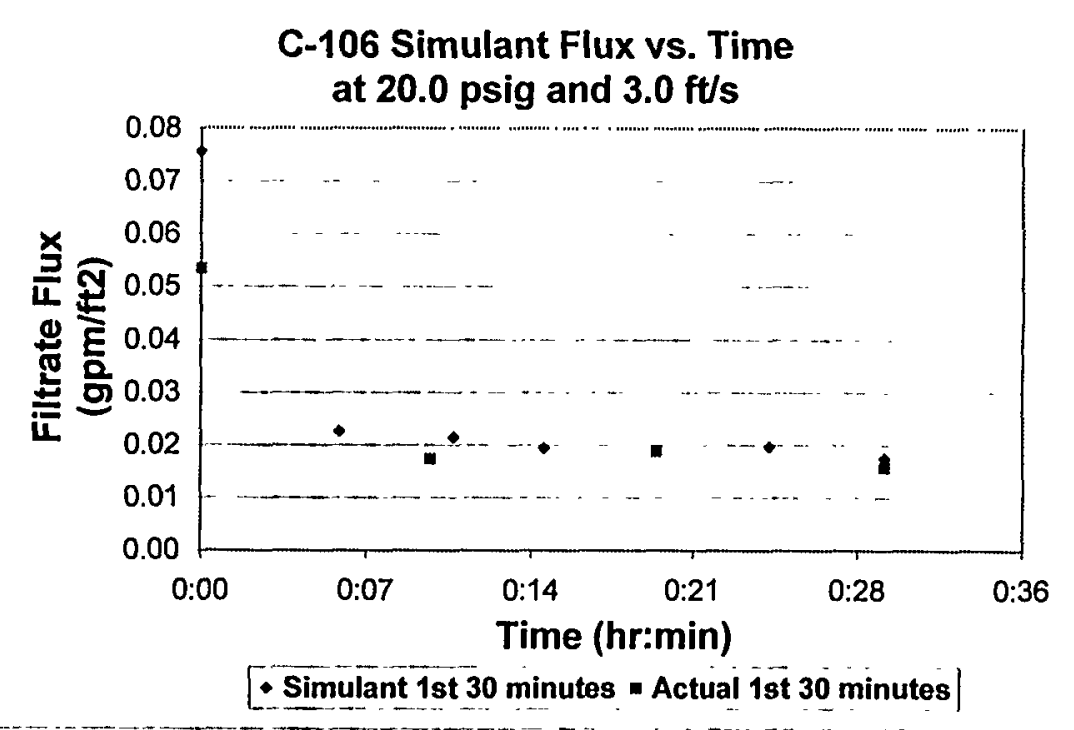

John Geeting Data

1 st 30 minutes

2nd 30 minutes

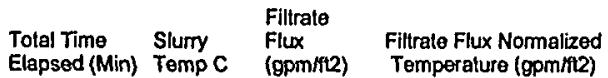

$\begin{array}{llll}0: 00 & 29.6 & 0.0354 & 0.0312 \\ 0: 10 & 29.3 & 0.0192 & 0.0170 \\ 0: 20 & 29.3 & 0.0171 & 0.0152\end{array}$

$\begin{array}{llll}0: 20 & 29.3 & 0.0171 & 0.0152 \\ 0: 30 & 29.3 & 0.0166 & 0.0147\end{array}$

$\begin{array}{llll}0.00 & 29.6 & 0.0607 & 0.0534\end{array}$

$\begin{array}{llll}0: 10 & 29.6 & 0.0197 & 0.0534 \\ 0.20 & 29.3 & 0.0211 & 0.0173\end{array}$

$\begin{array}{llll}0: 20 & 29.3 & 0.0211 & 0.0187 \\ 0: 30 & 29.3 & 0.0177 & 0.0157\end{array}$

0.0156 


\section{Condition 10}

C-106 Waste and C-106 Simulant

Filtrate Flux vs. Time

at Target Conditions of $27.0 \mathrm{psig}$ and $7.5 \mathrm{ft} / \mathrm{s}$

(1 Hour Tests Backpulsed Once After 30 Min)

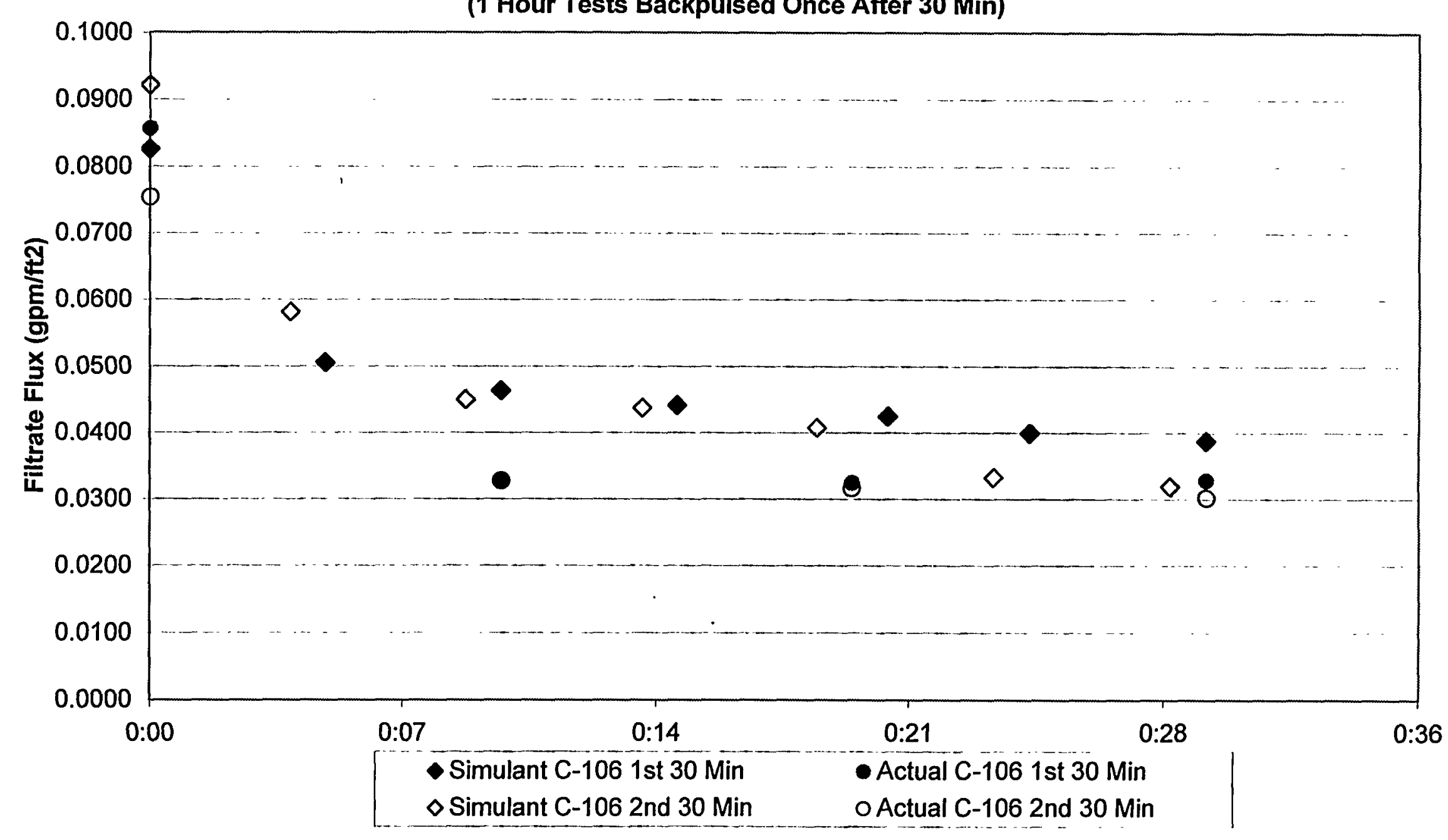




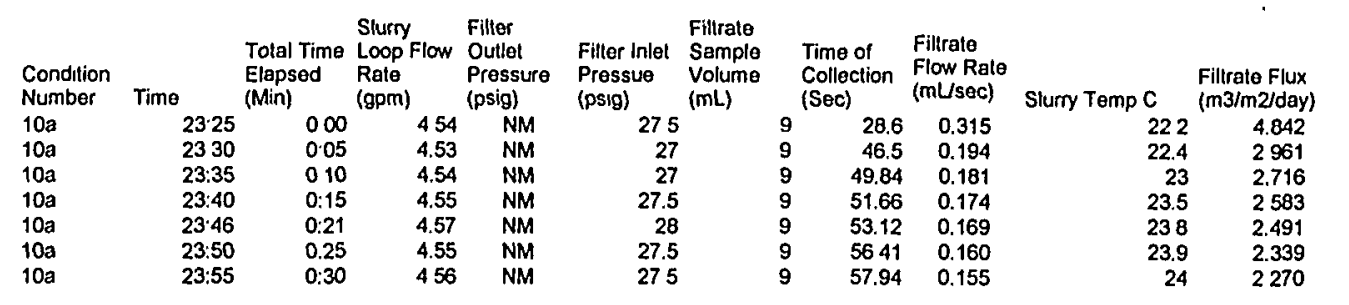
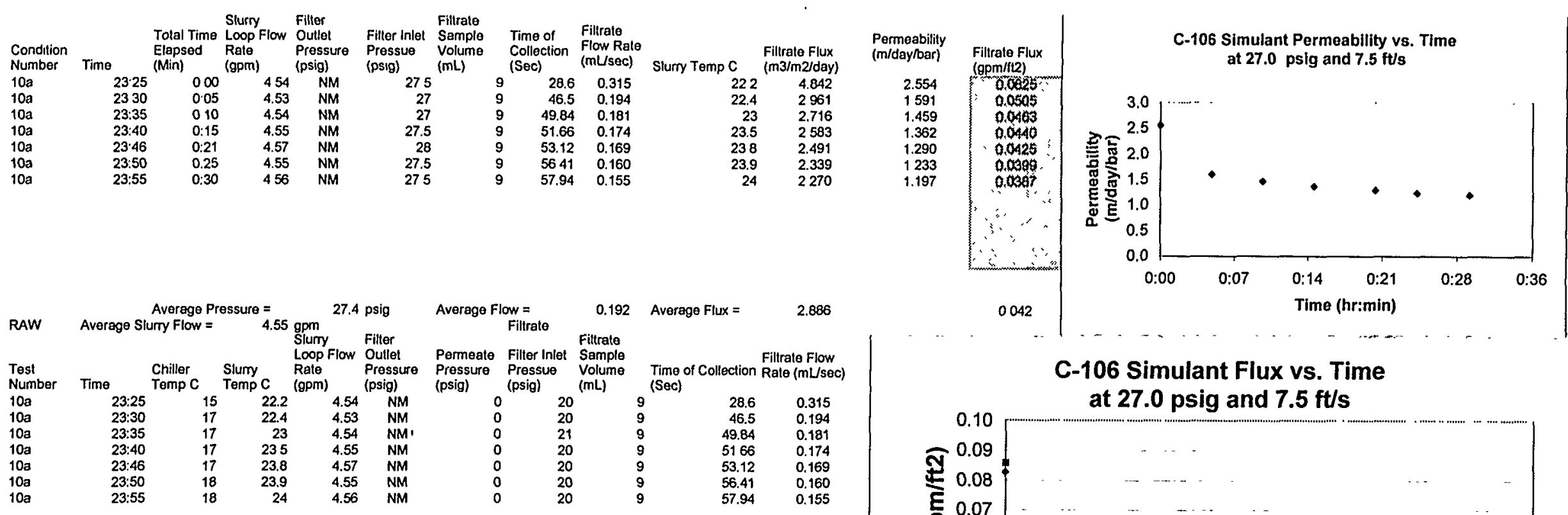

$\mathrm{NM}=$ Nol Measure 57.94
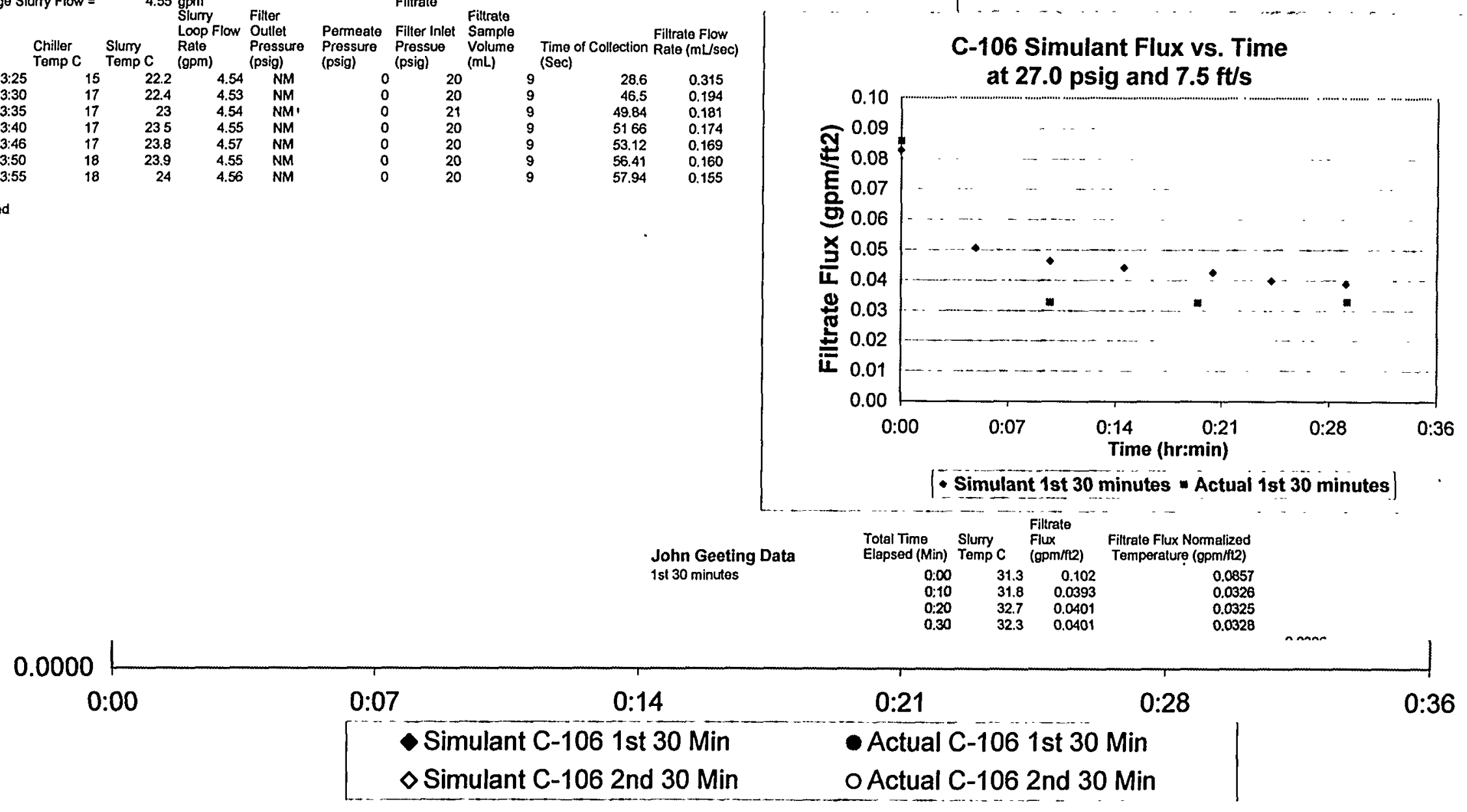


\begin{tabular}{|c|c|c|c|c|c|c|}
\hline $\begin{array}{l}\text { Condition } \\
\text { Number }\end{array}$ & Time & $\begin{array}{l}\text { Total Time } \\
\text { Elapsed } \\
\text { (Min) }\end{array}$ & $\begin{array}{l}\text { Shurry } \\
\text { Loop Flow } \\
\text { Rate } \\
\text { (gom) }\end{array}$ & $\begin{array}{l}\text { Filter } \\
\text { Outlet } \\
\text { Pressure } \\
\text { (psig) }\end{array}$ & $\begin{array}{l}\text { Filter Inlet } \\
\text { Pressuue } \\
\text { (psig) }\end{array}$ & $\begin{array}{l}\text { Fittrate } \\
\text { Sample } \\
\text { Volume } \\
\text { (mL) }\end{array}$ \\
\hline 100 & 14:11 & 0.00 & 3.67 & & & \\
\hline 100 & 14:15 & 0.04 & 3.74 & NM & 20 & \\
\hline $10 b$ & $14: 20$ & $0: 09$ & 3.7 & NM & 21 & \\
\hline 100 & $14: 25$ & $0: 14$ & 3.63 & NM & 20 & \\
\hline $10 \mathrm{~b}$ & 14:30 & 0:19 & 3.66 & NM & 20 & \\
\hline & 14:35 & $0: 24$ & 3.69 & NM & 20 & \\
\hline $10 b$ & $14: 40$ & $0: 29$ & 3.69 & NM & 20 & \\
\hline
\end{tabular}

\begin{tabular}{|c|c|c|}
\hline \multicolumn{2}{|c|}{$\begin{array}{l}\text { Time of } \\
\text { Collection } \\
\text { (Sec) }\end{array}$} & $\begin{array}{l}\text { Filtrale } \\
\text { Fiow Rate } \\
\text { (mL/sec) }\end{array}$ \\
\hline & & 0.404 \\
\hline & & 0.243 \\
\hline & 49.78 & 0.181 \\
\hline & 52.34 & 0.172 \\
\hline & 56.56 & 0.159 \\
\hline & 68.53 & 0.131 \\
\hline & 70.87 & 0.127 \\
\hline
\end{tabular}

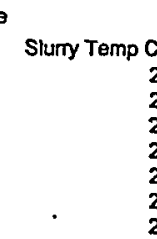

$\begin{array}{lr} & \\ & \text { Filtrale Flux } \\ \text { C } & \text { (m3/m2/day) } \\ 27.2 & 5.405 \\ 25.4 & 3.408 \\ 24.1 & 2.635 \\ 23.3 & 2.564 \\ 23.1 & 2.386 \\ 23.5 & 1.947 \\ 237 & 1.872\end{array}$

\begin{tabular}{c} 
Permaabiltty \\
(m/day/bar) \\
3.920 \\
2.472 \\
1.820 \\
1.859 \\
1.730 \\
1.412 \\
1.358 \\
\hline
\end{tabular}
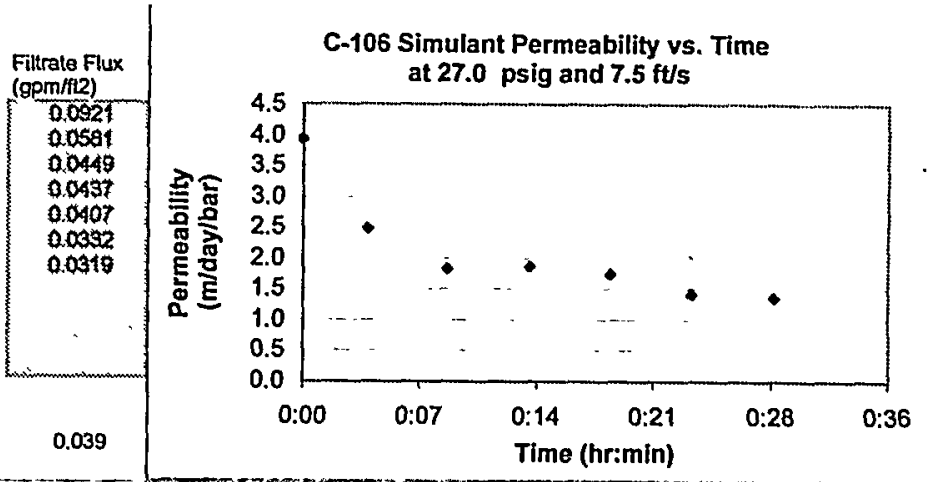

\begin{tabular}{|c|c|c|c|c|c|c|c|}
\hline & \multicolumn{4}{|c|}{ Average Pressure $=$} & \multicolumn{3}{|c|}{20.1 psig } \\
\hline & Average Sit & uny flow & & $3.68 \mathrm{~g}$ & & & \\
\hline $\begin{array}{l}\text { Test } \\
\text { Number }\end{array}$ & Time & $\begin{array}{l}\text { Chiller } \\
\text { Temp C }\end{array}$ & $\begin{array}{l}\text { Slumy } \\
\text { Temp C }\end{array}$ & & $\begin{array}{l}\text { Rate } \\
\text { (gpm) }\end{array}$ & & $\begin{array}{l}\text { ressur } \\
\text { rsig) }\end{array}$ \\
\hline & 14:11 & & & $27.2^{\circ}$ & & & \\
\hline & $14: 15$ & & & 25.4 & & 74 & NM \\
\hline $\mathbf{b}$ & $14: 20$ & & & 24. & & 3.7 & NM \\
\hline & $14: 2$ & & & & & & \\
\hline & 14: & & & & & & \\
\hline o & 14:35 & & & 23.5 & & & NM \\
\hline & & & & & & & \\
\hline
\end{tabular}

$\begin{array}{cr}\text { Average Flow }= & 0.20 \\ \text { Filtrate } & \text { Filtrate }\end{array}$

2.886

0.039 Time (hr:min)

Pressure Pressue Volume Time of Collection Rate (mLsec)

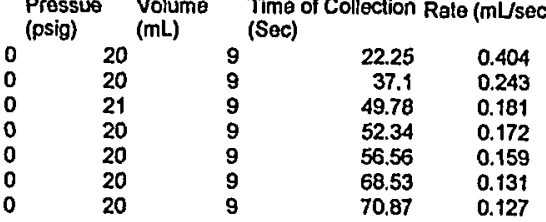

NM = Not Measured

68.53

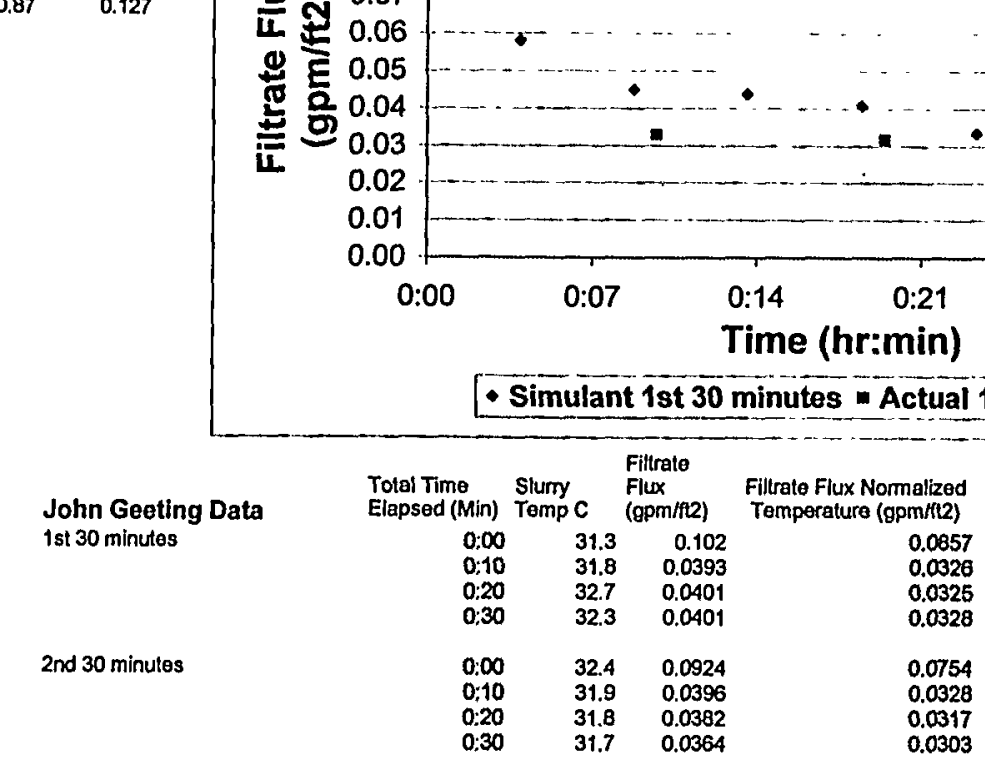




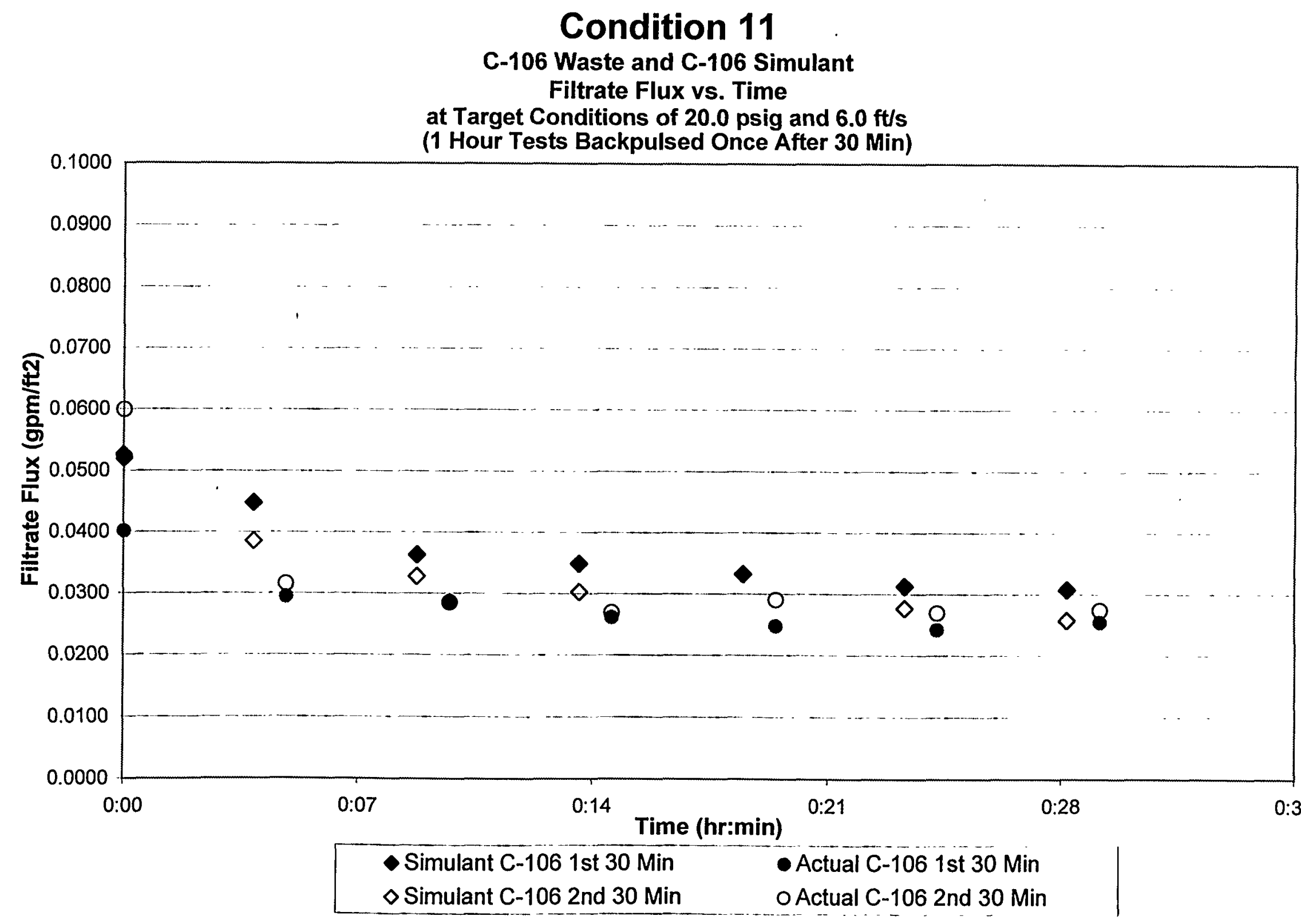




\begin{tabular}{|c|c|c|c|c|c|c|c|c|c|c|}
\hline $\begin{array}{l}\text { Condition } \\
\text { Number }\end{array}$ & Time & $\begin{array}{l}\text { Total Time } \\
\text { Elapsed } \\
\text { (Min) }\end{array}$ & $\begin{array}{l}\text { Slury } \\
\text { Loop Fiow } \\
\text { Rate } \\
\text { (gpm) }\end{array}$ & $\begin{array}{l}\text { Filter } \\
\text { Outlet } \\
\text { Pressure } \\
\text { (psig) }\end{array}$ & $\begin{array}{l}\text { Filler Inlet } \\
\text { Pressue } \\
\text { (psig) }\end{array}$ & $\begin{array}{l}\text { Filtrate } \\
\text { Sample } \\
\text { Volume } \\
\text { (mL) }\end{array}$ & $\begin{array}{l}\text { Time of } \\
\text { Collection } \\
\text { (Sec) }\end{array}$ & $\begin{array}{l}\text { Filtrate } \\
\text { Flow Rate } \\
\text { (mL/sec) }\end{array}$ & Slurry Temp C & $\begin{array}{l}\text { Filtrate Flux } \\
\text { (m3/m2/day) }\end{array}$ \\
\hline $11 a$ & 14:11 & 0.00 & $\quad 3.72$ & NM & 20 & & $9 \quad 43.16$ & 0.209 & 24 & 3.048 \\
\hline 11a & $14: 15$ & 0.04 & 368 & NM & 20 & & 50.12 & 0.180 & 24 & 2.625 \\
\hline 119 & $14: 20$ & 0.09 & 3.66 & NM & 21 & & 61.16 & 0.147 & 24.4 & 2.127 \\
\hline $11 a$ & $14: 25$ & $0: 14$ & 3.68 & NM & 20 & & 63.6 & 0.142 & 24.4 & 2.045 \\
\hline $11 \mathrm{a}$ & $14: 30$ & $0: 19$ & 3.69 & NM & 20 & & 66.34 & 0.136 & 24.6 & 1.950 \\
\hline $11 a$ & $14: 35$ & $0: 24$ & 3.67 & NM & 20 & & 69.6 & 0.129 & 25.1 & 1.832 \\
\hline 11a & $14: 40$ & $0: 29$ & 3.7 & NM & 20 & & 70.81 & 0.127 & 25.1 & 1.801 \\
\hline
\end{tabular}

\begin{tabular}{|c|c|}
\hline $\begin{array}{l}\text { Permeabilty } \\
\text { (m/day/bar) }\end{array}$ & Filtrate Flux \\
\hline 2.210 & 0.0520 \\
\hline 1.903 & 0.0447 \\
\hline 1.469 & 0.0063 \\
\hline 1.483 & 0.0349 \\
\hline 1.414 & 0,0392 \\
\hline 1.329 & 0.0342 \\
\hline 1.306 & 0.0307 \\
\hline & \\
\hline & \\
\hline
\end{tabular}
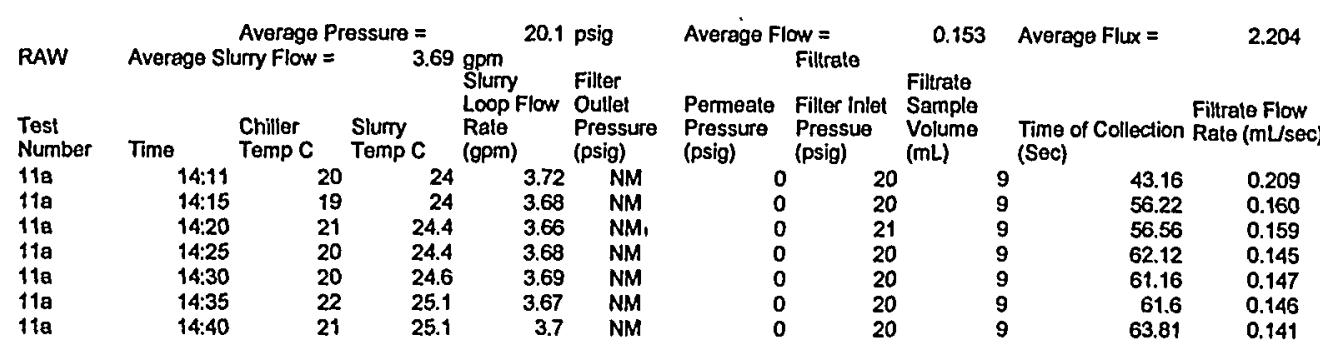

NM $=$ Nol Meesured

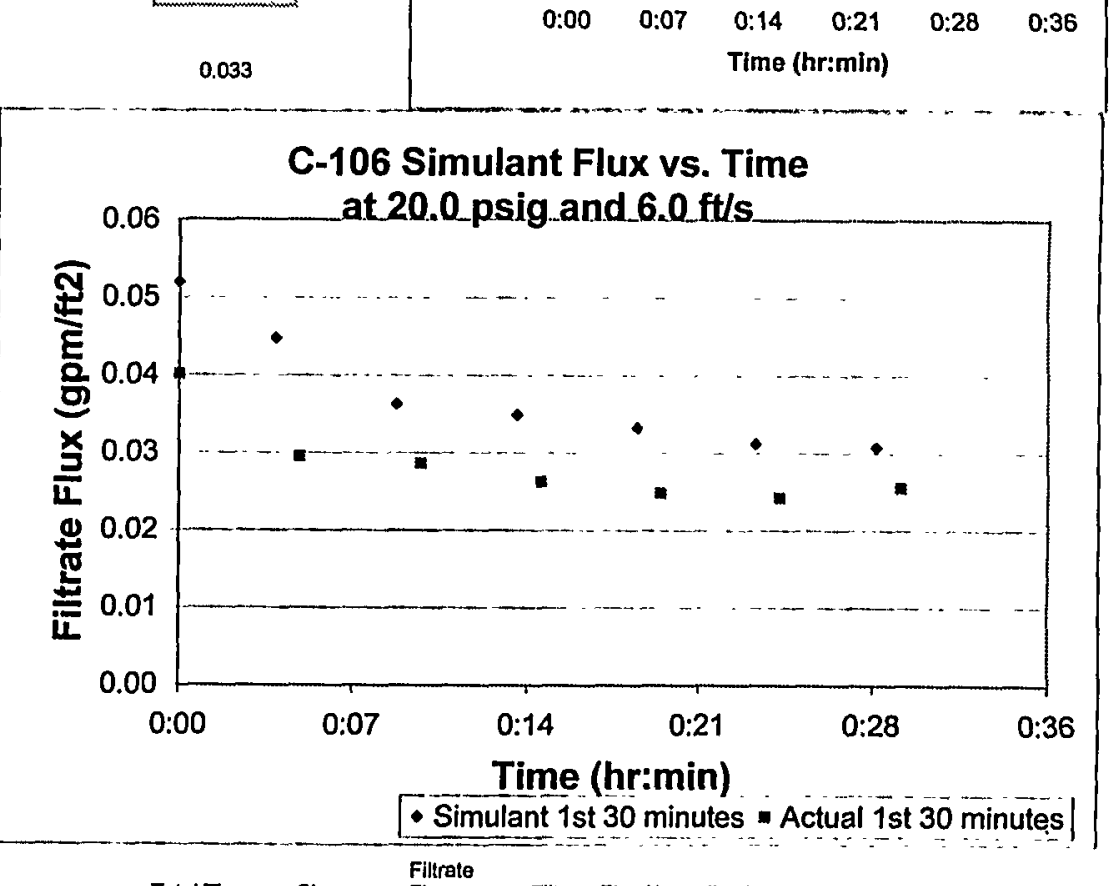

\begin{tabular}{|c|c|c|c|c|}
\hline John Geeting Data & $\begin{array}{l}\text { Total Time } \\
\text { Elapsed (Min) }\end{array}$ & $\begin{array}{l}\text { Slury } \\
\text { Temp C }\end{array}$ & $\begin{array}{l}\text { Filtrate } \\
\text { Flux } \\
\text { (gpm } f(12)\end{array}$ & $\begin{array}{l}\text { Filtrate Flux Normalized } \\
\text { Temperature (gpm/fitz) }\end{array}$ \\
\hline 1 st 30 minutes & $\begin{array}{l}0: 00 \\
0.05 \\
0: 10 \\
0: 15 \\
0: 20 \\
0: 25 \\
0: 30\end{array}$ & $\begin{array}{r}35 \\
33.8 \\
33.2 \\
33.1 \\
33 \\
32.9 \\
32.9\end{array}$ & $\begin{array}{l}0.0527 \\
0.0375 \\
0.0358 \\
0.0327 \\
0.0309 \\
0.0301 \\
0.0317\end{array}$ & $\begin{array}{l}0.0401 \\
0.0295 \\
0.0286 \\
0.0262 \\
0.0248 \\
0.0242 \\
0.0255\end{array}$ \\
\hline 2nd 30 minutes & $\begin{array}{l}0: 00 \\
0.05 \\
0: 10 \\
0: 15 \\
0: 20 \\
0: 25 \\
0: 30\end{array}$ & $\begin{array}{r}33.2 \\
33 \\
33.1 \\
32.9 \\
32.8 \\
33.4 \\
33.3\end{array}$ & $\begin{array}{r}0.075 \\
0.0393 \\
0.0356 \\
0.0335 \\
0.036 \\
0.0339 \\
0.0344\end{array}$ & $\begin{array}{l}0.0599 \\
0.0316 \\
0.0285 \\
0.0270 \\
0.0291 \\
0.0269 \\
0.0274\end{array}$ \\
\hline
\end{tabular}




\begin{tabular}{|c|c|c|c|c|c|c|c|c|c|c|c|}
\hline $\begin{array}{l}\text { Condition } \\
\text { Number }\end{array}$ & Time & $\begin{array}{l}\text { Total Time } \\
\text { Elapsed } \\
\text { (Min) }\end{array}$ & $\begin{array}{l}\text { Slurry } \\
\text { Loop Flow } \\
\text { Rate } \\
\text { (gpm) }\end{array}$ & $\begin{array}{l}\text { Filler } \\
\text { Oullet } \\
\text { Pressure } \\
\text { (psig) }\end{array}$ & $\begin{array}{l}\text { Filter Inlet } \\
\text { Pressue } \\
\text { (psig) }\end{array}$ & $\begin{array}{l}\text { Filtrate } \\
\text { Sample } \\
\text { Volume } \\
\text { (mL) }\end{array}$ & & $\begin{array}{l}\text { Time of } \\
\text { Collection } \\
\text { (Sec) }\end{array}$ & $\begin{array}{l}\text { Filltrale } \\
\text { Flow Rate } \\
\text { (mL/sec) }\end{array}$ & Slurry Temp C & $\begin{array}{l}\text { Filltrate Flux } \\
\text { (m3/m2/day) }\end{array}$ \\
\hline $11 \mathrm{~b}$ & $14: 11$ & 000 & 368 & NM & 20 & & 9 & 39 & 0231 & 272 & 3.084 \\
\hline $11 \mathrm{~b}$ & $14: 15$ & 0.04 & 369 & NM & 20 & & 9 & 55.97 & 0.161 & 254 & 2259 \\
\hline $11 \mathrm{~b}$ & $14 \cdot 20$ & 0.09 & 374 & NM & 21 & & 9 & 6829 & 0132 & 241 & 1921 \\
\hline $11 \mathrm{~b}$ & $14: 25$ & 0.14 & 37 & NM & 20 & & 9 & 75.63 & 0119 & 23.3 & 1.774 \\
\hline $1+b$ & $14: 35$ & $0: 24$ & 369 & NM & 20 & & 9 & 82.25 & 0.109 & 23.5 & 1.622 \\
\hline $11 \mathrm{~b}$ & $14: 40$ & $0: 29$ & 369 & NM & 20 & & 9 & 8797 & 0.102 & 23.7 & 1.508 \\
\hline
\end{tabular}

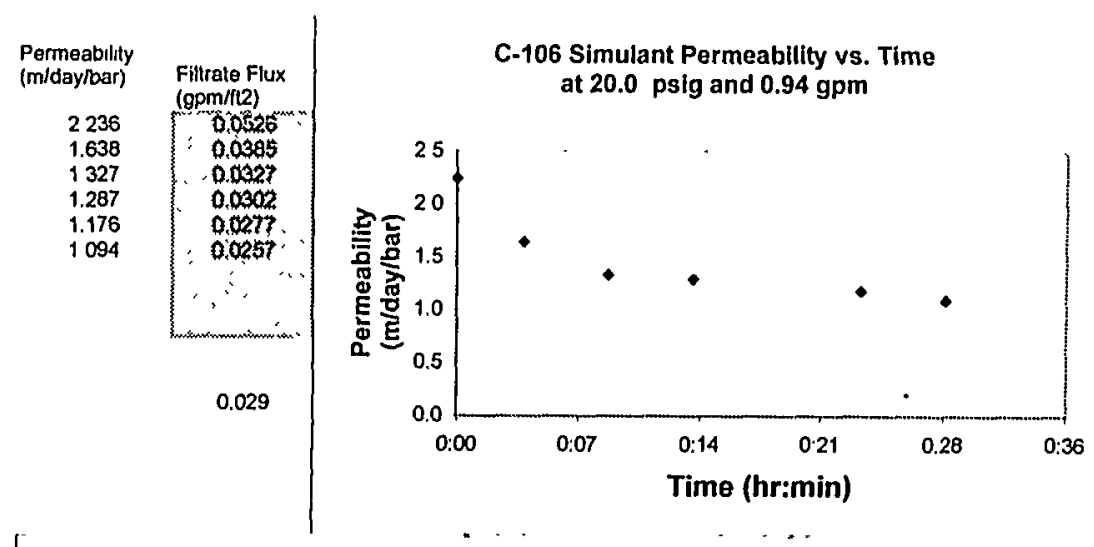

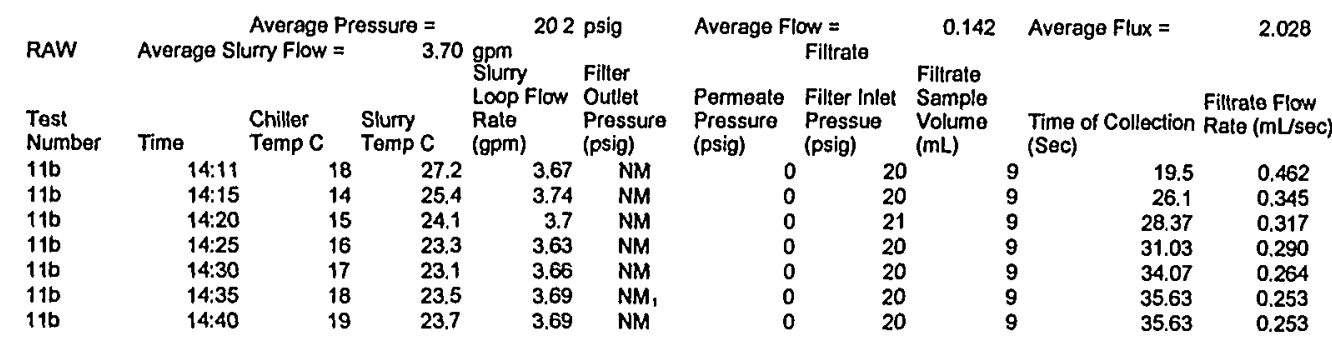

NM $=$ Not Measured

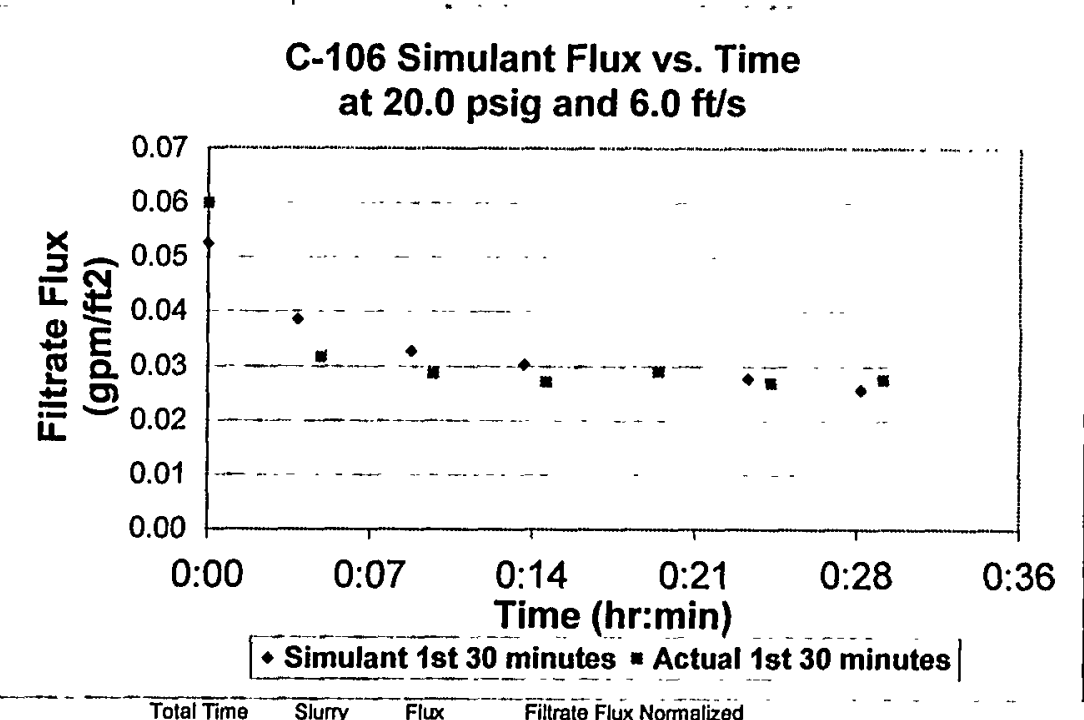

John Geeting Dats

$\begin{array}{lll}\text { Elapsed (Min) Temp C } & \begin{array}{l}\text { Flux } \\ \text { (gpminiz) }\end{array} & \text { Filtrate Flux Normalized } \\ \text { Temperature (gpm/fiz) }\end{array}$

$1 s t 30$ minutes

$\begin{array}{lrrl}0: 00 & 35 & 0.0527 & \\ 0: 05 & 33.8 & 0.0375 & 0.0401 \\ 0: 10 & 33.2 & 0.0358 & 0.0295 \\ 0: 15 & 33.1 & 0.0327 & 0.0286 \\ 0: 20 & 33 & 0.0309 & 0.0262 \\ 0: 25 & 32.9 & 0.0301 & 0.0248 \\ 0: 30 & 32.9 & 0.0317 & 0.0242 \\ & & 0.0255 \\ 0.00 & 33.2 & 0.075 & 0.0599 \\ 0: 05 & 33 & 0.0393 & 0.0316 \\ 0: 10 & 33.1 & 0.0356 & 0.0285 \\ 0: 15 & 32.9 & 0.0335 & 0.0270 \\ 0: 20 & 32.8 & 0.035 & 0.0291 \\ 0: 25 & 33.4 & 0.0339 & 0.0269 \\ 0.30 & 333 & 0.0344 & 0.0274\end{array}$




\title{
C-106 Filtration Simulant at 8 wt\% Solids Loading
}

\author{
$0.1 \mu \mathrm{m}$ Mott filter element
}




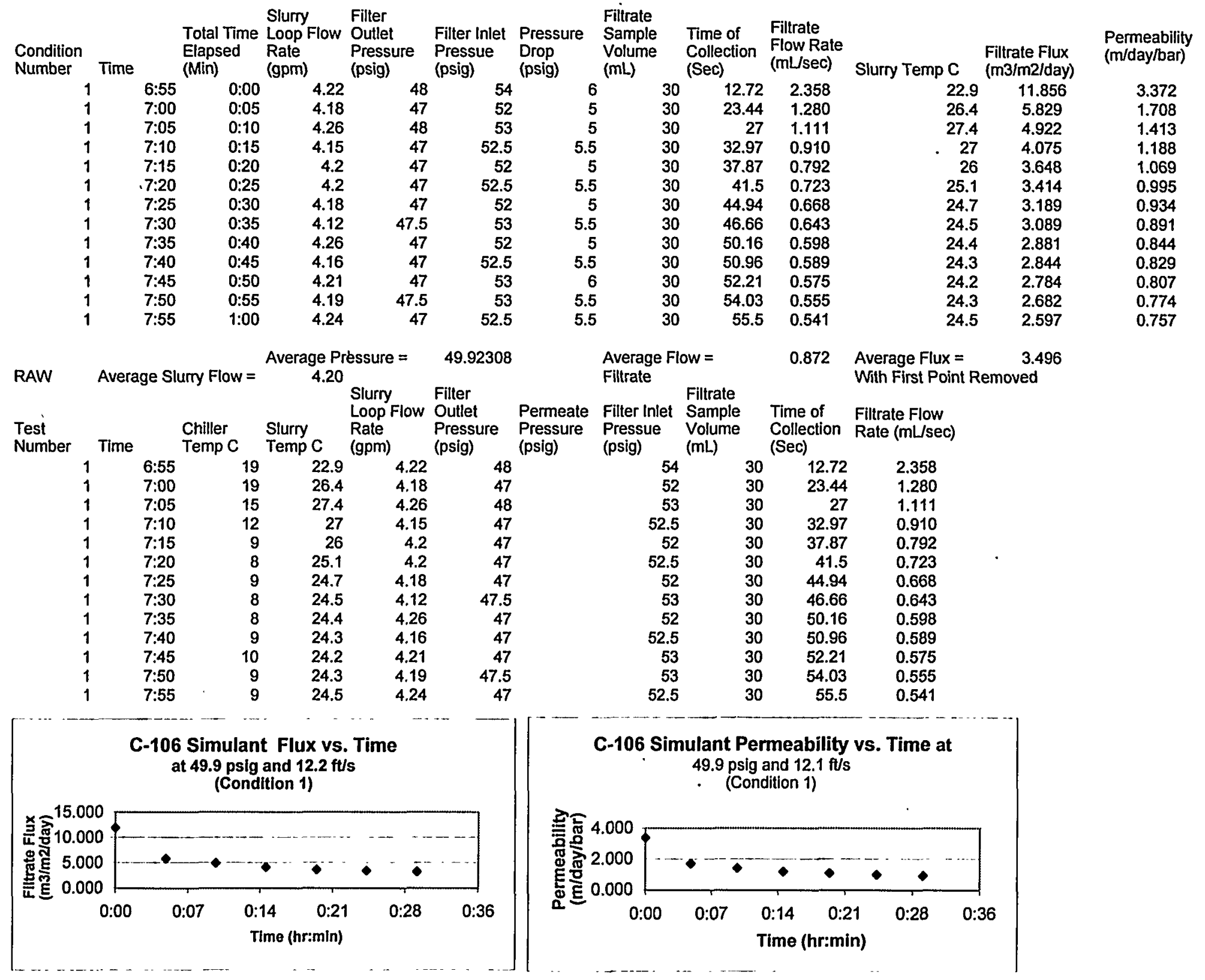




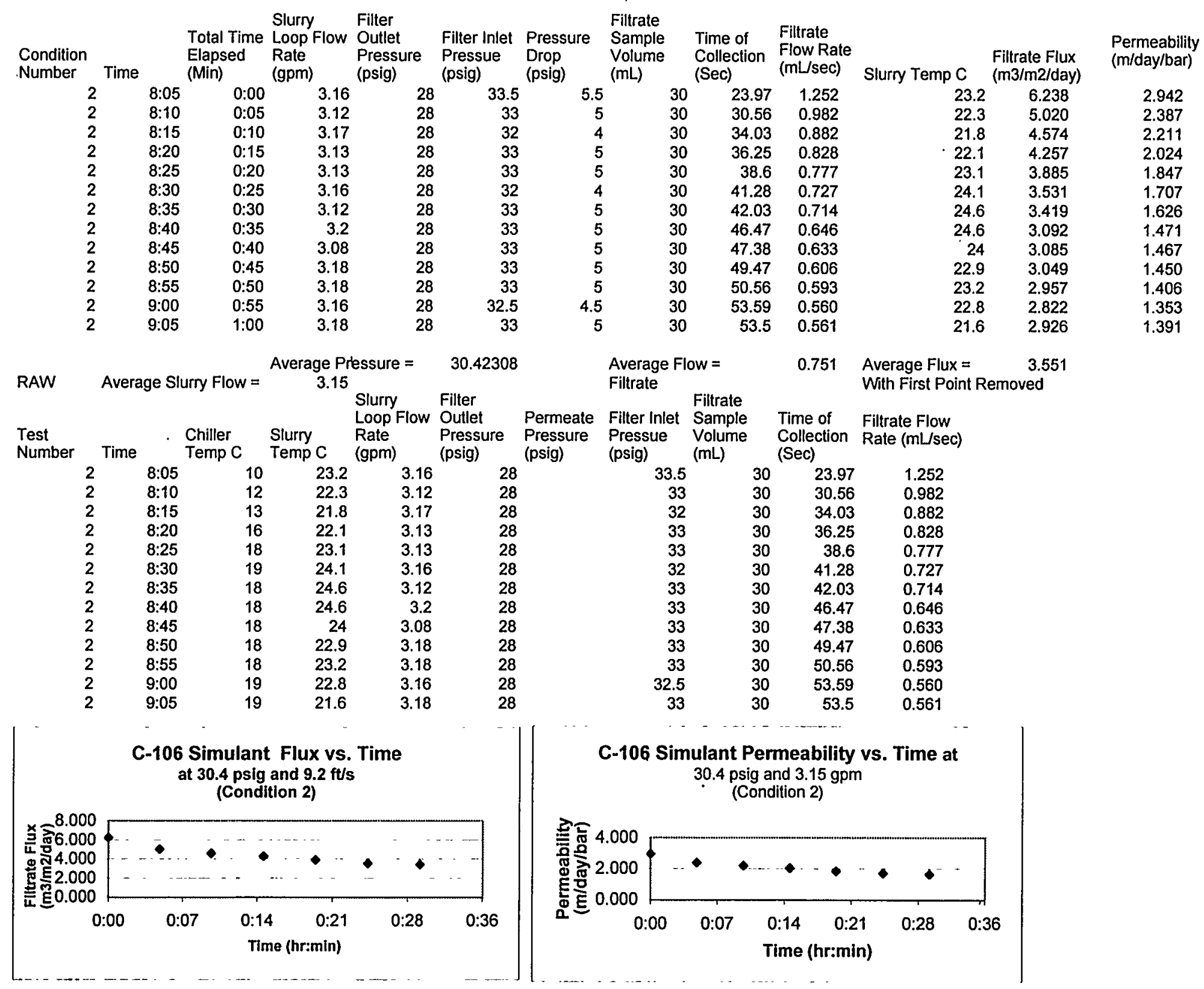




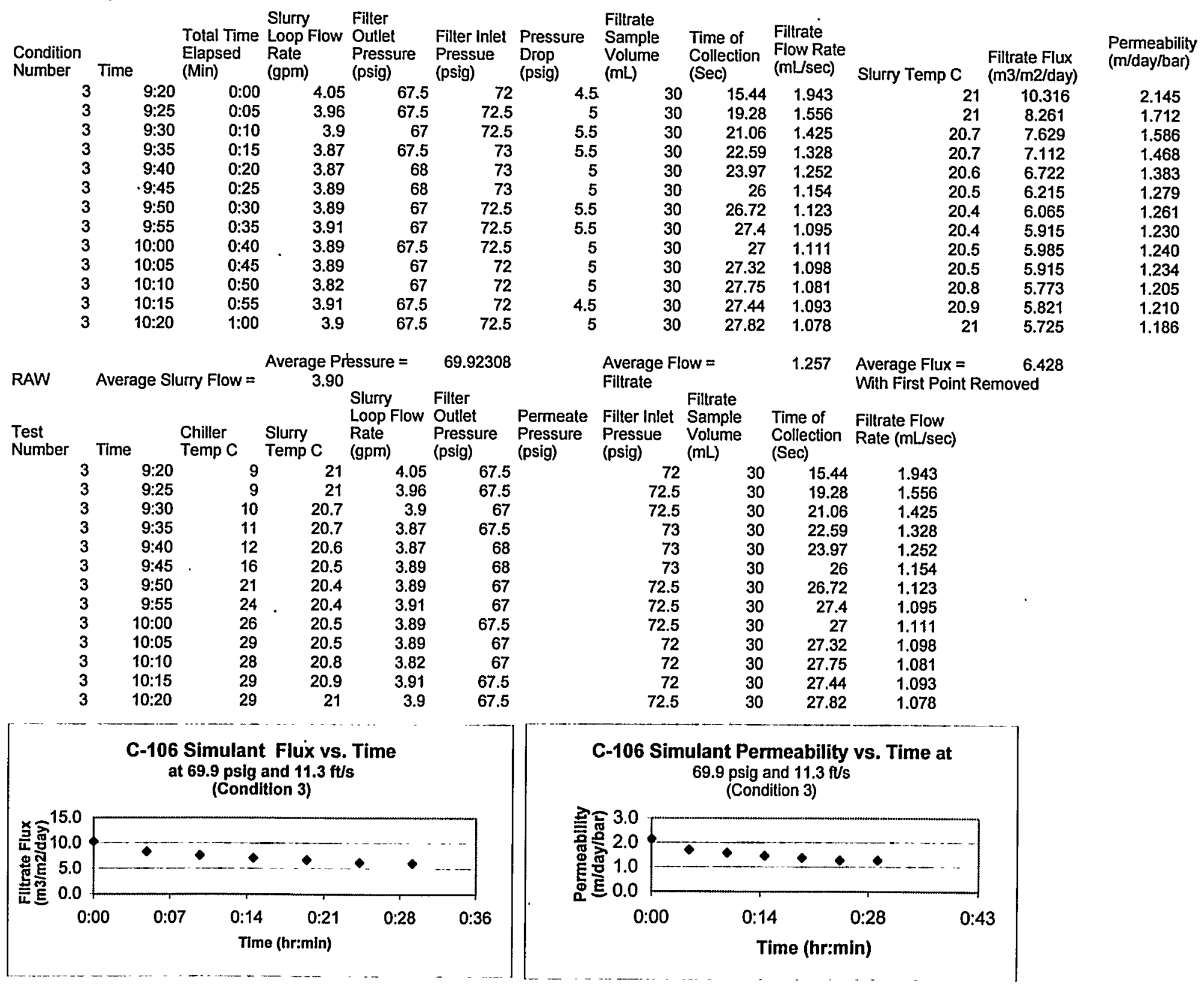




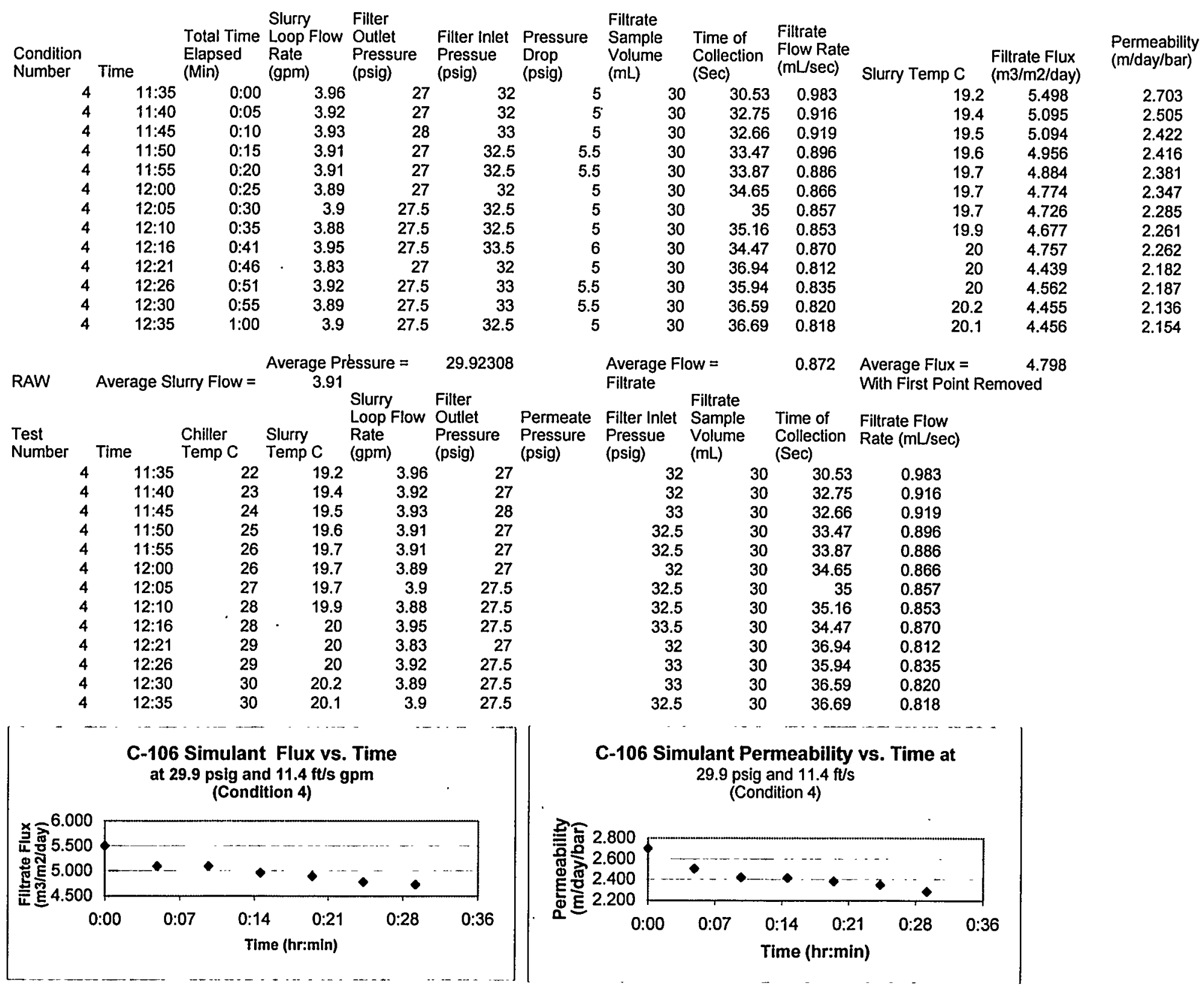




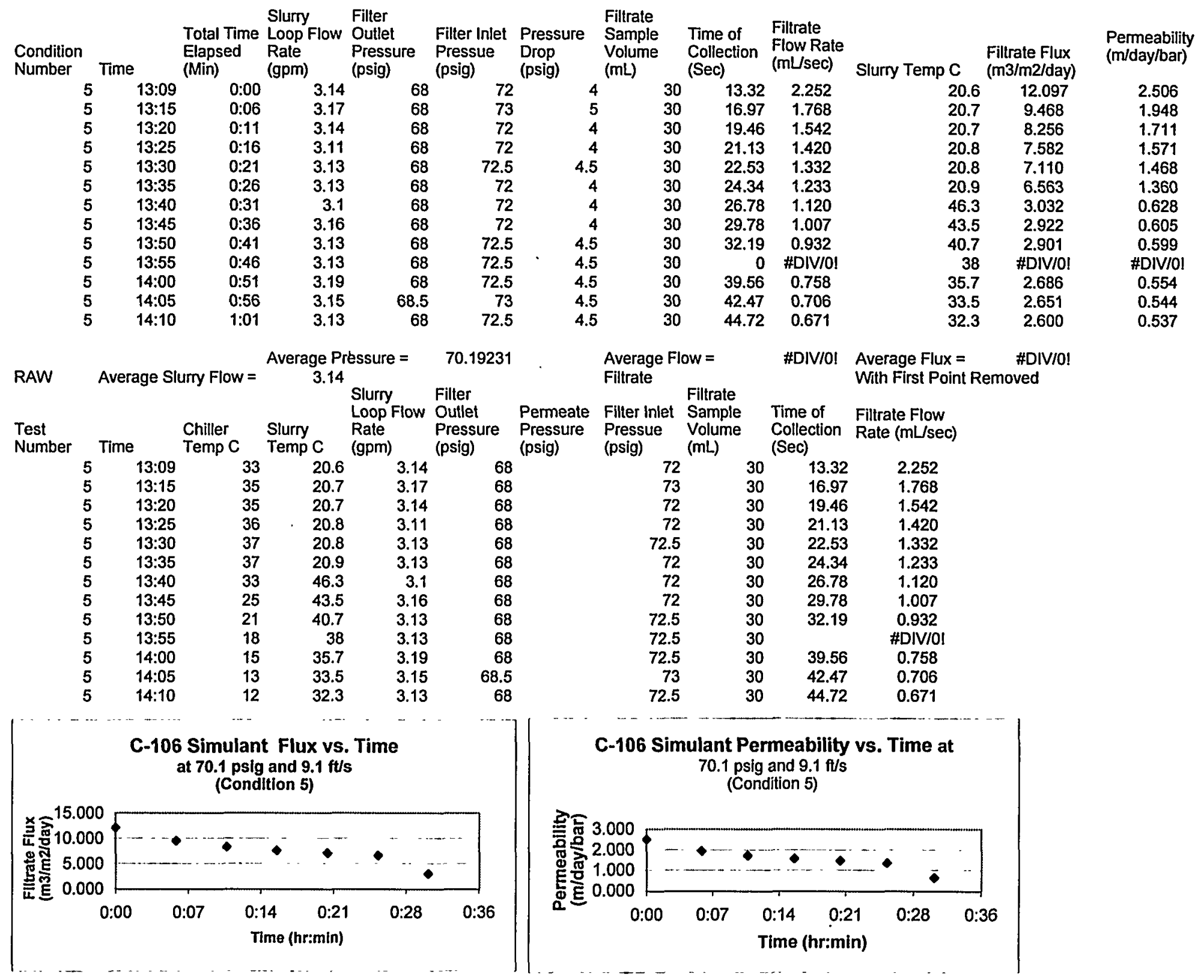




\begin{tabular}{|c|c|c|c|c|c|c|c|}
\hline $\begin{array}{l}\text { Condition } \\
\text { Number }\end{array}$ & Time & & $\begin{array}{l}\text { Total Time } \\
\text { Elapsed } \\
\text { (Min) }\end{array}$ & $\begin{array}{l}\text { Slurry } \\
\text { Loop Flow } \\
\text { Rate } \\
\text { (gpm) }\end{array}$ & $\begin{array}{l}\text { Filter } \\
\text { Outlet } \\
\text { Pressure } \\
\text { (psig) }\end{array}$ & $\begin{array}{l}\text { Filter Inlet } \\
\text { Pressue } \\
\text { (psig) }\end{array}$ & $\begin{array}{l}\text { Pressure } \\
\text { Drop } \\
\text { (psig) }\end{array}$ \\
\hline . & 6 & $2: 20$ & $0: 00$ & 4.24 & 47 & 53 & \\
\hline & 6 & $2: 25$ & $0: 05$ & 4.22 & 47 & 53 & \\
\hline & 6 & $2: 30$ & $0: 10$ & 4.17 & 46.5 & 53 & 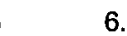 \\
\hline & 6 & $2: 35$ & $0: 15$ & 4.2 & 47 & 53 & \\
\hline & 6 & $2: 40$ & $0: 20$ & 4.22 & 47 & 53 & \\
\hline & 6 & $2: 46$ & $0: 26$ & 4.22 & 47 & 53 & \\
\hline & 6 & $2: 50$ & $0: 30$ & 4.15 & 46.5 & 52 & \\
\hline & 6 & $2: 56$ & $0: 36$ & 4.19 & 46.5 & 53 & \\
\hline & 6 & 3:00 & $0: 40$ & 4.17 & 47 & 53 & \\
\hline & 6 & 3:05 & $0: 45$ & 4.18 & 46.5 & 52.5 & \\
\hline & 6 & 3:10 & $0: 50$ & 4.2 & 47 & 53 & \\
\hline & 6 & $3: 15$ & $0: 55$ & 4.19 & 47 & 53 & \\
\hline & 6 & $3: 20$ & $1: 00$ & 4.19 & 47 & 53 & \\
\hline
\end{tabular}

Filtrate

Sample Time of Filtrate

$\begin{array}{lll}\text { Volume } & \text { Collection } & \begin{array}{l}\text { Flow Rate } \\ (\mathrm{mL} / \mathrm{sec})\end{array} \\ & (\mathrm{Sec}) & (\mathrm{s} / \mathrm{s})\end{array}$

Permeability

30

$21.56 \quad 1.391$ Slurry Temp C (m3/m2/day)

(m/day/bar)

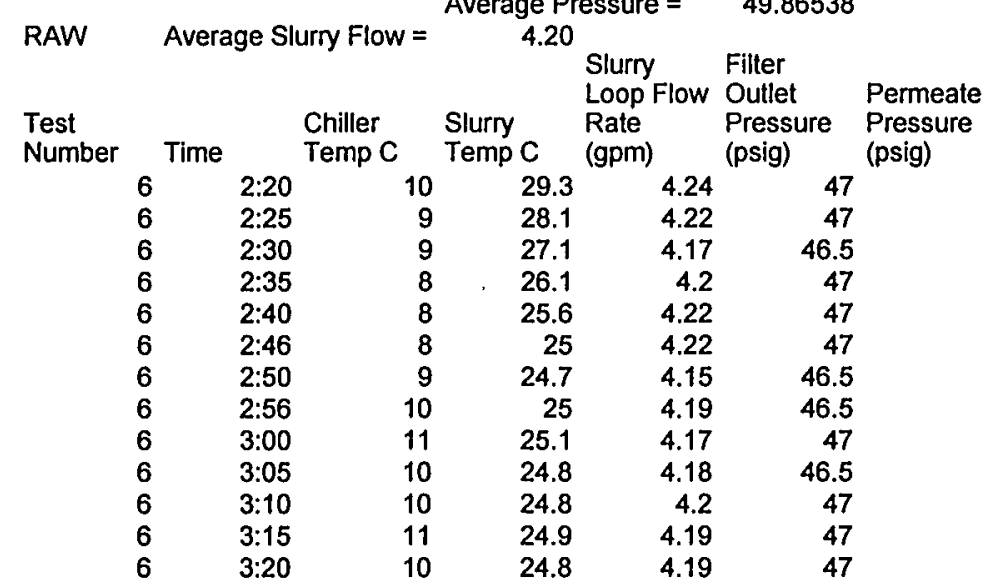

Average Flow $=$

Filltate

$24.53 \quad 1.223$

$26.1 \quad 1.149$

$\begin{array}{ll}27.81 & 1.079 \\ 28.87 & 1.039\end{array}$

$\begin{array}{ll}30.28 & 0.991\end{array}$

$31.78 \quad 0.944$

$31.81 \quad 0.943$

$32.72 \quad 0.917$

$34.25 \quad 0.876$

$34.56 \quad 0.868$

$35.66 \quad 0.841$

$\begin{array}{ll}28.1 & 5.313 \\ 27.1 & 5.134\end{array}$

$\begin{array}{ll}27.1 & 5.134 \\ 26.1 & 4.954\end{array}$

$\begin{array}{ll}26.1 & 4.954 \\ 25.6 & 4.840\end{array}$

$6 \quad 30$

30

$6 \quad 30$

$35.81 \quad 0.838$

$25 \quad 4.693$

$24.7 \quad 4.509$

4.467

$25.1 \quad 4.331$

$24.8 \quad 4.172$

$24.8 \quad 4.135$

$\begin{array}{ll}24.8 & 4.135 \\ 24.9 & 3.996\end{array}$

$24.8 \quad 3.990$

1.697

1.597

1.437

1.404

1.328

1.302

1.256

1.222

1.199

1.159
1.158

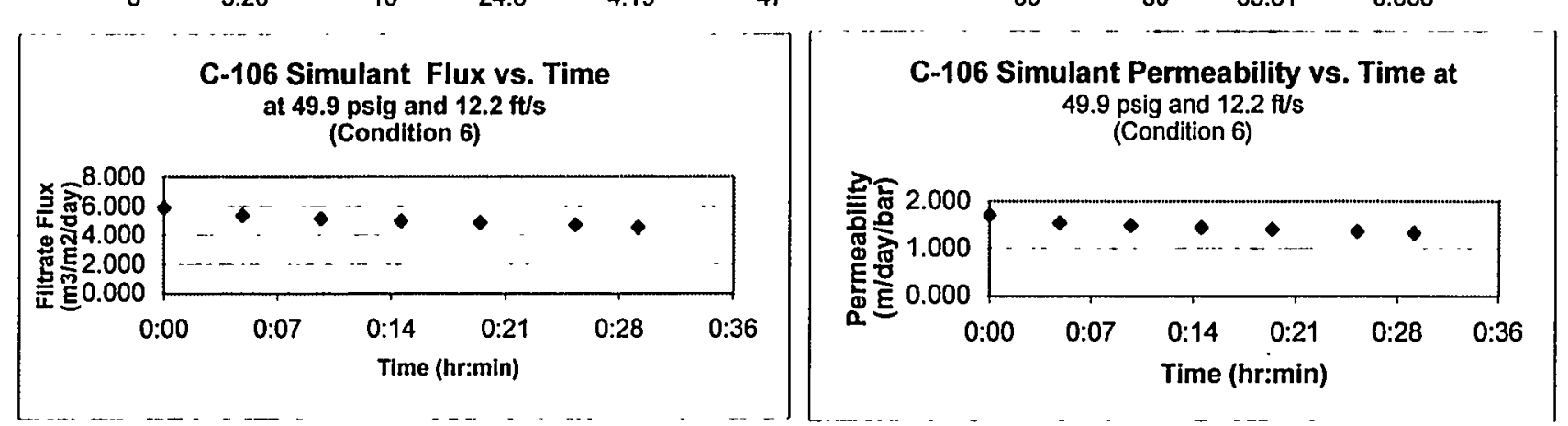




\title{
AZ-101/102 Filtration Simulant at 5 wt\% Solids Loading CUF Testing
}

\author{
0.1 $\mu \mathrm{m}$ Mott filter element
}




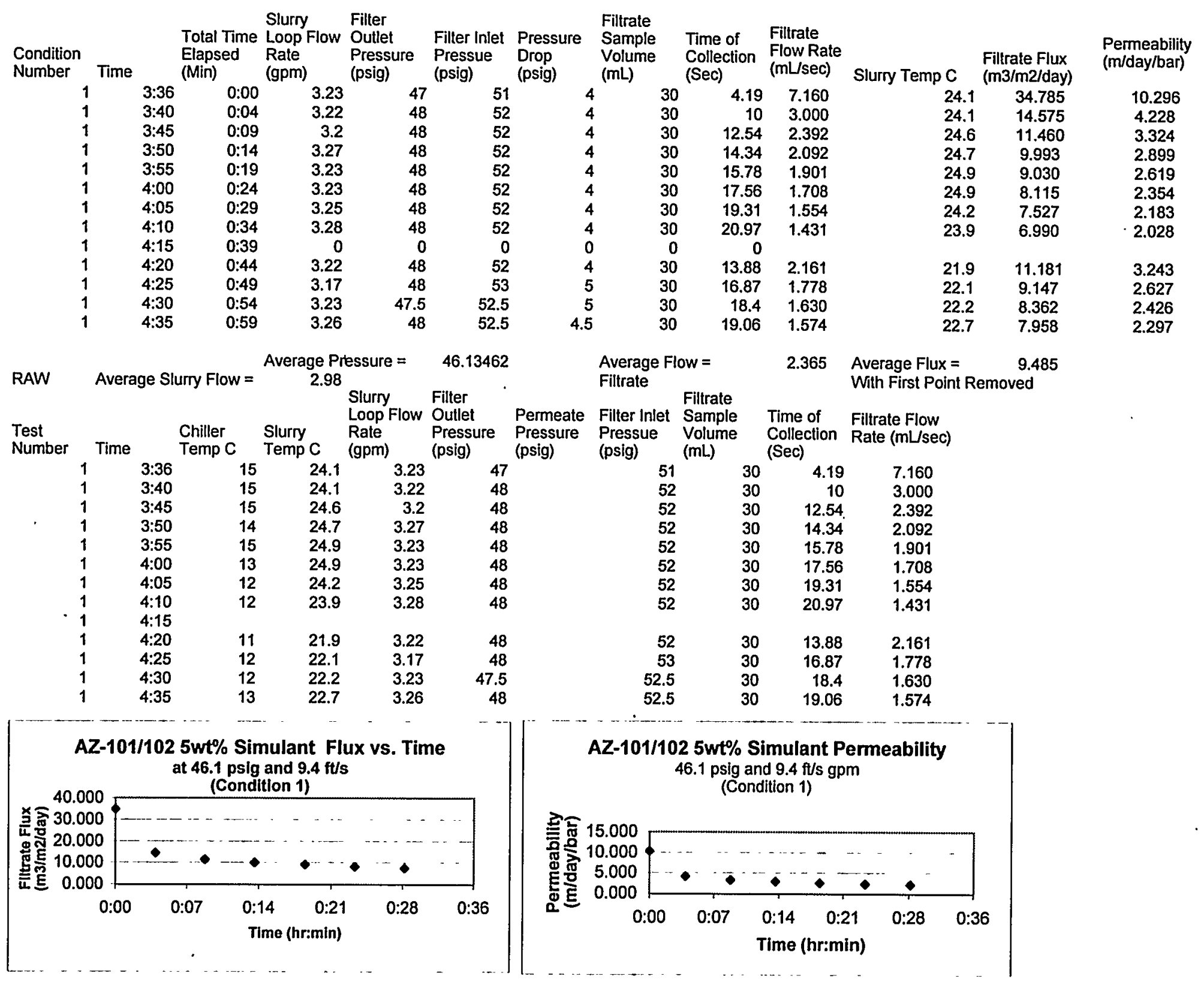




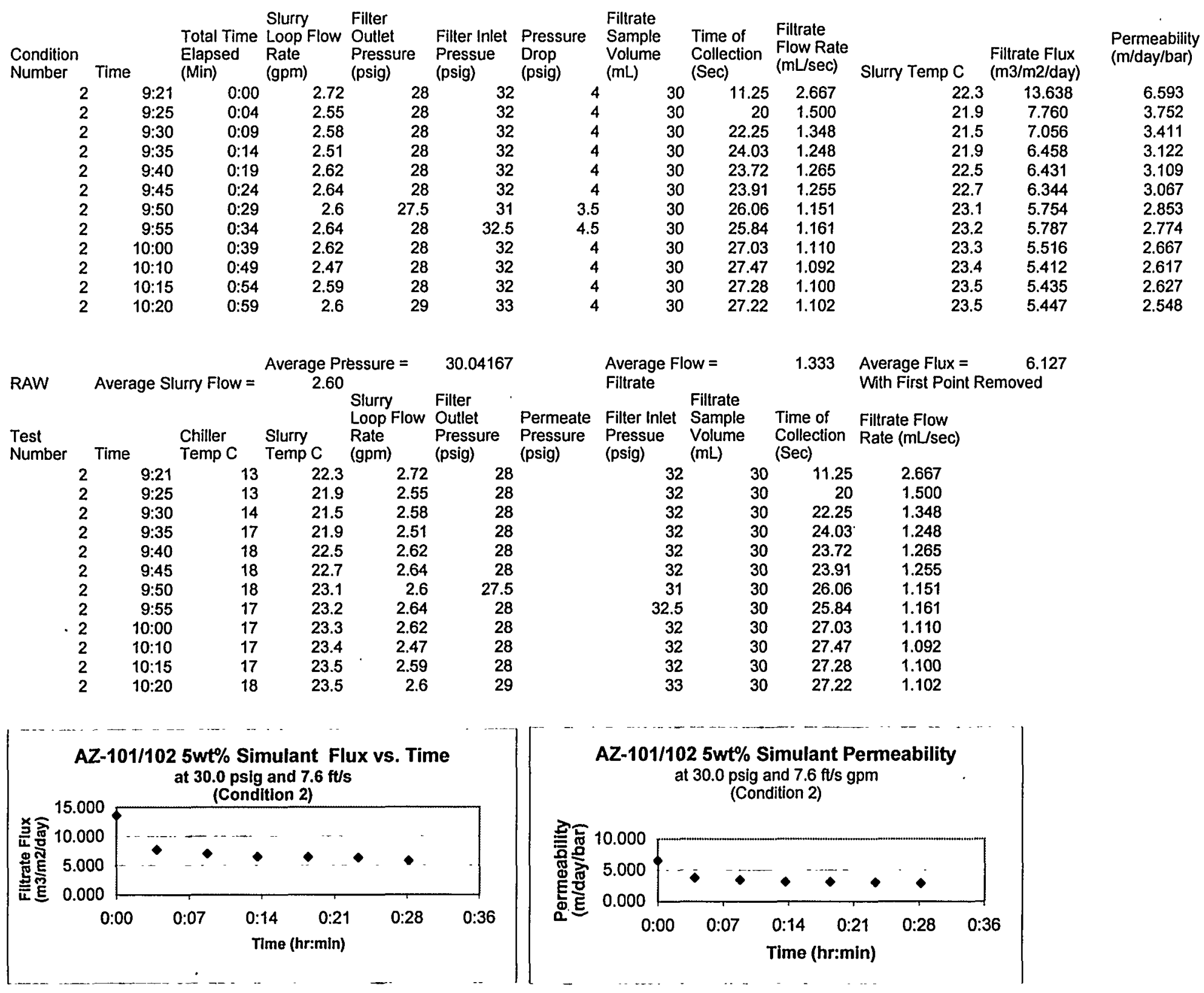




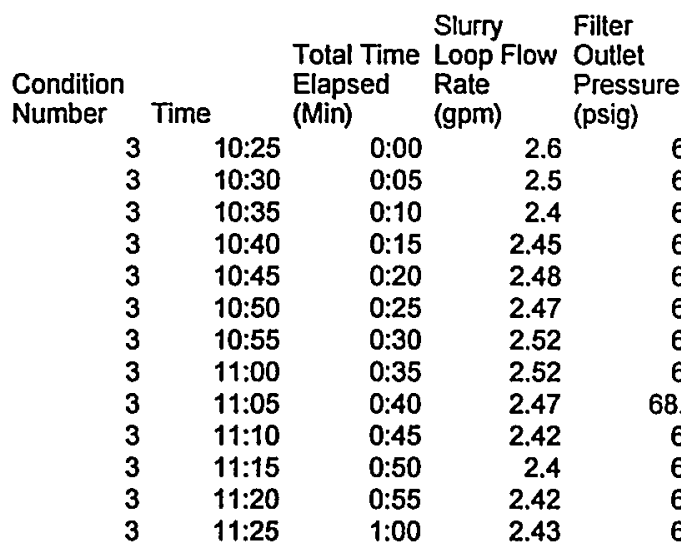

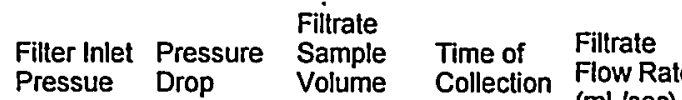
$\begin{array}{lrr}\text { (psig) }^{2} \text { (psig) } \\ 68 & 72 & 4 \\ 68 & 72 & 4 \\ 68 & 71.5 & 3.5 \\ 68 & 71.5 & 3.5 \\ 68 & 71.5 & 3.5 \\ 68 & 72 & 4 \\ 68 & 72 & 4 \\ 68 & 71.5 & 3.5 \\ 68 & 72 & 3.5 \\ 68 & 72 & 4 \\ 68 & 71 & 3 \\ 68 & 72 & 4 \\ 68 & 72 & 4\end{array}$ (mL) (Sec)

Fillrate Flux

Permeability

(m/day/bar)

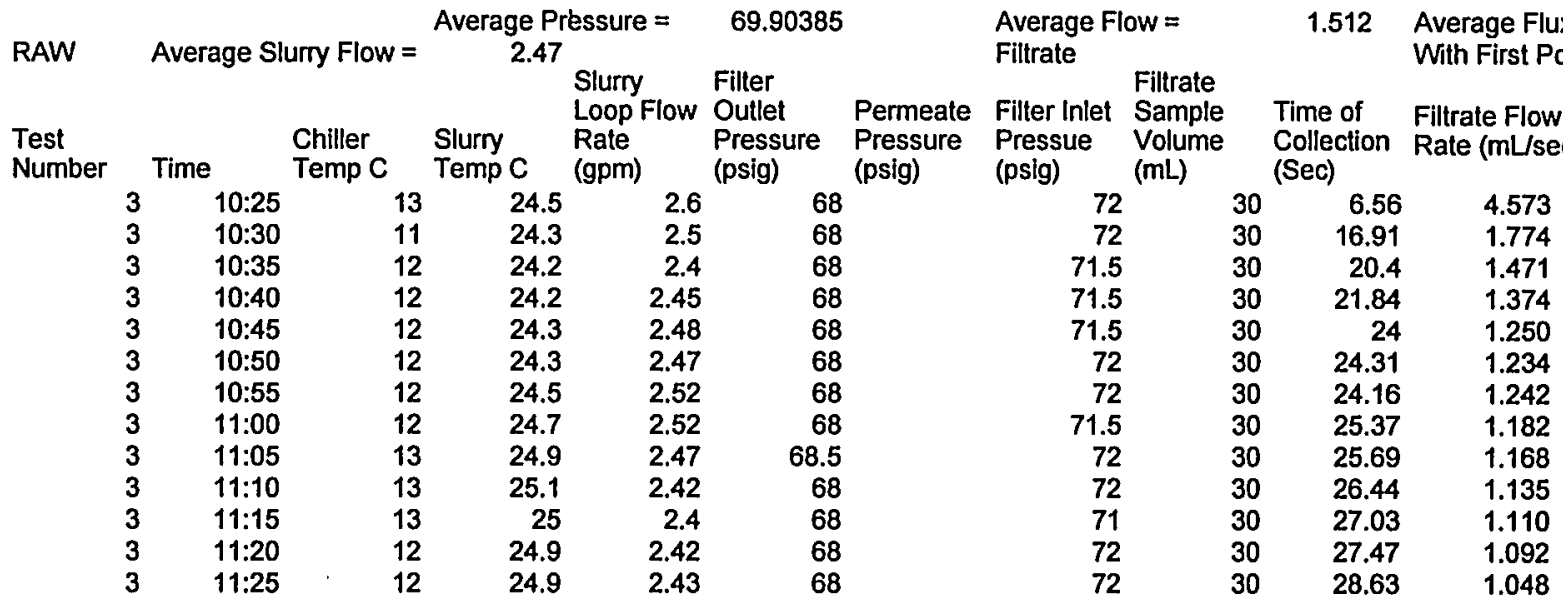

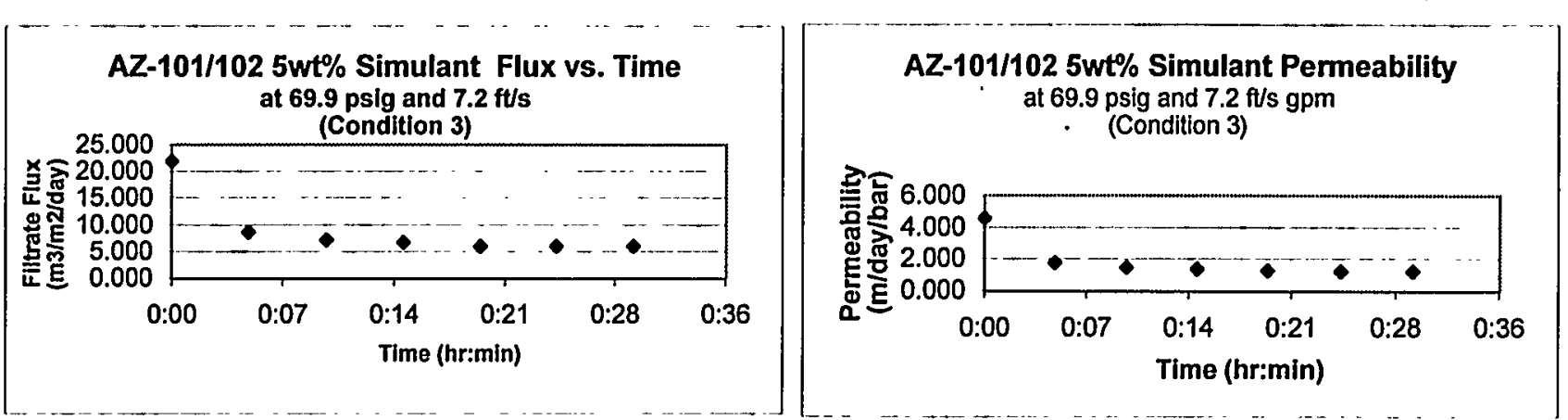




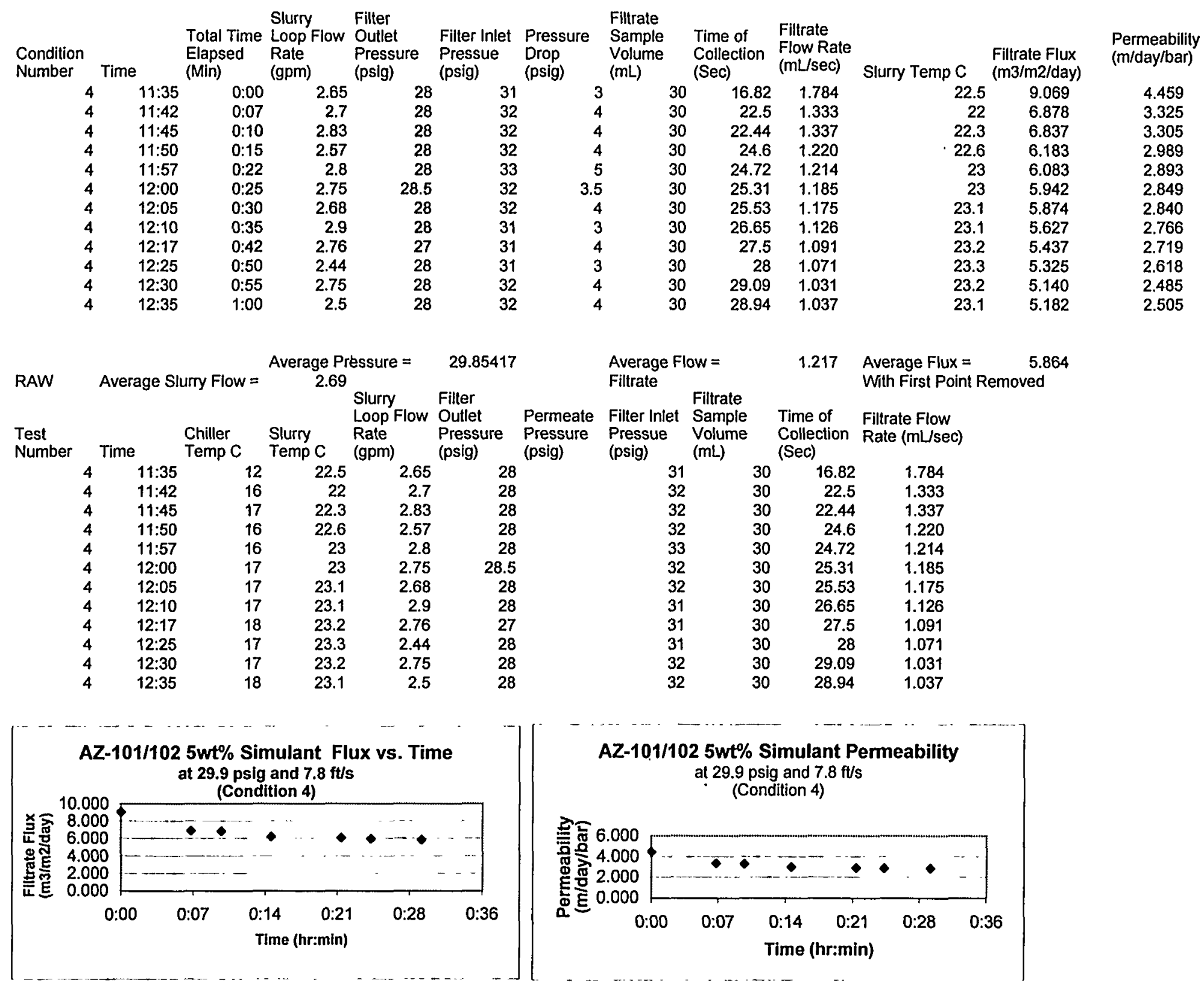




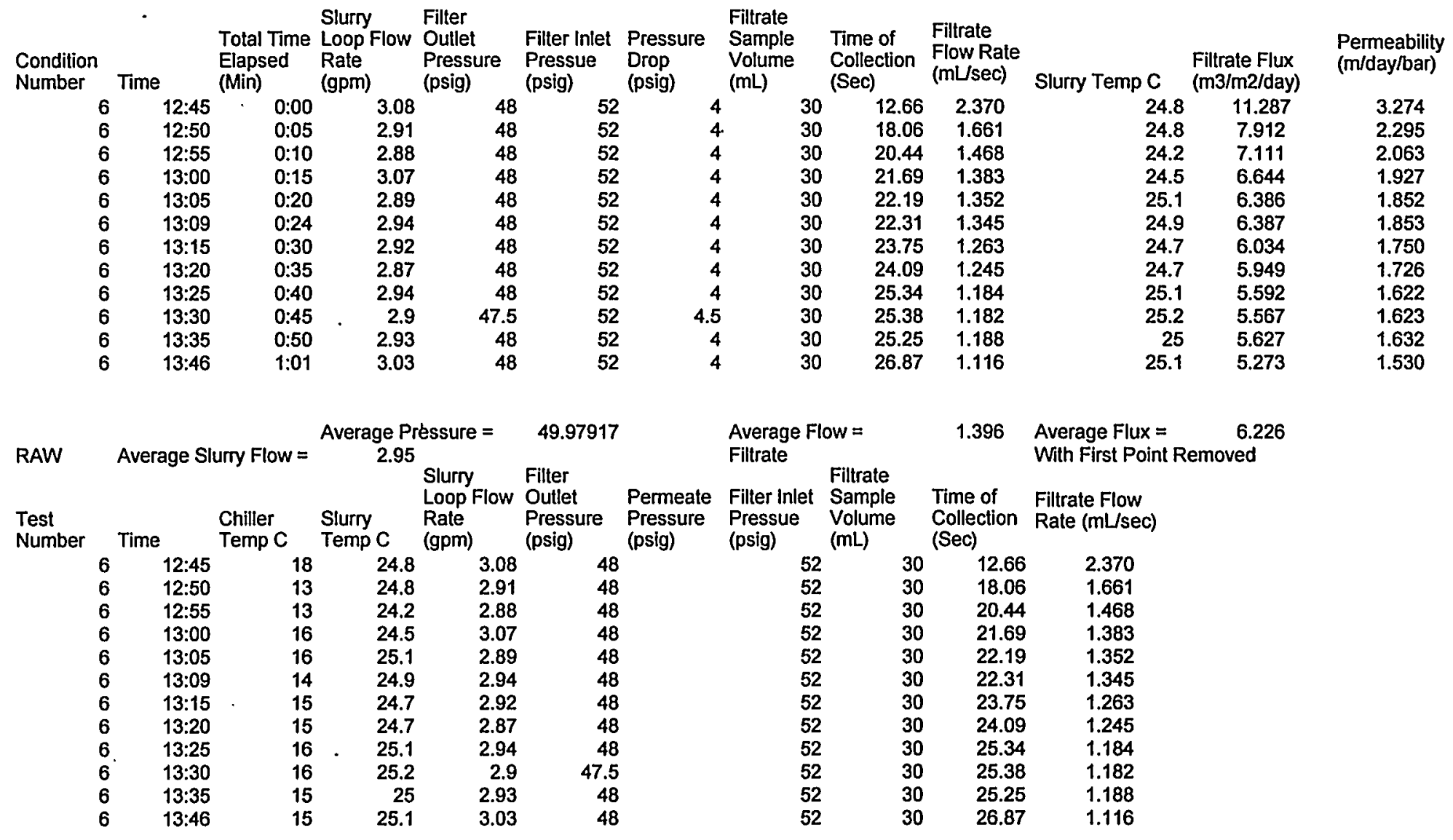
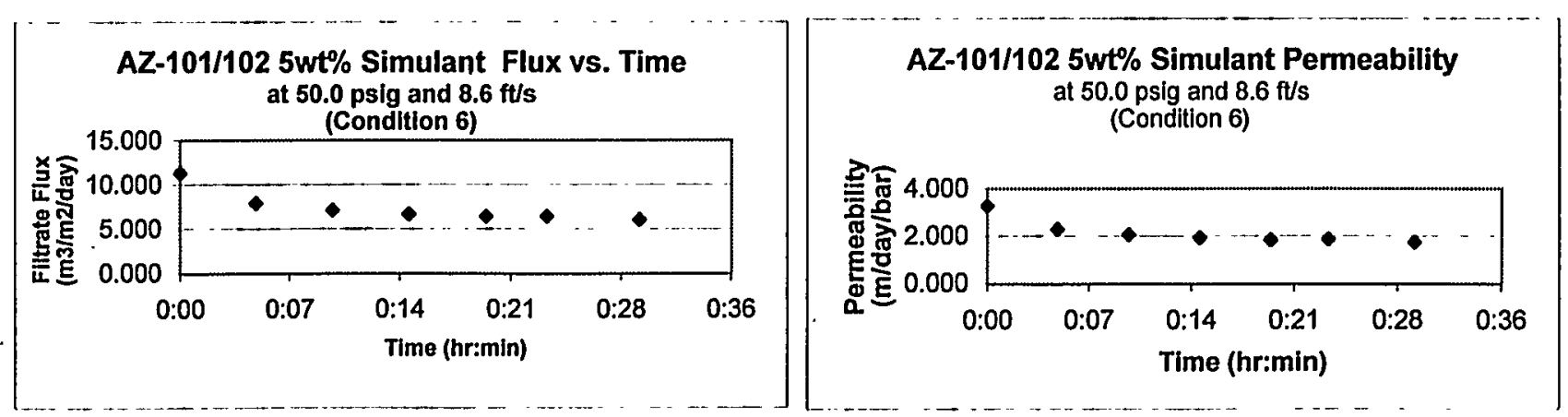


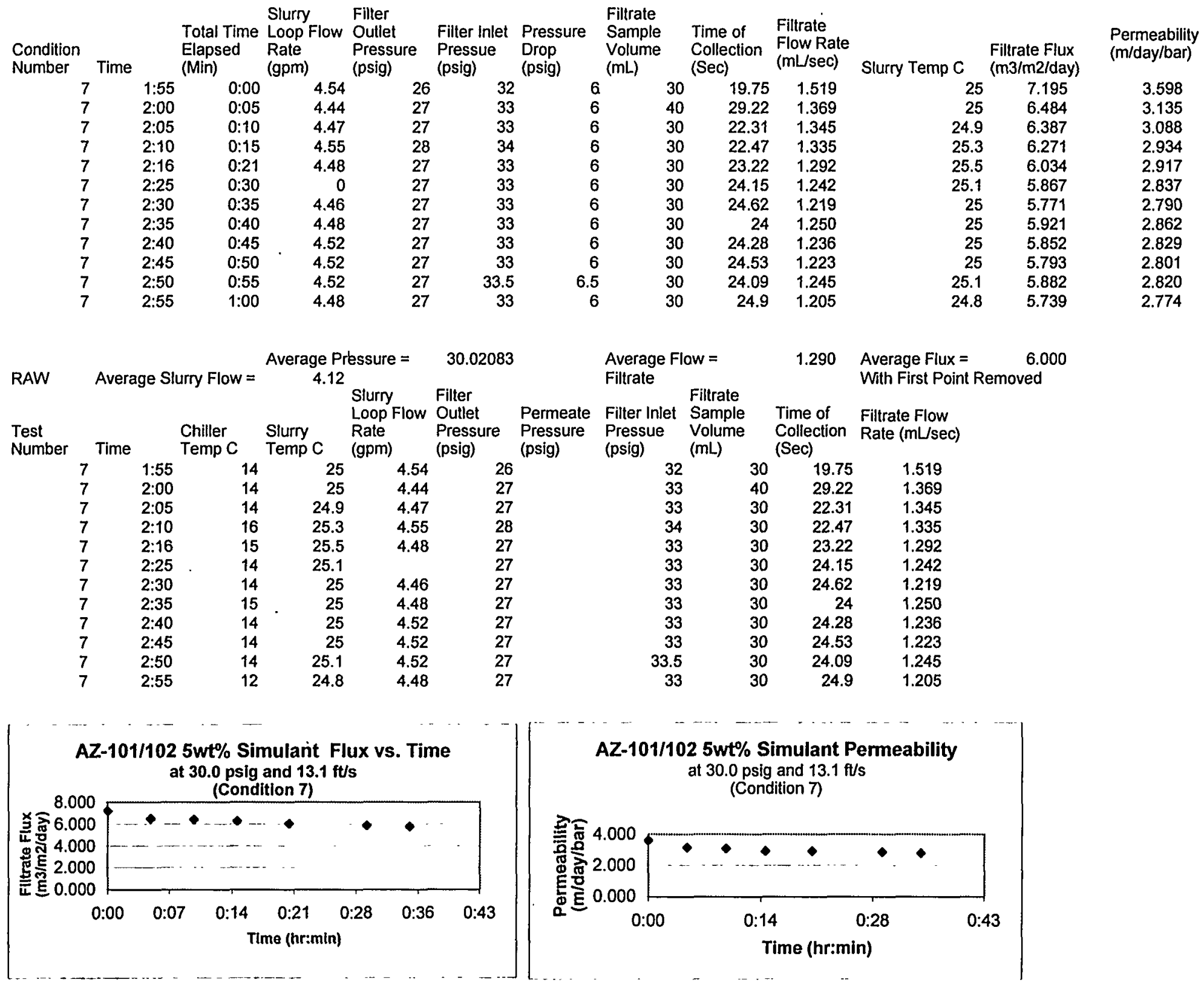




\title{
AZ-101/102 Filtration Simulant at $15 \mathrm{wt} \%$ Solids Loading CUF Testing
}

\author{
$0.1 \mu \mathrm{m}$ Motl filter element
}




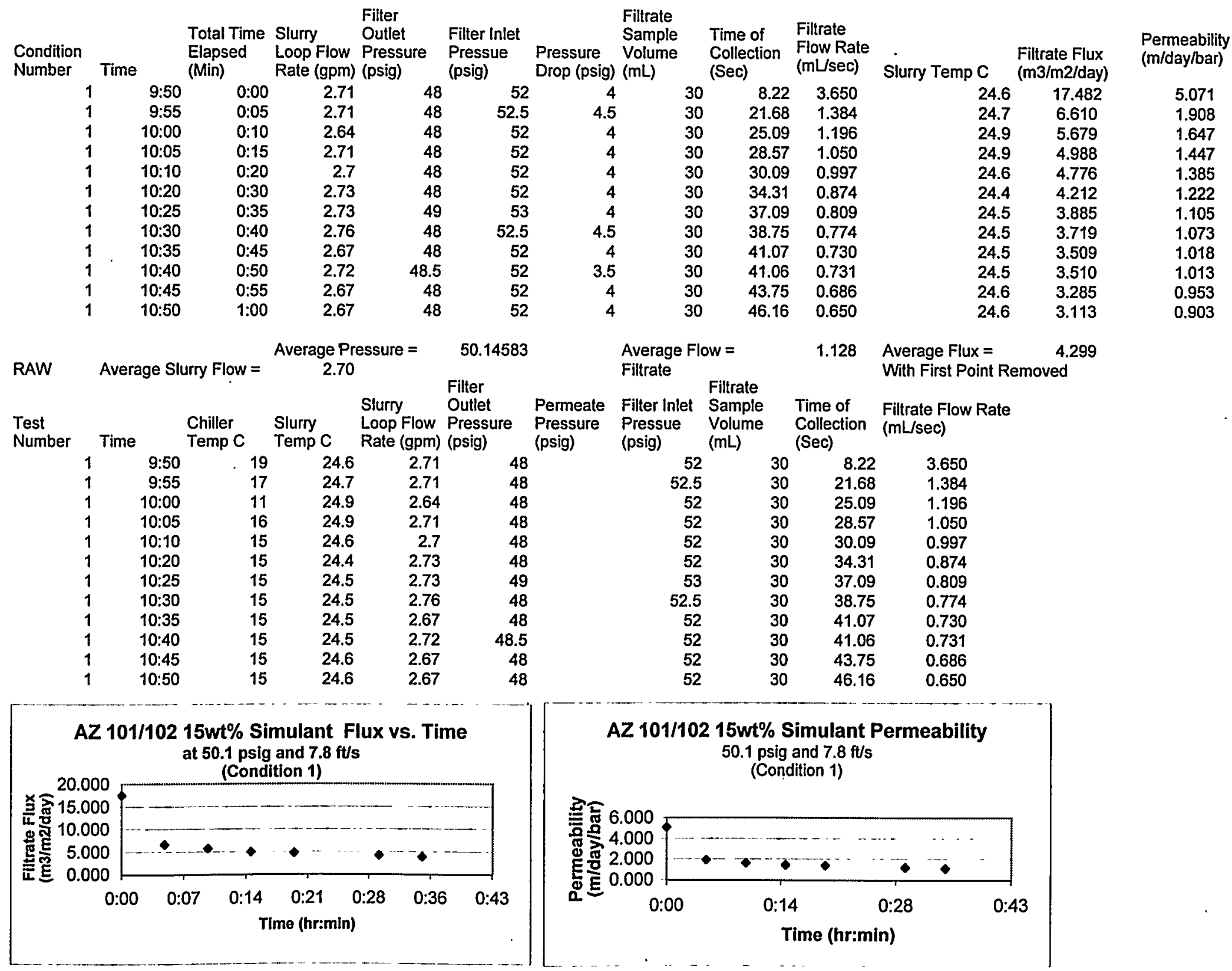




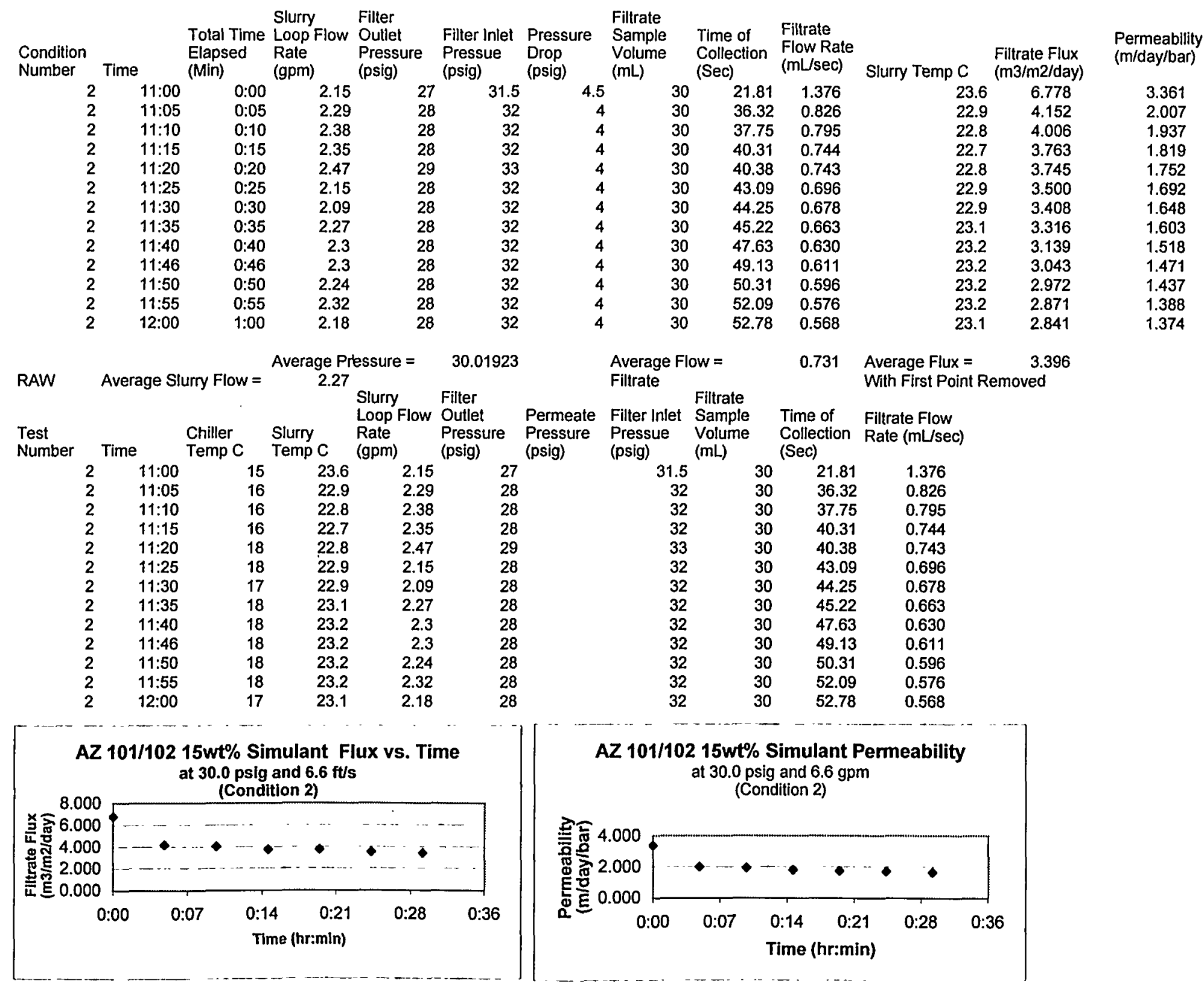




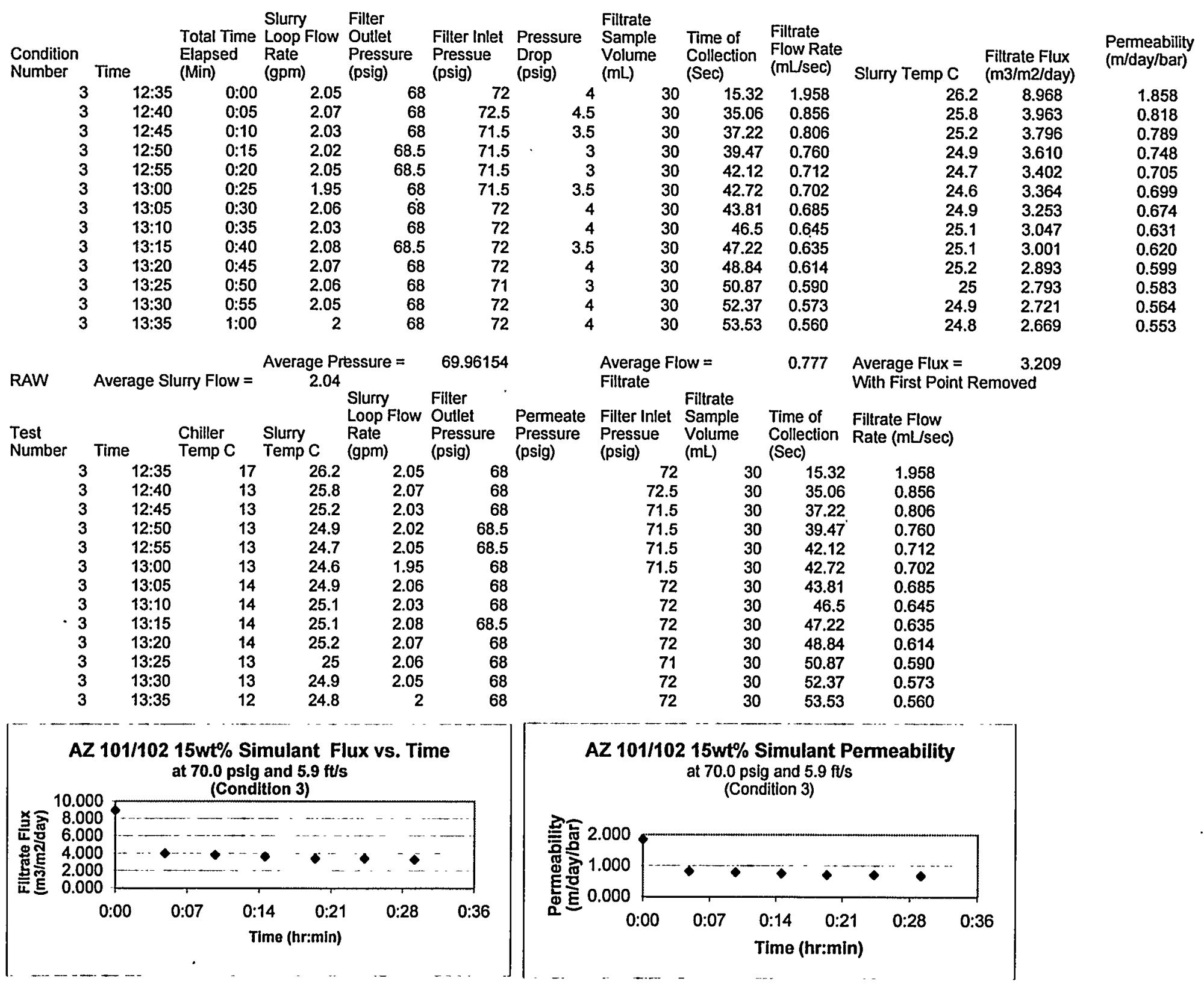




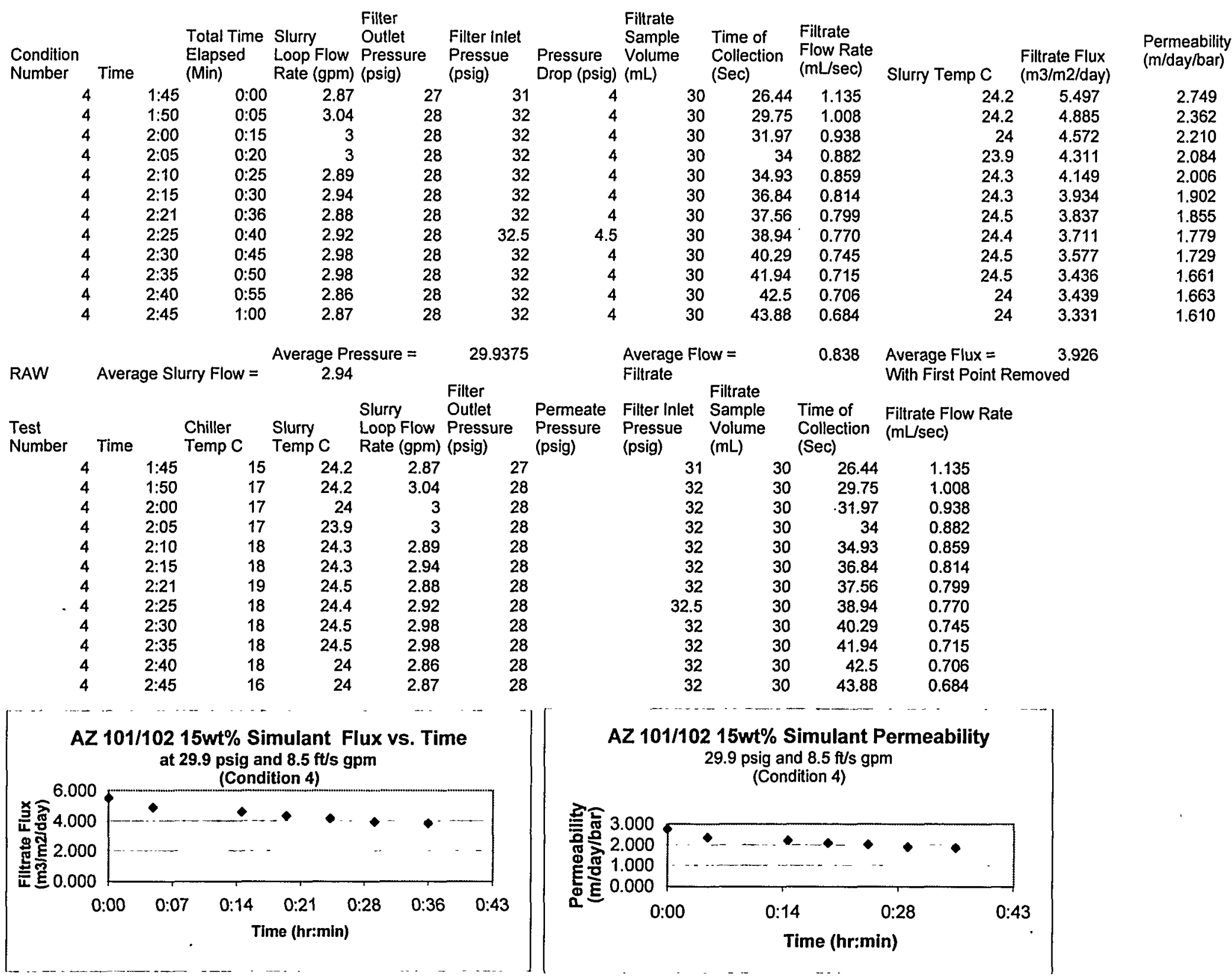




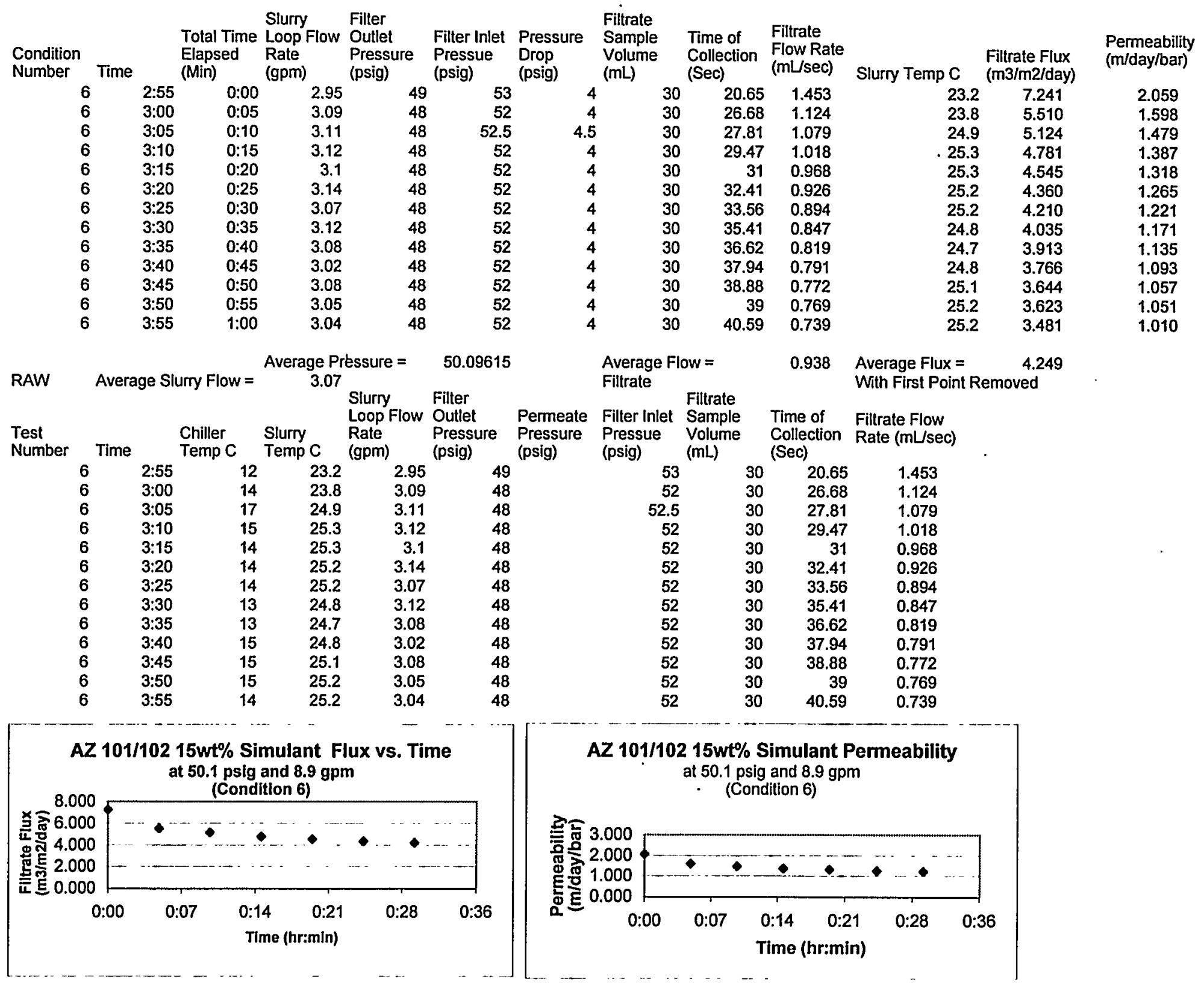




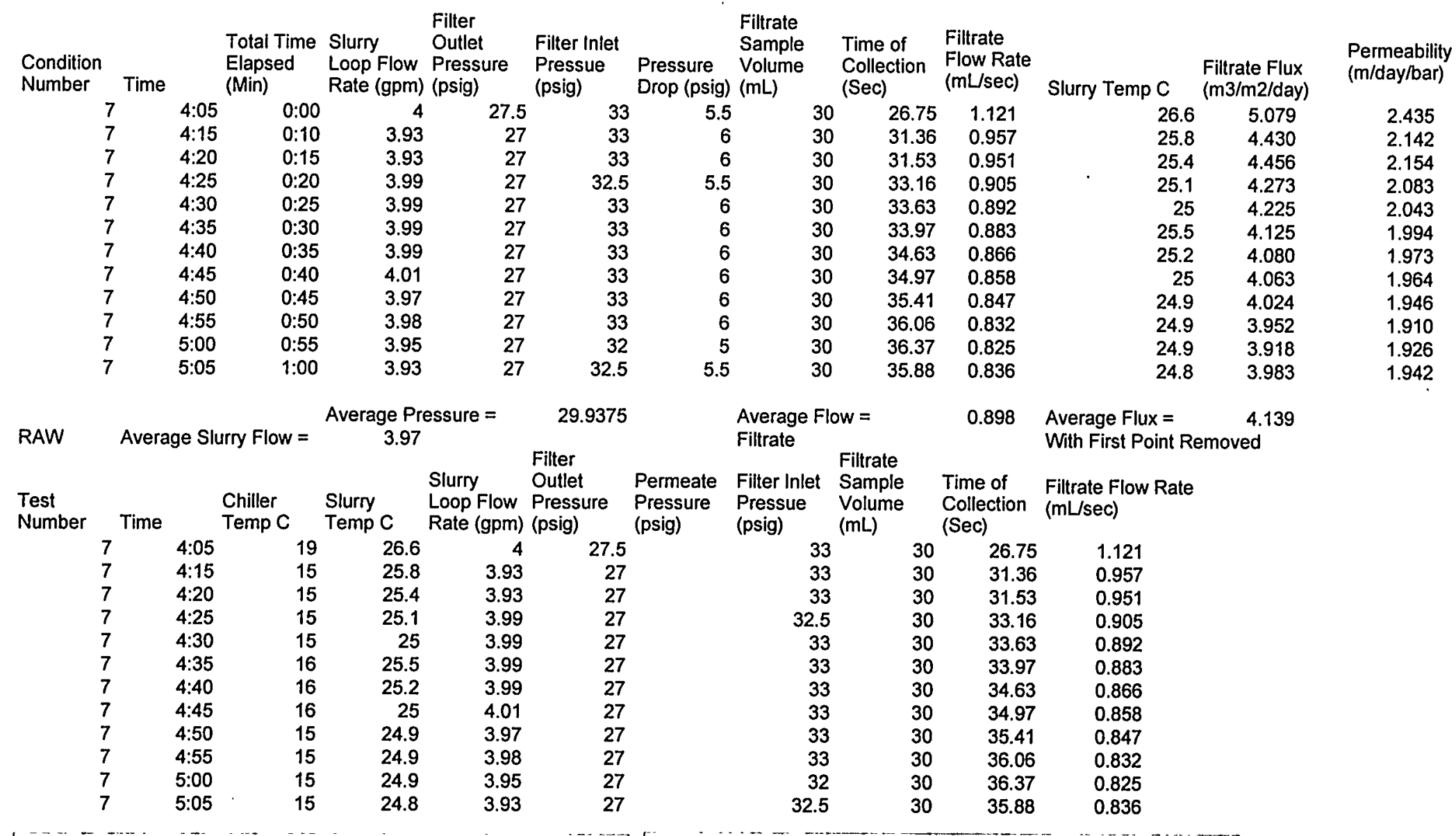

AZ 101/102 15wt\% Simulant Flux vs. Time at $29.9 \mathrm{psig}$ and $11.5 \mathrm{ft} / \mathrm{s}$

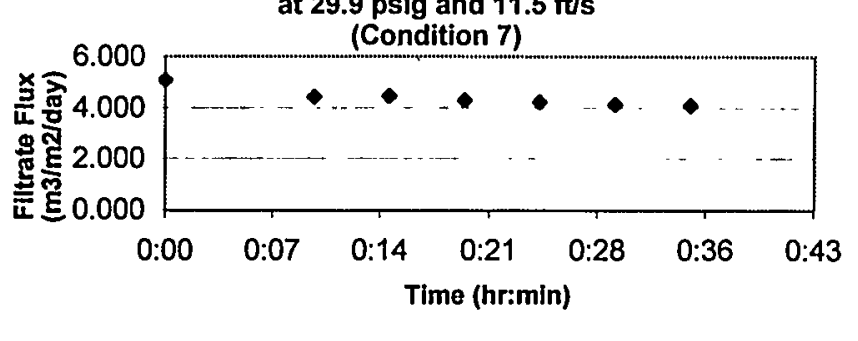

AZ 101/102 15wt\% Simulant Permeability

at $29.9 \mathrm{psig}$ and $11.5 \mathrm{ft} / \mathrm{s} \mathrm{gpm}$

(Condition 7)

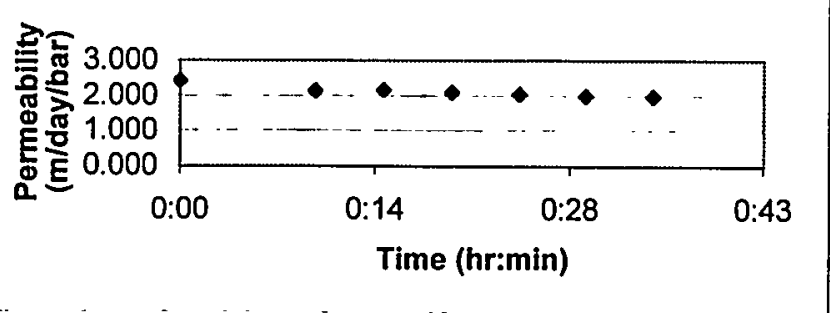




\section{Appendix D: Rheological Properties Raw Data}


0106 Simulant at $20 \mathrm{wt} \%$

R1201000

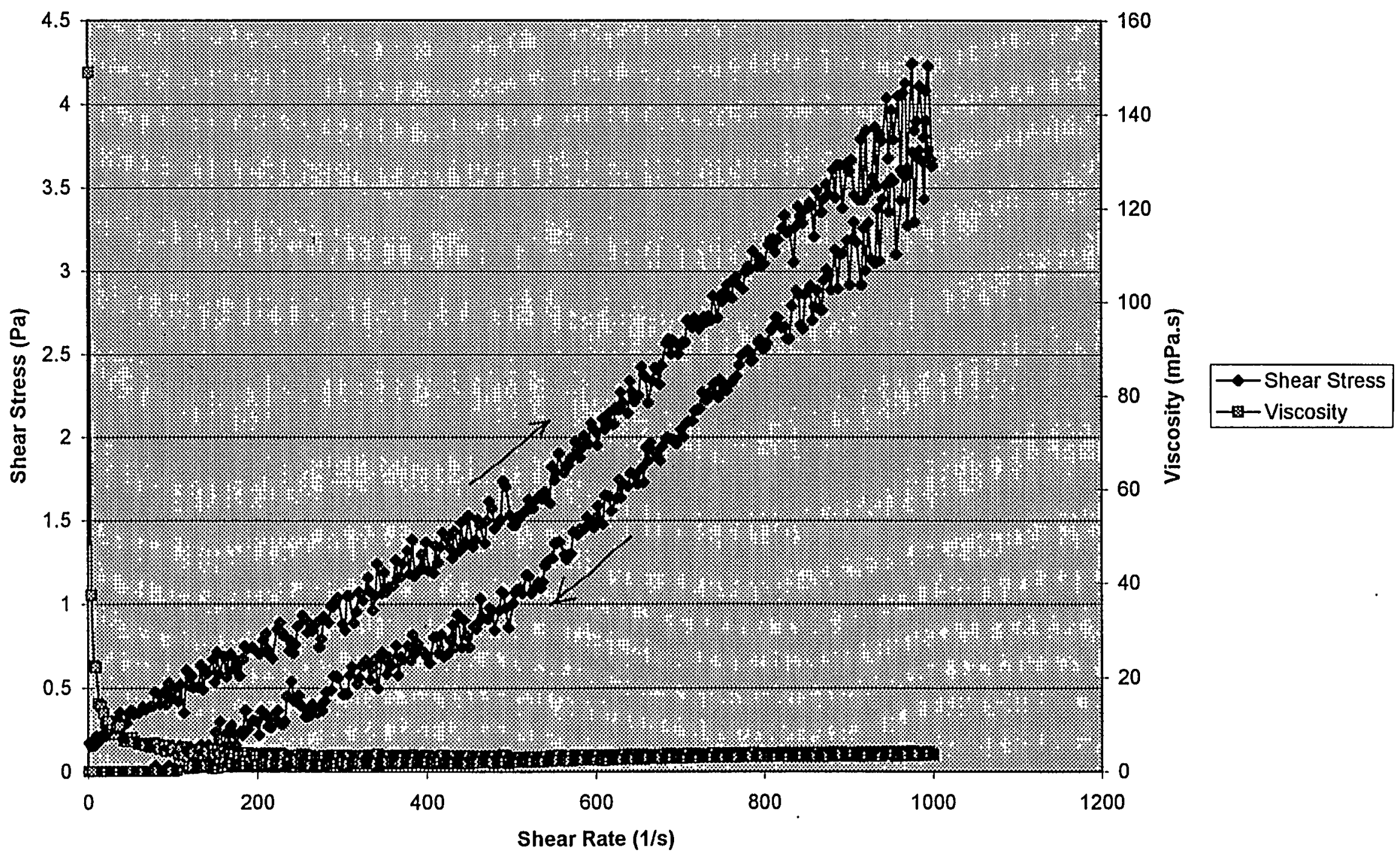




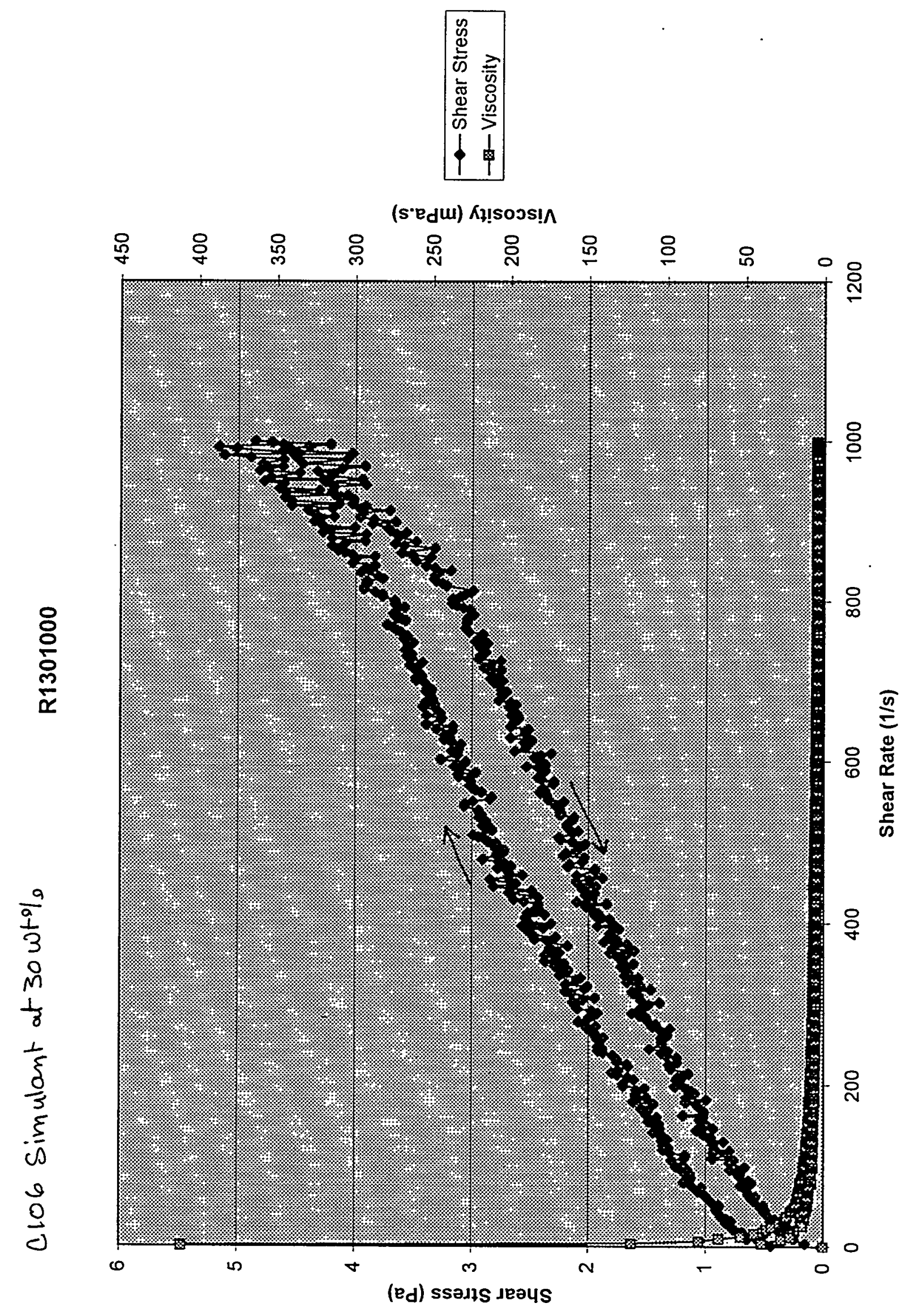




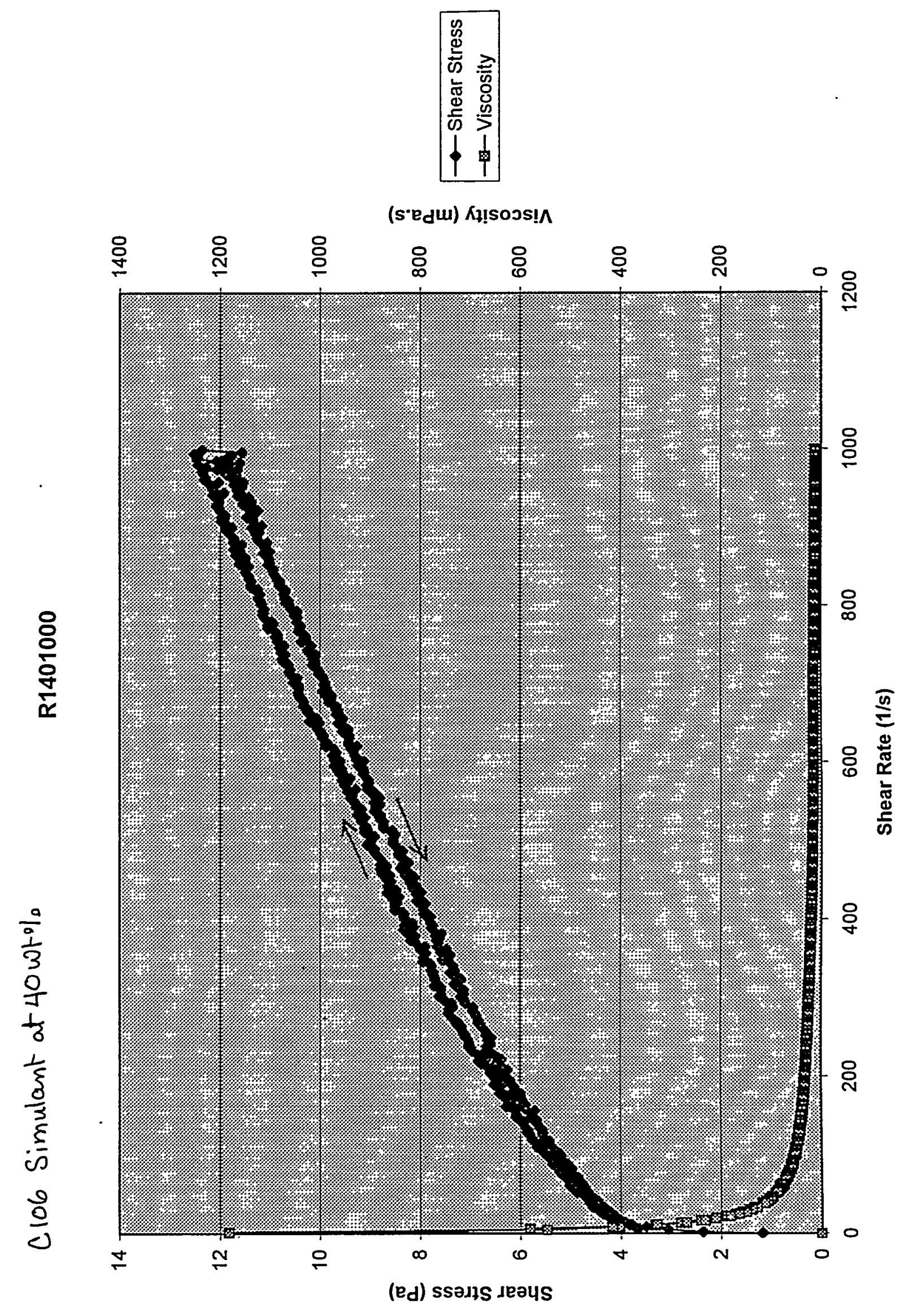


Azlo1/102 Simulant at 20 wt $\%$

A1201000

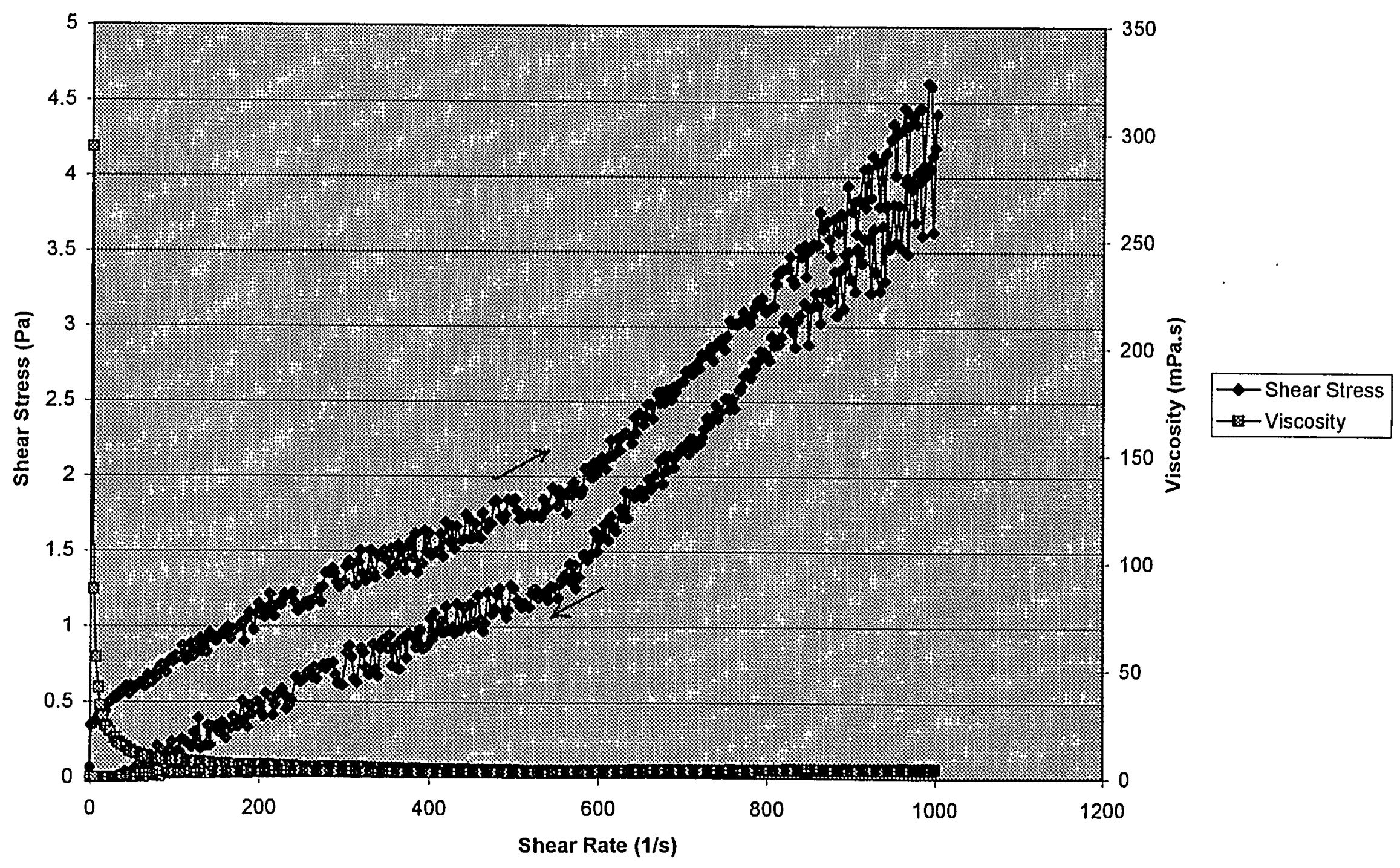




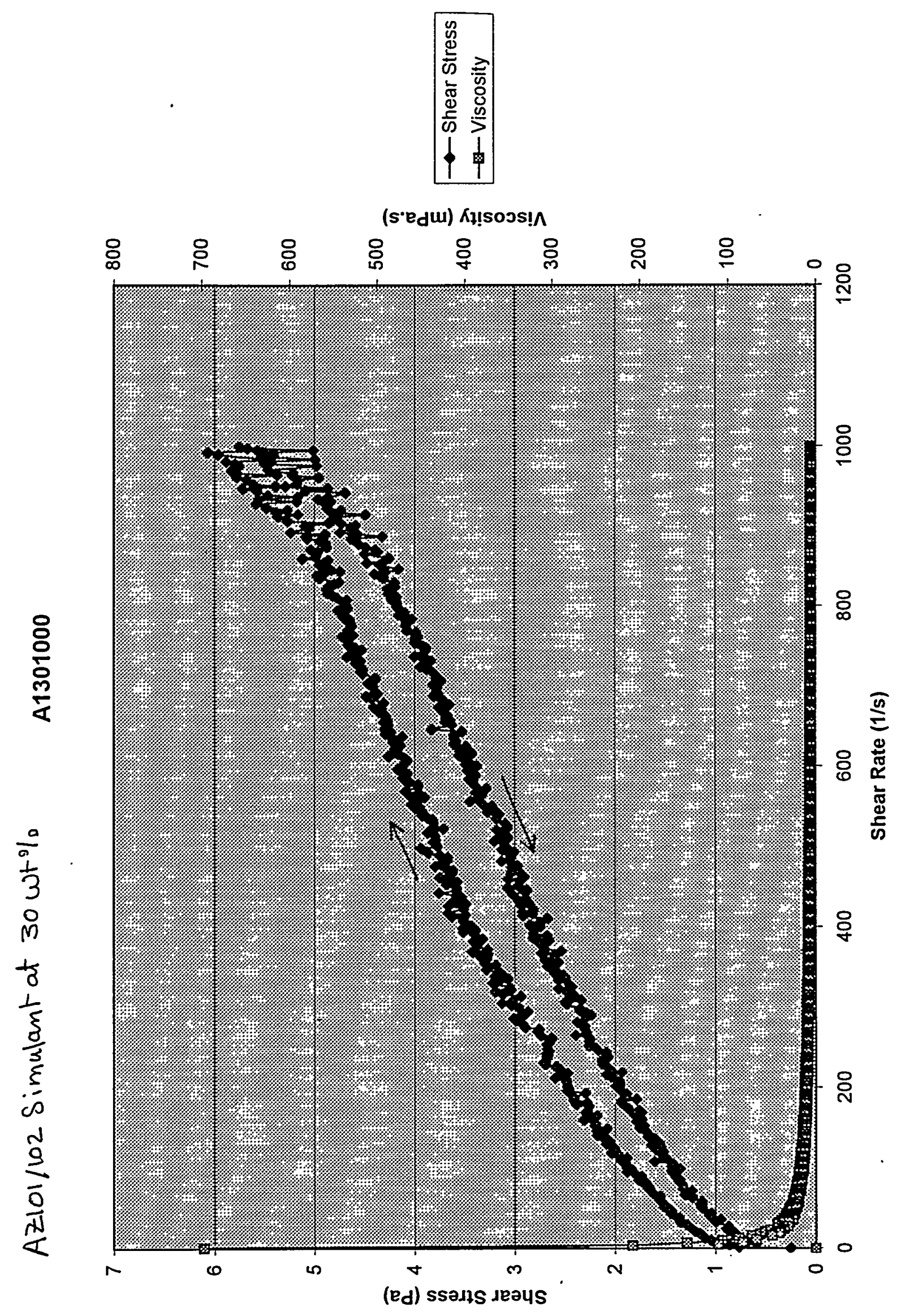




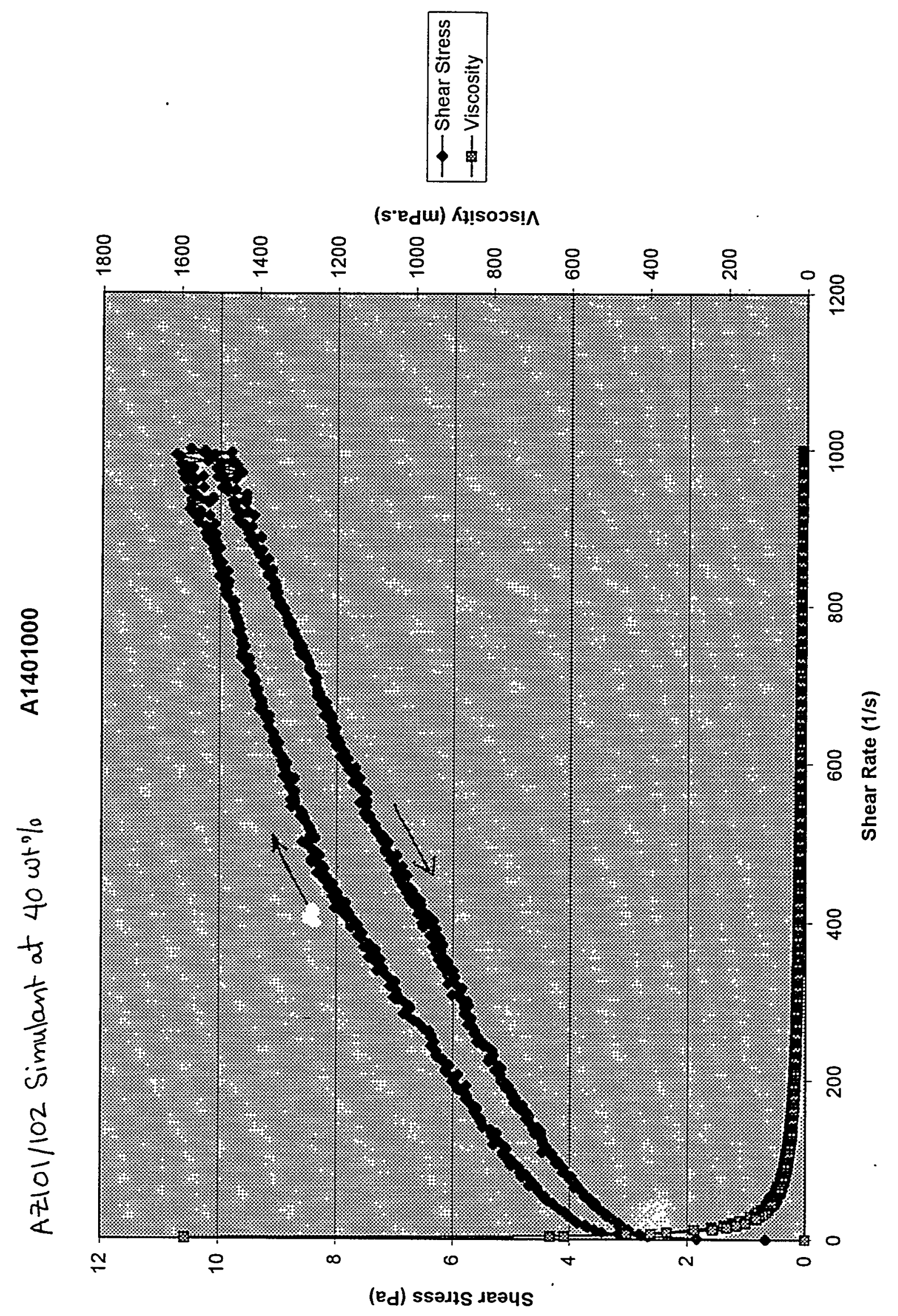




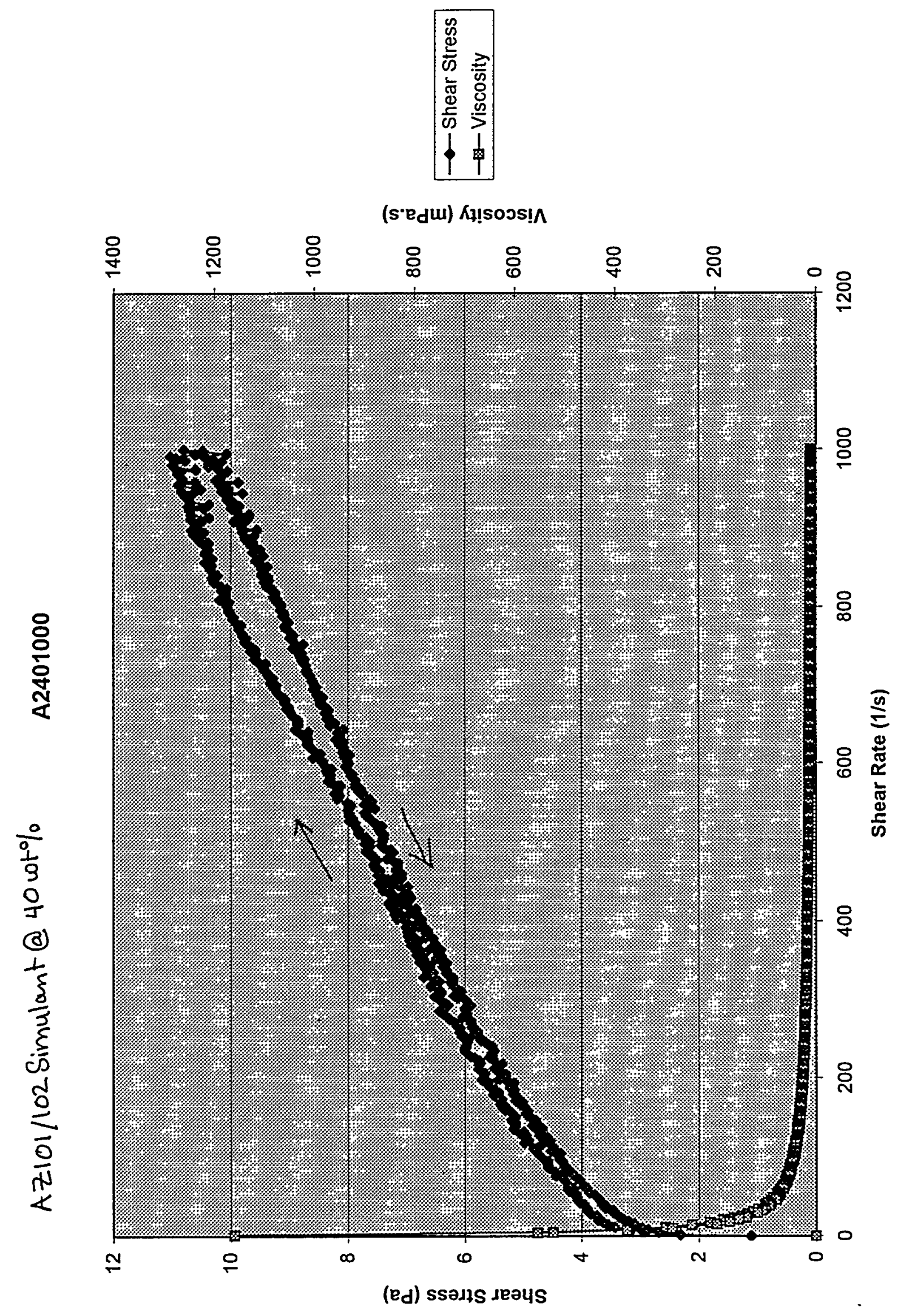




\section{Appendix E: Particle Size Distribution Raw Data}


Particle Size Distribution Plots

For NIST Traceable Standards from Duke Scientific Corporation 


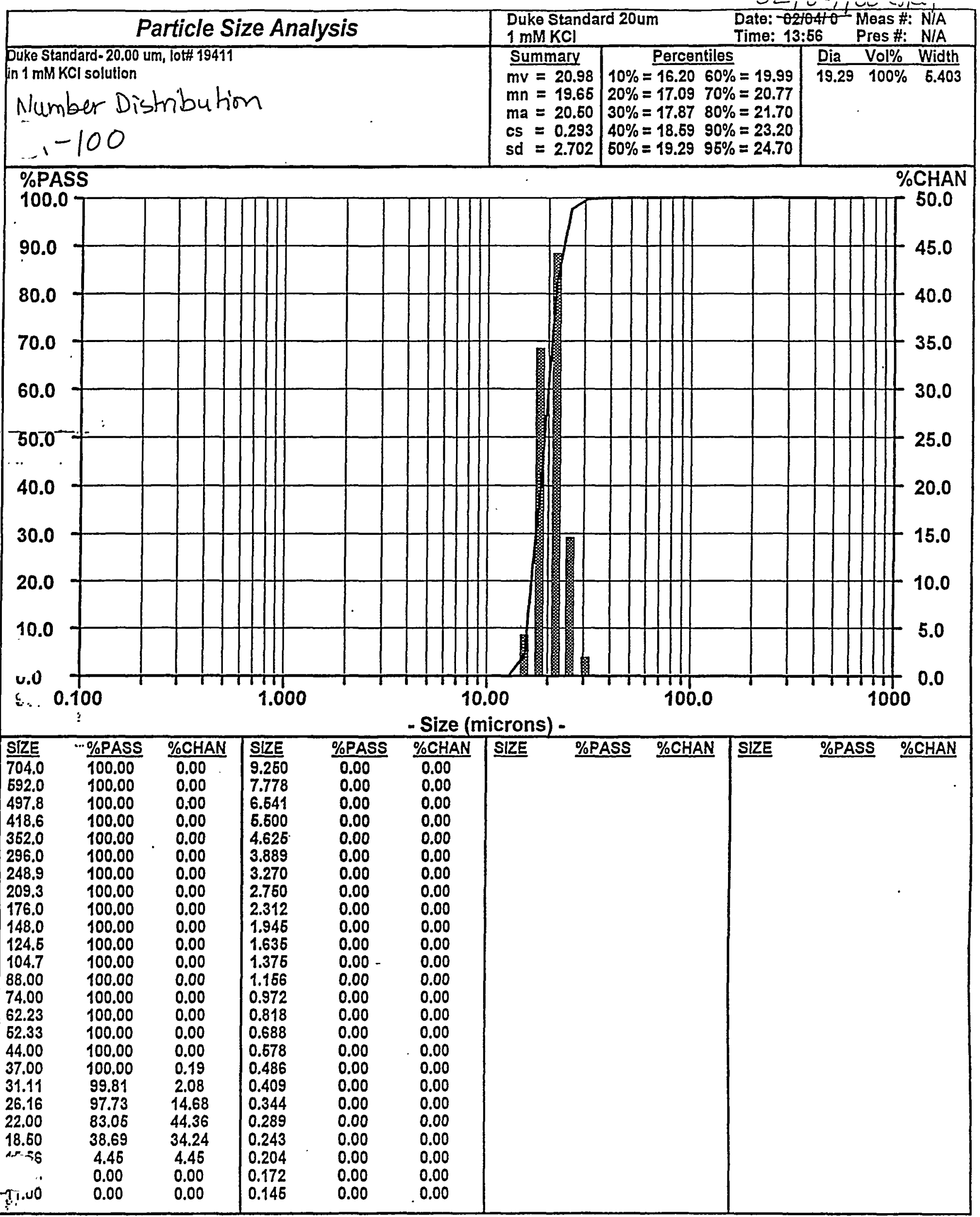
7 . i. . 


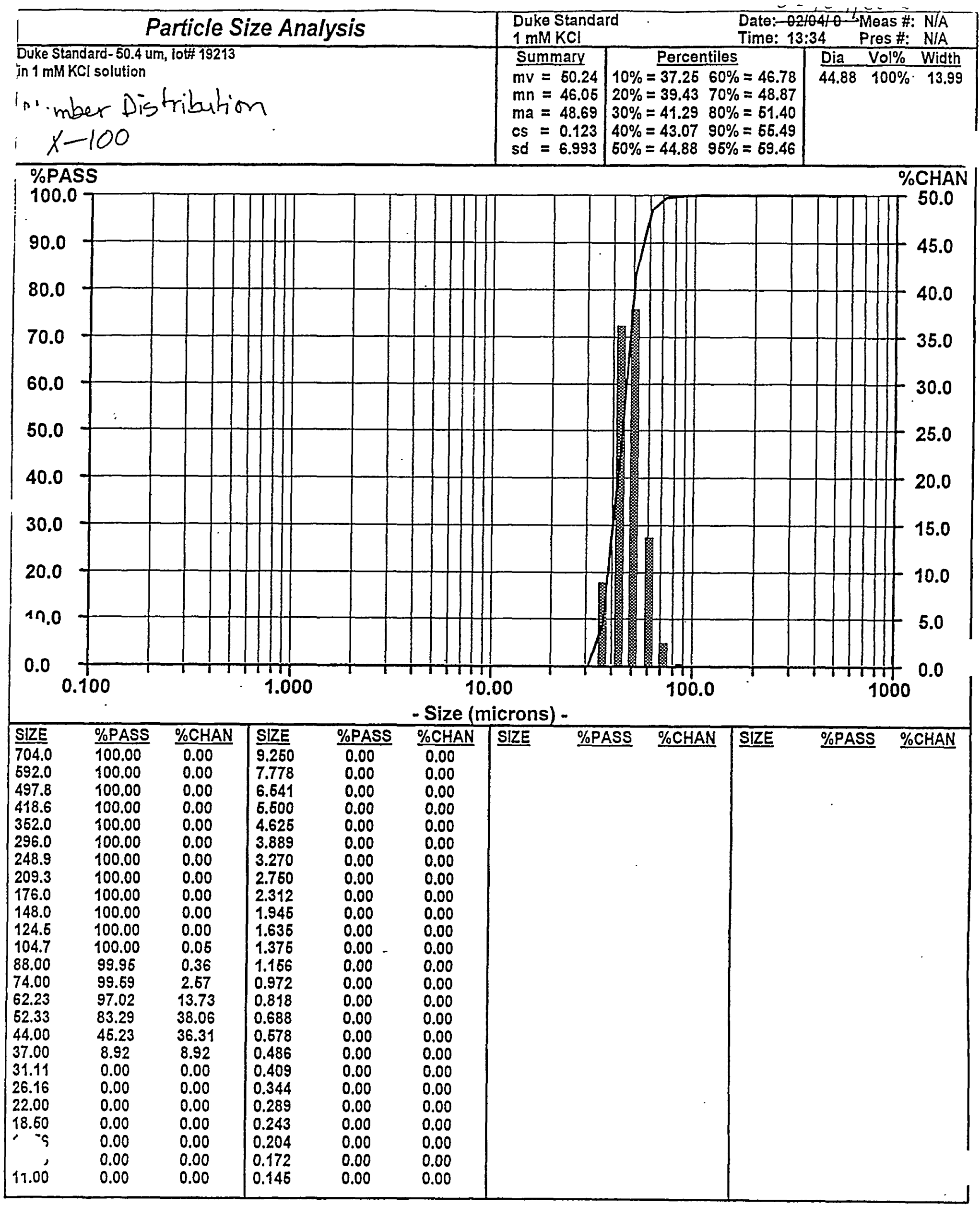




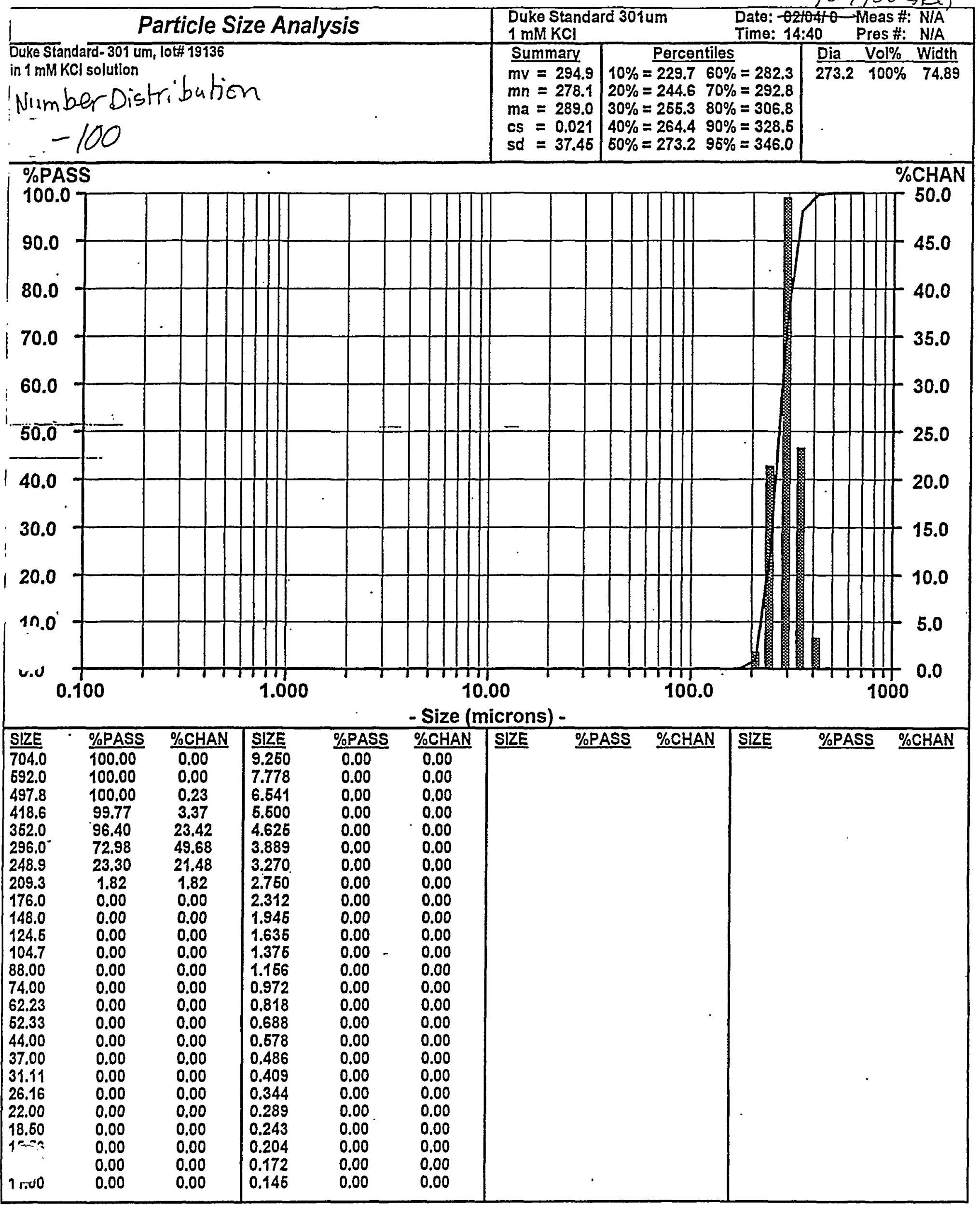




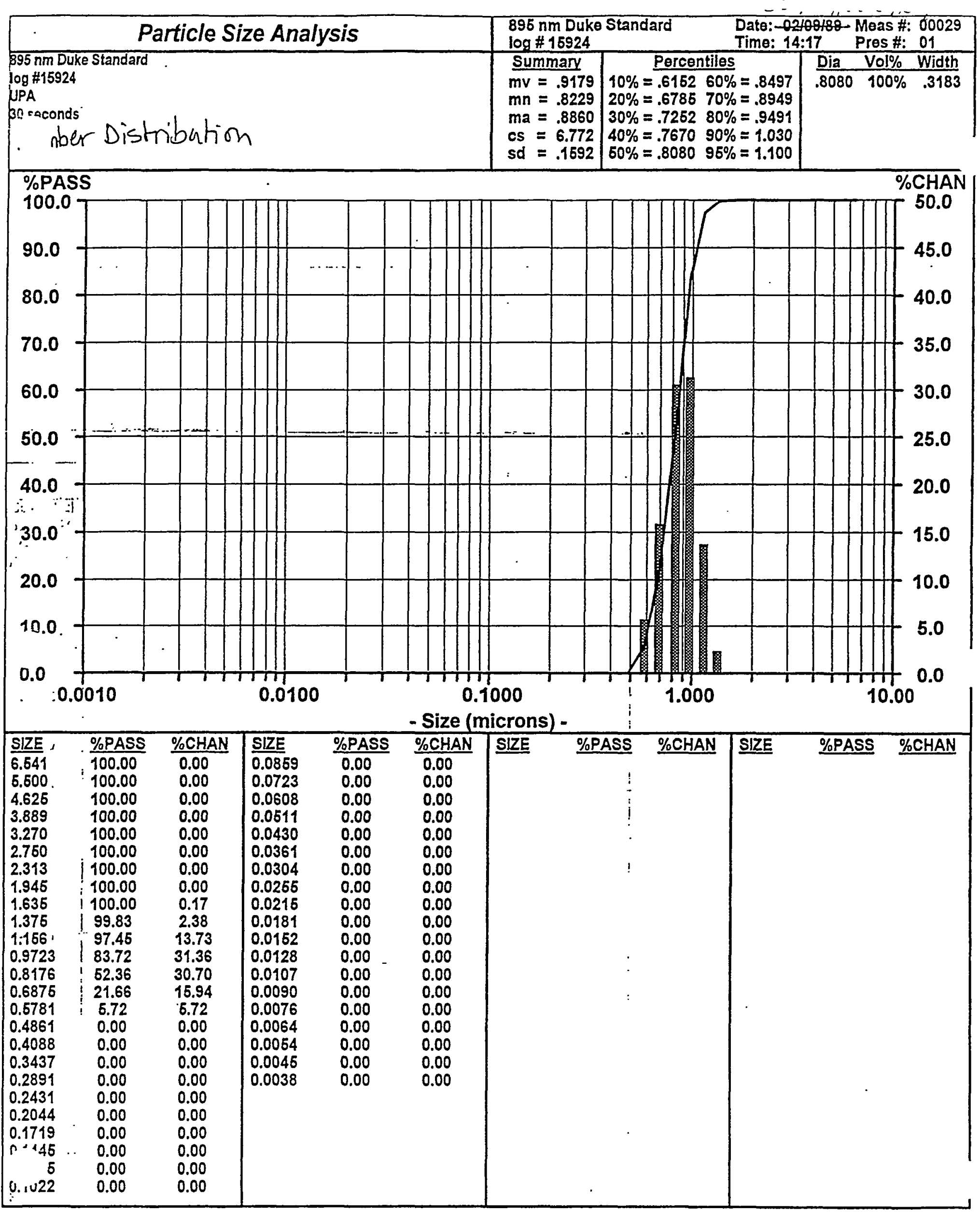




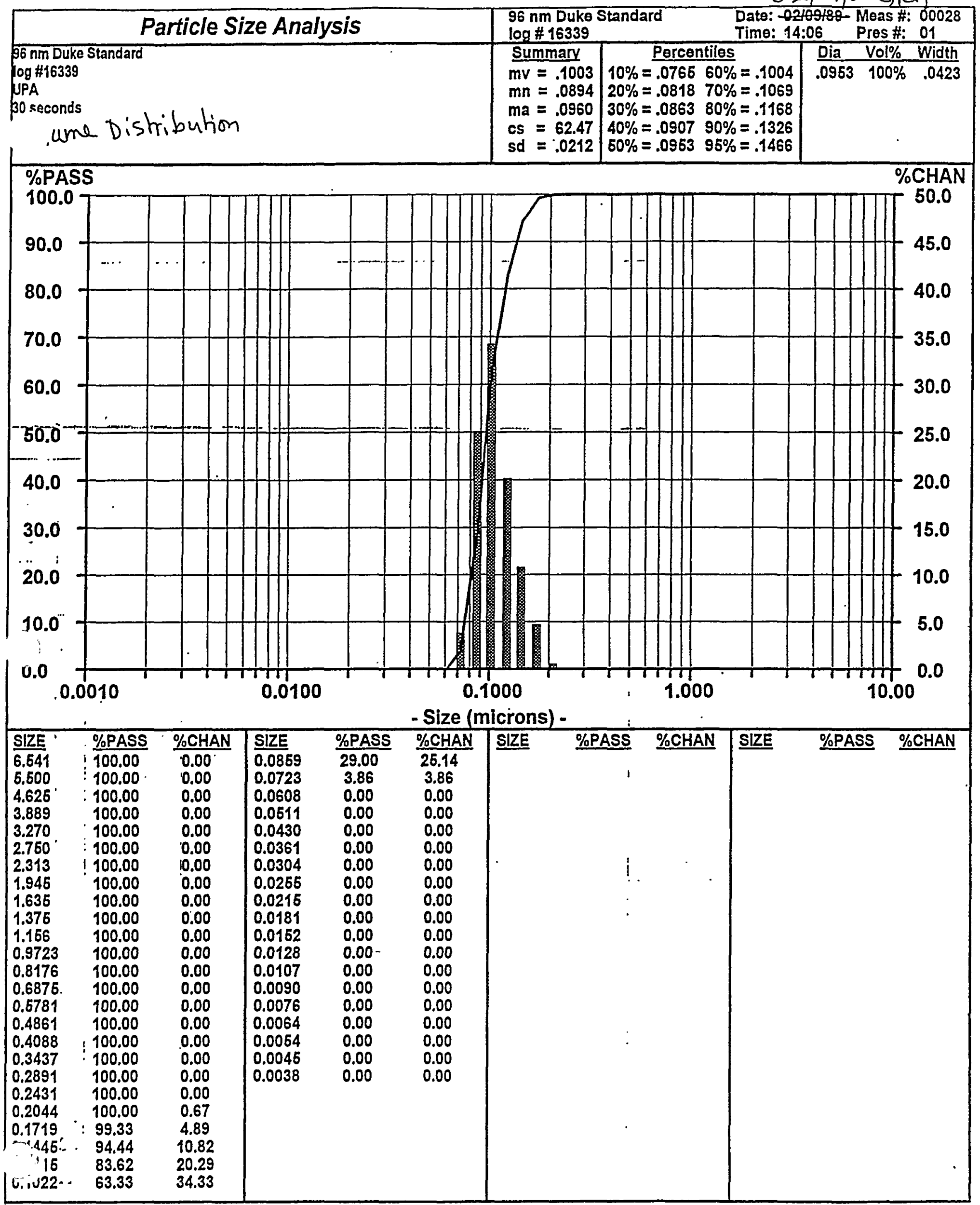




\section{AZ101/102 Filtration Simulant}




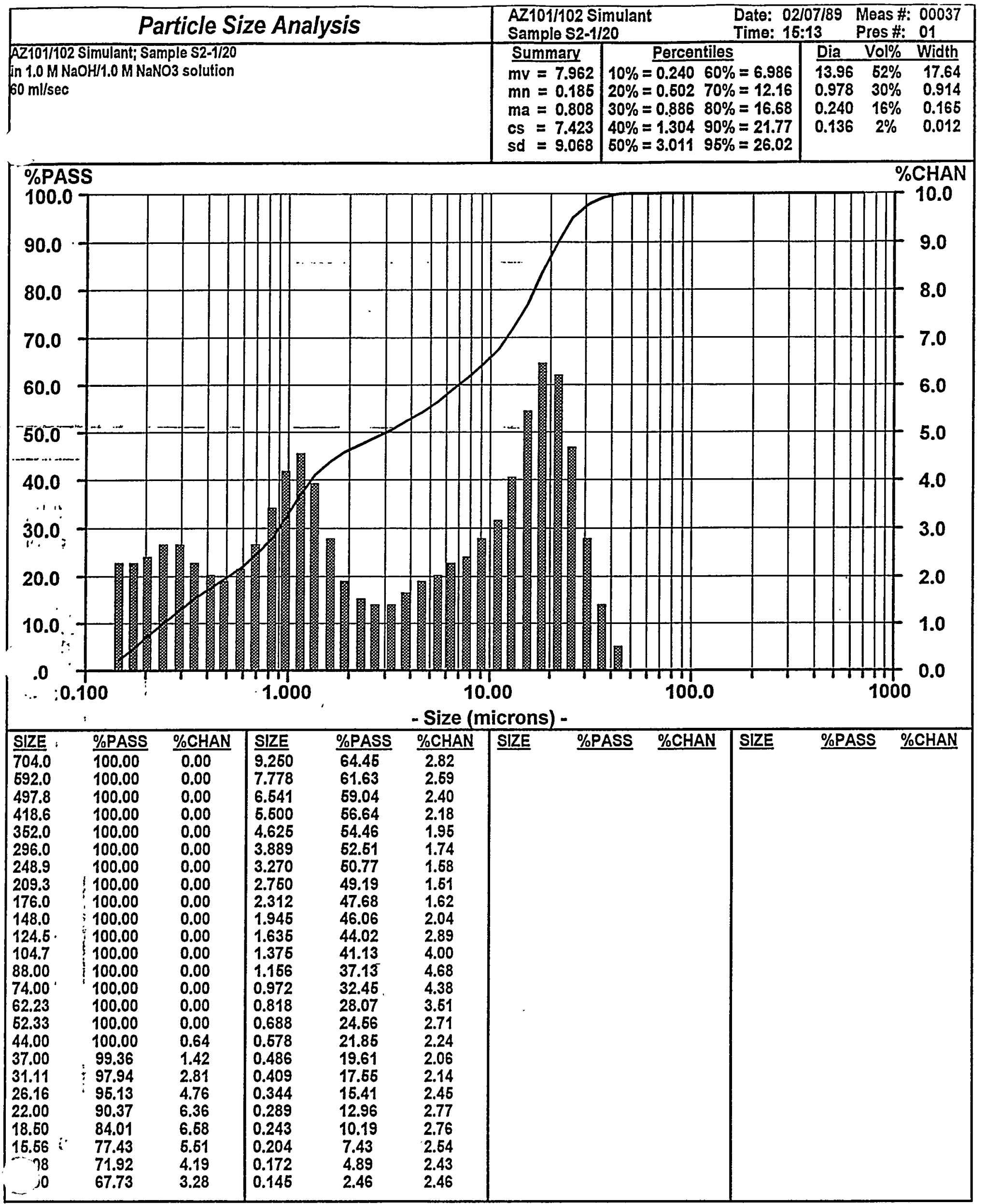


Particle Size Analysis

AZ101/102 Simulant; Sample S2-1/20

in 1.0 M NaOH/1.0 M NaNO3 solution

Sonicated at $40 \mathrm{~W}$ for $90 \mathrm{sec} ; 60 \mathrm{ml} / \mathrm{sec}$
AZ101/102 Simulant Sample S2-1/20

Summary

$m v=7.284$

$m n=0.186$

$\mathrm{ma}=0.673$

$\mathrm{sd}=8.619$ $c s=8.910$

Date: $02 / 07 / 89$ Time: 16:28

\begin{tabular}{ccc} 
& Pres \#: & 01 \\
\hline Dia & Vol\% & Width \\
\hline 13.31 & $51 \%$ & 17.16 \\
0.820 & $26 \%$ & 0.791 \\
0.232 & $23 \%$ & 0.184 \\
& & \\
& &
\end{tabular}

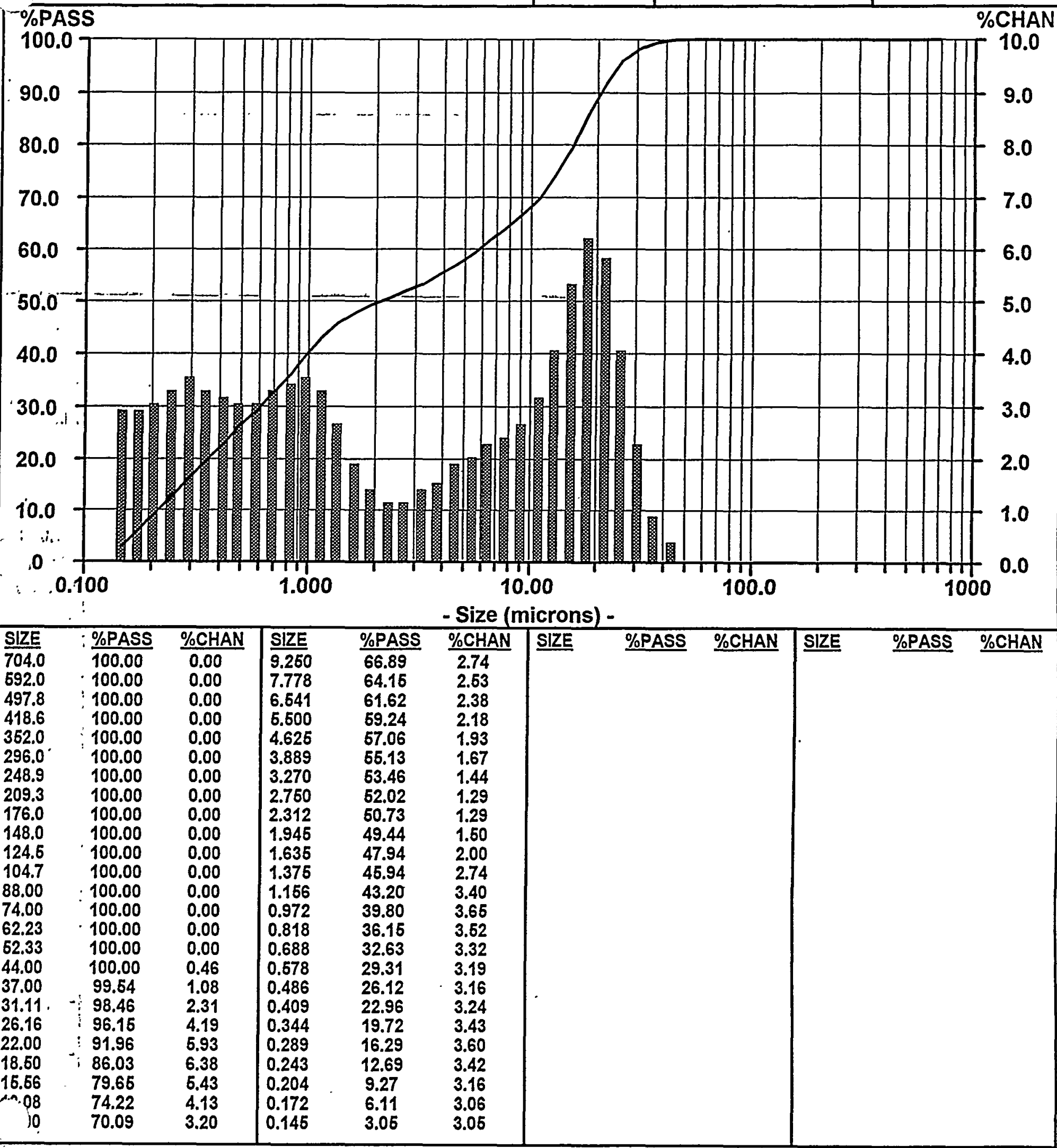




\section{Particle Size Analysis}

AZ101/102 Simulant; Sample S1-1/24

in $0.8 \mathrm{M} \mathrm{NaOH} / 1.0 \mathrm{M} \mathrm{NaNO} 3$ solution

Sonicated at $40 \mathrm{~W}$ for $90 \mathrm{sec} ; 60 \mathrm{ml} / \mathrm{sec}$
AZ101/102SimulantDUP Sample S1-1/24

Summary

$m v=8.881$

$m n=0.181$

$\mathrm{ma}=0.752$

$c s=7.983$

sd $=0.046$

Percentiles
$10 \%=0.128 \quad 60 \%=0.164$
$20 \%=0.133 \quad 70 \%=0.180$
$30 \%=0.13780 \%=0.207$
$40 \%=0.14490 \%=0.259$
$60 \%=0.15295 \%=0.321$

Date: 02/08/89 Meas \#: 00012 Time: 09:41 Pres \#: 01

Dia Vol\% Width

$\begin{array}{lll}0.162 & 100 \% & 0.092\end{array}$

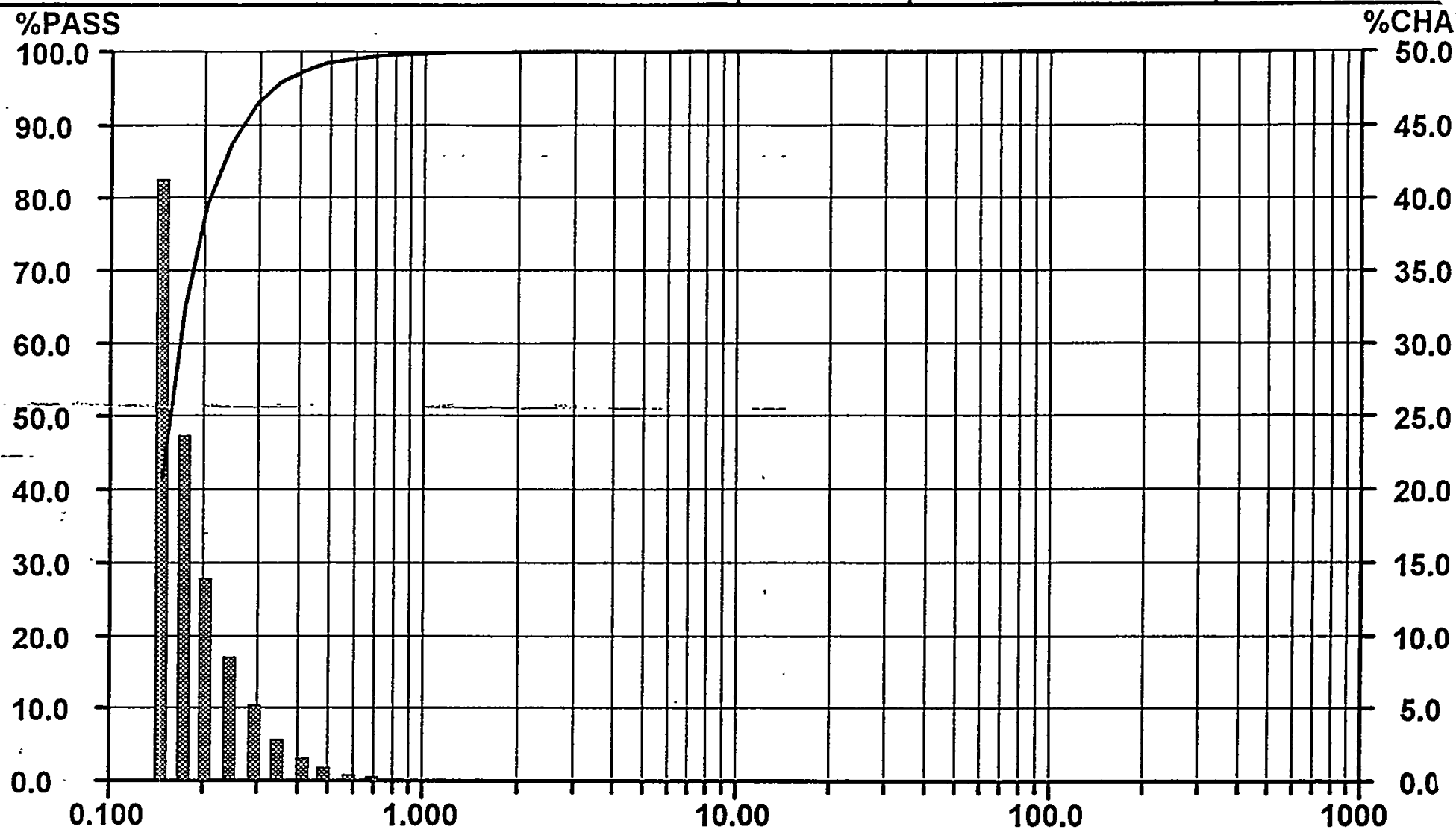

- Size (microns) -

S
7
6
4
3
2
1
8
7
6
5
3
3
2
2
1
1

\begin{tabular}{l}
\hline SIZE \\
\hline 704. \\
692. \\
497. \\
418. \\
352. \\
296. \\
248. \\
209. \\
176. \\
148. \\
124. \\
104. \\
88.0 \\
74.00 \\
62.23 \\
52.3 \\
44.00 \\
37.00 \\
31.11 \\
26.16 \\
22.00 \\
18.60 \\
15.66 \\
13.08 \\
11.00
\end{tabular}

\begin{tabular}{ll|ll} 
\%PASS & \%CHAN & SIZE & \%PASS \\
\hline 100.00 & 0.00 & 9.260 & 100.00 \\
100.00 & 0.00 & 7.778 & 100.00 \\
100.00 & 0.00 & 6.541 & 100.00 \\
100.00 & 0.00 & 6.600 & 100.00 \\
100.00 & 0.00 & 4.625 & 100.00 \\
100.00 & 0.00 & 3.889 & 100.00 \\
100.00 & 0.00 & 3.270 & 100.00 \\
100.00 & 0.00 & 2.750 & 100.00 \\
100.00 & 0.00 & 2.312 & 100.00 \\
100.00 & 0.00 & 1.945 & 100.00 \\
100.00 & 0.00 & 1.635 & 99.99 \\
100.00 & 0.00 & 1.375 & 99.97 \\
100.00 & 0.00 & 1.156 & 99.93 \\
100.00 & 0.00 & 0.972 & 99.85 \\
100.00 & 0.00 & 0.818 & 99.71 \\
100.00 & 0.00 & 0.688 & 99.48 \\
100.00 & 0.00 & 0.678 & 99.12 \\
100.00 & 0.00 & 0.486 & 98.64 \\
100.00 & 0.00 & 0.409 & 97.69 \\
100.00 & 0.00 & 0.344 & 95.96 \\
100.00 & 0.00 & 0.289 & 93.03 \\
100.00 & 0.00 & 0.243 & 87.80 \\
100.00 & 0.00 & 0.204 & 79.20 \\
100.00 & 0.00 & 0.172 & 65.11 \\
100.00 & 0.00 & 0.145 & 41.35
\end{tabular}

$\%$ CHAN SIZE

418.6

352.0

296.0

248.9

209.3

176.0

148.0

124.6

104.7

88.00

74.00

62.23

62.33

44.00

37.00

31.11

26.16

22.00

18.60

15.66

13.08

11.00

\begin{tabular}{c}
$\% \mathrm{CH}$ \\
\hline 0.00 \\
0.00 \\
0.00 \\
0.00 \\
0.00 \\
0.00 \\
0.00 \\
0.00 \\
0.00 \\
0.01 \\
0.02 \\
0.04 \\
0.08 \\
0.14 \\
0.23 \\
0.36 \\
0.58 \\
0.95 \\
1.63 \\
2.93 \\
5.23 \\
8.60 \\
14.09 \\
23.76 \\
41.36
\end{tabular}




\begin{tabular}{|c|c|c|c|c|c|}
\hline Particle Size Analysis & \multicolumn{2}{|c|}{$\begin{array}{l}\text { AZ101/102Simulant } \\
\text { Sample S5-1/24 }\end{array}$} & $\begin{array}{l}\text { Date: } 02 / 08 / 89 \\
\text { Time: } 10: 10\end{array}$ & \multicolumn{2}{|c|}{$\begin{array}{l}\text { Meas \#: } 00020 \\
\text { Pres \#: } 01 \\
\end{array}$} \\
\hline $\begin{array}{l}\text { AZ101/102 Simulant; Sample S5-1/24 } \\
\text { in 0.8 M NaOH/1.0 M NaNO3 solution } \\
40 \mathrm{~m} / \mathrm{sec}\end{array}$ & $\begin{array}{l}\text { Summary } \\
\text { mv }=6.016 \\
m n=0.186 \\
m a=0.719 \\
c s=8.360 \\
s d=6.782\end{array}$ & $\begin{array}{c}\text { Percentiles } \\
10 \%=0.22460 \%=5.181 \\
20 \%=0.40670 \%=8.957 \\
30 \%=0.72180 \%=12.39 \\
40 \%=1.06890 \%=16.69 \\
50 \%=1.92995 \%=20.10\end{array}$ & $\begin{array}{l}\text { Dia } \\
10.68 \\
0.884 \\
0.228\end{array}$ & $\begin{array}{r}\text { Vol\% } \\
50 \% \\
30 \% \\
20 \%\end{array}$ & $\begin{array}{r}\text { Width } \\
13.33 \\
0.780 \\
0.180\end{array}$ \\
\hline
\end{tabular}

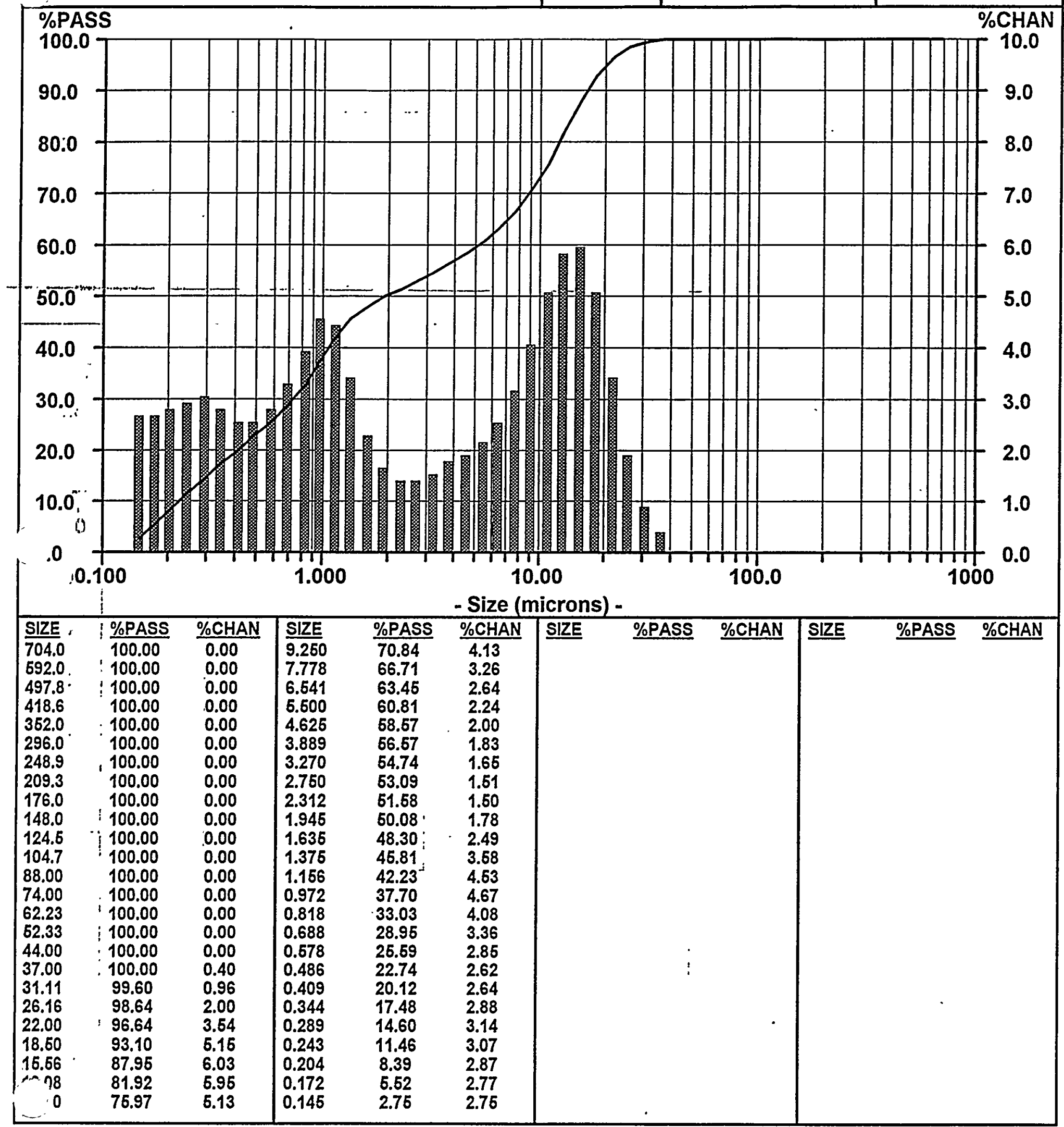




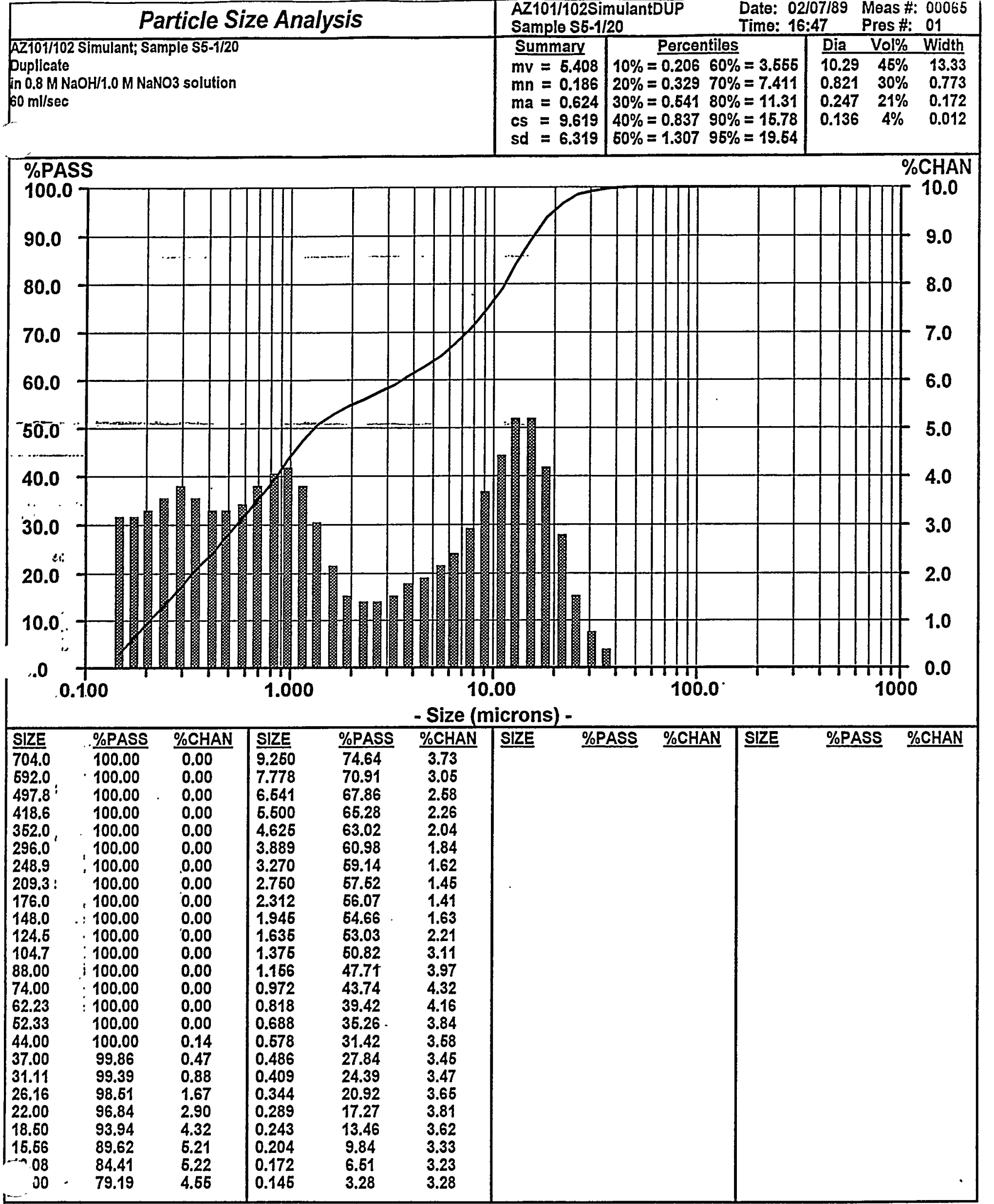




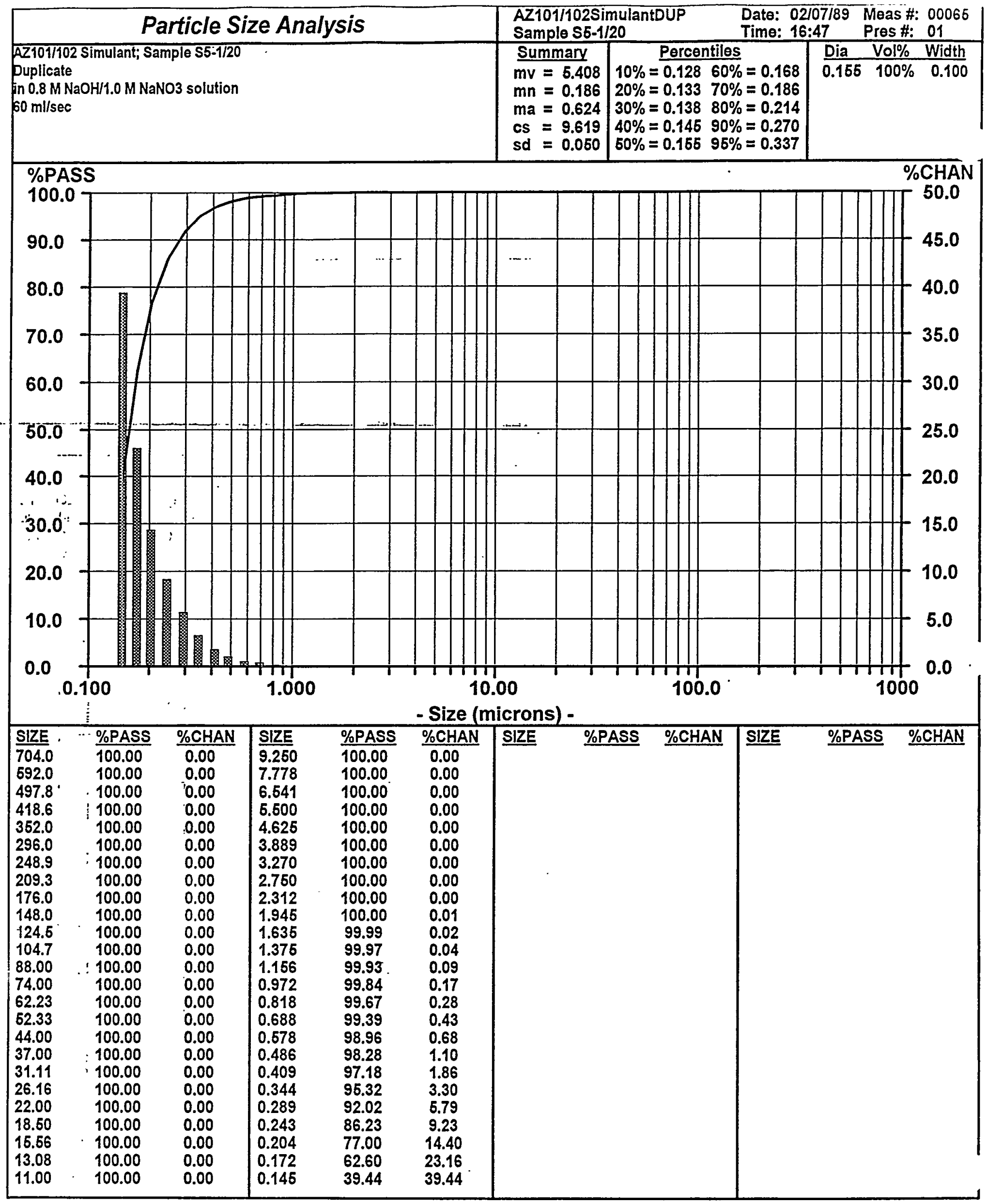




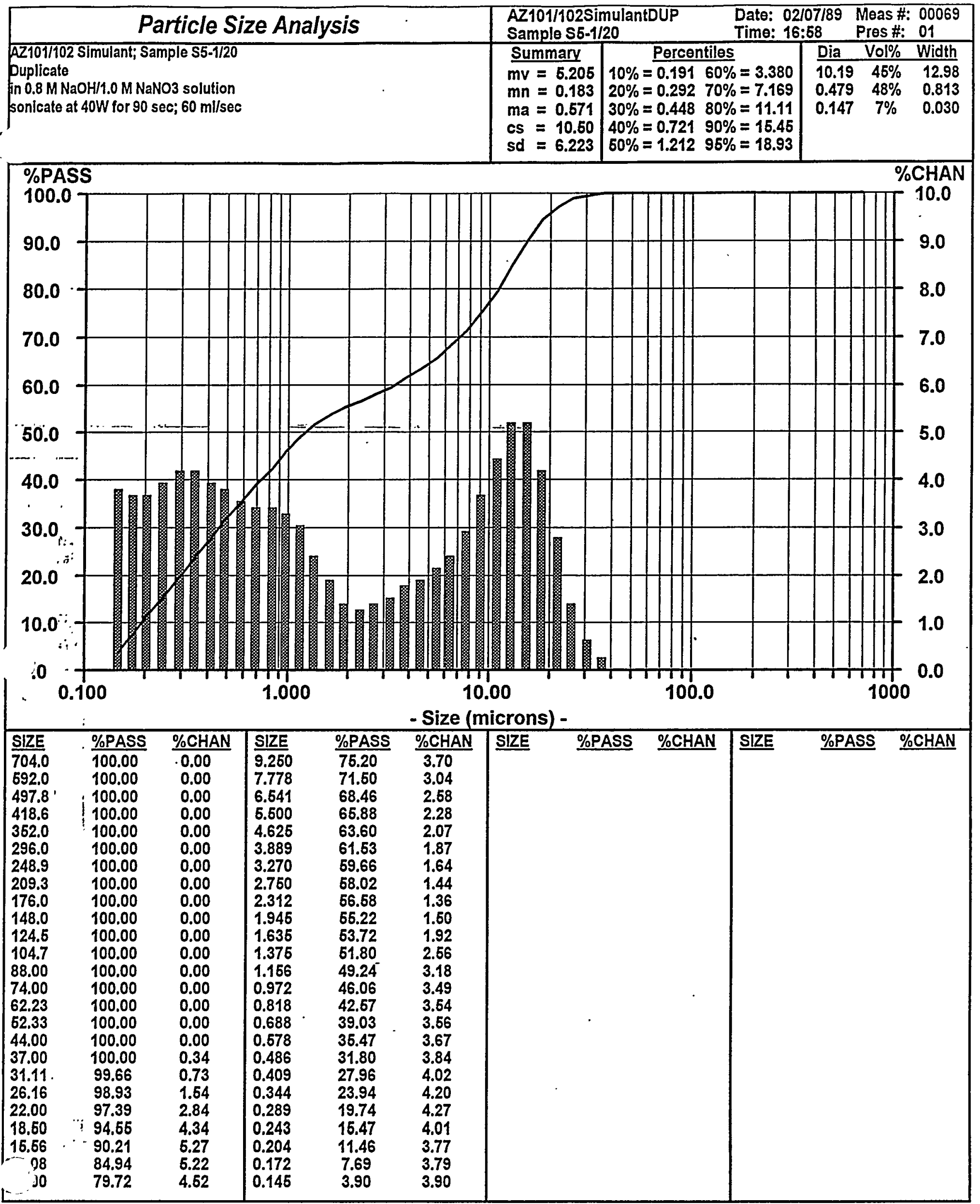




\section{C-106 Filtration Simulant}




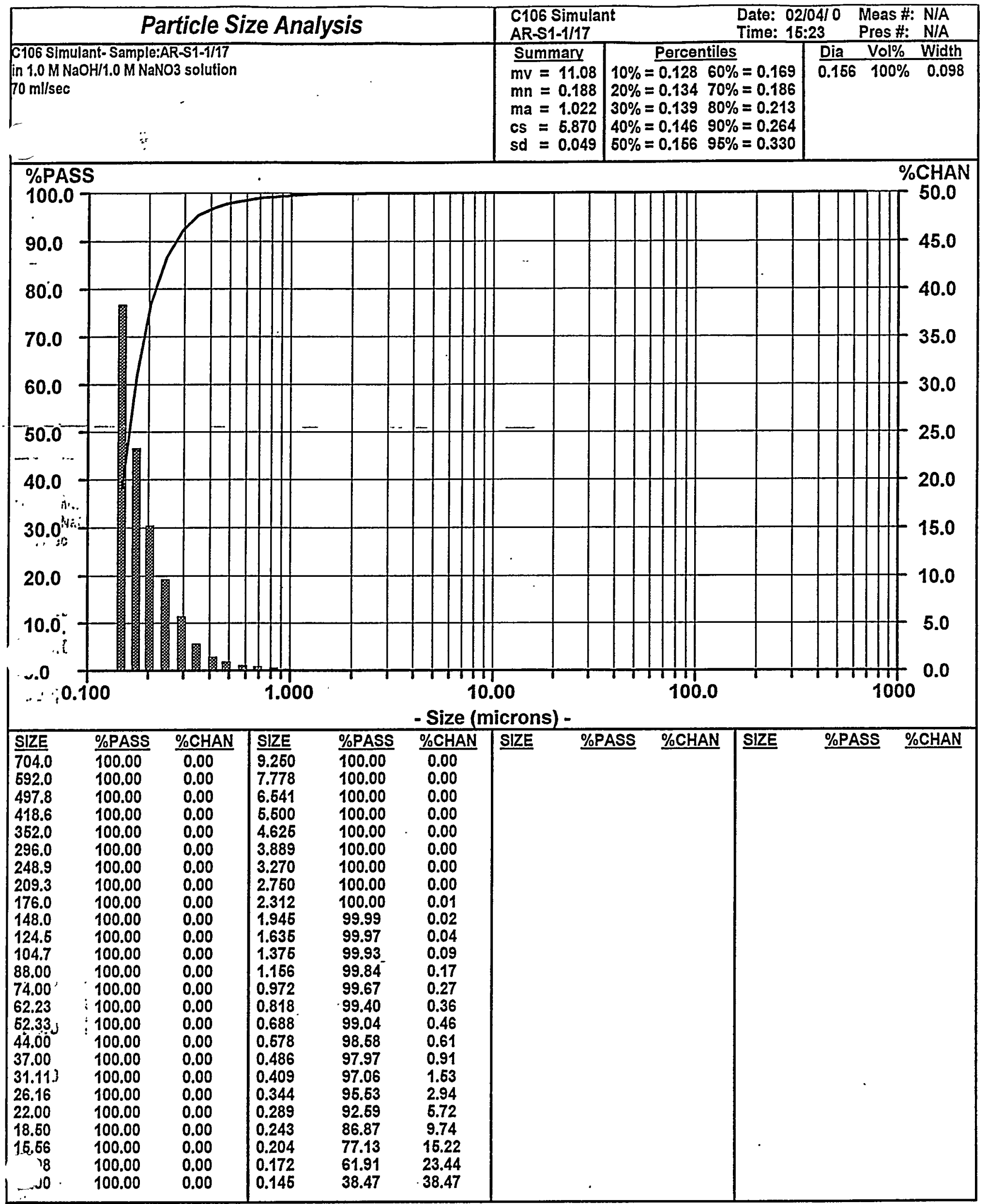




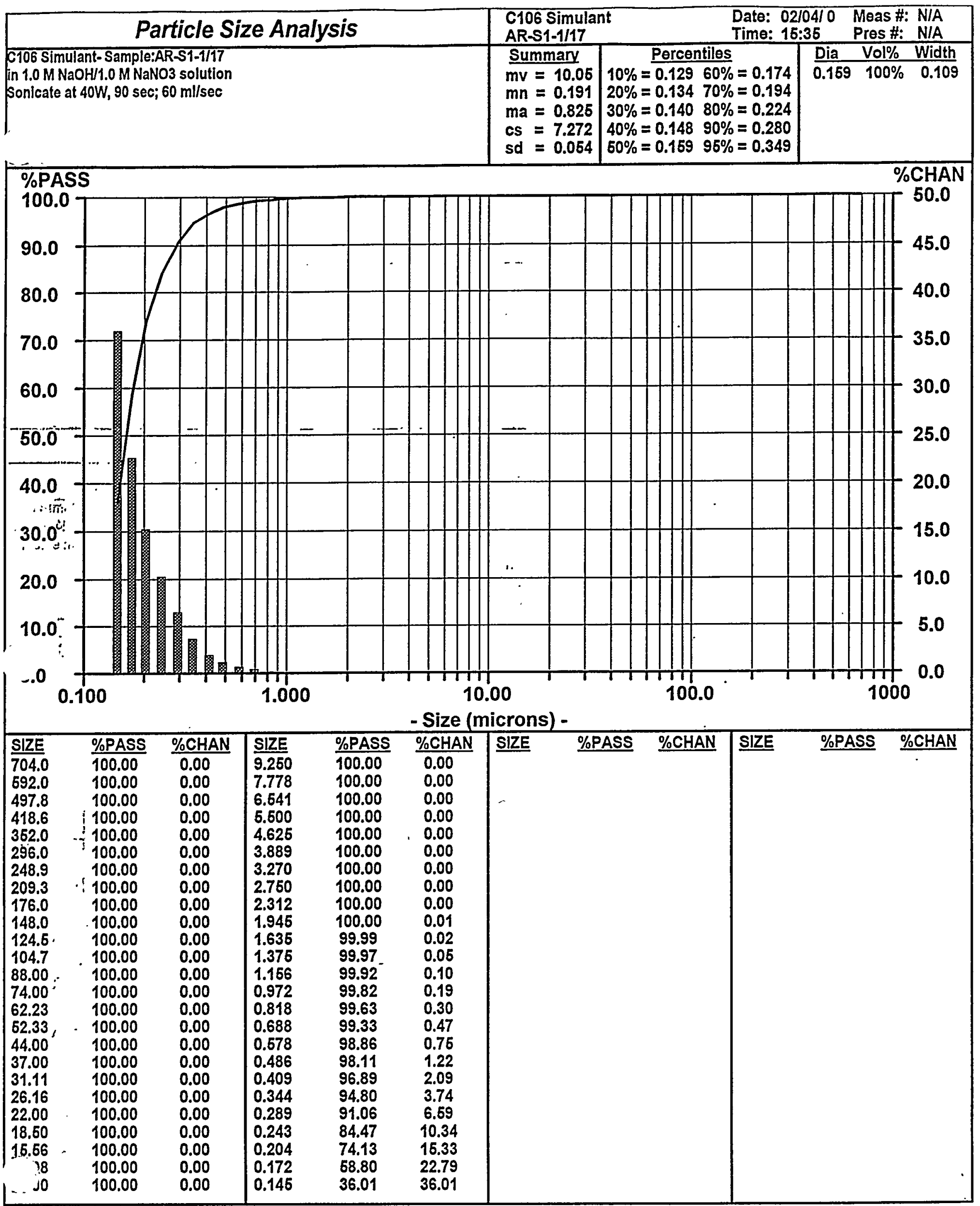




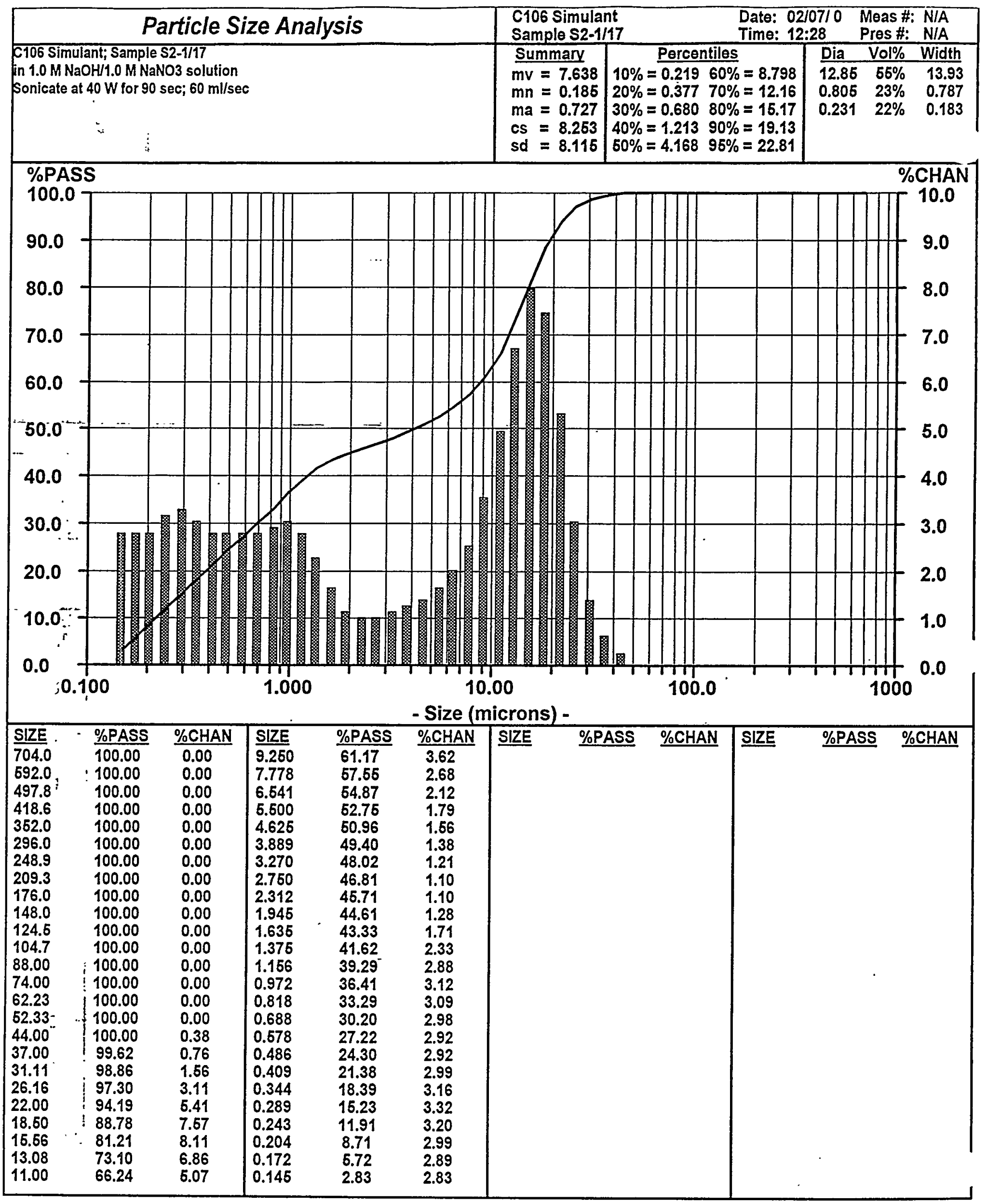




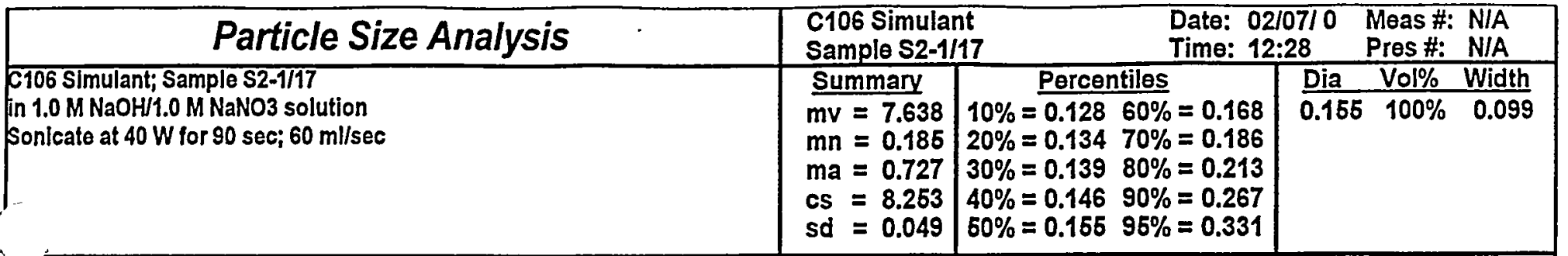

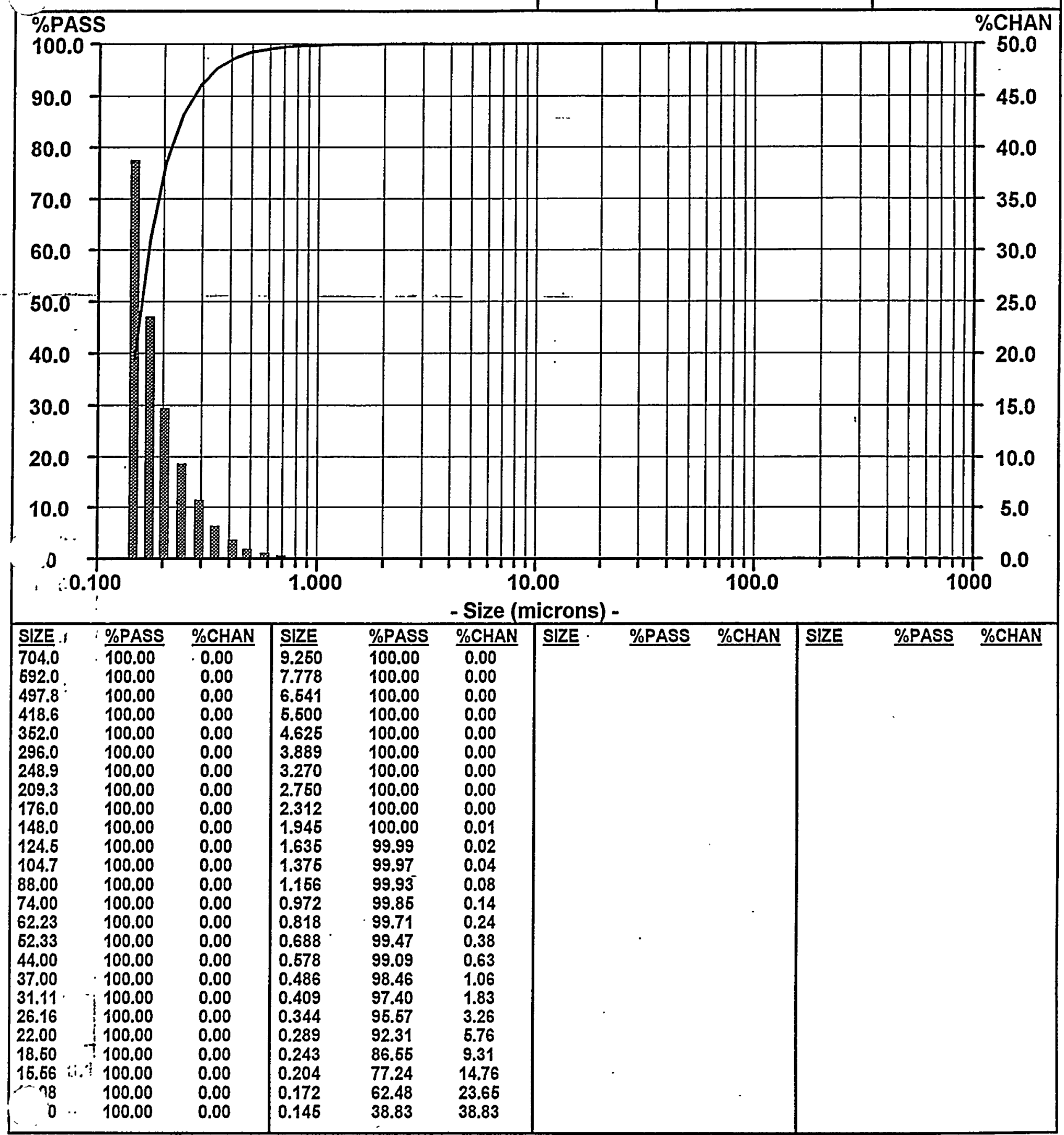




\begin{tabular}{|c|c|c|c|c|c|}
\hline Particle Size Analysis & $\begin{array}{l}\text { C106 Simula } \\
\text { Sample S2-1 }\end{array}$ & $\begin{array}{l}\text { Date: } 02 \\
\text { Time: } 12\end{array}$ & $\begin{array}{l}7710 \\
5\end{array}$ & $\begin{array}{l}\text { Meas \#: } \\
\text { Pres \#: }\end{array}$ & $\begin{array}{l}\text { N/A } \\
\text { N/A }\end{array}$ \\
\hline $\begin{array}{l}\text { 106 Simulant; Sample S2-1/17 } \\
\text { in } 1.0 \mathrm{M} \mathrm{NaOH} / 1.0 \mathrm{M} \mathrm{NaNO3} \text { solution } \\
\text { so } \mathrm{ml} / \mathrm{sec}\end{array}$ & $\begin{array}{l}\text { Summary } \\
\text { mv }=7.624 \\
m n=0.186 \\
m a=0.761 \\
c s=7.883 \\
\text { sd }=8.119\end{array}$ & $\begin{array}{l}\text { Percentiles } \\
10 \%=0.230 \quad 60 \%=8.762 \\
20 \%=0.424 \quad 70 \%=12.16 \\
30 \%=0.746 \quad 80 \%=15.20 \\
40 \%=1.20090 \%=19.16 \\
60 \%=3.963 \quad 95 \%=22.81\end{array}$ & $\begin{array}{l}\text { Dia } \\
13.12 \\
0.805 \\
0.212\end{array}$ & $\begin{array}{c}\text { Vol\% } \\
54 \% \\
30 \% \\
16 \%\end{array}$ & $\begin{array}{l}\text { Width } \\
13.48 \\
0.868 \\
0.143\end{array}$ \\
\hline
\end{tabular}

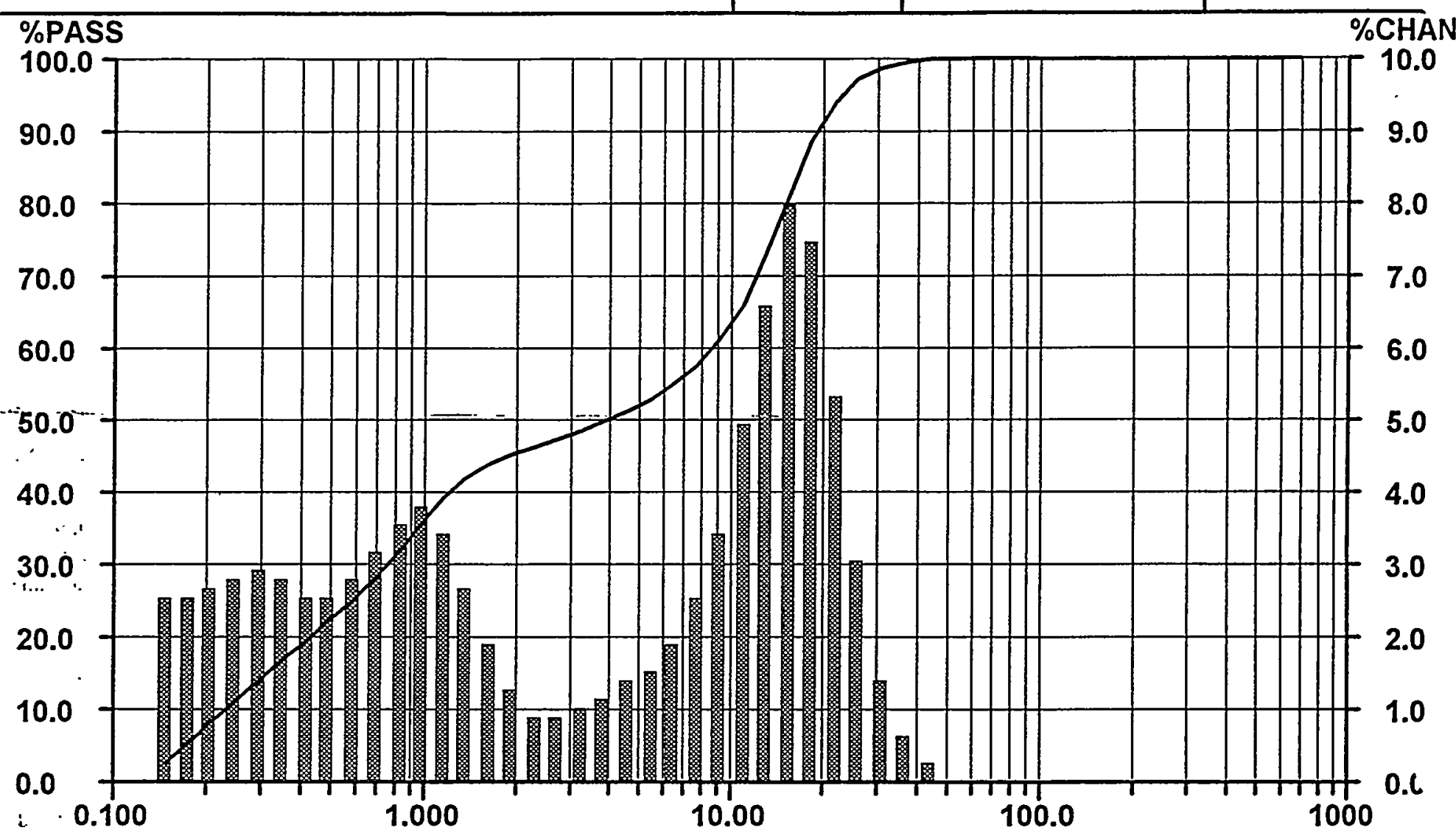

- Size (microns) -

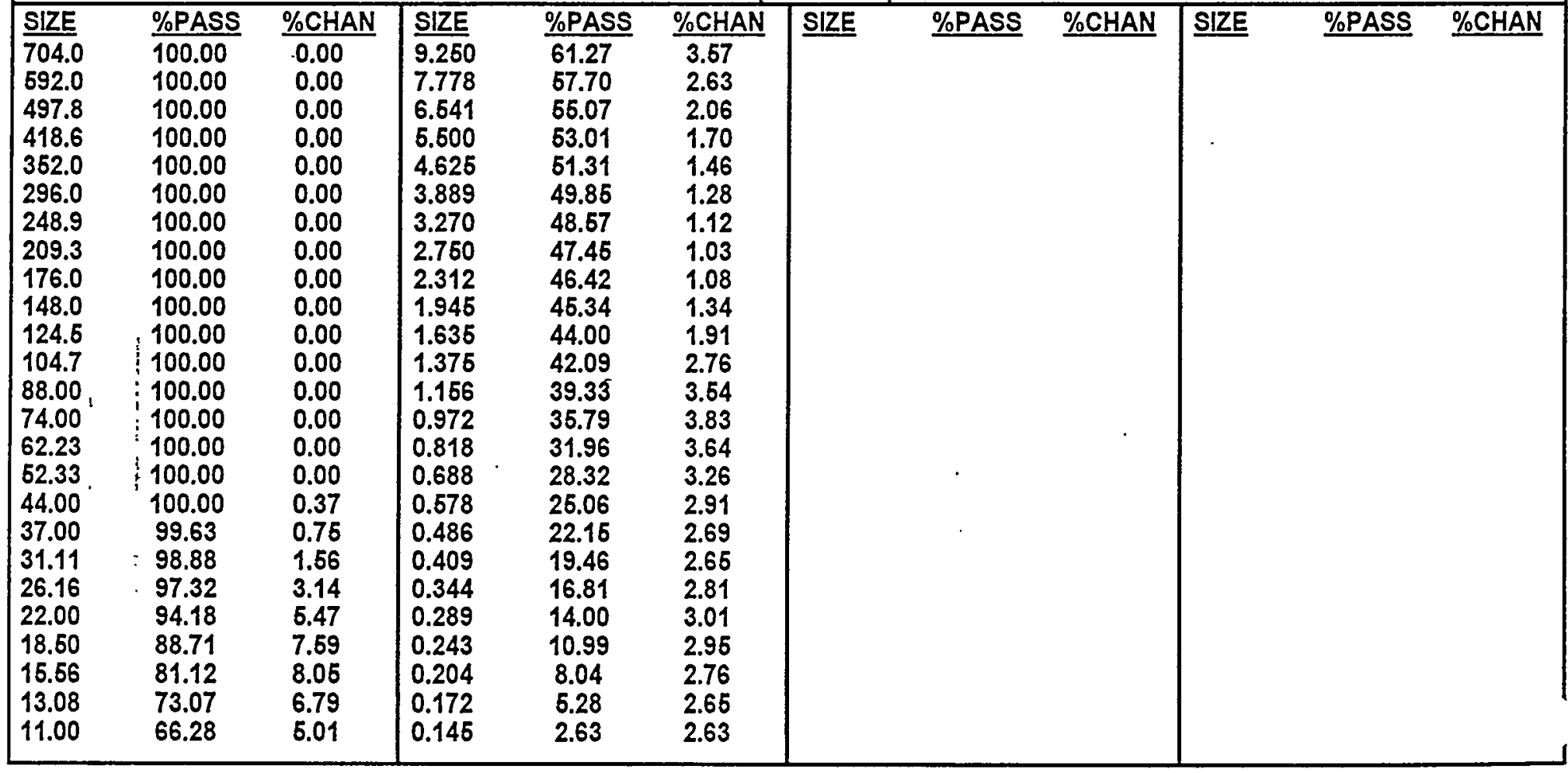




\begin{tabular}{|c|c|c|c|c|c|}
\hline Particle Size Analysis & $\begin{array}{l}\text { C106 Simula } \\
\text { Sample S4-1 }\end{array}$ & $\begin{array}{l}\text { Date: } 02 \\
\text { Time: } 14\end{array}$ & 1710 & $\begin{array}{l}\text { Meas \# } \\
\text { Pres \#: }\end{array}$ & $\begin{array}{l}\text { N/A } \\
\text { N/A }\end{array}$ \\
\hline $\begin{array}{l}\text { C106) Simulant; Sample s4-1/17) } \\
\text { in } 1.0 \mathrm{M} \mathrm{NaOH} / 1.0 \mathrm{M} \mathrm{NaNO3} \text { solution } \\
40 \mathrm{ml} / \mathrm{sec}\end{array}$ & $\begin{array}{l}\text { Summary } \\
\mathrm{mv}=4.149 \\
\mathrm{mn}=0.184 \\
\mathrm{ma}=0.688 \\
\mathrm{cs}=8.717 \\
\mathrm{sd}=4.720\end{array}$ & $\begin{array}{c}\text { Percentiles } \\
10 \%=0.218 \quad 60 \%=3.196 \\
20 \%=0.40870 \%=6.403 \\
30 \%=0.69380 \%=8.838 \\
40 \%=1.01790 \%=11.31 \\
50 \%=1.542 \quad 95 \%=13.13\end{array}$ & $\begin{array}{l}\text { Dia } \\
8.646 \\
0.939 \\
0.206\end{array}$ & $\begin{array}{l}\text { Vol\% } \\
42 \% \\
41 \% \\
17 \%\end{array}$ & $\begin{array}{l}\text { Width } \\
7.690 \\
1.184 \\
0.143\end{array}$ \\
\hline
\end{tabular}

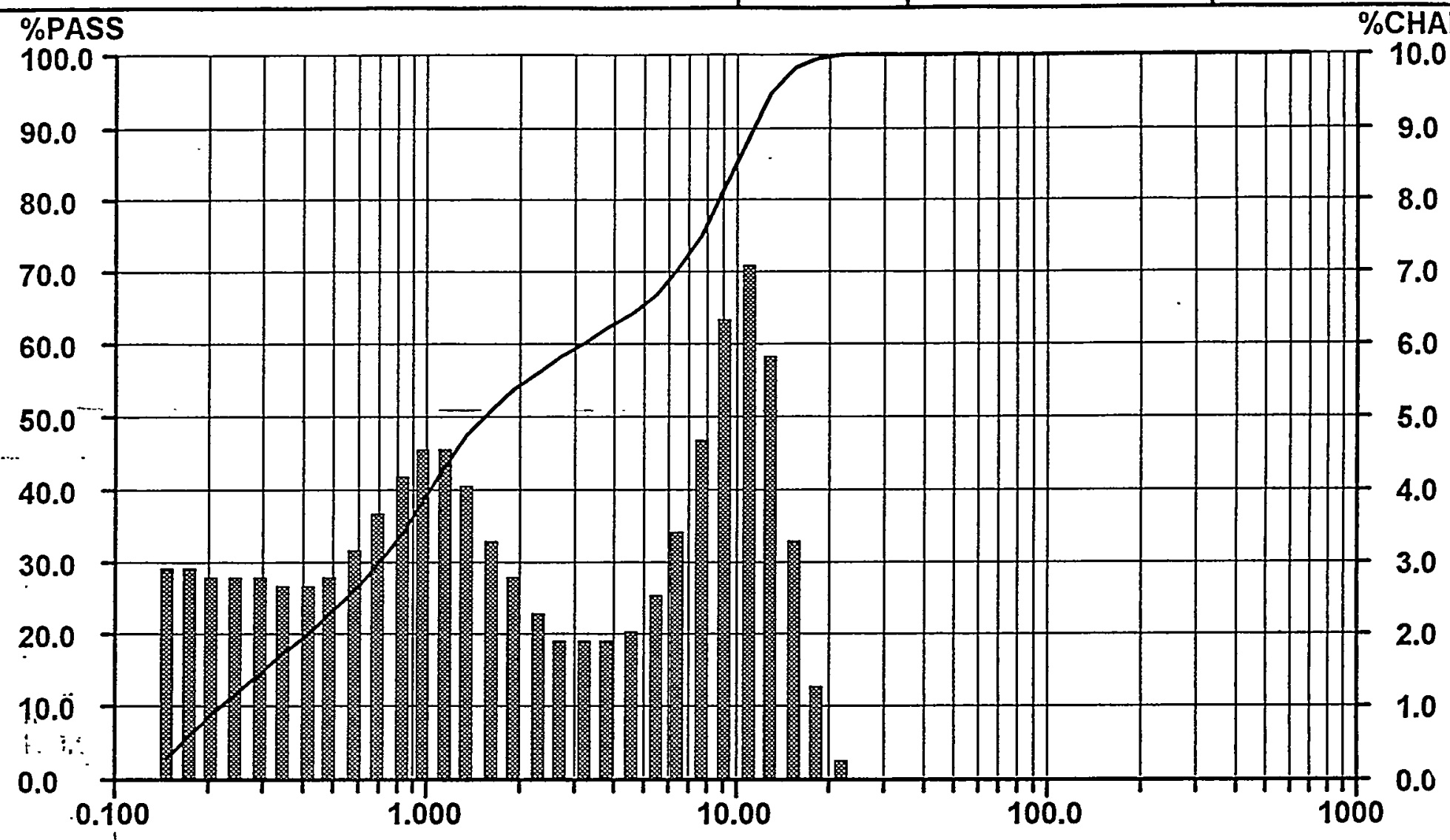

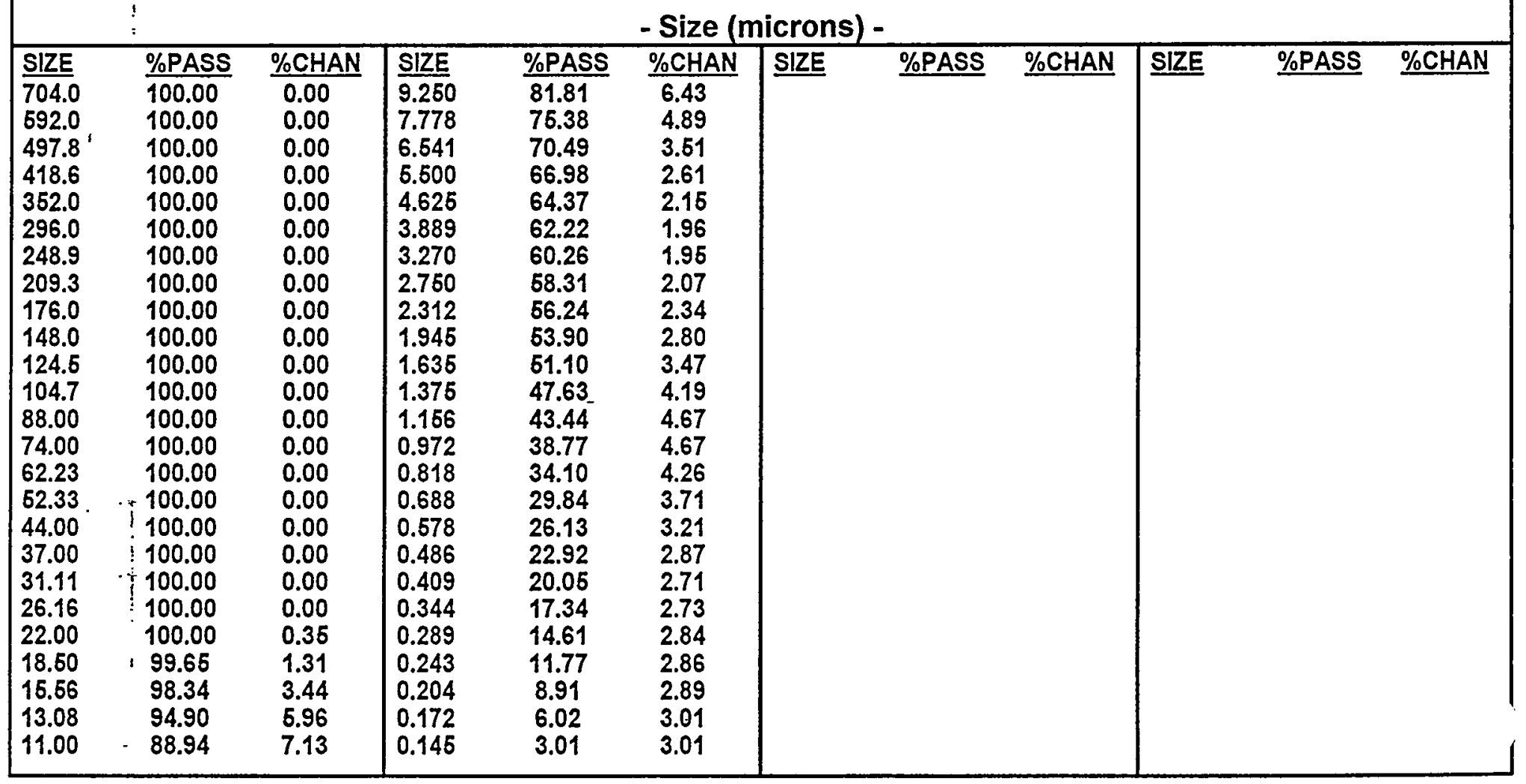




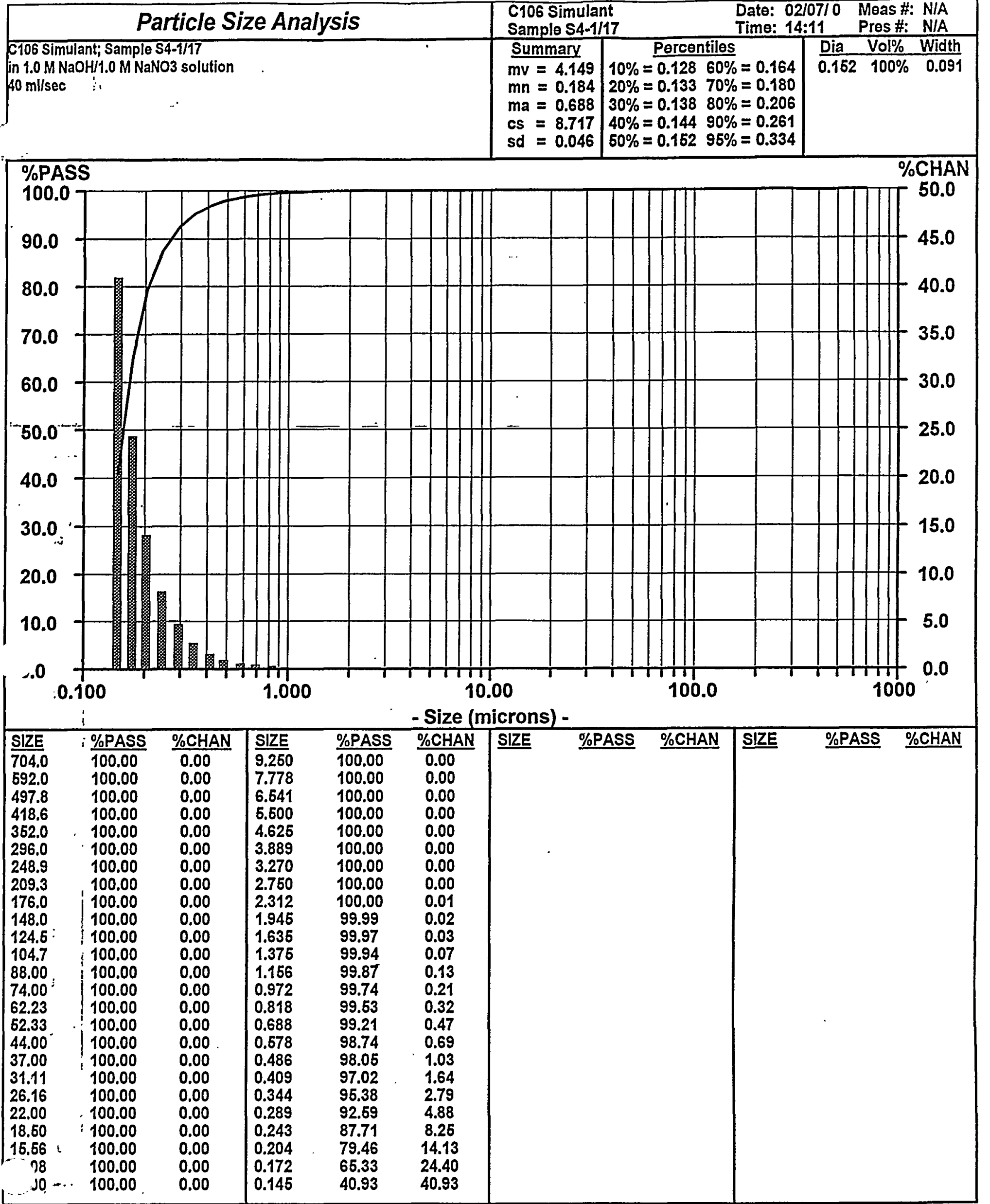




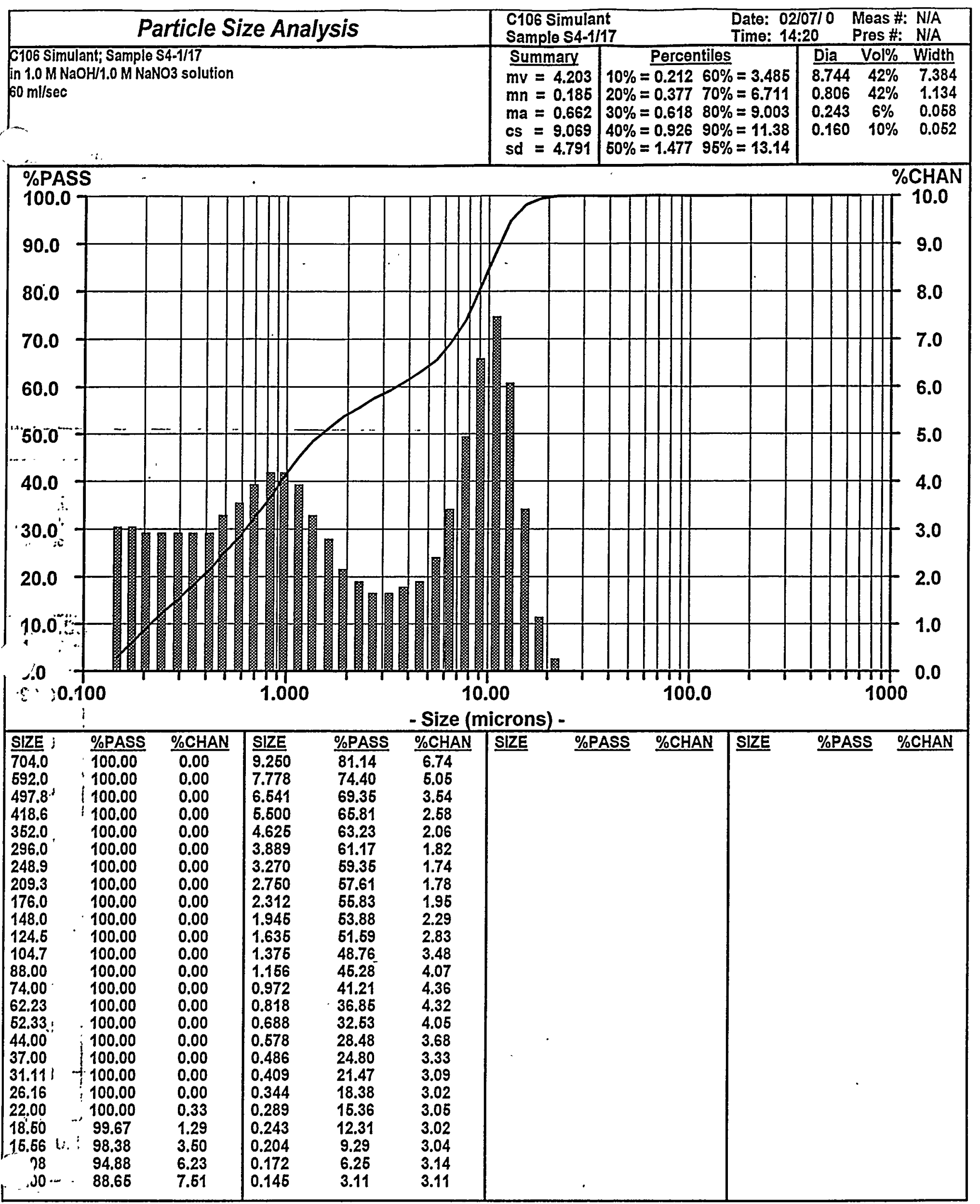




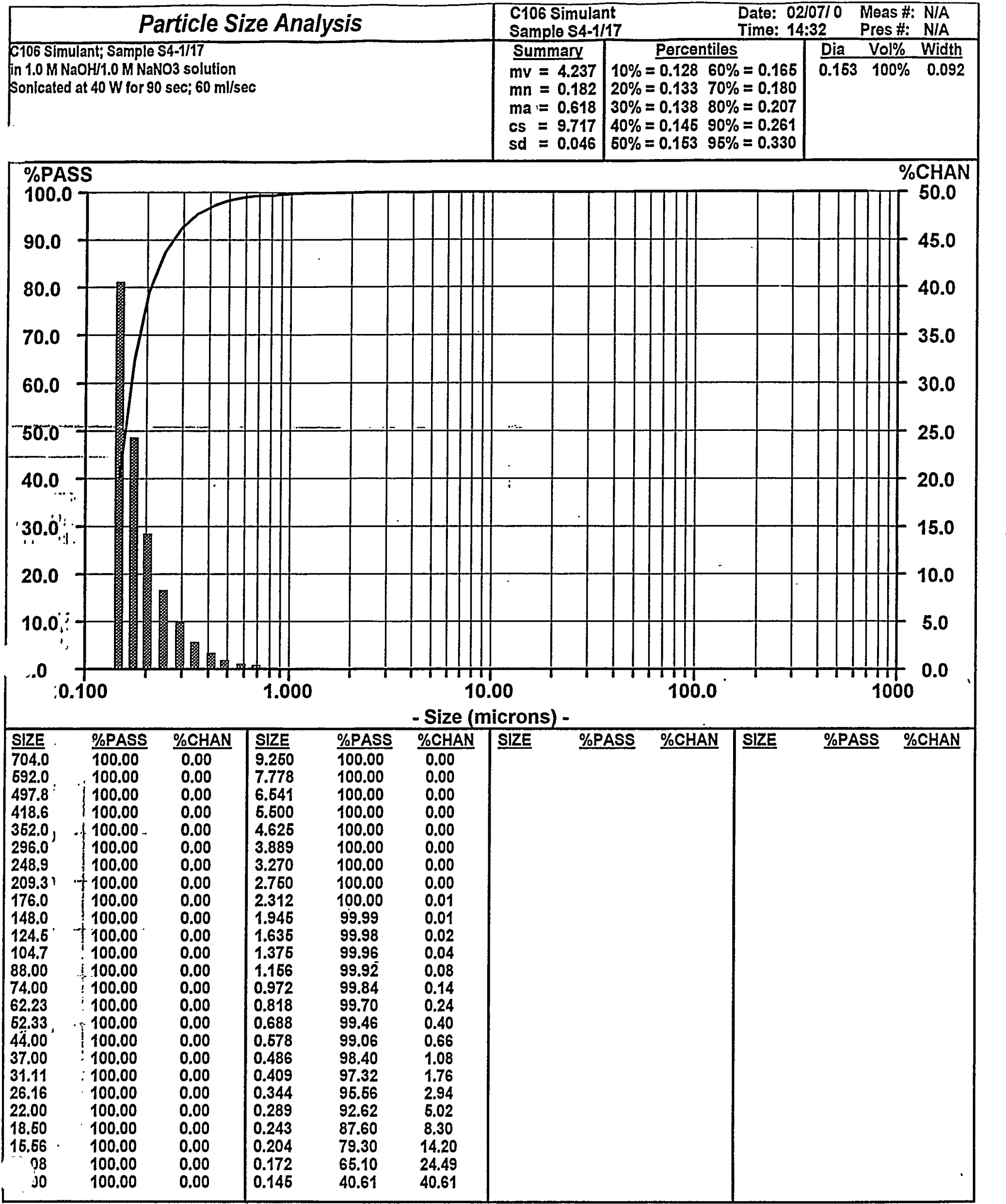


PNWD-3042

BNFL-RPT-038 Rev. 0

\section{Distribution}

No. of

Copies

OFFSITE

2 DOE/Office of Scientific and Technical Information

No. of

Copies

ONSITE

6 British Nuclear Fuels, Limited M. E. Johnson (4) BN-FL
A. Thompson
BN-FL
P. Townson
BN-FL

23 Pacific Northwest National Laboratory
K. P. Brooks
K6-24
J. G. Darab
K3-59
J. M. Davis
P7-28
G. R. Golcar (10)
K6-24
L. K. Jagoda
K6-24
D. E. Kurath
P7-28
E. V. Morrey (3)
P7-28
Technical Report Files (5)

Distr. 1 